\title{
VARIABILIDADE ESPACIAL DE PARÂMETROS DE SOLO E PLANTA
}

\author{
BEATRIZ MONTE SERRAT PREVEDELLO
}

Orientador: PAULO LEONEL LIBARDI

Tese apresentada à Escola Superior de Agricultura "Luiz de Queiroz", da Universidade de São Paulo, para obtenção do título de Doutor em Agronomia. Área de Concentração: Solos e Nutrição de Plantas.

PIRACICABA

Estado de São Paulo - Brasil

Janeiro - 1987 
Celso

e aos nossos filhos:

Daniel

Iuciano

Enarigo

Juliana 
$-\mathrm{i} i-$

A todos que,

direta ou indiretamente, contribuiram para a

execução deste trabalho, 


\section{SURÁRTIO}

pāgina

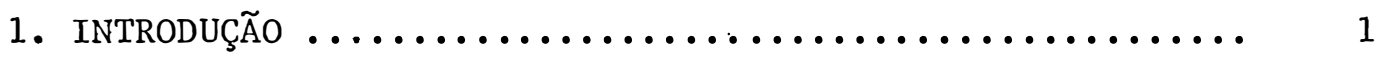

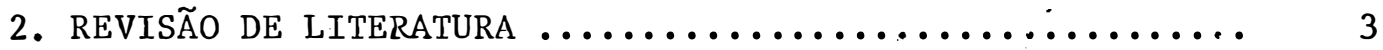

2.1. Variabilidade espacial dos solos ............. 3

2.2. Teoria das variäveis regionalizadas ........... 5

2.2.1. Funções de estacionaridade ............. 5

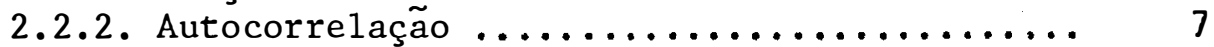

2.2.3. Semivariância ...................... 14

2.3. Aplicação da geoestatística na ārea agronômica .... 19

3. MATERIAL E MÉTODOS .......................... 24

3.1. Local ............................... 24

3.2. Caracterização da ārea experimental ........... 24

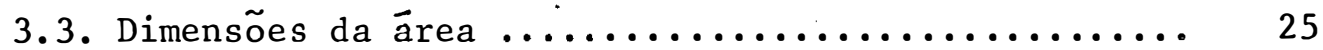

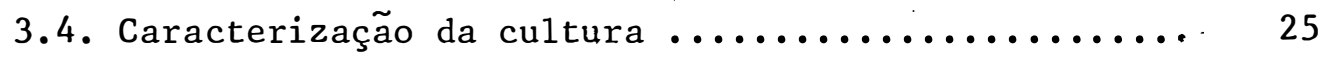

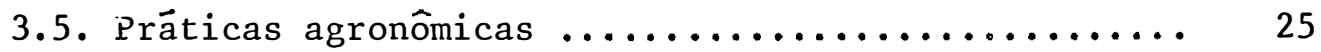

3.6. Amostragens e determinações ....................... 27

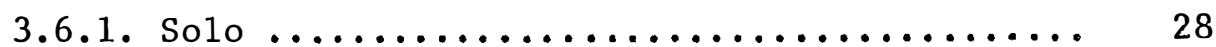

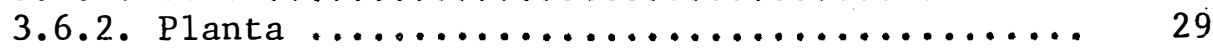

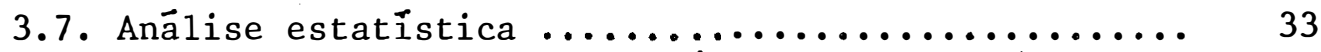

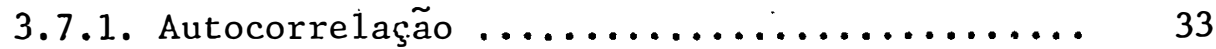

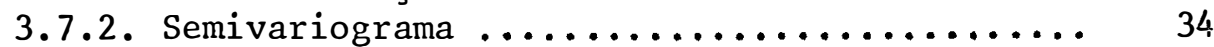

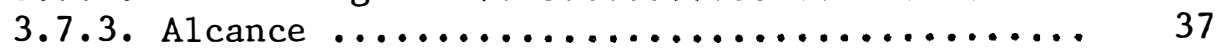

4. RESULTAdOS ................................ 39

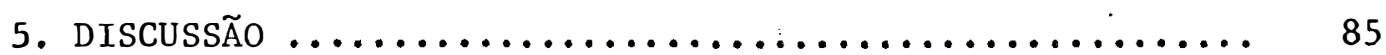

5.1. Autocorrelograma e semivariograma para uma direção . 86

5.2. Autocorrelogramas e semivariogramas para duas e to-

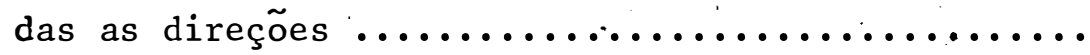




\section{RESUMO}

PREVEDELLO, B.M.S., Doutorado, Escola Superior de Agricultura "Luiz de Queiroz", Universidade de São Paulo, janeiro de 1987, 166 p. Variabilidade espacial de parâmetros de solo e planta. Professor Orientador: P.L. LIBARDI.

Com o objetivo de estudar a magnitude da variabilidade espacialde uma ärea cultivada, considerada homogênea para propósitos de experimentação agrícola, foi empregada a "Teoria das Variáveis Regionalizadas" (Geoestatística). o experimento foi desenvolvido num Paleudalf óxico (Terra Roxa Estruturada), localizado no campus da Universidade de São Paulo - Escola Superior de Agricultura "Luiz de Queiroz", em Piracicaba. Utilizou-se a cultura de arroz de sequeiro em uma parce1a de 4810 metros quadrados, demarcada a intervalos regulares de 10 metros nas duas direções, para a amostragem de solo e planta. No material amostrado, procederam-se determinações químicas e de componentes da produção, globalizando 47 parâmetros. Com os dados obtidos, foram calculados os momentos estatísticos, autocorrelação e semivariância, de cada variáve1. A partir disso, construiram-se os autocorrelogramas e os semivariogramas, os quais permitiram a determinação do alcance pelas seguintes metodologias: comprimento do autocorrelograma (ka), comprimento do semivariograma (kv), limite superior 
da autocorrelação (a), e escala integral (E.I.). Verificou-se que o valor de E.I., o qual define o diâmetro de āreas homogêneas, foi aproximadamente a metade do de $\mathrm{ka}$. As dependências espaciais, em gera1, mostraram-se de longo alcance na direção do comprimento da parcela, apresentando redução quando foram englobadas outras direções. A partir da aplicação da "Teoria das Variáveis Regionalizadas", foi possîvel estabelecer sub-unidades de amostragem ou de manejo individua" lizado, e também definir sub-parcelas consideradas independentes. A parcela experimental apresentou relação de dependência espacial, acima de 10 metros, em 41 das variáveis consideradas, pelo valor de a. Entretanto, pelo conceito de escala integral, a ārea total em estudo não se mostrou homogênea para nenhum dos 47 parâmetros levantados, quando foram analisados os três critērios de direção. 


\section{SUMMARY}

PREVEDELLO, B.M.S., Ph.D., Escola Superior de Agricultura "Luiz de Queiroz", University of São Paulo, January. 1987, 166 p. Spatia1 variability of soil and plant parameters. Adviser: P.L. Libardi.

The objective of this work was to study the magnitude of the spatial variability of a cultivated area considered homogeneous for agricultural purposes, using the Theory of Regionalized Variables (Geostatistics). The experiment was carried out in an Oxic Paleudalf located at the Piracicaba Campus of the University of São Paulo, Piracicaba (SP), Brazil. The field experiment consisted of a $4810 \mathrm{~m}^{2}$ plot divided into $10 \mathrm{~m}$ regular grid intervals where a high land rice crop was grown. Analytical and yield components determinations were made in the sampled material, resulting a total of 47 parameters. For each of these variables, statistical moments, auto-correlations and semi-variances were calculated, and,hence auto-correlograms and semi-variograms to determine the correlation distance using the following methodologies: auto-correlogram length, ka; semi-variogram length, kv; auto-correlation upper limit, $\underline{a}$; and integral scale, F.I. It was verified that the E.I. value, which defines the diameter of homogeneuus areas, was approximately half of the ka value. The spatial dependence, in general; were of long range in the direction 
of the plot length, decreasing when other directions were included. From the theory of regionalized variables, it was possible to establish sub-areas of sampling or of individual management, and, also, to define sub-plots to be considered independent. The experimental plot has shown spatial dependence relations, beyong $10 \mathrm{~m}$, in 41 of the considered variables according to the a concept. However, from the integral scale concept, the total area studied did not show homogeneity in none of the 47 parameters studied when three criteria of direction were used. 


\section{INTRODUÇÃO}

Visando a melhoria da produtividade e qualidade das plantas cultivadas, a ciência agronômica tem estabelecido relações entre os diversos fatores de produção e o desenvol.vimento das culturas. Neste aspecto, a anālise estatística das variáveis medidas tem se mostrado importante às interpretações dos resultados.

Os experimentos de campo, utilizados como fase de pesquisas iniciadas em laboratório ou casas-de-vegetação, necessitam, para atender as hipóteses básicas da estatística clássica, minimizar os efeitos provocados pela variabilidade natural existente no sistema solo-planta-atmosfera.

As observações realizaidas em condições de campo podem, no entanto, incluir considerações sobre sua variabilidade espacial ou temporal. Assim, com o conhecimento das posições relativas das amostragens ou medidas feitas a campo, a variabilidade espacial passa a ser utilizada como um fator positivo, identificando interações importantes, nas conclusões experimentais.

0 estudo da dependência espacial de determinados parâmetros do solo ou da planta, atravēs da teoria das variāveis regionalizadas (geoestatística), permite a interpretação e a projeção dos resultados com base na estrutura da sua variabilidade natural. Por exemp1o, permite separar, nas respostas das culturas, a proporção referente ao tratamento ou manejo, daquela correspondente às di- 
ferenças de solos, entre pontos de um mesmo campo.

0 presente trabalho tem por objetivo estudar, numa ārea conșiderada homogênea para propōsitos de experimentação agrĩcola, a magnitude da variabilidade espacial (i) de algumas propriedades físicas e químicas do solo, (ii) do teor de alguns nutrientes na planta de arroz, e (iii) de componentes da produção da cultura de arroz. 
2. REVISÃO DE LITERATURA

Recenteș pesquisas em ciências agronômicas têm dado ênfase à variabilidade espacial, quando se conduz experimentos sob condições de campo. Com base nos objetivos do presente trabalho, apresenta-se, a seguir, uma revisão de literatura iniciando-se por aspectos gerais ligados à variabilidade dos solos, apresentando depois os conceitos principais da teoria das variăveis regionalizadas e, finalmente, a utilização destà nova alternativa estatística em outros ramos da agronomia.

\subsection{Variabilidade espacial dos solos}

Com o interesse de avaliar o efeito da variabilidade das propriedades de solos cultivados no campo e estabelecer distâncias e modelos de amostragens, Montgomery* em 1913 e Waynick* em 1918, citados por VIEIRA et alii (1983), realizaram experimentos onde os

*MONTGOMERY, E.G. Experiments in wheat breeding: experimental error in the nursery and variation in nitrogen and yield. Bur. Plant. Indust., Dep. Agr. Est. Unidos, Boletim 269, 1913. $\overline{61 \text { p. }}$

*WAYNICK, D.D. Variability in soils and its significance to past and future soil investigations. I. Statistical study of nitrification in soils. Univ. Cal. Publ. Agr. Sci., 3: 240$270,1918$. 
pontos das observações eram previamente estabelecidos.

Mc BRATNEY (1984) afirma que o grande feito agronômico de Fisher, na década de 20, foi descobrir uma solução tecnológica para problemas de variação do solo, em experimentos de campo. Atravēs da casualização e formação de blocos, foi resolvido, sem estimar, o efeito do solo e outras variāveis ambientais incontroláveis. Outro resultado, ressaltando o sucesso dos métodos estatísticos de Fisher, è a redução marcante da covariância depois do ano de 1920. Entretanto, ainda de acordo com Mc BRATNEY (1984), os cientistas do solo, durante um período de 60 anos, não têm explicado com suficiente clareza para estatísticos e agrônomos a importância do solo no desenvolvimento das culturas e de que modo o solo pode ser levado em consideração.

BECKETT \& WEBSTER (1971) mostraram como a variância e o coeficiente de variação de diferentes propriedades do solo aumentam à medida que cresce o tamanho da ārea. Isto sendo vālido tanto para características físicas como químicas do solo, e se tem calculado que os coeficientes de variação podem ter valores entre 20 e $65 \%$ em áreas maiores que 10 hectares.

Jā em 1968, Ba11 \& Williams*, citados por GUROVICH (1982), realizaram estudos da variabilidade das propriedades químicas de solos não cultivados. O coeficiente de variação para vários parâmetros, neste estudo, ficou em torno de $33 \%$, o que levou estes autores a concluir que, em qualquer estudo pedológico e ecológico, è indispensáve1 considerar quantitativamente a variabilidade espacial, para uma melhor compreensão das observações realizadas.

*BALL, D.F. \& WILLIAMS, W.M. Variability of soil chemical properties in two uncultivated brow earths. J. Soil Sci., 19: 379-391, 1968. 
CASSEL \& BAVER (1975), estudando a densidade global e a retenção de água de um solo, na sua camada superficial, concluiran que o número de amostras, para avaliar corretamente estes parâmetros, dentro de limites de confiança estabelecidos, è pouco prático, sendo mais conveniente considerar quantitativamente a variabilidade espacial dos parâmetros, separando unidades de solo mais homogêneas, atravēs de técnicas geoestatísticas.

0 desenvolvimento da "Teoria das Variāveis Regionalizadas" (Geoestatística), por Matheron, em 1963, visando resolver problemas de geologia e mineração, vem recentemente sendo aplicada em diversos outros ramos da ciência, como na Agronomia (VIEIRA et alii, 1983).

Textos bäsicos sobre este assunto são encontrados em DAVIS (1973), DAVID (1977), JOURNELL \& HUIJBREGTS (1978), CLARK (1979) e, mais especificamente na ārea agronômica, em VIEIRA et alii (1983), REICHARDT (1985), CAMPBELL (1985) e WEBSTER (1985).

\subsection{Teoria das Variáveis Regionalizadas}

Consideremos $x$ um ponto no espaço $R^{3}$ e $Z(x)$ o valor da função de interesse neste ponto. Tal função é chamada de variāvel regionalizada (DAVID, 1977).

\subsubsection{Funções de estacionaridade.}

A aparente continuidade da função estā ligada à suposição de que os valores de um parâmetro do solo, em localizações vizinhas, sejam aproximadamente o mesmo ou que, pelo menos, estejam 
relacionados. Alēm desta propriedade, a variāvel regionalizada pode apresentar outros atributos que se encontram descritos em

LANDIM (1985).

No campo agronômico, tais variāveis podem ser: o teor de um elemento no solo ou na planta, a espessura de um horizonte, a extensão de uma unidade de solo, os valores de componentes da produção de uma cultura (peso de matéria seca e de grãos, número de plantas e outros), quantidade de nutrientes extraídos pela cultura, e outros.

Como uma variāvel regionalizada è um resultado ünico de uma função casual (ou ao acaso), è impossível fazer-se inferências estatísticas baseando-se em apenas uma amostra (LANDIM, 1985). Para resolver este impasse, a geoestatística tem introduzido hipóteses com respeito ao tipo de função casual, sendo aqui referidos: (i) hipótese de estacionaridade de ordem 2, e (ii) hipótese intrínseca. Estas hipóteses são apresentadas, segundo JOURNEL \& HUIJBREJTS (1978), pägina 32, partindo da mais restrita para a mais geral, isto é, se a função $\ddot{\bar{e}}$ estacionāria de segunda ordem, então esta função também é intrínseca, não sendo o inverso necessariamente verdadeiro.

A hipótese de fraca estacionaridade, ou estacionária de ordem 2 (ou, ainda, conceito de homogeneidade usado por GUTJAHR, 1984), considera que: (1) o valor esperado da variáve1 regionalizada $\mathrm{Z}(\mathrm{x})$ é o mesmo em todo o campo de interesse, e (2) a covariância espacial de uma variāvel regionalizada $\mathrm{Z} \dot{(x)}$ è a mesma para todo o campo de interesse, implicando na ocorrência de variância finita. A hipōtese intrînseca tem importância em casos onde não ocorre variância finita. Esta considera, apenas, 
que a média dos valores de $\mathrm{Z}(\mathrm{x})$ e a variância dọ incrementós $\mathrm{Z}(\mathrm{x})$ $z(x+L)$ ocorrem independentemente da localização (onde $L$ é um vetor possuindo direção e comprimento).

Quando existe estacionaridade de ordem 2 e, consequentemente, a estacionaridade da variância, as funções autocorrelação e semivariograma são instrumentos equivalentes para caracterizar a cor- . relação entre observações de um mesmo parâmetro, separadas por L. No caso de ser unicamente cumprida a hipōtese intrínseca, só é válido o uso da função semivariograma (ou função intrínseca) (VAUCLIN et alii, 1982).

\subsubsection{Autocorrelação,}

A função autocorrelação expressa a correlação linear entre uma série espacial (temporal) e a mesma série num espaço (tempo), quantificando a mudança de forte dependência para uma situação de independência dos valores de um determinado parâmetro (DAVIS, 1973; GAJEM et alii, 1981; NIELSEN \& CASSEL, 1984).

Para a caracterização da função autocorrelação, è necessārio que a função satisfaça a hipótese de estacionaridade de ordem 2. Nestas condições, a função autocorrelação pode ser definida pela equação (1):

$$
\rho(L)=\operatorname{cov}[z(x), z(x+L)] / \sigma^{2}
$$

onde $\rho(L)$ é o valor da autocorrelação, e $\sigma^{2}$ a variância, ambos da população.

A estimativa de $\rho(L)$ usando dados de amostragem è representada por $r(L)$. 
correlação os parâmetros são modelados por uma função ao acaso, com suficientes propriedades para garantir a existência desta função. Como tal função pode depender da ārea ou volume da região delimitada, a sua validade não pode ser satisfatoriamente testada. Embora seja requerida uma forma de estacionaridade, a função autocorrelação tem certas vantagens em relação a outros métodos, por apresentar valores normalizados para o intervalo $-1,1$, inclusive facilitando a interpretação dos valores.

0 autocorrelograma é um gräfico de $r(L)$ em função da distância ou "lag" L. o valor máximo é 1 para $\mathrm{L}=0$ e tende a decrescer com o aumento de L. Quando L è 1 e os pontos $1,2, \ldots, n$ são igualmente espaçados, a correlação é feita de $x_{1} \operatorname{com} x_{2}, x_{2} \operatorname{com} x_{3}$, $\ldots x_{n-1} \operatorname{com} x_{n} \cdot$ Para $L=2$, a correlação é feita de $x_{1} \operatorname{com} x_{3}, x_{2}$ $\operatorname{com} x_{4}, \ldots x_{n-2} \operatorname{com} x_{n}$, e assim por diante.

Três tipos de autocorrelogramas sugeridos por GAJEM (1981) são mostrados na Figura 1. o primeiro (A) è um caso típico com $r(L)$ decrescendo gradualmente, nivelando em torno de zero. No caso (B), o valor de $\mathrm{r}(\mathrm{L})$ declina rapidamente dentro do 10 "1ag", a partir do que, mostra a independência entre as amostras. No 39 tipo (C), o coeficiente de autocorrelação cai mais lentamente, indicando dependência a longo alcance.

VAUCLIN et alii (1982) apresentam um autocorrelograma onde os valores decrescem para zero com o aumento da distância, chegando a valores negativos significativamente diferentes de zero. Os autores relatam que nestas condições esta série de dados não pode ser caracterizada pela função autocorrelação, por ser tendenciosa (apresentando um "drift"). Este problema poderā ser contornado através da confecção do autocorrelograma residual (baseado nos va-- 


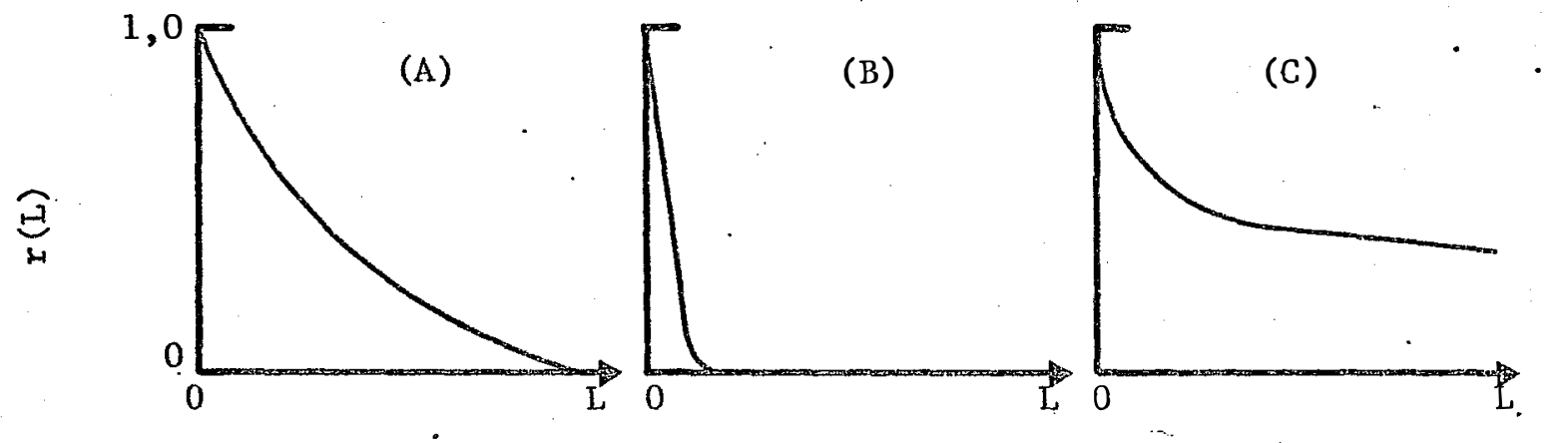

FIGURA 1 - Tipos de autocorrelogramas. 
lores médios). RUSSO \& BRESLER (1981) e GAJEM et alii. (1981), quando analisaram um autocorrelograma aprésentando valores negativos para resultados de parâmetros hidráulicos, consideraram, para efeito prātico, condições semelhantes à Figura 1(A). GUROVICH \& STERN (1983), trabalhando com a variabilidade espacial de valores de condutividade hidräulica, obtiveram um autocorrelograma com valores negativos. Estes autores relataram que este fato indicava a existência de uma correlação negativa, ou seja, os valores pequenos de condutividade da origem estão associados com valores grandès no centro do campo, que no caso, correspondia aos 45 metros.

Sendo o alcance definido pelo intervalo no qual as amostras espaciais mantêm relação de dependência, ou pelo intervaio de amostragem que poderā ser representado por uma ūnica amostra, vārias técnicas para a sua determinação têm sido sugeridas. Considerando a definição de autocorrelograma, onde no "lag" zero o r(L) è sempre igual a 1, e que, de maneira geral, à medida que a distância $L$ aumenta, os valores de $r(L)$ tendem a decrescer para $r(L)$ igual a zero, WEBSTER \& CUANALO (1975) consideram que a dependência entre os valores termina na distância correspondente ao ponto (ka) onde a curva do autocorrelograma corta o eixo das abscissas. NIELSEN \& CASSEL (1984) apresentam o valor $\lambda$, também chamado de comprimento da autocorrelação e definem a distância entre observações, além da qual a $r(L)$ é menor ou igual a.1/e (onde "e" è a base do logaritmo neperiano), equivalente a 0,37 , conforme a eq. (2), onde r é o coeficiente de autocorrelação e L é o "lag" (Figura 2).

$$
r(L)=\exp (-L / \lambda)
$$

Outro critério para determinar o alcance é através do 


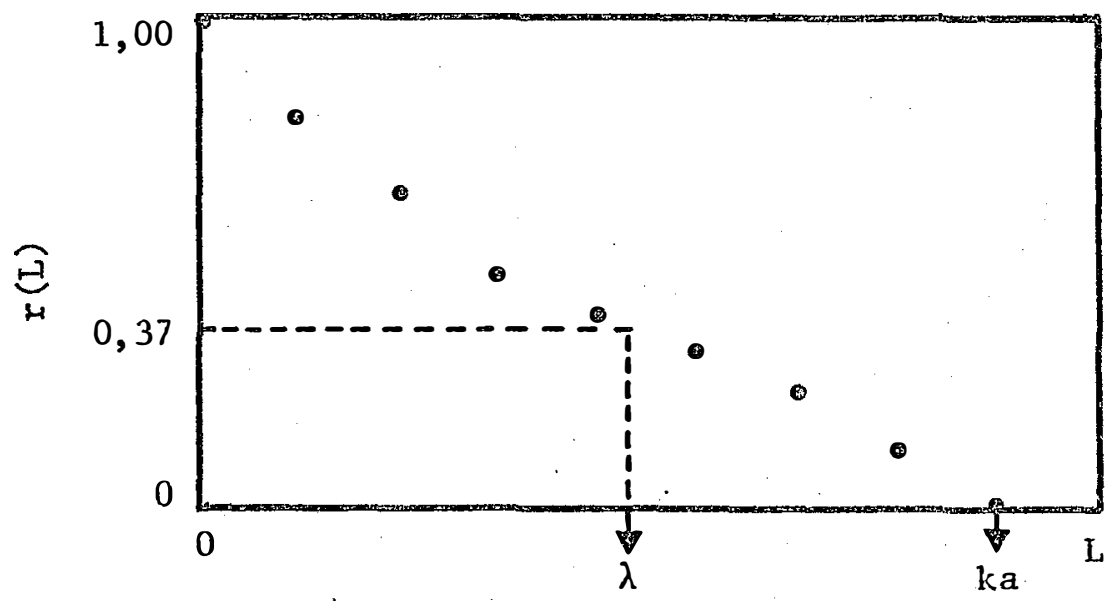

FIGURA 2 - Alguns tipos de determinação do alcance (baseado no autocorrelograma). 
conceito de escala integral (E.I.), uma vez que o seu valor representa o diâmetro de uma ārea circular, dentro da qual as observações são consideradas homogêneas, ou seja, é a ärea sob a função $r(L)$. Num processo bidimensional, esta 'ärea corresponde, conforme BRESLER et alii. (1981), à eq. (3):

$$
\text { E.I. }=\left[2 \int_{0}^{\infty} r(\mathrm{~L}) \mathrm{L} d \mathrm{~L}\right]^{1 / 2} \text {. }
$$

observando-se que pära processos unidimensionais, uma série de tempo, por exemplo, ou observaçōes em um traçado, a escala integral corresponde à integral exata da função autocorrelação. Vārios autores têm citado e utilizado deste critério de determinação, o qual também permite delimitação de āreas uniformes dentro do campo, entre eles, RUSSO \& BRESLER (1981), VAUCLIN et alii.(1982), GUROVICH \& STERN (1983a), CAMPBELL (1985) e LIBARDI et alii. (1986). CAMPBELL (1985) cita que o alcance seria definido por mais de um valor de E.I. a fim de ser atingida a independência entre amostras. HAAN (1977), ao adaptar o limite de confiança do coeficiente de correlação aos resultados da autocorrelação, no qual se determina o intervalo onde os valores $r(L)$ não diferem de zero, permite assim que seja estabelecido o alcance da autocorrelação valor a, como é indicado pela Figura 3. A eq. (4) apresenta os limites de confiança com probabilidade de 95\%, isto é, dentro deste intervalo, os valores de $\mathrm{r}(\mathrm{L})$ não diferem de zero.

$\left.\begin{array}{l}\text { superior } \\ \text { inferior }\end{array}\right\}$ limite $=\{-1 \pm 1,96 \sqrt{n-2}\} /(n-1)$

onde n é o nümero da série espacial, HAAN (1977) observa ainda que 


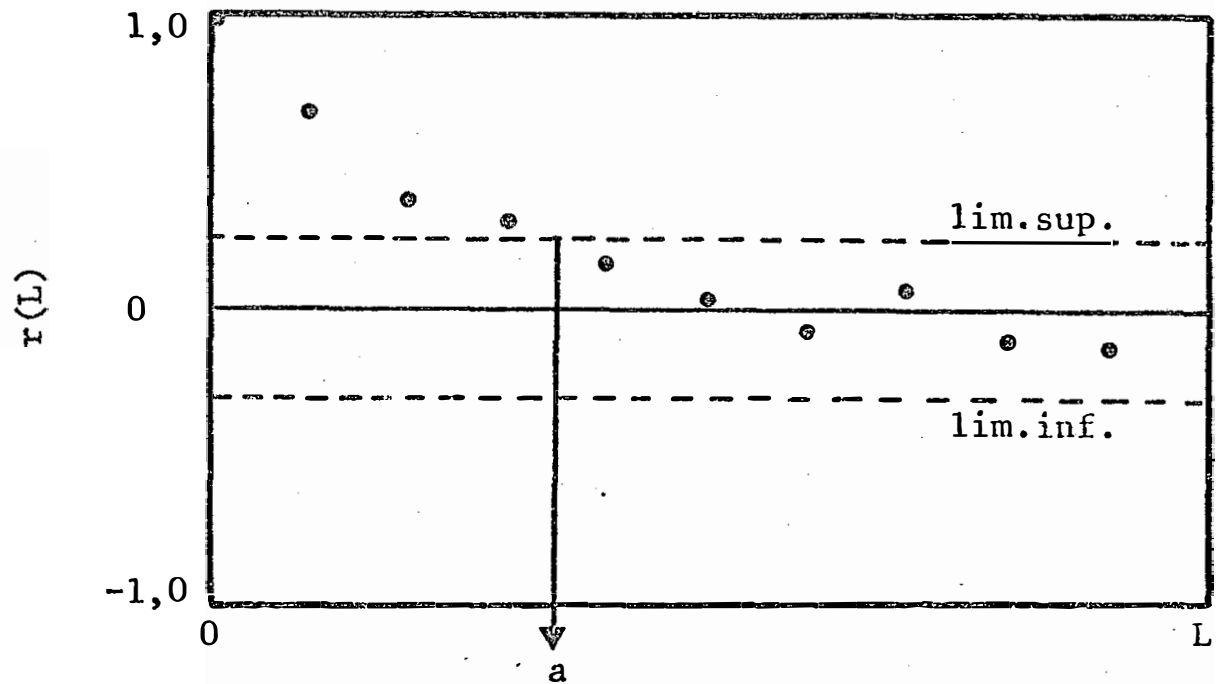

FIGURA 3 - Alcance determinado pelo critério dos limites para autocorrelograma. 
este critério è válido para grande número de observações da sērie espacial em relação aos números de distâncias regulares ("lags") utilizados na anālise do autocorrelograma, pois sob estas condições,r(L) se aproximarā da distribuição normal.

DAVIS (1973) cita o cálculo da zona de influência (Z.I.), pela distribuição Z (valores obtidos em tabelas estatísticas), a qual pode ser determinada pela eq. (5), sugerindo não ser recomendado o uso de $\mathrm{L}<\mathrm{n} / 4$ e de $\mathrm{n}<50$.

$$
z_{L}=|r(L)| \sqrt{n-L}
$$

GAJEM et alii.(1981) comparam os valores dó alcance obtido por escala integral e pela zona de influência e obtiveram alcances menores com E.I. do que com Z.I.

Ao apresentuar a análise espacial e temporal em ecologia, CORMACK \& ORD (1979) sugerem que, na prática, os limites de autocorrelação podem seir definidos por $\pm 2 \sqrt{n}$, obtendo, como exemplo, para $n=114$, o valor de $\pm 0,187$, enquanto que, pela eq. (4), obteríamos $+0,175$ e $-0,192$.

Os aspectos estatísticos tanto de limites de confiança como de zona de influência, estão apresentados com maiores detalhes nos livros didāticos de estatística (SNEDECOR \& COCHRAN, 1980, por exemplo).

\subsubsection{Semivariância}

Dependendo do objetivo dos estudos de variabilidade espacial, alguns autores preferem ò uso da função semivariância. A função autocorrelação apresenta vantageñs, como jā citado no item anterior. Entretanto, quando se trata de estimativa de valores, principalmente em situações bidimensionais, e ainda quando são necessārias condi- 
ções de menor grau de estacionaridade, a função semivariância ganha maior ênfase.

Suponha-se que no local xé obtido o valor $\mathrm{Z}(\mathrm{x})$ para um parâmetro do solo, e para o local $x+L$ o valor $Z(x+L)$ para o mesmo parâmetro (onde L é o vetor jā anteriormente citado "lag"). Desta forma, a variância $\mathrm{s}^{2}$ calculada para este par de valores é a so-. ma do quadrado da diferença de cada valor individual com a média $\bar{Z}$ (WEBSTER, 1985), conforme indicado na eq. (6).

$$
s^{2}=[z(x)-\bar{z}]^{2}+[z(x+L)-\bar{z}]^{2}
$$

Com o desenvolvimento desta equação, onde a média $\overline{\mathrm{Z}}$ é:

$$
[\mathrm{Z}(\mathrm{x})+\mathrm{Z}(\mathrm{x}+\mathrm{L})] / 2
$$

obtēm-se a eq. (7):

$$
s^{2}=\frac{1}{2}[z(x)-z(x+L)]^{2}
$$

A terminologia para $\mathrm{s}^{2}$ da eq. (7) varia, sendo encontrados termos para a função gräfica como: variograma e semivariograma. WEBSTER (1985) esclarece que, embora seja largamente usado o termo semivariância, é importante lembrar que $\mathrm{s}^{2}$ é a variância dessas duas observações; e se, além disso, ocorrem n pares de observações separadas pelo mesmo "lag" L, então a média poderā ser definida conforme a eq. (8):

$$
\bar{s}^{2}=\frac{1}{2 n} \sum_{i=1}^{n}\left[z\left(x_{i}\right)-z\left(x_{i}+L\right)\right]^{2}
$$

Onde a hipótese intrínseca è mantida, o mesmo grau de diferença nas propriedades atuais do solo em qualquer dois lugares 
distanciados de L. Nestas circunstâncias, o valor da amostra $\overline{\mathrm{s}}^{2}$ na eq. (8) é um estimador sem tendências de $\gamma(L)$, o qual corresponde à semivariância média da população.

Na forma gráfica, a função semivariância, ou o semivariograma, apresenta em condições ideais o seguinte comportamento: (i) para um "lag" zero, a função semivariância è zero ou não mostra variância; (ii) com o aumento de L, $\gamma(\mathrm{L})$ cresce gradualmente e aproxima-se de uma constante (C, a variância da população), atingindo um patamar denominado de "sill" (CLARK, 1979).

A dependência das observações é avaliada pela estrutura do semivariograma, e a distância na qual estas começam a ficar independentes, próximo à variância da população, a qual é chamada de alcance ou raio de influência $(\lambda)$

Existem vários outros modelos de semivariogramas, sendo mais comumente usados: o modelo esférico, o exponencial, e o linear (Figura 4), enquanto que outros modelos poderão ser mais apropriados para situações particulares (CLARK, 1979; VIEIRA et alii, 1981; GUTJAHR, 1985).

BURGESS \& WEBSTER (1980) comentam que, pela definição, $\gamma(L)=0$ quando $L=0$, mas que, entretanto, na prática, as curvas dos valores da semivariância não passam necessariamente pela origem. Em vez disto, pode aparecer um valor finito e positivo para $\gamma(L)$ em valores de L próximos de zero. Este fenômeno é conhecido como efeito pepita (efeito "nugget"). Este efeito abrange flutuações no solo que ocorrem a distâncias mais curtas que o intervalo de amostragem, definindo tambēm a precișão da interpolação. GUTJAHR 

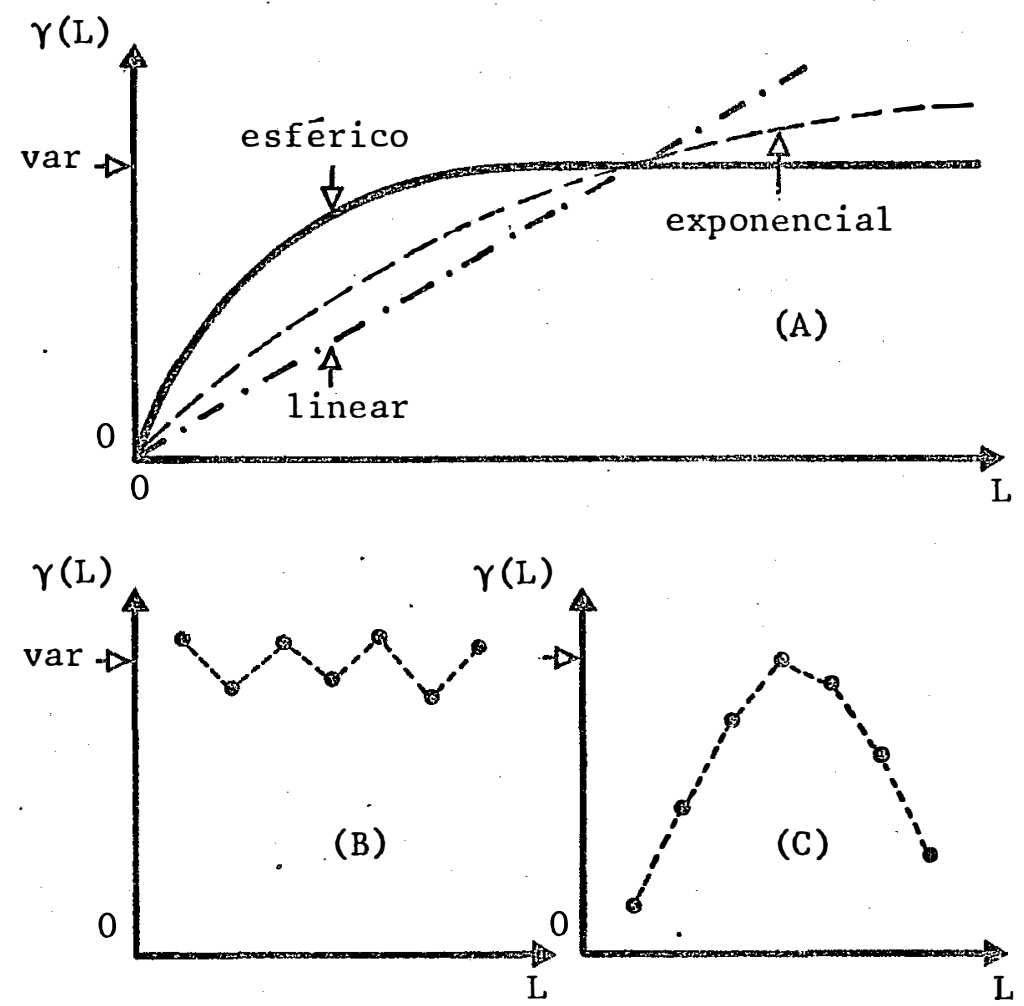

FIGURA 4 - Alguns modelos de semivariogramas. 
(1984) considera ser o efeito pepita um padrão para a medida de erros de estimativas.

GUROVICH \& STERN (1983a) indicam algumas situações präticas de ocorrência dos modelos dos semivariogramas da Figura 4. Para o caso da situação (b), consideram um semivariograma sem nenhuma estrutura, onde as observações estão distribuidas ao acaso no espaço (por outros autores é chamado de efeito "nugget" puro). 0 semivariograma da situação (c) indica uma forma de estrutura espacial, na qual os valores de $Z$ localizados a grandes distâncias se tornam similares aos valores de $\mathrm{Z}$ na origem, isto $\bar{e}$, existe periodicidade.

A determinação do alcance a partir do semivariograma tem sido sugerida por vārios autores. Se $\gamma(L)$ aproxima-se do máximo assintoticamente, então o alcance $\lambda$ pode ser determinado, para propósitos prāticos, no ponto onde a função atinge o valor da variância da população (ou variância tota1). Os pontos que se apresentarem em menores distâncias que o alcance serão espacialmente dependentes. Pares de observações mais espaçadas que $\lambda$ não estão relacionados entre si, a menos que ocorram variações periódicas do parâmetro no solo (BURGGES \& WEBSTER, 1980).

Como o alcance para o semivariograma, geralmente, è considerado como a distância na qual a função atinge o patamar ("sill"), e como, na prática, este patamar não é sempre bem definido, CLARK (1979), BURGGES \& WEBSTER (1980), VIEIRA et alii. (1983) e outros, utilizam para o alcance, o ponto em que a tangente dos primeiros pontos da curva representativa da função semivariância atinge a altura do patamar ("sili"), e estabelecem ser esta distância equivalente a $2 / 3$ do alcance, seguindo estes autores uma alternativa proposta por Matheron. 
Uma vez que o valor da variância da população pode apresentạr um intervalo de confiança através dos limites obtidos pelo qui-quadrado, como apresenta SNEDECOR \& COCHRAN (1980, página 103), poderia assim ser estabelecido o ponto em que a função não difere da variância da população, com a distância correspondendo ao alcance. Ainda pela variação dos gamas médios, conforme apresentado por VIEIRA (1981), este valor do alcance poderia ser obtido pelo erro padrão do gama. Os valores de $\gamma(L)$ que apresentarem erros que atinjam a variância da população, poderiam ser utilizados como referência no gräfico para estabelecer a distância além da qual as observações passarão a ser independentes.

\subsection{Aplicação da geoestatística na ärea agronômica}

0 método geoestatístico tem sido utilizado em estudos de classificação e de levantamento de solos, podendo-se citar, entre outros, WEBSTER (1973), WEBSTER \& CUANALO (1975), WEBSTER \& BUTLER (1976), Mc BRATNEY \& WEBSTER (1981a), BUONA (1985), GRUIJTER \& MARSMAN (1985) e WILDING (1985). WEBSTER \& CUANALO (1975), por exemplo, observou existir relação entre $\mathrm{pH}$ do solo e a sua litologia, encontrando, em um traçado de $3,2 \mathrm{~km}$, amostrado de 10 em 10 metros, forte autocorrelação para os valores de $\mathrm{pH}$, decrescendo próximo aos 230 metros. Ocorrendo o mesmo para valores de argila no horizonte superficial, enquanto para os valores de silte, a função autocorrelação decresceu próximo aos 400 metros.

Vārios outros estudos do solo utilizam o método geoestatístico, entre eles os ligados às suas propriedades físicas, 
químicas e biológicas.

XU \& WEBSTER_(1984), trabalhando em uma ārea de 3635 $\mathrm{Km}^{2}$, nà China, coletaram 102 amostras da superfície do solo, que foram irregularmente espaçadas. Os semivariogramas obtidos para matéria orgânica, nitrogênio, fósforo e areia, apresentaram-se lineares com um grande efeito "nugget" e pequena variação no alcance para estes parâmetros. Os valores de $\gamma(\mathrm{L})$ obtidos para o potássio oscilaram em torno da variância da população, desde os "1ags" iniciais, indicando independência entre as observações (efeito "nugget"puro). Os valores de $\mathrm{pH}$ do solo apresentaram forte dependência espacial com um semivariograma do tipo exponencial. Concluem os autores que a amostragem do solo para determinação do $\mathrm{pH}$ poderá sér efetuada a cada $1,3 \mathrm{Km}$, obtendo erro padrão máximo de 0,2 unidades de $\mathrm{pH}$ para blocos de $1 \mathrm{Km}$ x $1 \mathrm{Km}$.

O'HALLORAN et alii (1985), estudando fósforo do solo em uma ārea de $10,5 \mathrm{~m} \times 40 \mathrm{~m}$, retirando 132 amostras regularmente espaçadas, concluiram que mais de $90 \%$ da variação do teor de $\mathrm{P}$ do solo foi devida à sua mudança textural (negativamente correlacionado com o conteúdo de areia). Consideram os autores que a intensi-dade de amostragem poderá ser significativamente reduzida em estudọs de mudanças temporais do teor de $\mathrm{P}$ do solo, em locais experimentais.

VAUCLIN et alii (1983) coletaram amostras de solo espaçadas de $10 \mathrm{~m}$ em uma ārea de $40 \mathrm{~m}$ x $70 \mathrm{~m}$. Obtiveram a estabilização da função semivariograma próximo aos $30 \mathrm{~m}$ para areia e argila e aos $50 \mathrm{~m}$ para silte.

Um estudo da variabilidade espacial do solo quanto à propriedade biológica, ’’ apresentado por WOLLUM et alii (1984), avaliando a população de Rhizobium japonicum em dois tipós de solo. 
As propriedades hídricas do solo, analisadas sob o ponto de vista da Teoria das Variāveis Regionalizadas, são encontradas em trabalhos como RUSSO \& BRESLER (1981), VIEIRA et alii (1981), GAJEM et alii. (1981), GUROVICH (1982), GUROVICH \& STERN (1983a,b), NIELSEN et a1ii. (1983), NIELSEN \& CASSEL (1984), DUFFY (1985), WIERENGA (1984), WAGENET (1984), LIBARDI et alii. (1986), e outros.

Embora outras teorias, com amostras regionalizadas, sejam comumente utilizadas em. levantamentos ecológicos, como as observadas em CORMACK \& ORD (1979), na ārea agronômica vem sendo utilizada a geoestatística, sendo a maioria dos trabalhos ligados às propriedades do solo (citados anteriormente) e poucos ligados aos parâmetros de produção e à planta em si.

Uma das primeiras informações associando a variabilidade espacial que se observa nos rendimentos das culturas, em relação à água de irrigação, foi apresentada por Bresler et alii*, em 1981 (GUROVICH, 1982). Outro trabalho sobre este assunto foi publicado por BRESLER et alii (1981).

MC BRATNEY \& WEBSTER (1981b) apresentam um estudo considerando a variabilidade espacial obtida na produção de trigo. VIEIRA et alii. (1983), utilizando os dados de produção de trigo e de percentagem de nitrogênio nos grãos, obtidos por Mọtgomery* em 1913, encontraram estrutura do semivariograma, para o primeiro, com patamar ("sil1") próximo a $1 / 5$ da distância total, sendo que os va-

*BRESLER, E.; DAGAN, G.; HANKS, J. Statistical analysis of crop yield under controlled line-source irrigation. (in press). (comunicaciōn persona1). 1981. .

*MONTGOMERY, E.G. Experiments in wheat breeding: experimenta1 error in the nursey and variation in nitrogen and yield. Bur. Plant Indust., Dep. Agr. Est. Unidos, Bo1. 269, 1913. $61 \mathrm{p}$. 
lores da \% de $\mathrm{N}$ nos grãos apresentaram semivariogramas com estrutura muito pouco definida. Neste trabailho de VIEIRA et alii (1983) foram analisados ainda os dados dos experimentos de Waynick* de 1918 em delineamento circular, e de Waynick \& Sharp* de 1919 para outras propriedades do solo.

MC BRATNEY (1984) apresenta dois experimentos de campo, relacionados com a variação encontrada na distribuição da produção de culturas. 0 autor fez análise geoestatística com os dados originais de Batchelor \& Reed*, para produção de laranja em 1918, e com os dados de Gomez e Gomez*, para a produção de arroz, no ano de 1976. Tais dados foram obtidos de pontos distanciados regularmente. Os resultados dos autocorrelogramas foram confrontados, ambos bidimensionais, sendo observada a existência de maior anisotropia na distribuição espacial da produção de arroz do que na de laranja.

UEHARA et alii. (1985), além de apresentar dados de comportamento espacial de propriedades físicas e químicas do solo, em āreas de grandes extensões, apresentam também resultados de um experimento com arroz, o qual será citado a seguir. Em uma ārea de $28 \mathrm{~m} \times 28 \mathrm{~m}$, foram feitas 116 amostragens, sendo que as linhas diagonais e as centrais possuiam espaçamentos menores. Estas amostras

*WAYNICK, D.D. Variability in soils and its significance to past and future soil investigations. I. Statistical study of nitrification in soils. Univ. Cal. Publ. Agr. Sci., $\underline{\text { 3: }}$ 243-270, 1918.

*WAYNICK, D.D. \& SHARP, L.T. Variability in soils and its significance to past and future soil investigations. II. Variation in nitrogen and carbon in field soils and their relation to the accuracy of field trials. Univ. Cal. Pub1. Agr. Sci., 4: 121-139, 1919.

*BATCHELOR, L.D. \& REED, H.S. Relation of the variability of fruit trees to the accuracy of field trials. J. Agric. Res., 12: 245283, 1918.

*GOMEZ, K.A. \& GOMEZ, A.A. Statistical methods for agricultural research with emphasis on rice. IRRI, Los Baños, p. 208-209, 1976. 
constaram de coletas de plantas para obtenção dos componentes da produção e de amostras de solo, as quaiis foram analisadas para saturação em alumínio, pH e outras propriedades químicas do solo. 0 efeito da toxidez por alumínio foi refletido na produção de grãos, apresentando uma correlação negativa de 0,51 entre a saturação de alumínio (\%) e o peso de grãos secos $\left(\mathrm{g} / \mathrm{m}^{2}\right)$. 0 alcance da dependência espacial para os componentes da produção foi maior do que para as propriedades do solo, embora estas sejam consideradas de influência no desenvolvimento das plantas. 0 coeficiente de correlação mais elevado foi obtido para o peso de grãos secos $\left(\mathrm{g} / \mathrm{m}^{2}\right)$ x cálcio trocável (meq/100 g), no valor de 0,55. 0 autor, analisando os resultados encontrados, acredita que a variabilidade natural do solo poderá ser explorada para responder questões agronômicas.

Aparentemente, esta etapa do uso da geoestatística em relação ao rendimento dos cultivos, está em seu início e as perspectivas de desenvolvimento parecem de grande interesse em muitas disciplinas (GUROVICH, 1982). 


\section{MATERIAL E MÉTODOS}

3.1. Loca1

A ārea estudada estā situada em Piracicaba, estado de São Paulo, no campus da Universidade de São Paulo - Escola Superior de Agricultura "Luiz de Queiroz", a 100 m do Posto Agrometeorológico do Departámento de Física e Meteorologia, localizado a $580 \mathrm{~m}$ acima do nível do mar, com coordenadas geogräficas de $22^{\circ} 42^{\prime} 30^{\prime \prime}$ de latitude su1 e $45^{\circ} 38^{\prime} 00^{\prime \prime}$ de longitude oeste.

\subsection{Caracterização da ārea experimental.}

o local possui relevo ondulado, mas a ārea experimental é praticamente plana, apresentando aproximadamente $6 \%$ de declividade no sentido SW-NE.

0 solo do local foi classificado por RANZANI et alii. (1966) como uma Terra Roxa Estruturada, série "Luiz de Queiroz". De acordo com a classificação americana (ESTADOS UNIDOS, 1975), è um Paleudalf óxico. Este tipo de solo apresenta um perfil homogêneo muito profundo, com lençol freático a vários metros abaixo da sua superfície. 
Muitas culturas foram pesquisadas anteriormente nessa ārea, sendo as principais: pastagens, café, cana-de-açūcar, arroz de sequeiro, feijão e milho. As duas ūltimas culturas estiveram recentemente instaladas na ārea (1/3 feijão e 2/3 milho).

\subsection{Dimensões da ārea}

Com 4810 metros quadrados, a ārea experimental foi locada com 37 m no sentido SW-NE e $130 \mathrm{~m}$ no sentido NW-SE e estaqueada de 10 em 10 metros, conforme a Figura 5. As estacas representam a localização espacial de cada metro quadrado estudado.

\subsection{Caracterização da cultura}

A cultura instalada foi arroz de sequeiro, cultivar 164, desenvolvido pelo Instituto Agronômịco do Estado de São Paulo, Campinas, em 1980. Este cultivar apresenta ciclo precoce, porte médio, resistência moderada ao acamamento e à seca, sensibilidade moderada ao Brusone, e sua origem vem da hibridação e seleção posterior dos cultivares Dourado Precoce e IAC-1246 (FONSECA et alii, 1983).

\subsection{Prāticas agronômicas}

A adubação manual constou de $10 \mathrm{~g}$ por metro linear, da 


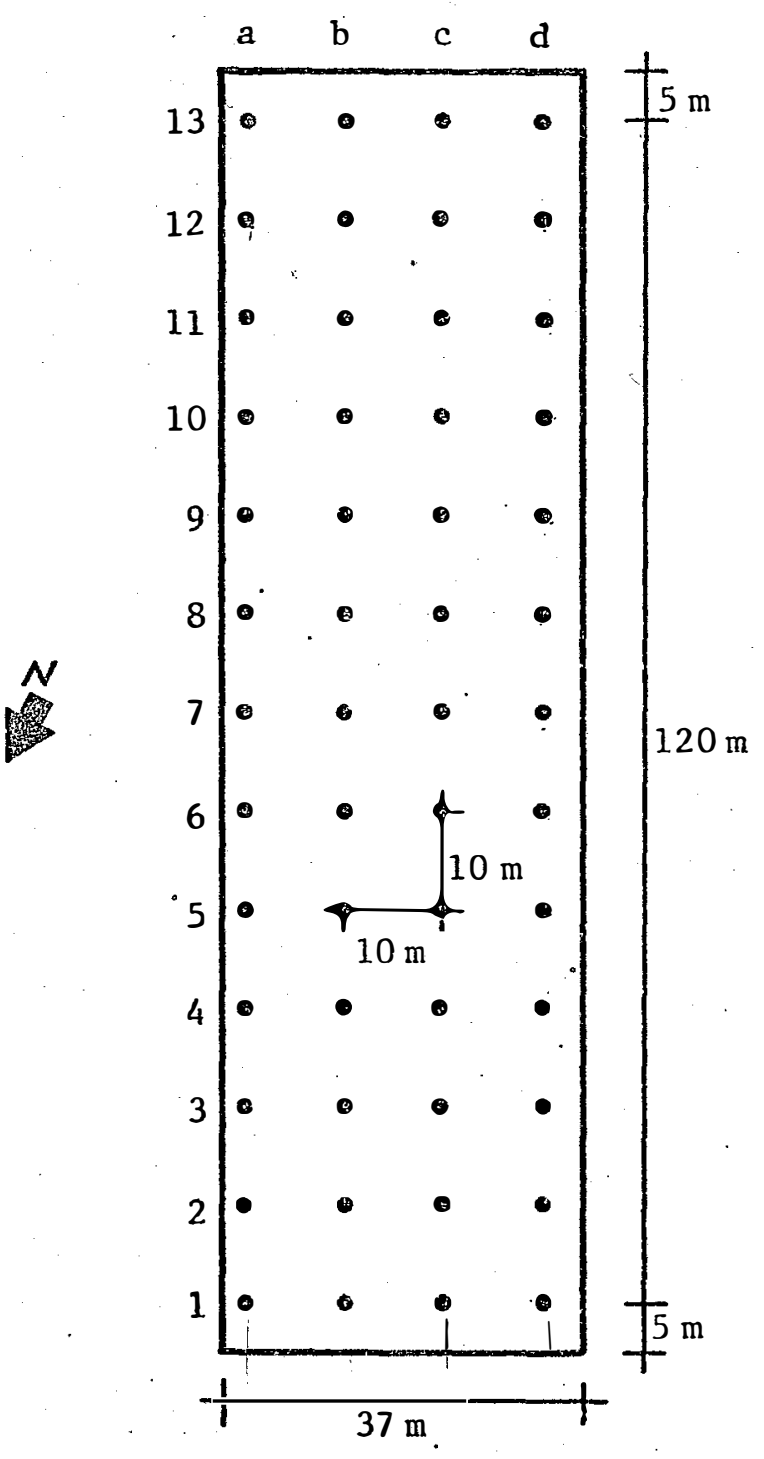

FIGURA 5 - Dimensões da ärea experimental. 
fórmula 10:10:10, correspondendo a $200 \mathrm{Kg}$ de NPK/ha, visando as necessidades nutricionais da cultura e a manutenção da fertilidade do solo.

A anālise química do solo apresentou os seguintes resultados (média de 52 amostras): 0,20 me $\mathrm{PO}_{4}^{-} / 100 \mathrm{ml}$ de terra; 0,55 me $\mathrm{K}^{+} / 100 \mathrm{ml}$ de terra; 4,57 $\mathrm{me} \mathrm{Ca}^{++} / 100 \mathrm{ml}$ de terra; 1,19 me $\mathrm{Mg}^{++} / 100 \mathrm{ml}$ de terra; $0,12 \mathrm{me} \mathrm{Al}^{+++} / 100 \mathrm{ml}$ de terra; 2,93 me $\mathrm{H}^{+} / 100 \mathrm{~m} 1$ de terra e $1,06 \%$ de carbono orgânico.

Após a adubação em $16 / 10 / 84$, foi realizada a semeadura manual em $17 / 10 / 84$, com 60 sementes viáveis por metro linear e espaçamento de $50 \mathrm{~cm}$ entre linhas.

A capina manual foi necessāria duas vezes antes das plantas atingirem $40 \mathrm{~cm}$ de altura.

No final da fase vegetativa, a irrigação foi necessāria, sendo realizada por aspersão, procurando-se manter uniformidade na distribuição de água.

A colheita individual da amostragem de cada metro quadrado foi iniciada aos 117 dias após a semeadura, sendo terminada em três dias. A área total foi colhida em seguida.

\subsection{Amostragens e determinações}

Todas as amostras tiveram como referência as 52 estacas, as quais foram identificadas por uma letra e um número, conforme Figura 5. 


\subsubsection{Solo}

Para as determinações, tanto químicas quanto físicas do solo, a camada superficial do solo (0-20 $\mathrm{cm}$ de profundidade) foi amostrada junto às estacas, em duas fases: uma, antes da adubação (a.a.) e outra, pös-colheita (p.c.).

As determinações analíticas, exceto $\mathrm{Zn}$, feitas no Laboratório de rotina do Departamento de Solos, Geologia e Fertilizantes da ESALQ/USP, fioram:

- Anālise Física

- granulometria: pelo método da pipeta (KILMER \& ALEXANDER, 1949) e com dispersão das amostras, feitas segundo PAULETTO (1978).

- Anālises Químicas.

- Zn: feita no laboratório de Nutrição Mineral do Departamento de Química, pela extração com DTPA e leitura no espectrofotômetro de absorção atômica (seguindo metodologia descrita por LINDSAY \& NORVELL, 1978).

As anālises a seguir seguiram metodologia descrita por CATANI \& JACINTHO (1974):

- pH em ägua: pelo potenciômetro, numa relação so1o/āgua de $1: 2,5$.

- carbônico orgânico: por via úmida, através da oxidação com $\mathrm{K}_{2} \mathrm{Cr}_{2} \mathrm{O}_{7}$ em presença de $\mathrm{H}_{2} \mathrm{SO}_{4}$ e titulação do excesso do oxidante com $\mathrm{FeSO}_{4} \cdot 7 \mathrm{H}_{2} \mathrm{O}$.

- fósforo: por extração com $\mathrm{H}_{2} \mathrm{SO}_{4} \quad 0,05 \mathrm{~N}$ e leitura em fotocolorímetro.

- cālcio e cálcio + magnésio: pela extração com KC1 
1N e titulação com EDTA:

- potāssio: pela fotometria de chama, apōs extração com ácido nïtrico $0,05 \mathrm{~N}$.

- alumínio: pela extração com KC1 1N e titulação com $\mathrm{NaOH} \quad 0,025 \mathrm{~N}$.

- acidez titulável pela extração com acetato de cálcio pH 7,0 e titulação com $\mathrm{NaOH} 0,025 \mathrm{~N}$.

\subsubsection{P1anta}

Para as determinações dos teores de $\mathrm{N}, \mathrm{P}, \mathrm{K}$ e $\mathrm{Zn}$ e para a àvaliação dos parâmetros de produção e da altura das plantas, a ārea de 1 metro quadrado, correspondente a cada estaca, foi considerada conforme a Figura 6 .

Em cada metro quadrado de terreno, além das contagens e medidas feitas a campo, foram coletadas 20 plantas (parte aérea) representativas desta ārea. Destas vinte plantas, dez foram usadas para a contagem e pesagem dos grãos e as outras dez, para a determinação da matéria seca e anālise de teores de nutrientes.

\subsubsection{Produção e seus componentes.}

- nümero de perfilhos por metro quadrado: contados por ocasião da colheita;

- número de panículas por metro quadrado: contados por ocasião da colheita;

- porcentagem de grãos chochos: obtida pela divisão do número de grãos chochos por metro quadrado peḷo número total dos grãos por 


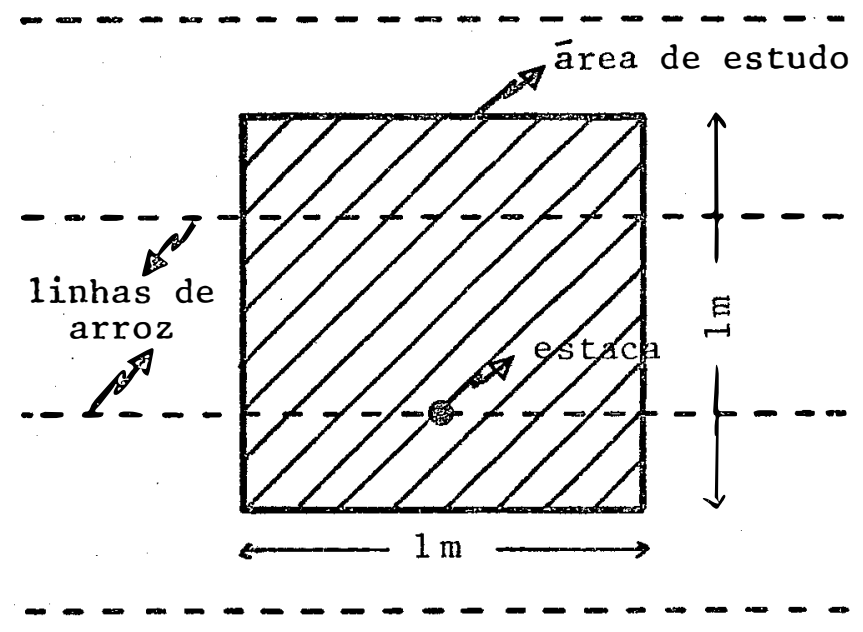

FIGURA 6 - Localização de āreas de estudo por estaca. 
metro quadrado, sendo o resultado multiplicado por 100;

- número de grãos cheios por panícula:'obtido pela contagem de todos os grãos cheios em cada 10 panículas representativas de um metro quadrado e divisão por 10;

- produção de grãos $\left(\mathrm{g} / \mathrm{m}^{2}\right)$ : obtida pela pesagem dos grãos cheios de 10 panículas, secos em estufa a $60^{\circ} \mathrm{C}$ até peso constante, e, após feita a correção para $13 \%$ de umidade, foi realizado o cálculo para o número de panículas por metro quadrado;

- peso de 100 grãos (g): obtido pela divisão do peso dos grãos cheios em 10 plantas pelo número de grãos cheios nestas 10 plantas representativas de cada metro quadrado, sendo o resultado multiplicado por 100;

- perfilhamento efetivo: obtido pela divisão do número de panículas por metro quadrado pelo nümero de perfilhos totais nesta mesma ärea.

\subsubsection{Altura}

A altura ( $\mathrm{cm})$ foi medida por ocasião da colheita, do nível do solo até a extremidade da panícula do colmo mais alto, de acordo com EMBRAPA (1977). Cada metro quadrado foi separado em 10 grupos de plantas, obtendo-se, assim, a média de 10 medidas por metro quadrado.

3.6.2.3. Rendimento de matéria seca

As 10 plantas coletadas, para esta determinação e para a análise do teor de nutrientes, foram lavadas em água de torneira, a seguir com solução de $\mathrm{HCl} 0,02 \mathrm{~N}$ e, finalmente, duas vezes em àgua destilada. Após, foram levadas à estufa a $60^{\circ} \mathrm{C}$ por 48 ho- 
ras, sendo, então, pesadas. Assim foi avaliado o rendimento de matéria seca da parte aérea, compreendendo: colmos, folhas, rāquis e panículas(grãos chochos e cheios) de 10 plantas representativas de cada metro quadrado. 0 valor de massa obtido foi multiplicado pelo número de perfilhos $/ \mathrm{m}^{2}$, obtendo-se a massa de matéria seca em $\mathrm{g} / \mathrm{m}^{2}$.

3.6.2.4. Indice de colheita.

0 Indice de colheita foi obtido pela relação entre a produção de grãos e o rendimento de matéria seca da parte aérea (DONALD, 1962).

\subsubsection{Anālise química.}

As 10 plantas utilizadas na determinação do rendimento de matéria seca foram moídas em moinho Wiley atē passarem por peneira 60 (malha de diâmetro igual a 0,25 mm) e encaminhadas ao 1aboratōrio de anālise de plantas do Instituto Agronômico do Estado de São Paulo, em Campinas (SP).

Conforme BATAGLIA et alii. (1978), as plantas foram analisadas para os teores de:

- nitrogênio: pela digestão com ācido sulfúrico e destilação da amônia em micro-Kjeldah1 e titulação com solução de HCl.

- fósforo: pela digestão com ācido e determinação colorimétrica do complexo fosfovanado-molíbdico.

- potässio e zinco: pela digestão com ácido e determinação do elemento por espectrofotometria de absorção atômica. 


\subsection{Anālise estatística}

Os dados obtidos foram analisados e interpretados através da Teoria das Variáveis Regionalizadas (Geoestatística), procedendo a autocorrelação e semivariância, conforme os programas no Anexo A, baseados nas informações fornecidas por CLARK (1979), VIEIRA (1981) e VIEIRA et alii (1983).

\subsubsection{Autocorrelação.}

A anālise da autocorrelação foi feita para examinar a relação espacial dos parâmetros relacionados ao solo è planta.

Estando os pontos distanciados regularmente, onde a unidade básica de distância é. o "lag" (L), foram determinados os coeficientes de autocorrelação $r(L)$ para diversos "lags", nas direções: (i) do comprimento do experimento, obtendo-se o $r(L)$ para uma direção; (ii) do comprimento e largura, obtendo-se o $r(L)$ médio para duas direções; e (iii) do comprimento, largura e todas as diagonais, obtendo-se o $\mathrm{r}(\mathrm{L})$ médio para tödas as direções. 0 coeficiente de autocorrelação foi estimado pela eq. (9) (WARRICK \& NIELSEN, 1980).

$$
r_{L}=c_{L} /(s)^{2}
$$

com

$$
c_{L}=\left(\underset{n-L-1}{\stackrel{1}{n}} \underset{i=1}{n=L}\left(Z_{(x)}-m\right)\left(Z_{(x+L)}-m\right)\right.
$$

e

$$
S=\left(\sum_{i=1}^{n}(z(x)-m)^{2} /(n-1)\right)^{1 / 2}
$$


onde $r(L)$ è o coeficiente de autocorrelação no "lag" L; m è a mé$\operatorname{dia}\left(m=\sum_{x=1}^{n} Z(x) / n\right) ; \quad s \quad e ́$ o desvio padrão dos $n$ valores observados e cada um "1ag" L foi equivalente a $10 \mathrm{~m}$.

Com os valores calculados da autocorrelação para os vārios intervalos, construiram-se os autocorrelogramas, os quais são diagramas de autocorrelação em função do "lag" L (valor 1 para o vizinho mais próximo, 2 para o seguinte com dois intervalos de L, valores fracionados para os casos de pontos distanciados em diagonais e assim por diante, conforme a Figura 7).

\subsubsection{Semivariograma}

A dependência espacial entre observações vizinhas de uma mesma série também foi expressa através de semivariogramas, os quais são diagramas dos valores da semivariância em função da distância.

A semivariância é definịda por VAUCLIN et alii. (1982), como metade da variância da diferença $\left(Z_{(x)}-Z_{(x+L)}\right)$, onde $Z$ é o valor da observação, $x$ é a posição de uma determinada amostra, $x+L$ é a posição da outra amostra, e L é a orientação relativa de uma em relação a outra do par de amostras estudadas ("1ag").

Pela equação 8 (item 2.2.3) foi calculada a semivariância, onde n é o número de pares de observações.

Para o semivariograma, utilizaram-se, além de todas as direções, a decomposição em quatro ângulos, conforme Figura 8. 

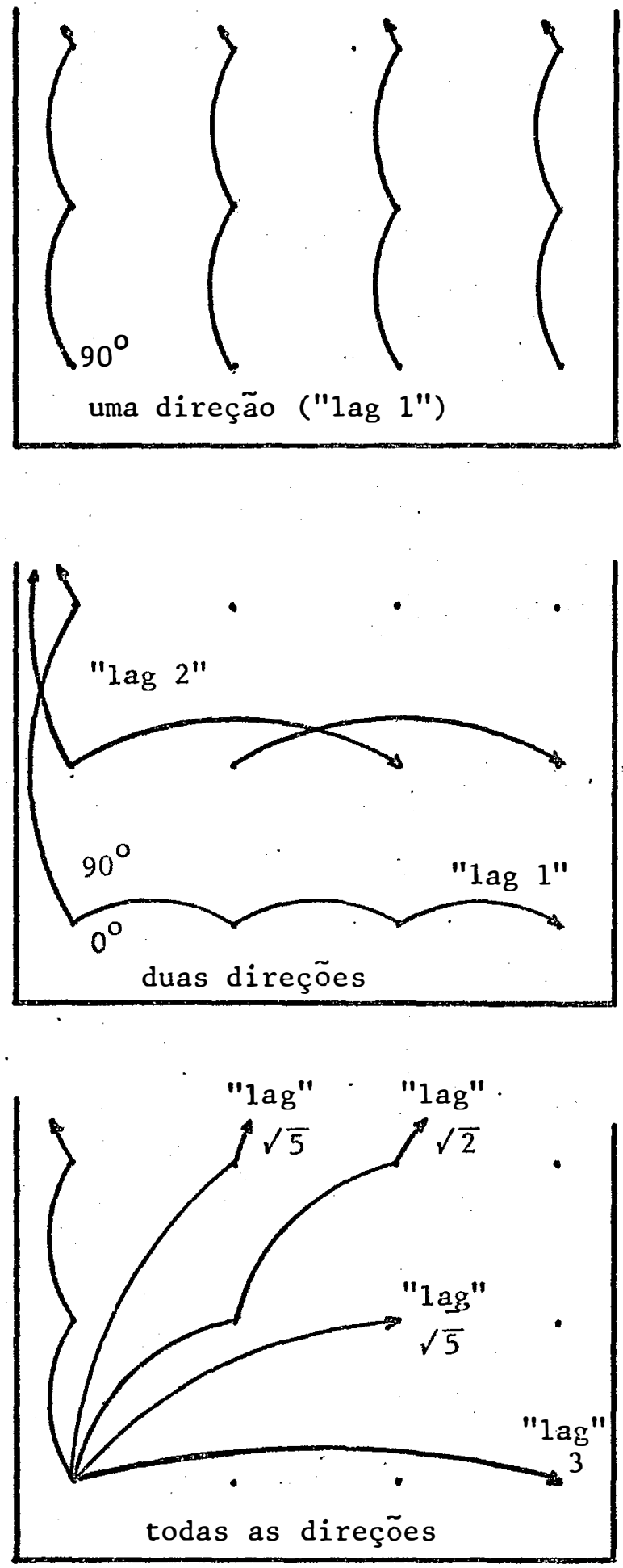

FIGURA 7 - Exemplo da tomada de pares para o autocorrelograma. 


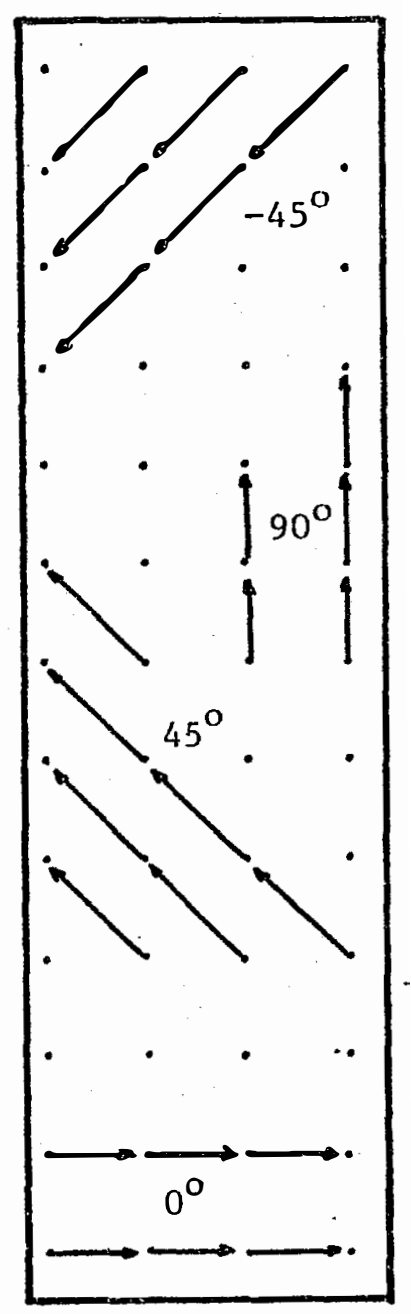

FIGURA 8 - Ângulos de decomposição do semivariograma. 


\subsubsection{Alcance}

0 tamanho de possíveis parcelas independentes e o número de amostras a serem coletadas na ārea, foram estabelecidos através do alcance para cada parâmetro estudado.

0 alcance, também denominado raio de influência, indica a distância entre observações além da qual a dependência é considerada nula.

Três metodologias foram seguidas para sua determinação: (i) escala integral; (ii) intervalo de confiança; ' e (iii) erro padrão do gama.

(i) A escala integral é a ärea abaixo da curva da função de autocorrelação. Para processos bidimensionais, a escala integral (E.I.) é definida pela eq. 3 (item 2.2.2), indicando o tamanho de uma subunidade dentro do campo, que pode ser considerada homogênea, com respeito às propriedades ou parâmetros em estudo (BRESLER et alii, i981; GUROVICH \& STERN, 1983a).

Os semivariogramas, correspondentes a cada autocorrelograma, foram sempre consultados, suprimindo dúvidas ou confirmando o seu comportamento.

(ii) 0 intervalo de confiança de 95\% (eq. 4, item 2.2.2) foi utilizado para verificação dos limites superior e inferior, de valores de $r(L)$, os quais não diferem de zero, deixando assim de estarem correlacionados. 0 número total de observações foi de $\mathrm{n}=52$ e o número de "lags" considerados foi de atē $\mathrm{L}=7$, uma vez que as observações foram subdivididas em quatro linhas de 13 cada. Com isto, procurou-se manter a validade do critério segundo HAAN (1977) (item 2.2.2). 
Desta forma, os limites superior e inferior foram de $r(L)=0,2521$ e $r(L)=-0,2914$, respéctivamente.

Realizou-se também o intervalo de confiança para a variância (qui-quadrado), o qual è vālido para populações de distribuição normal (SNEDECOR \& COCHRAN, 1980, página 103). Este intervalo visou verificar quando a semivariância não difere da variância da população amostrada. $\bar{A}$ medida que a distância aumenta, os valores de $\gamma(\mathrm{L})$ tendem a girar ao redor da variância da população amostrada representado por um patamar ("sill") no gräfico do semivariograma, indicando independência entre cada amostra.

(iii) 0 erro padrão do gama (EPG) foi calculado segundo VIEIRA (1982) pela eq. (10) e eq. (11).

$$
\begin{aligned}
& E P G=\sqrt{G V} / \sqrt{n-L} \\
& G V=\frac{1}{n_{(L)}} \cdot \Sigma\left[\frac{\left(Z(x)-z_{(x+L)}\right)^{2}}{2}\right]^{2}-\gamma_{(L)}^{2}
\end{aligned}
$$

onde GV é a variação dos gamas médios; n-L é o número de pares a considerar; $\mathrm{n}_{(\mathrm{L})}$ é o número de pontos amostrados; $\mathrm{z}$ é o valor da observação; x è a posição; L è o "lag" e $\gamma_{(L)}$ è o valor da semivariância estimado por $\mathrm{s}^{2}$ (eq. 8), para um determinado "1ag".

Através do erro de cada gama, foi possível estabelecer os $\gamma_{(L)}$ que não diferiram da variância da população amostrada, auxiliando, também, na determinação do alcance, ou seja, a distância dentro da qual existe dependência entre as amostras. 


\section{RESULTADOS}

Us valores de todos os parâmetros obtidos a partir de medições a campo, de análises de laboratório e de equações utilizando dados originais, estão apresentados no Anexo B. No Anexo C encontram-se os resultados calculados para a função autocorrelação, $r(L)$, e para a função semivariância, $\gamma(L)$.

A Tabela 1 contém a média, variância, desvio padrão, coeficiente de variação, coeficiente de simetria e curtose, para as 52 amostras de cada variável considerada.

Os autocorrelogramas e semivariogramas podem ser observados nos grä́icos das Figuras de 9 a 41, os quais foram elaborados levando em consideração uma direção $\left(90^{\circ}\right)$, duas direções $\left(0^{\circ}\right.$ e $90^{\circ}$ ) e todas as direções da distribuição das amostras no campo, conforme Figura 7.

Os gráficos das Figuras 42 e 43 exemplificam uma situação de limite fixo para o autocorrelograma (eq. 4) e semivariograma (SNEDECOR \& COCHRAN, 1980), respectivamente. Estes dois grāficos indicam ainda o alcance, pelo valor a. Um exemplo para limite variāvel, considerando o número de pares, é apresentado para o autocorrelograma na Figura 44 e para semivariograma na Figura 45, indicando, também, os respectivos alcances $(\lambda)$.

Através de diversas formas de se obter o alcance de cada variāvel, foi construída a Tabela 2. Nesta, constam os resul- 
tados da escala integral (E.I., eq. 3), o ponto aproximado (ka e kv), onde a função autocorrelograma atinge o zero e a função semivariância atinge a variância da população ("comprimento da autocorrelação" e "comprimento da semivariância", respectivamente) e o ponto aproximado, valor a (eq. 4), onde a função autocorrelação atinge o limite fixo superior, abaixo do qual não é significativamente diferente de zero $(r(L)=0,2521)$.

0 grāfico da Figura 46 exemplifica uma situação de decomposição do semivariograma para as direções $0^{\circ}, 90^{\circ}, 45^{\circ} \mathrm{e}-45^{\circ}$, onde também se observa o semivariograma que engloba todas as direções.

Outro exemplo de possível obtenção de alcance é encontrado no gráfico da Figura 47, o qual mostra a amplitude do erro do gama médio, calculado pela eq. (10). 


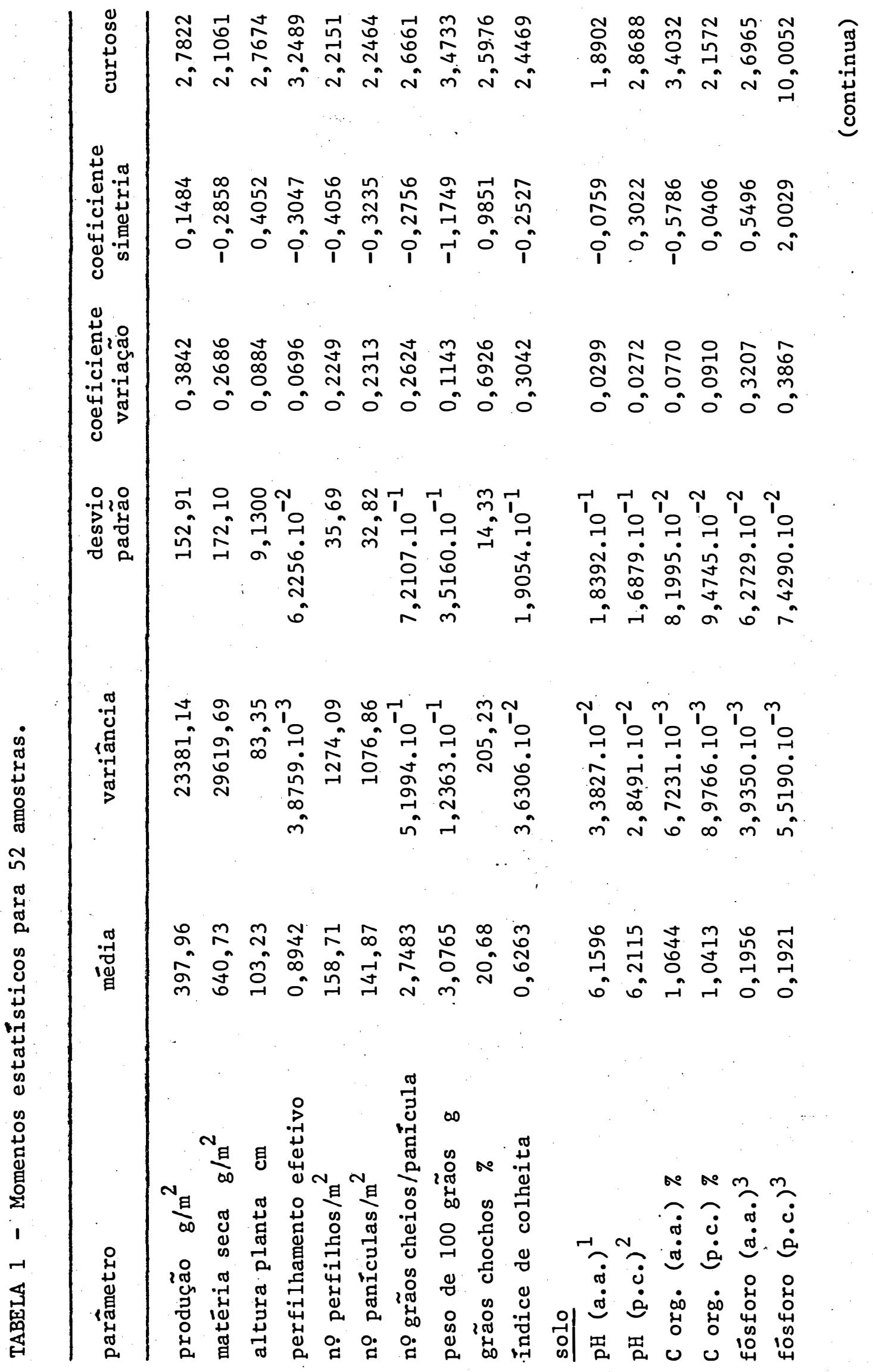




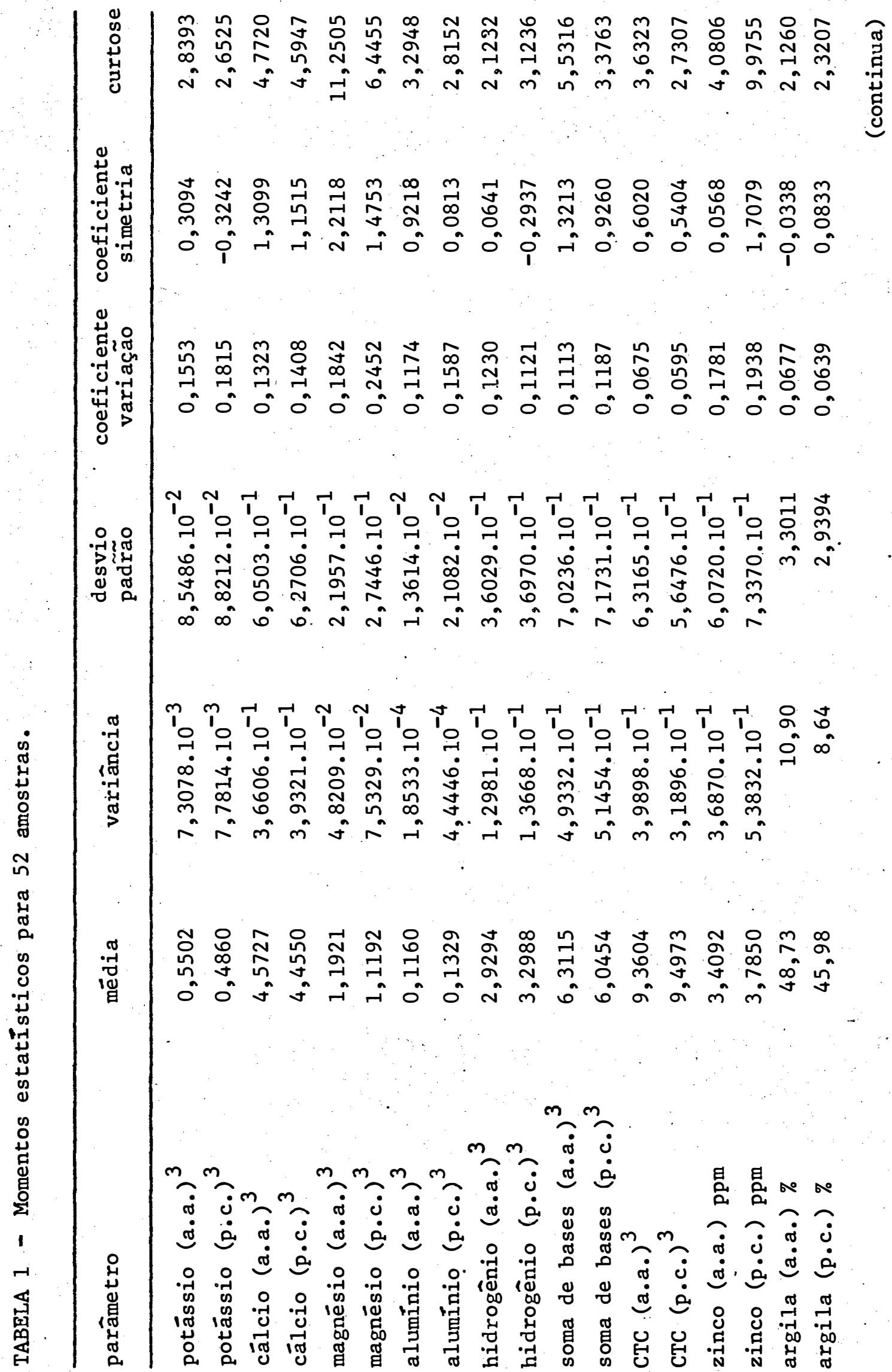




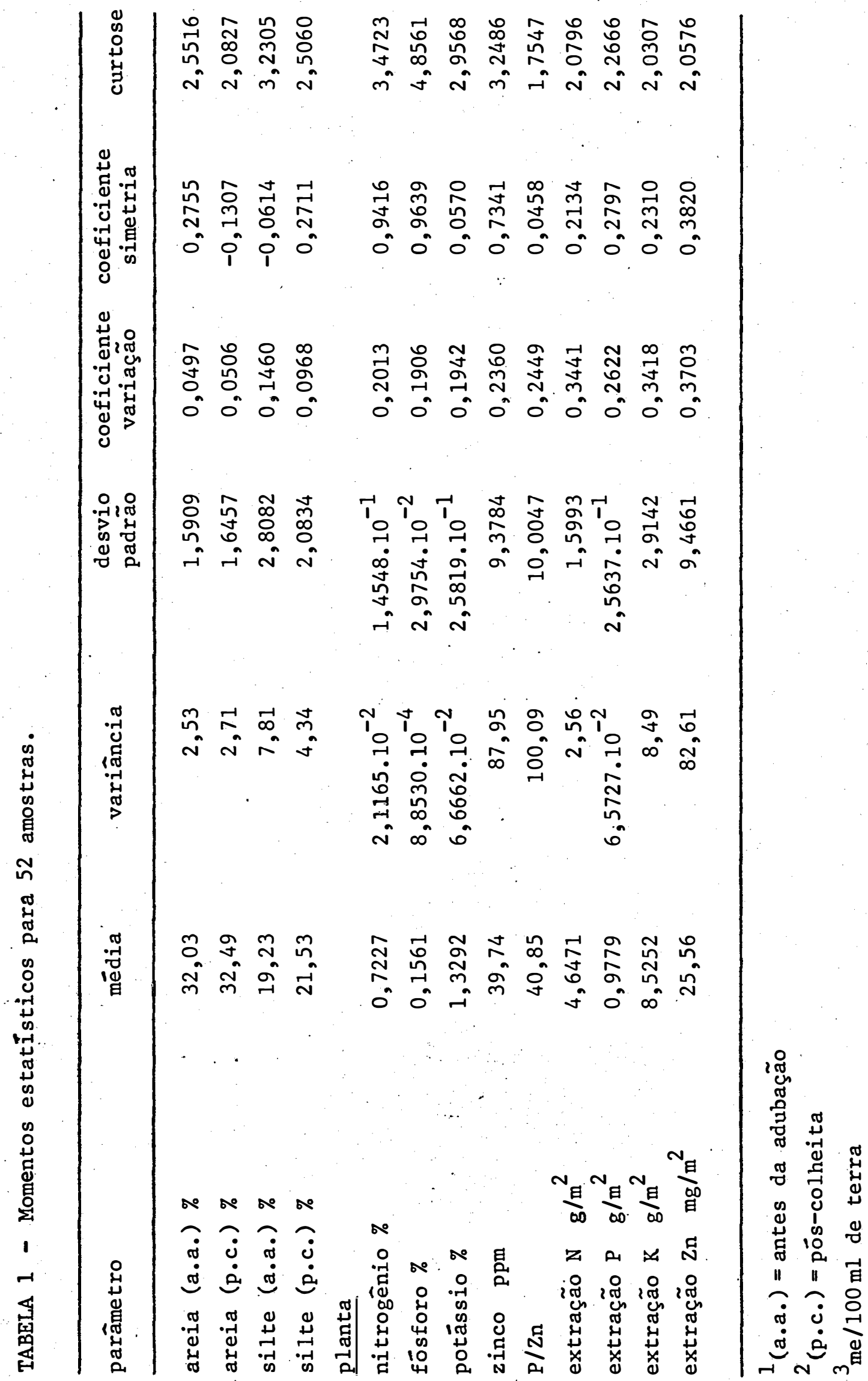



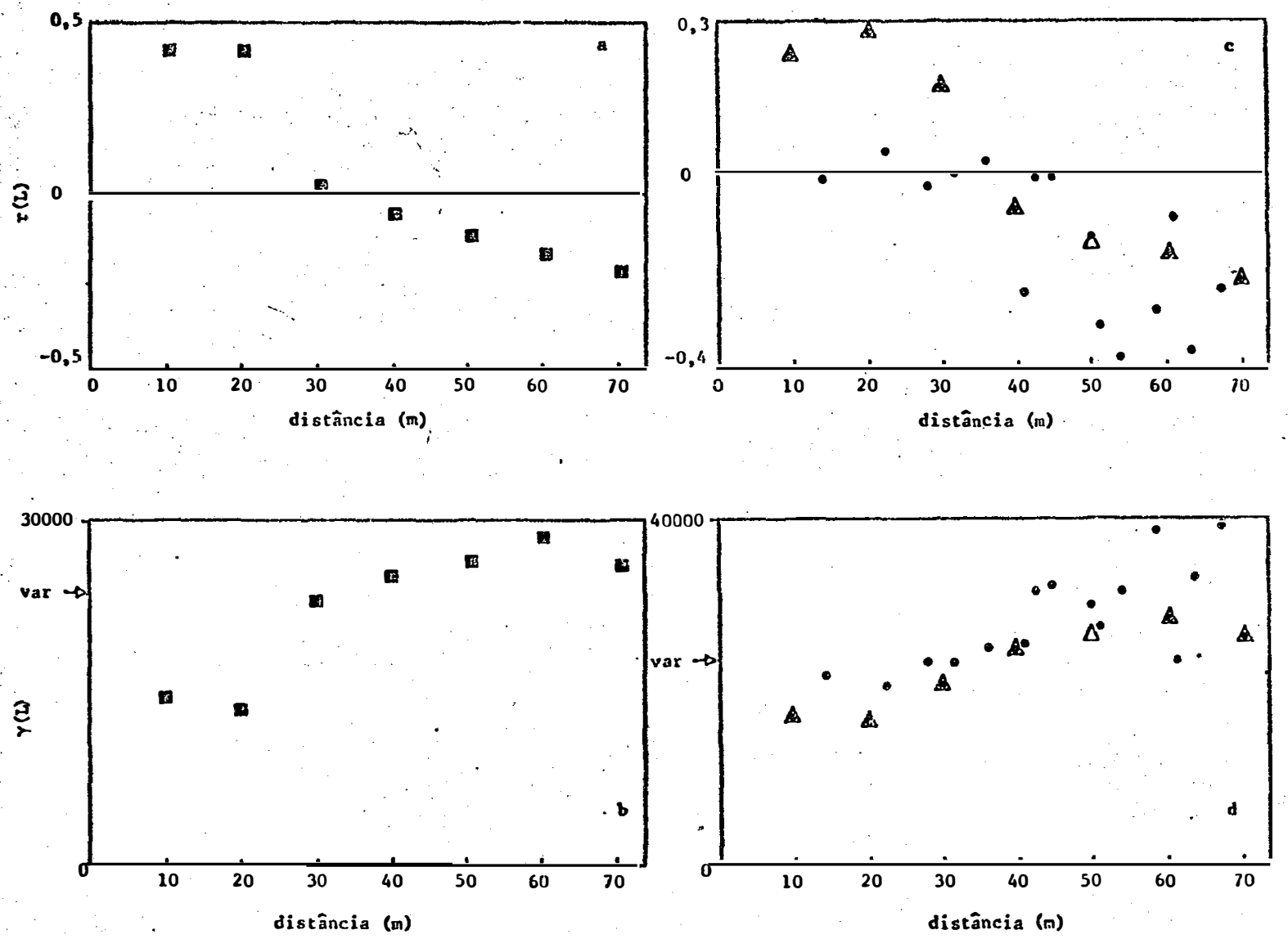

FIGURA 9 - Autocorrelogramas, $r(L)$ e semivariogramas, $Y(L)$ da produção de arroz para uma (圈), duas $(\Delta)$ e todas $(0)$ as direções. 

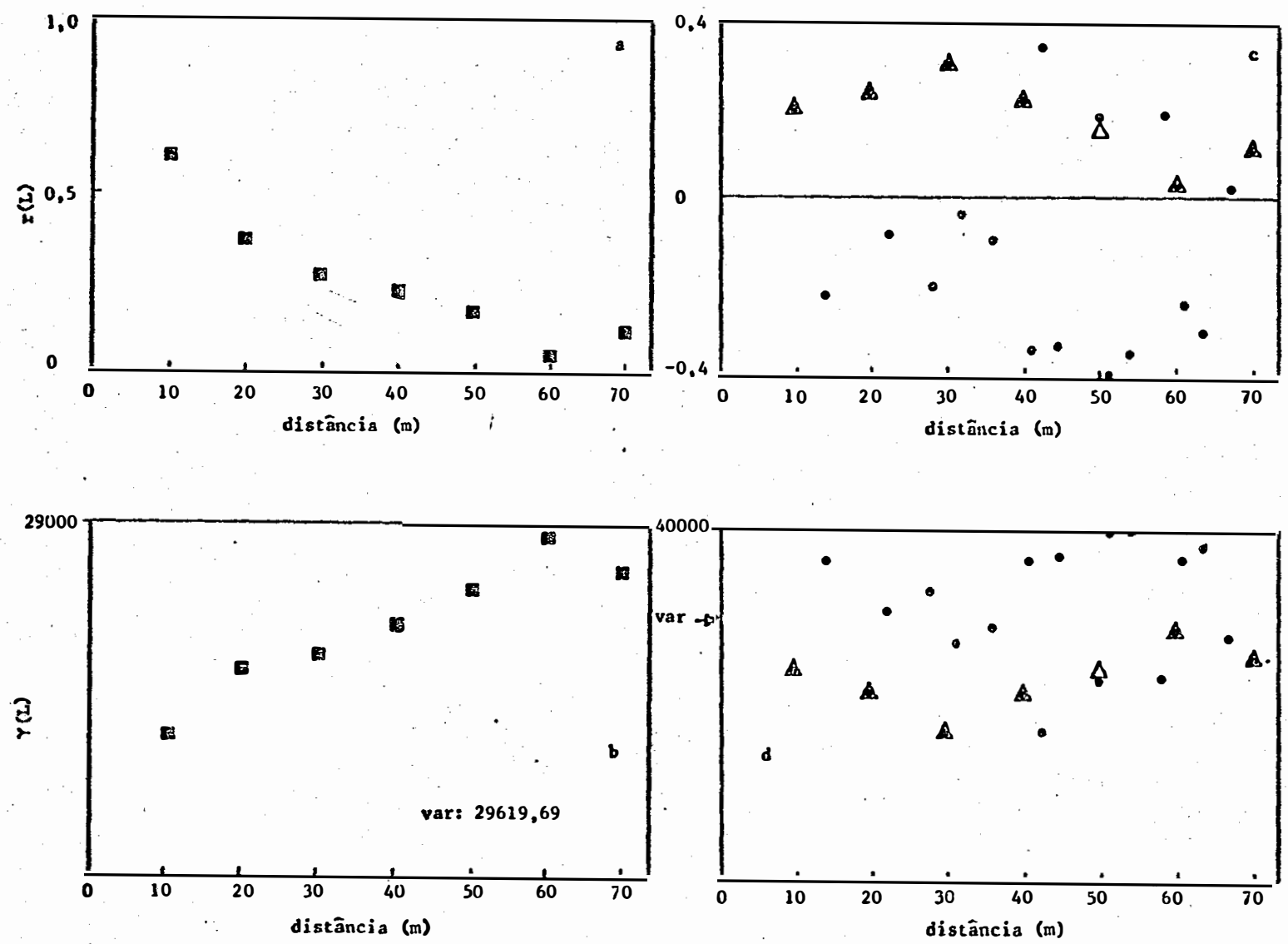

FIGURA 10 - Autocorrelogramas, $r(L)$ e semivariogramas, $\gamma(L)$ da matéria seca para uma (圈), duas $(\Delta)$ e todas $(\bullet)$ as direções. 

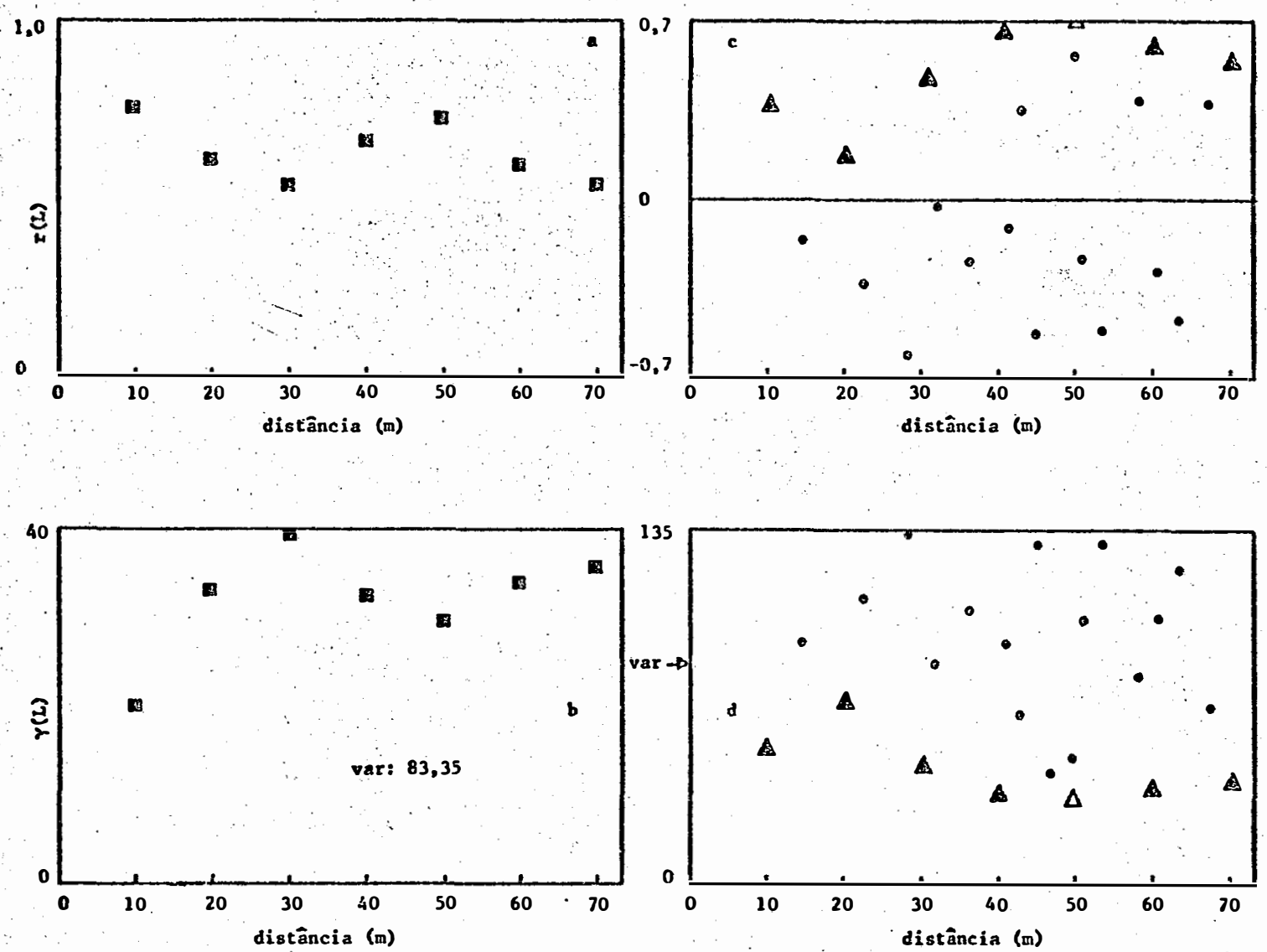

FIGURA 11 - Autocorrelogramas, $r(L)$ e semivariogramas, $\gamma(L)$ da altura de plantas para uma (国), duas $(\Delta)$ e todas $(\bullet)$ as direções. 

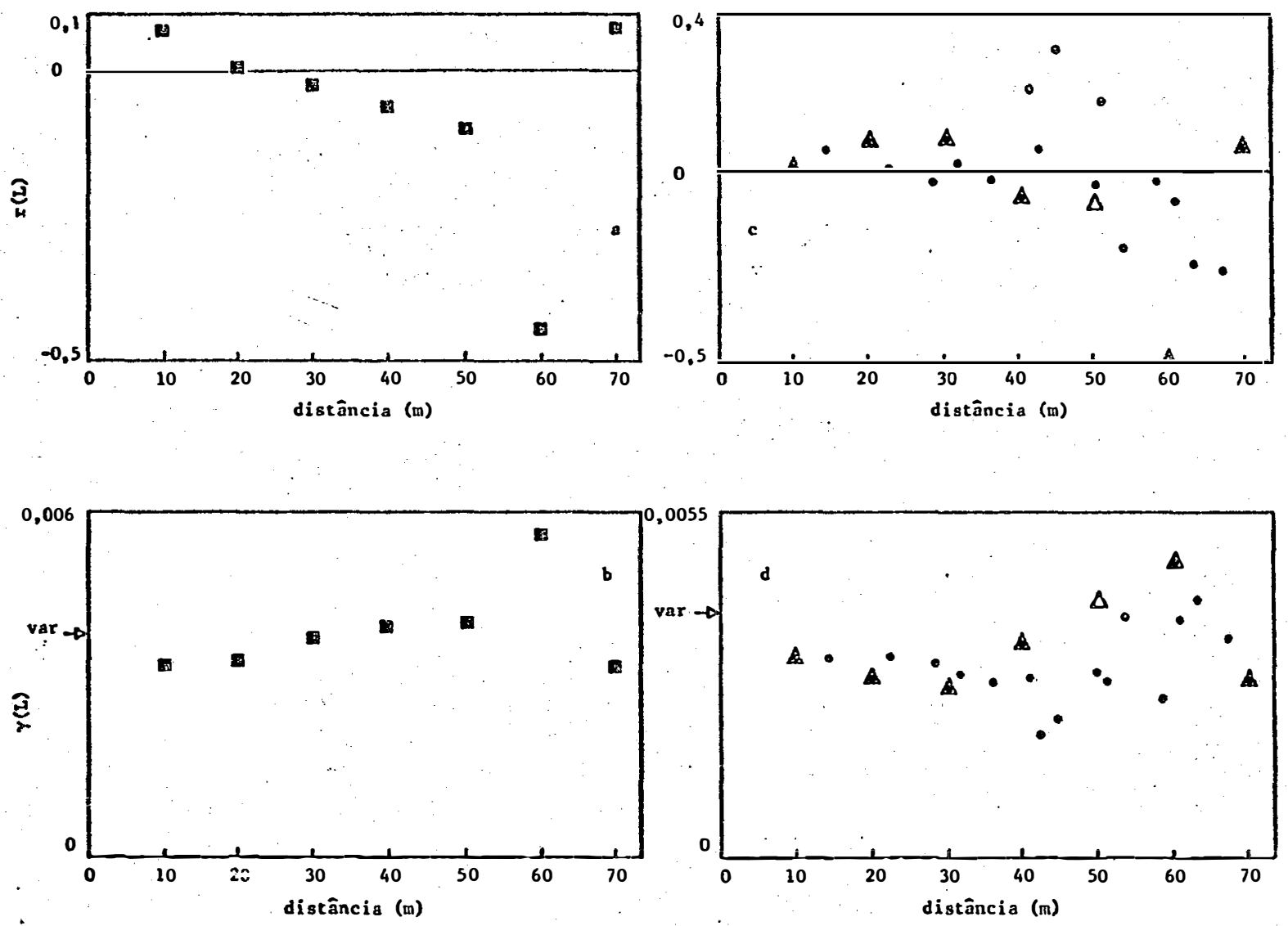

FIGURA 12 - Autocorrelogramas, $r(L)$ e semivariogramas, $\gamma(L)$ do perfilhamento efetivo para uma ( ) duas $(\Delta)$ e todas ( $\bullet$ ) as direções. 

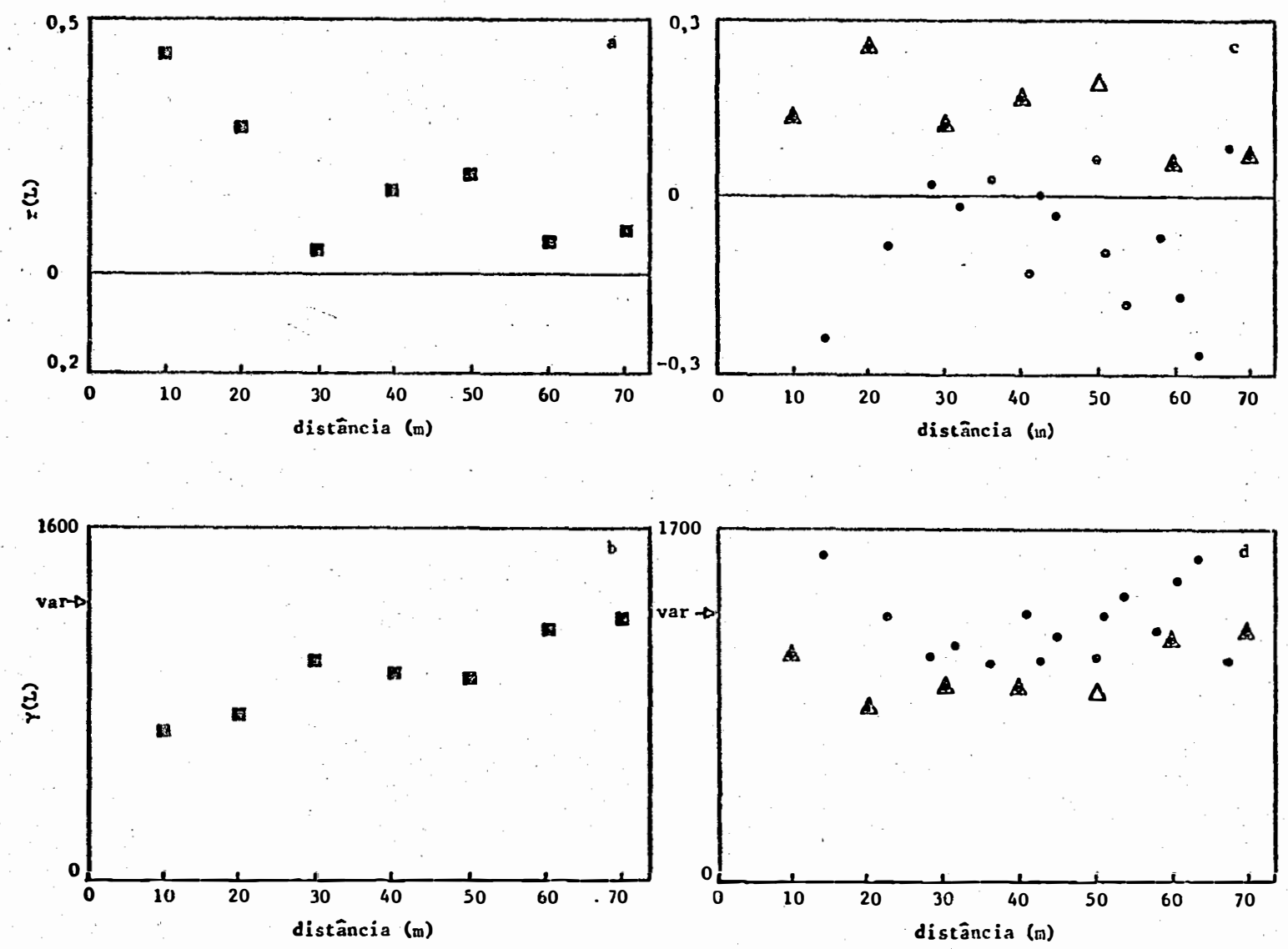

FIGURA 13 - Autocorrelogramas, $r(L)$ e semivariogramas, $\gamma(L)$ do número de perfilhos para uma $($ 国), duas $(\Delta)$ e todas $(\bullet)$ as direções. 

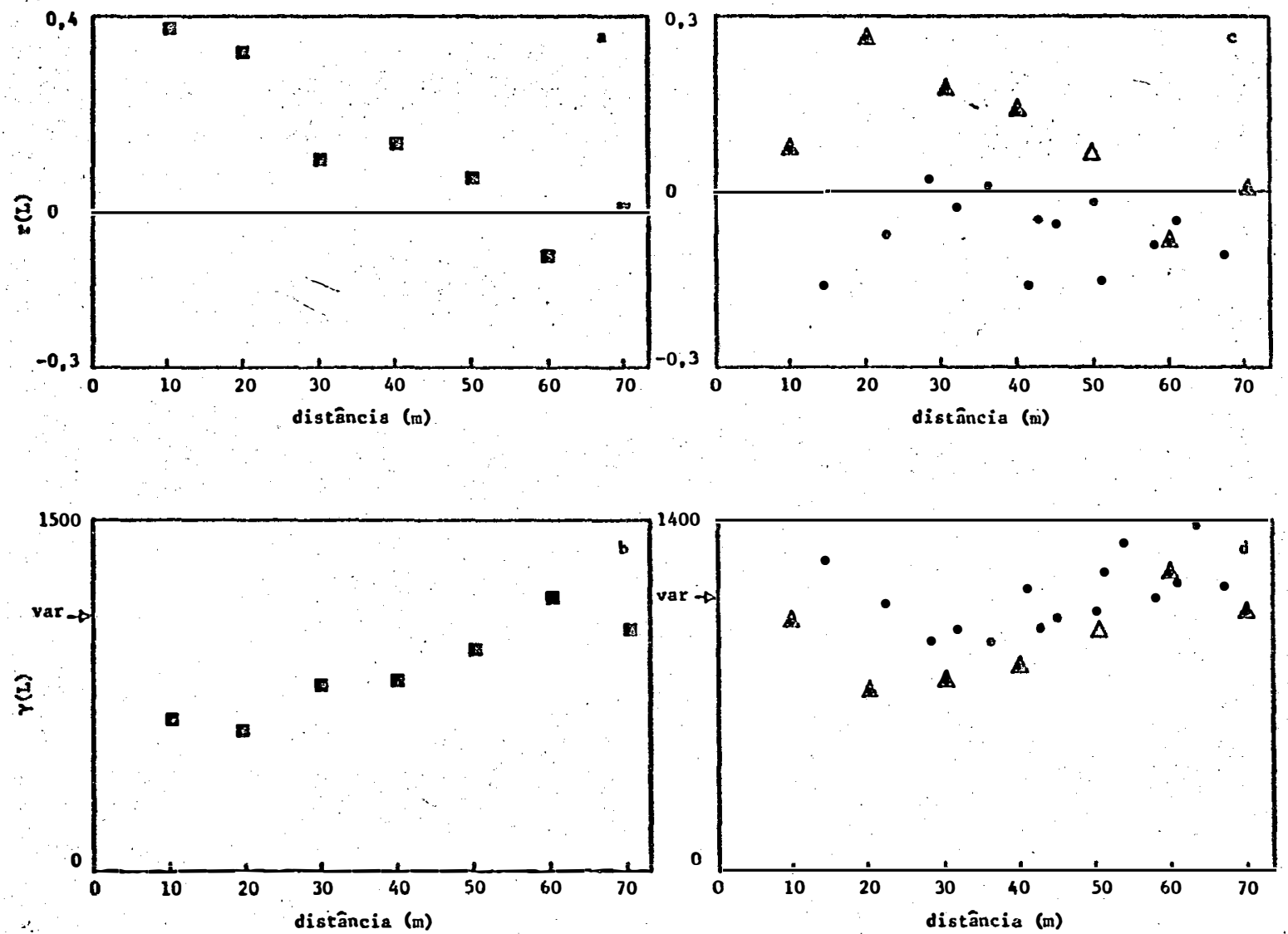

FIGURA 14 - Autocorrelogramas, $r(L)$ e semivariogramas, $\gamma(L)$ do número de. panículas para uma (⿴囗大 $)$, duas $(\Delta)$ e todas $(\bullet)$ as direções. 

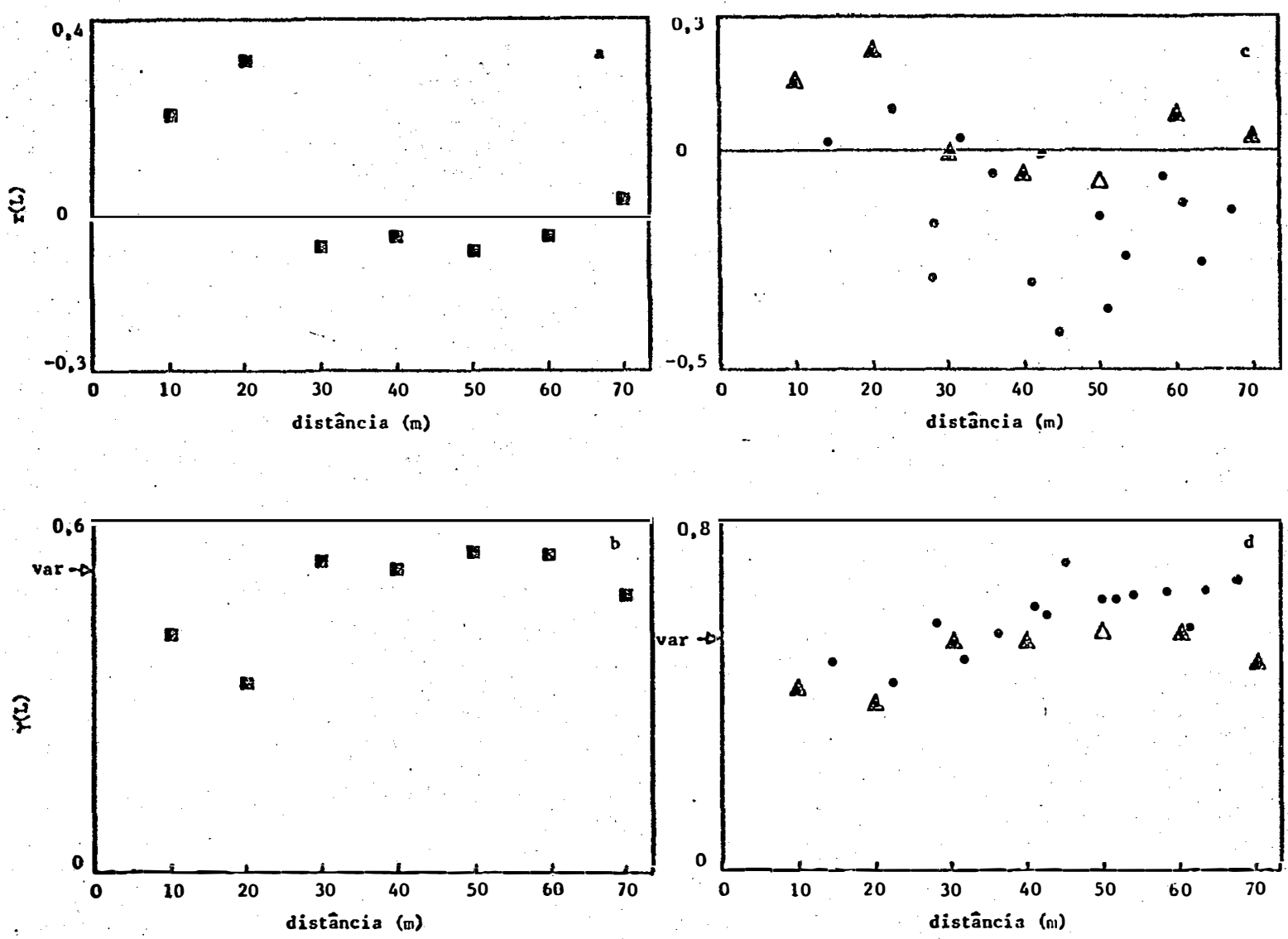

FIGURA 15 - Autocorrelogramas, $r(L)$ e semivariogramas, $Y(L)$ do número de grãos cheios/panícula para uma $(\mathbf{H})$, duas $(\Delta)$ e todas $(\bullet)$ as direções. 

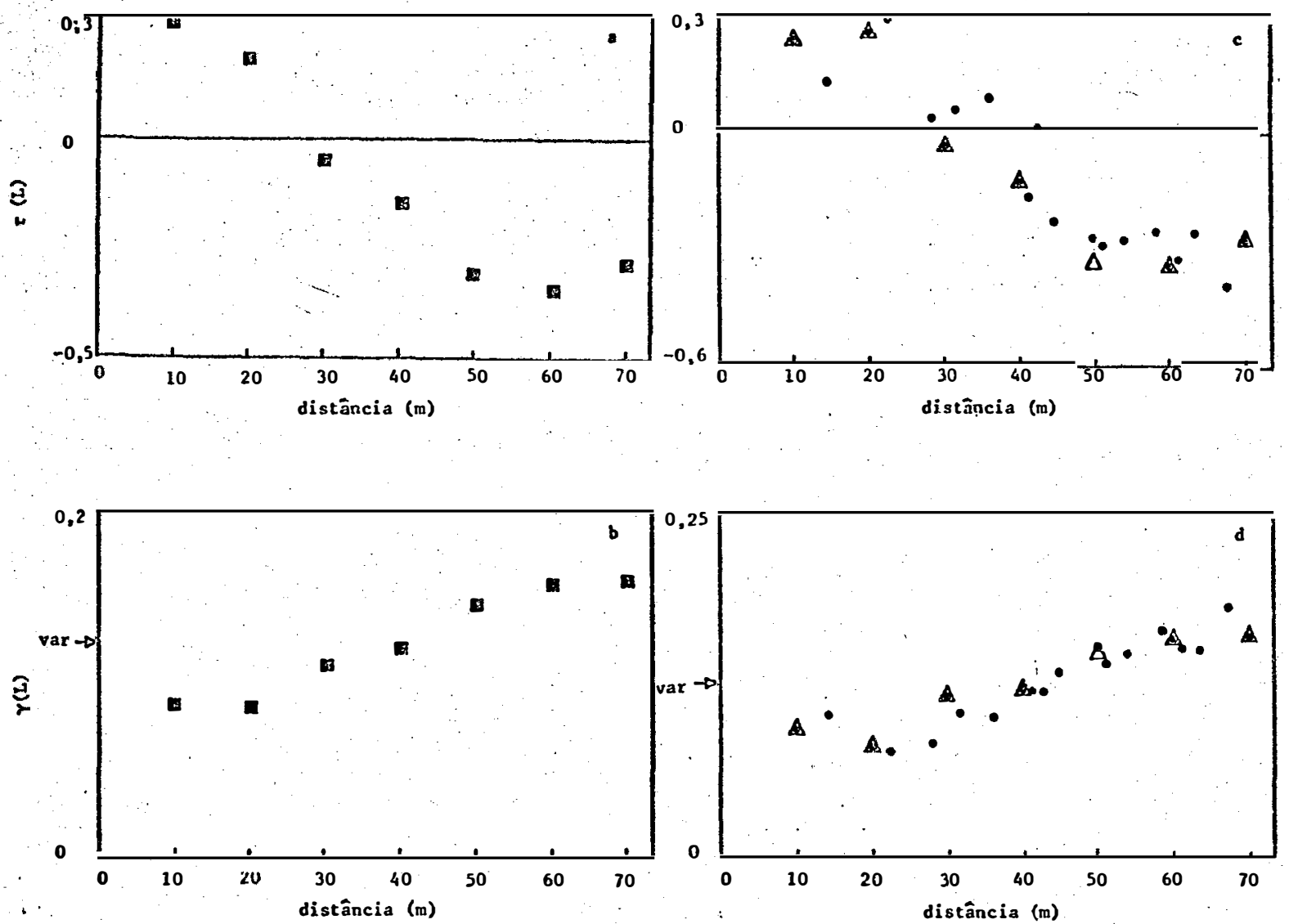

FIGURA 16 - Autocorrelogramas, $r(L)$ e semivariogramas, $\gamma(L)$ do peso de. 100 grãos para uma $(\Delta)$, duas $(\Delta)$ e todas $(0)$ as direções. 

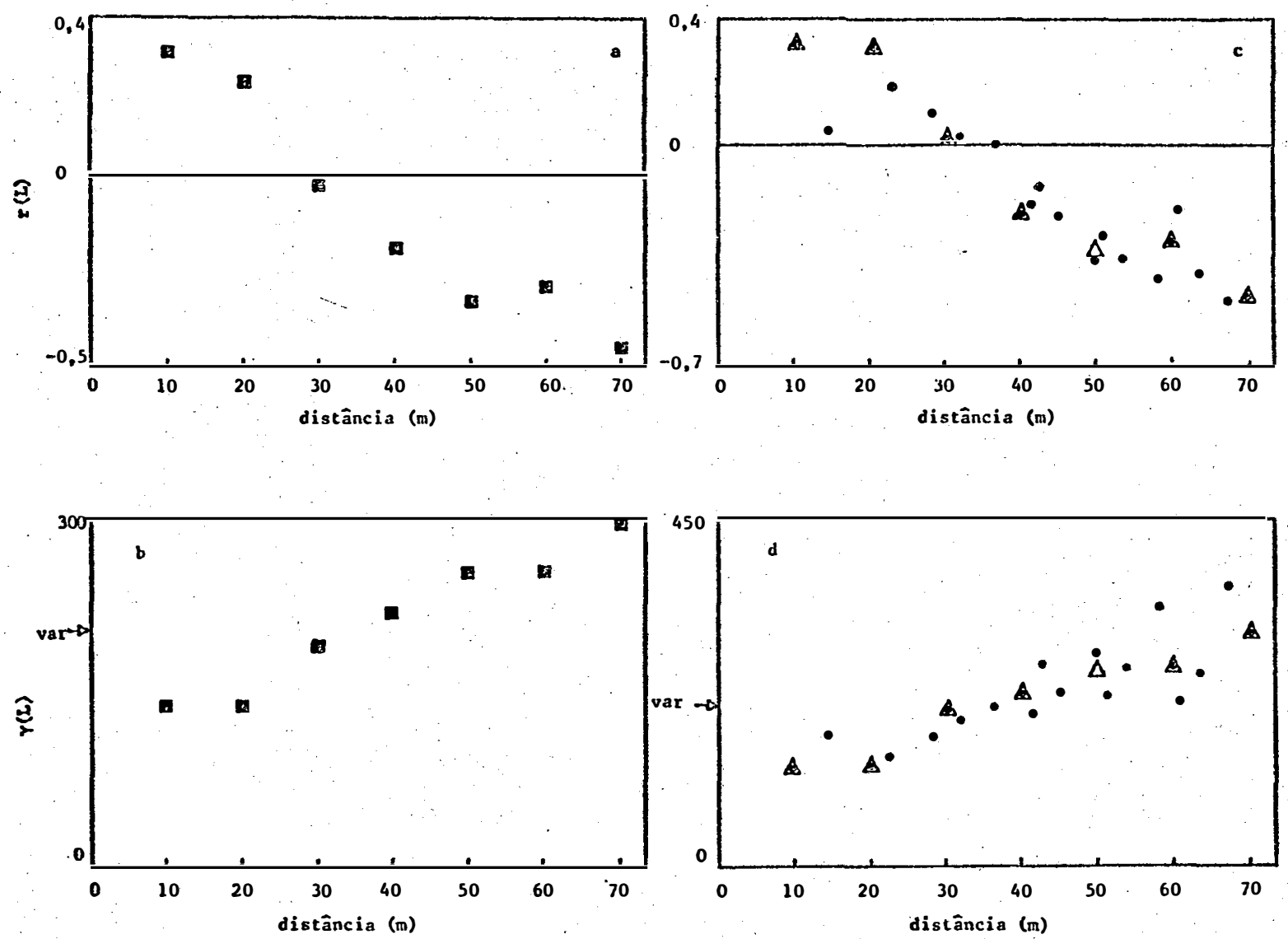

FIGURA 17 - Autocorrelogramas, $r(L)$ e semivariogramas, $Y(L)$ da \% de grãos. chochos para uma ( $\left.{ }^{\prime}\right)$, duas $(\Delta)$ e todas $(\bullet)$ as direções. 

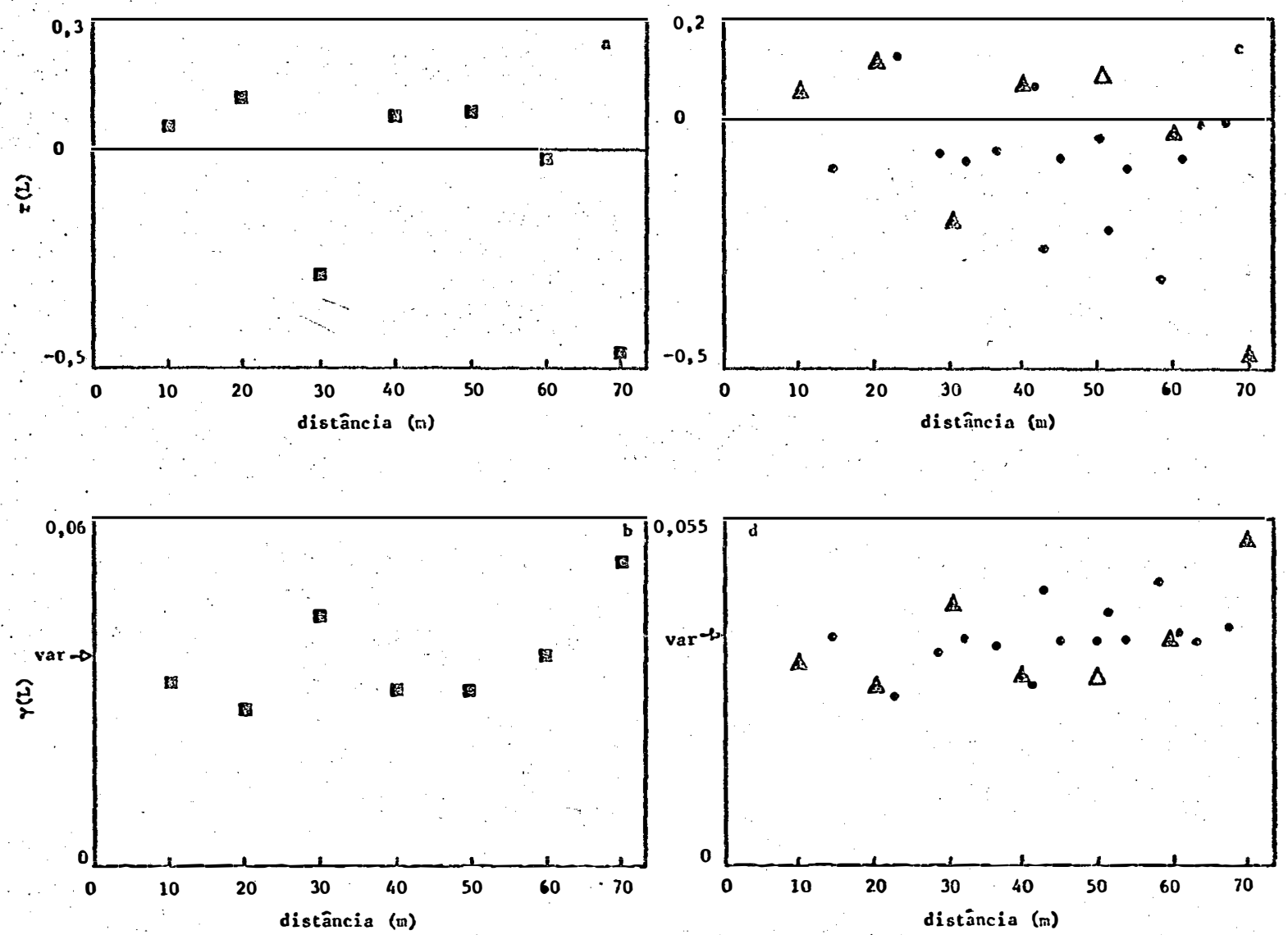

FIGURA 18 - Autocorrelogramas, $r(L)$ e semivariogramas, $\gamma(L)$ do indice de. colheita para uma ( $⿴ 囗$, duas $(\Delta)$ e todas $(\bullet)$ as direções. 

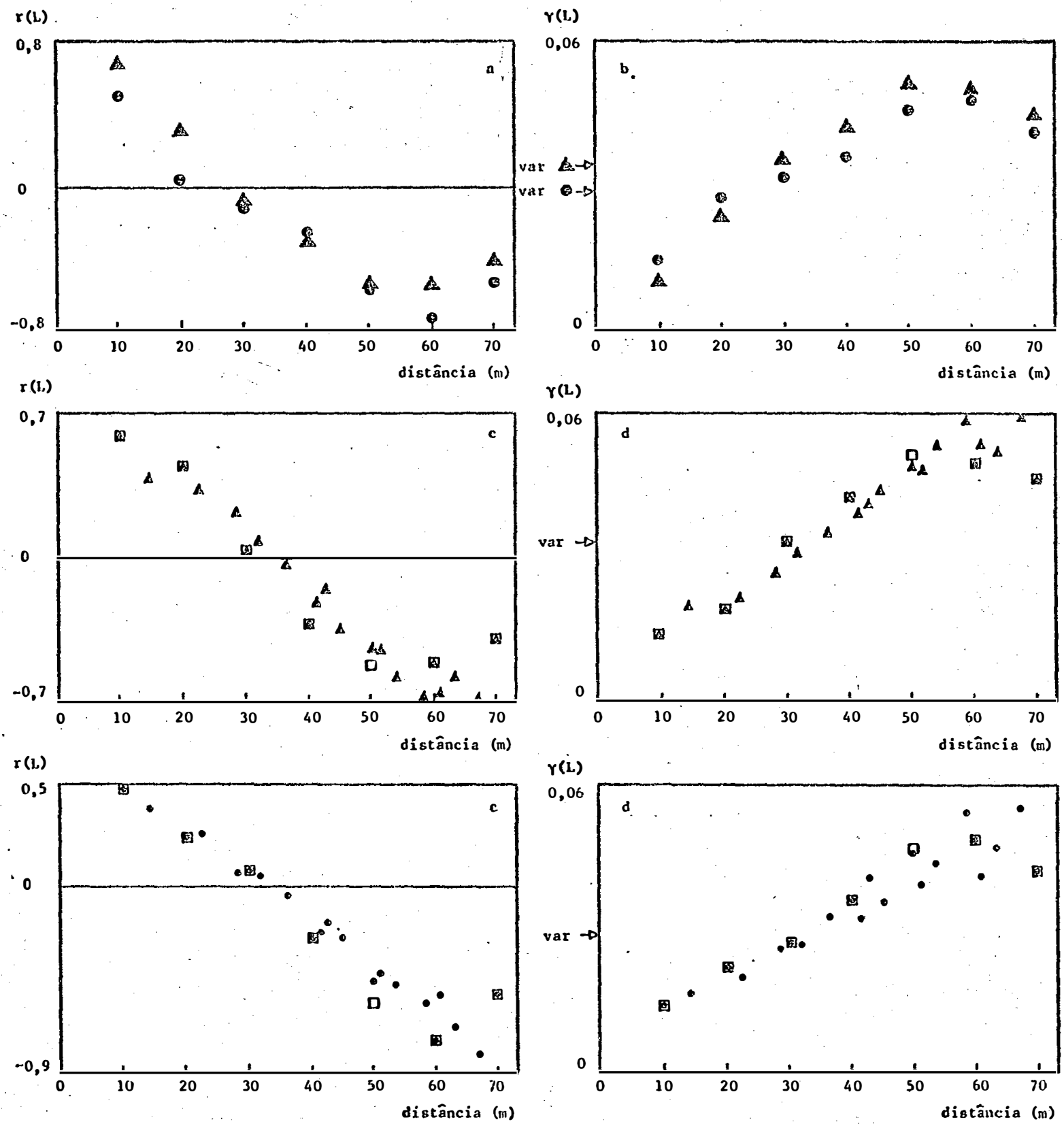

FIGURA 19 - Autocorrelogramas, $r(L)$ e semivariogramas, $\gamma(L)$ do pH do solo.

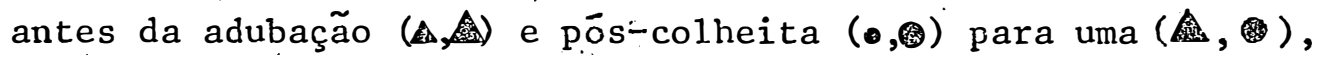
duas $(\square)$ e todas $(\mathbb{A}, \mathbb{0})$ as direções. 
$r(L)$
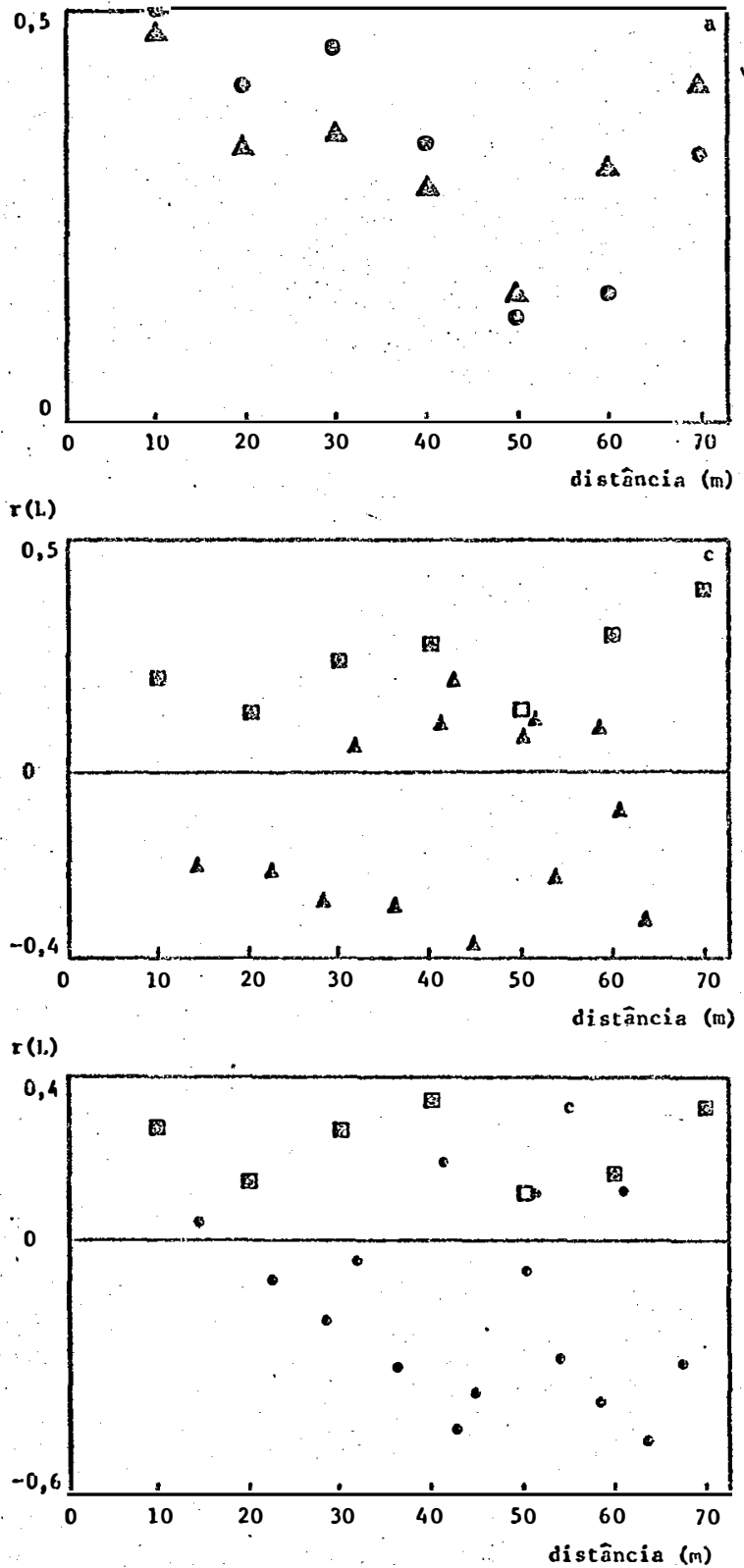

$\gamma(\mathrm{L})$

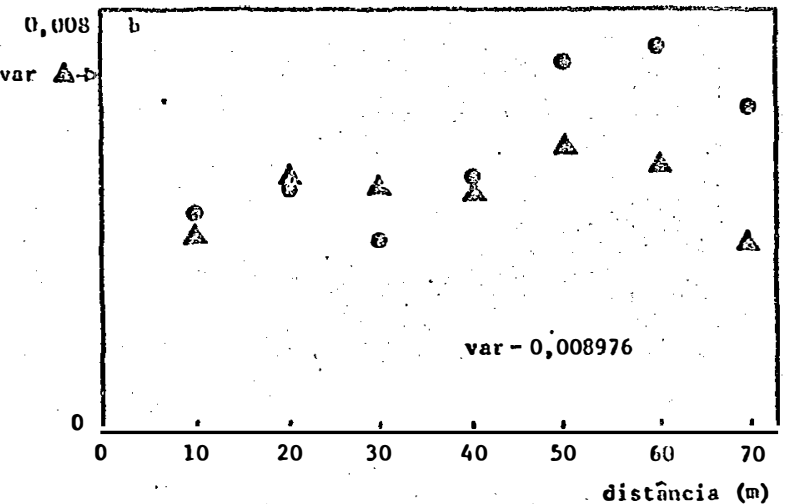

$r(2)$
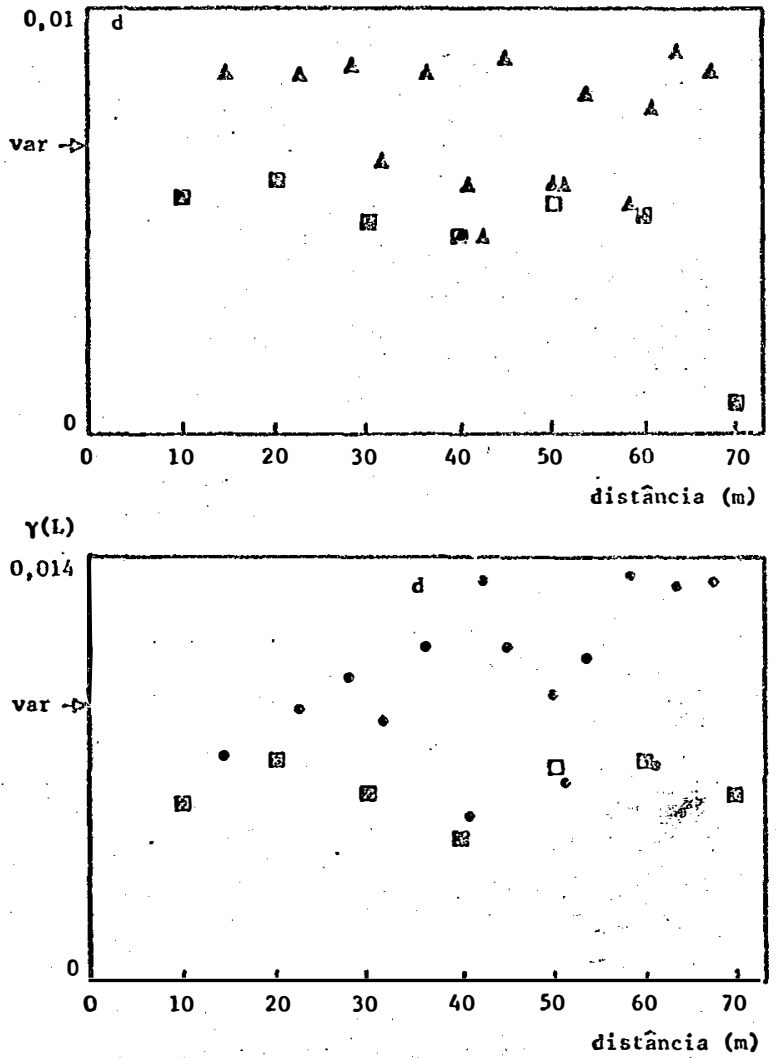

FIGURA 20 - Autocorrelogramas, $r(L)$ e semivariogramas, $\gamma(L)$ do carbono orgânico do solo antes da adubação (s) e pós-colheita

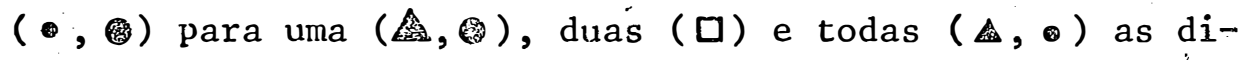
reções. 


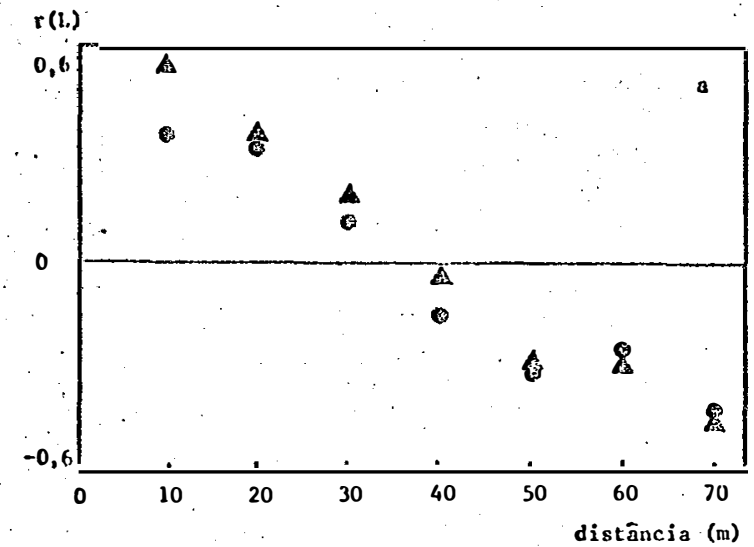

$\gamma(L)$
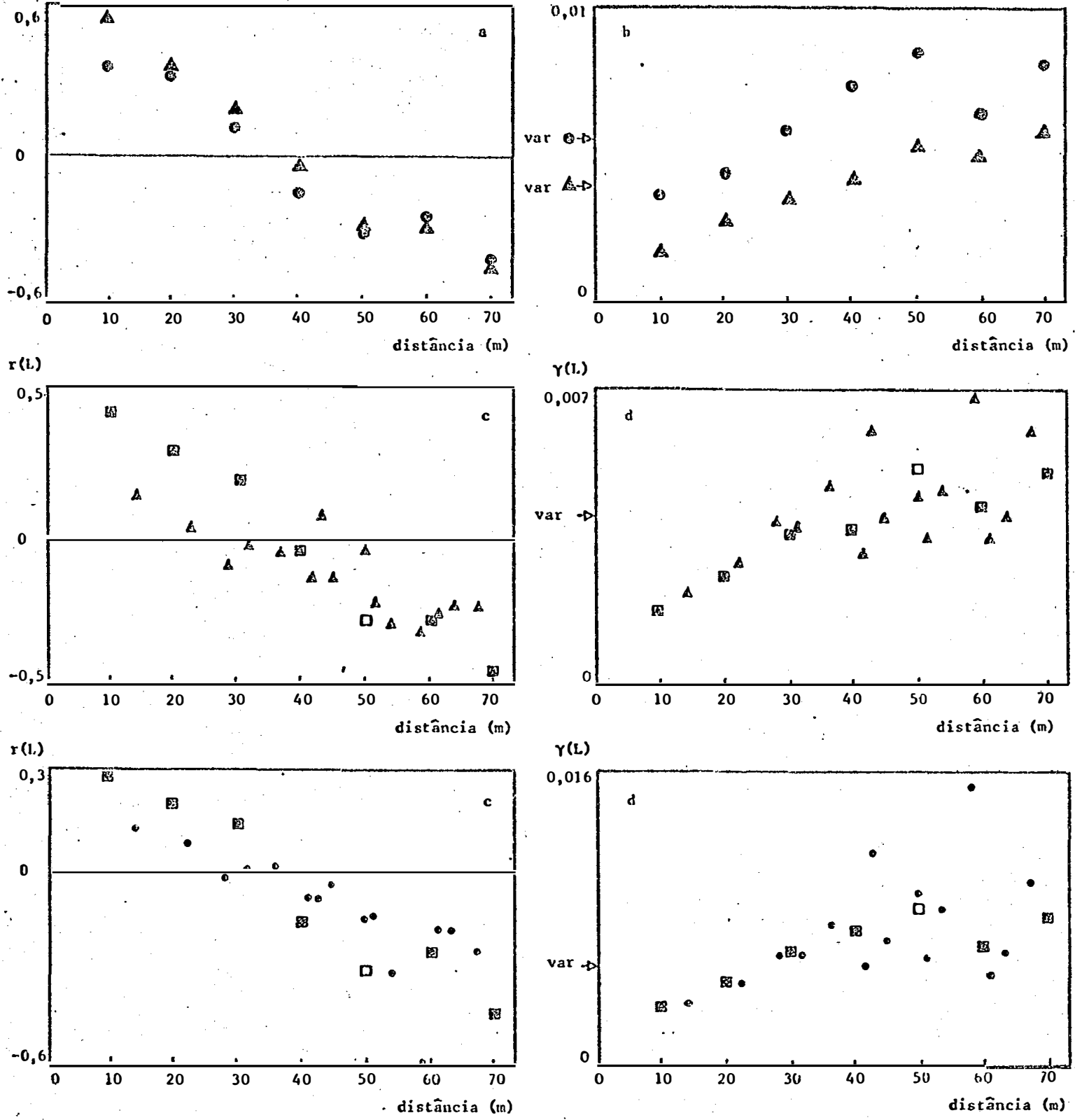

FIGURA 21 - Autocorrelogramas, $r\left(J_{1}\right)$ e semivariogramas, $\gamma(L)$ do fösforo do solo antes da adubação (A, e pós-colheita (, 0 ) para uma (A), duas (口) e todas (A, ) as direções. 

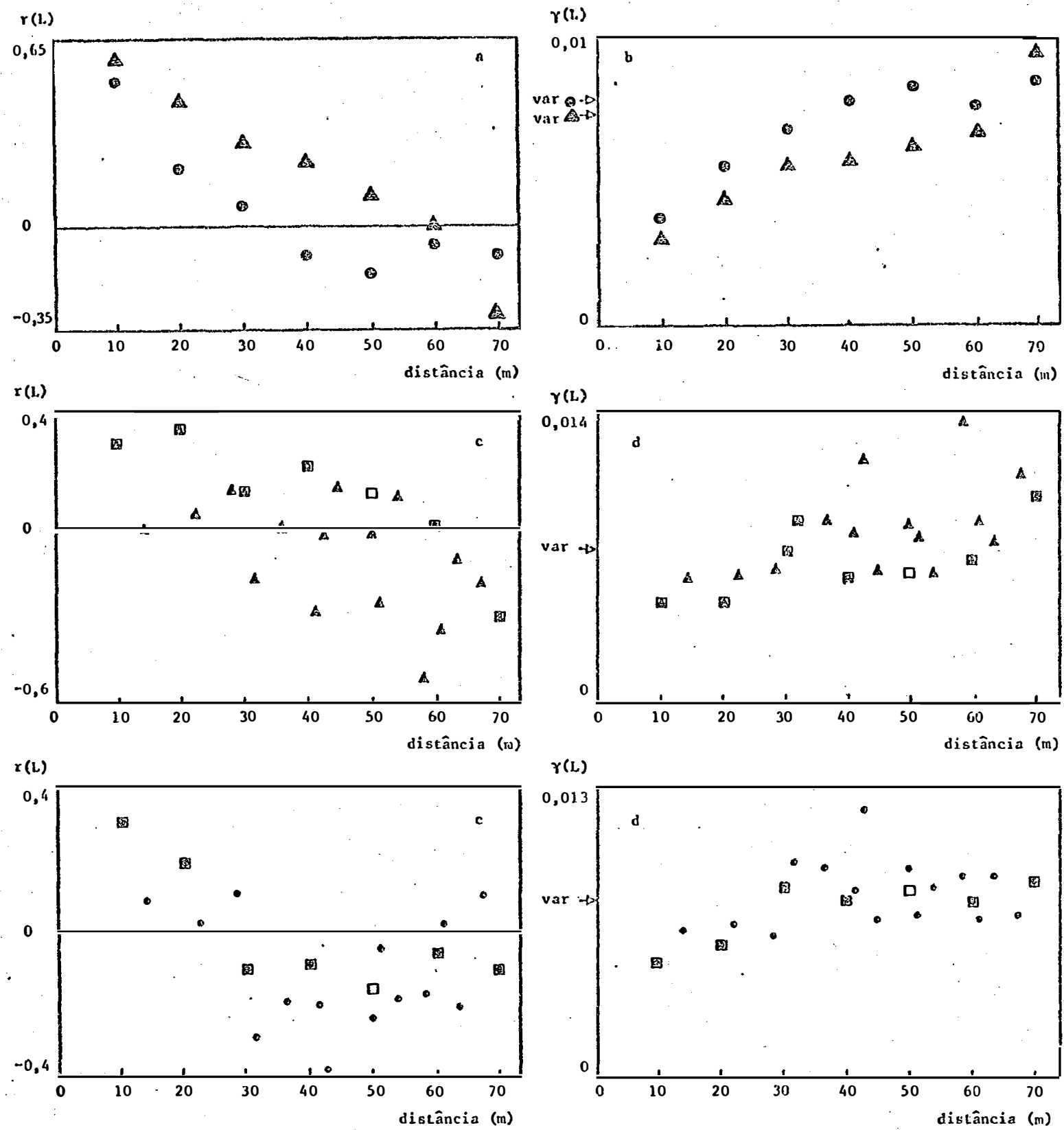

FIGURA 22 - Autocorrelogramas, $r(L)$ e semivariogramas, $\gamma(L)$ do potássio. do solo antes da adubação (会, e pós-colheita ( , , para uma (盛, ), duas $(\square)$ e todas $(\mathbb{\Delta}, \bullet)$ as direções. 

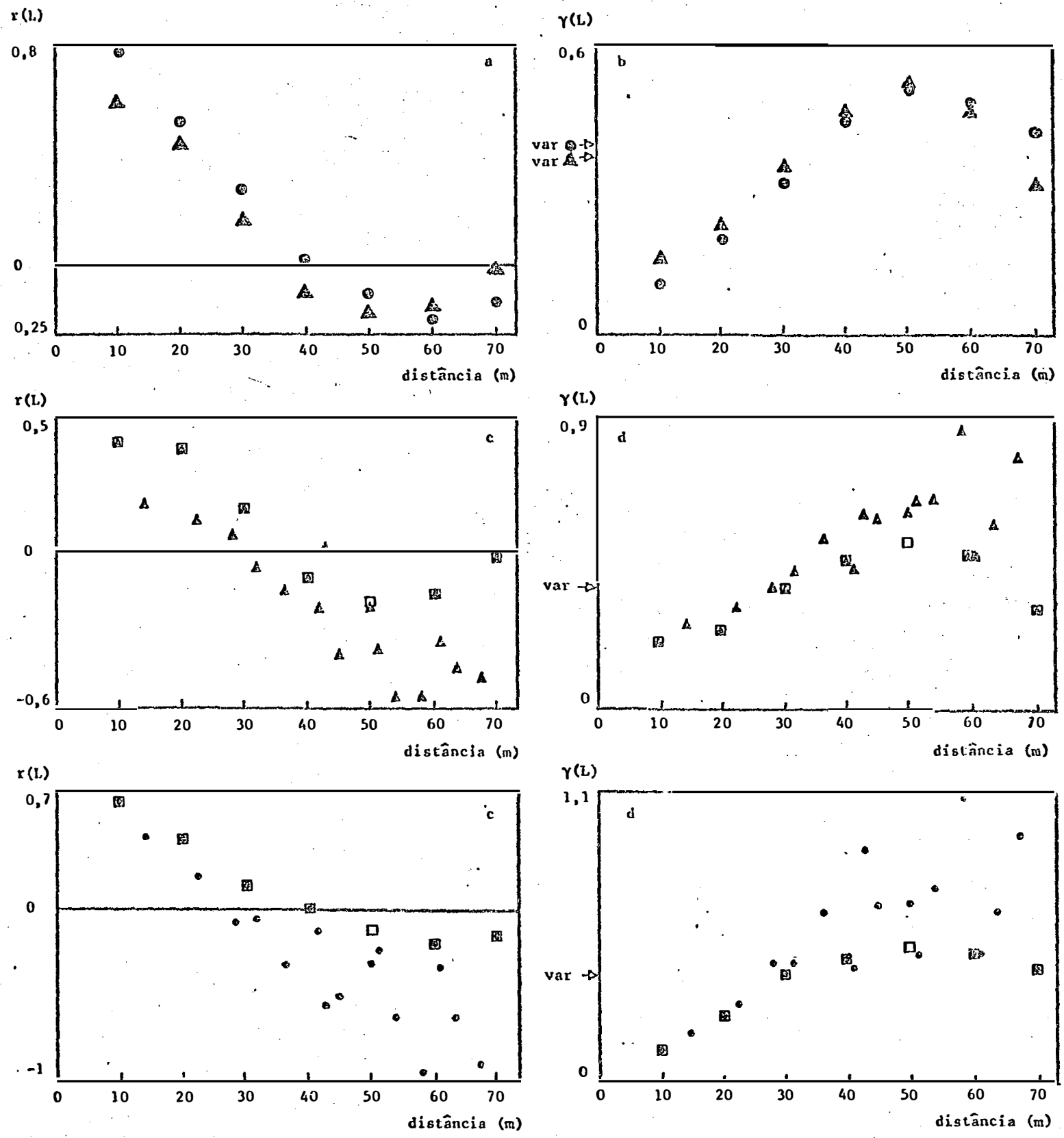

FIGURA 23 - Autocorrelogramas, $r(L)$ e senivariogramas, $\gamma(L)$ do cálcio do

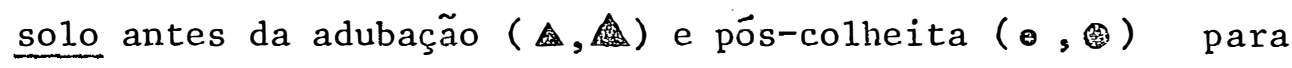
uma $(\mathbb{N})$, duas $(\square)$ e todas $(\mathbb{A}, \boldsymbol{)})$ as direções. 
$r(L)$
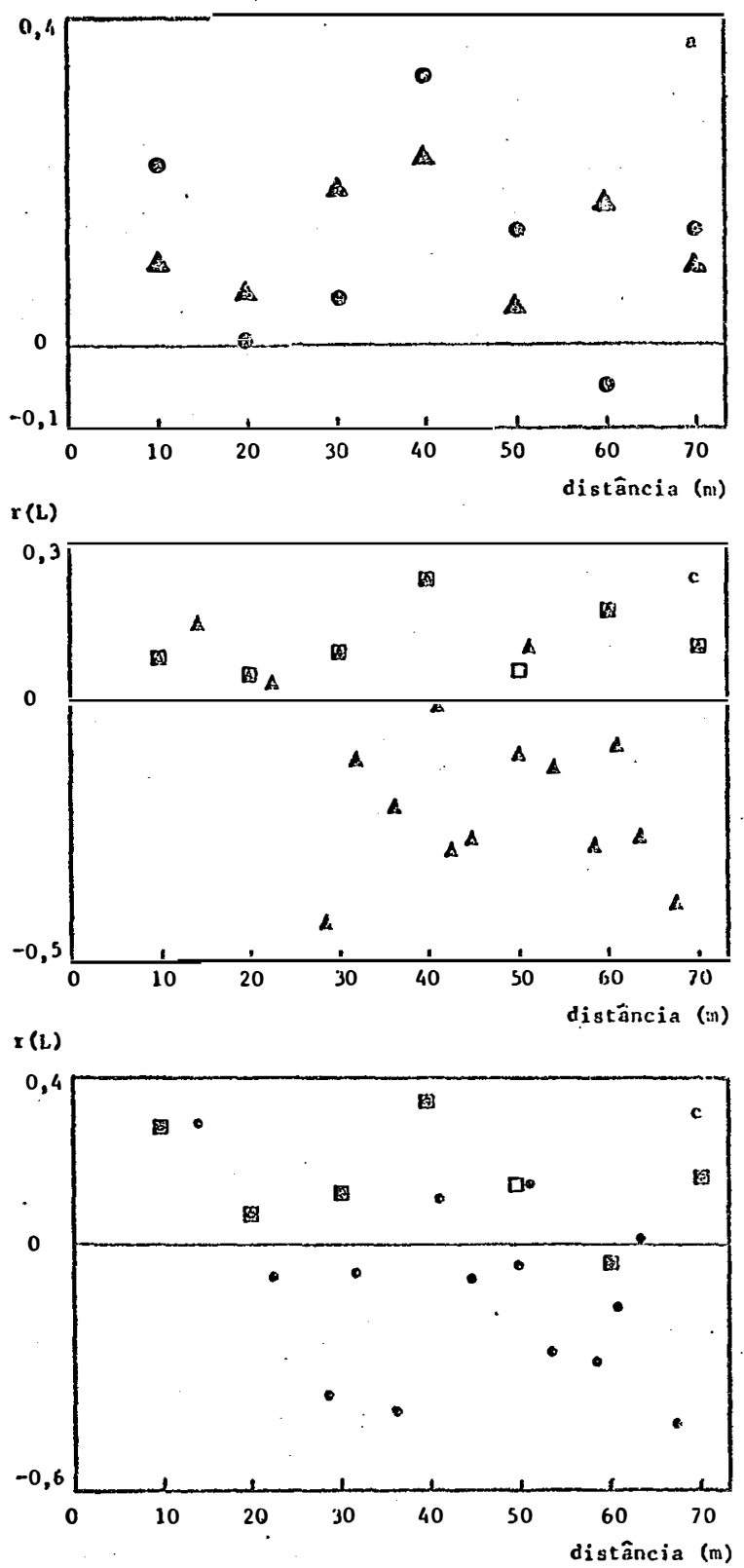

$r(L)$
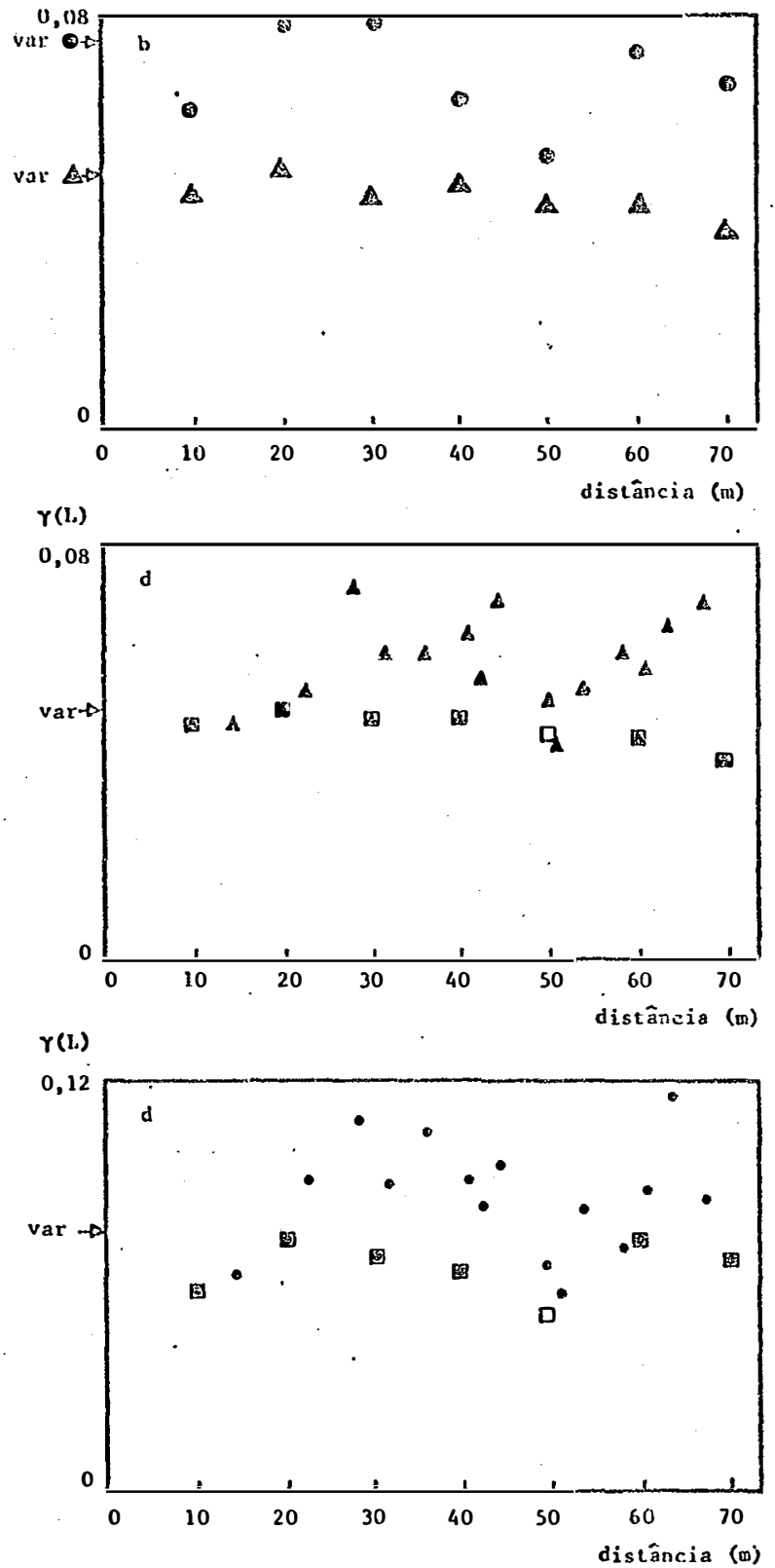

FIGURA 24 - Autocorrélogramas, $r(\mathrm{I})$ e semivariogramas, $\gamma(\mathrm{L})$ do magnésio.

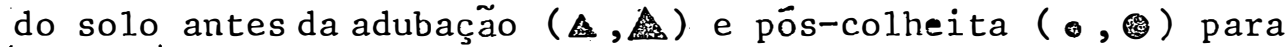
uma ( $)$, duas $(\square)$ e todas $(\mathbb{A}, \mathbb{*}$ ) as direções: 
r(L)

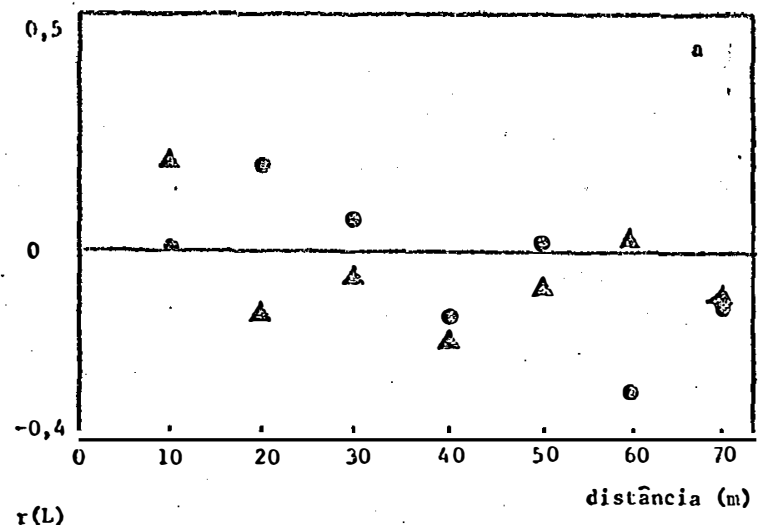

$r(L)$

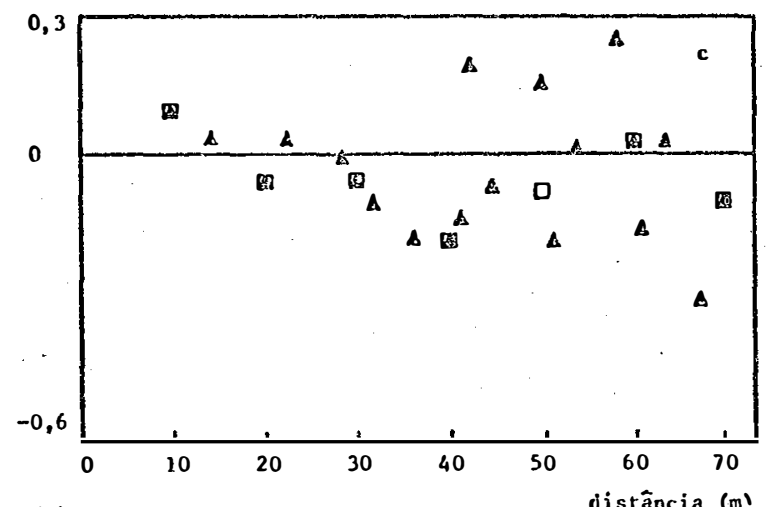

$r(L)$

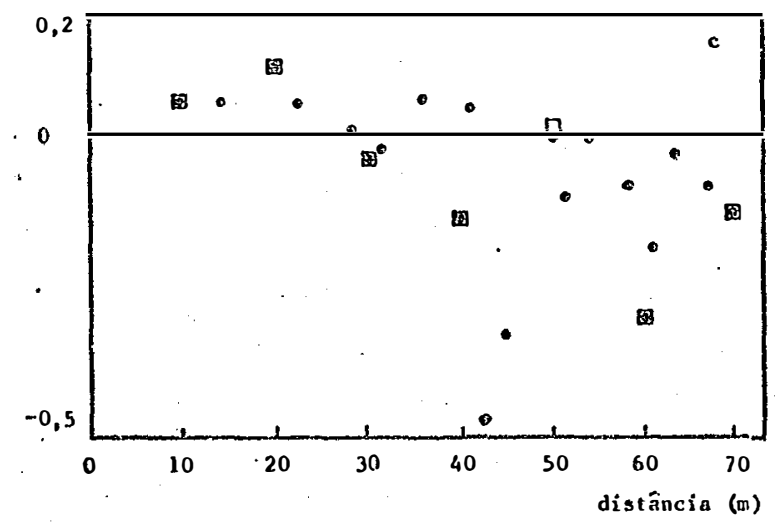

$Y(L)$

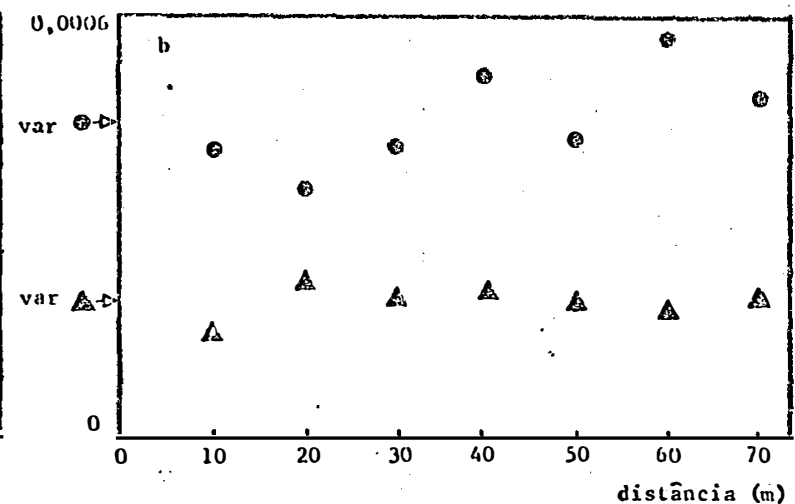

$r(L)$

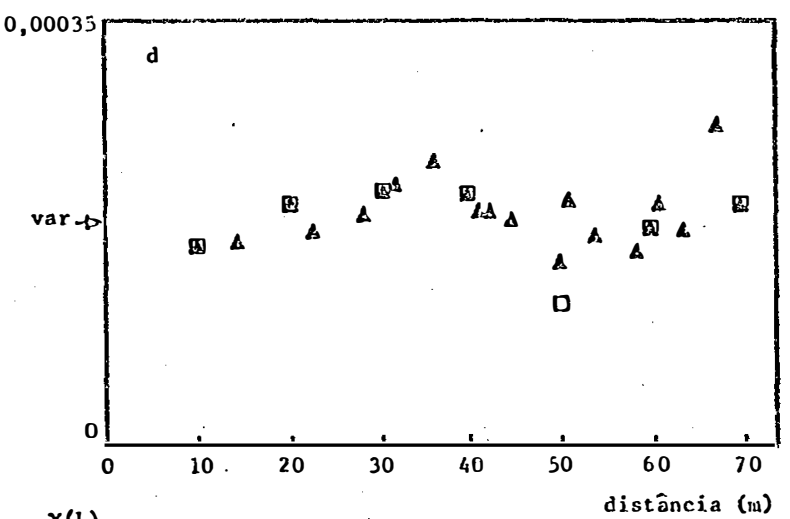

$r(L)$

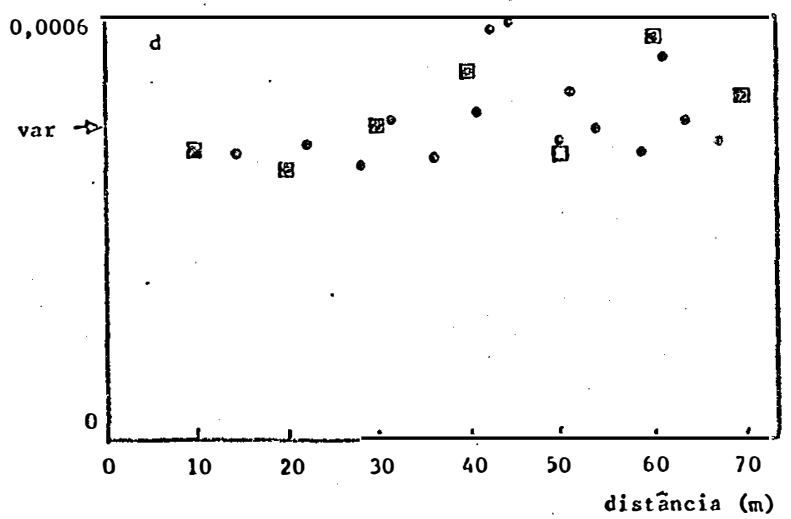

FIGURA 25 - Autocorrelogramas, $r(L)$ e semivariogramas, $\gamma(L)$ do alumínio. do solo antes da adubação (A , e pös-colheita ( 0 , para

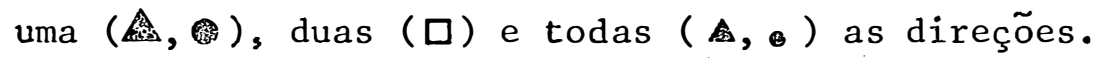


$r(L)$

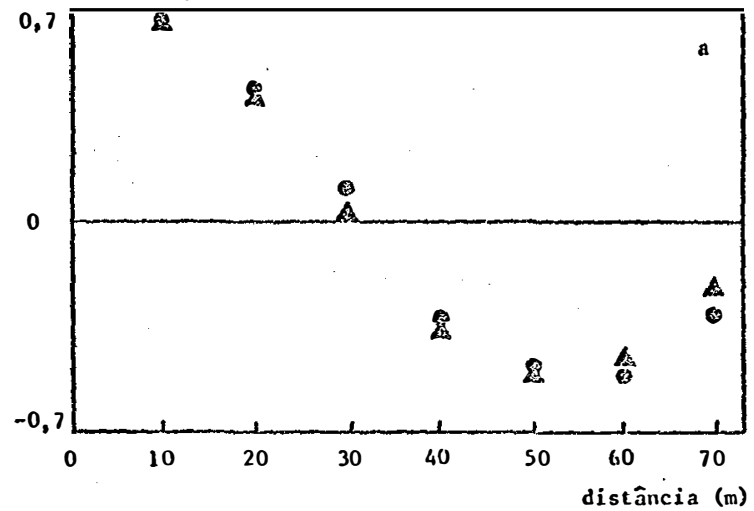

$r(\mathrm{~L})$

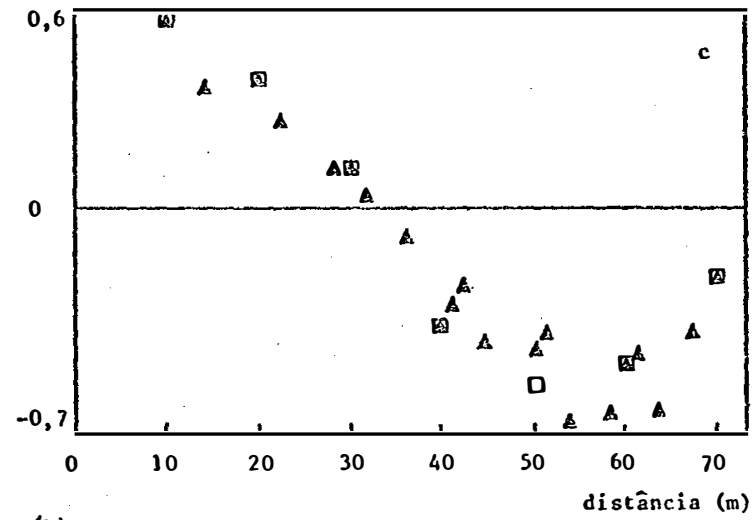

$r(L)$

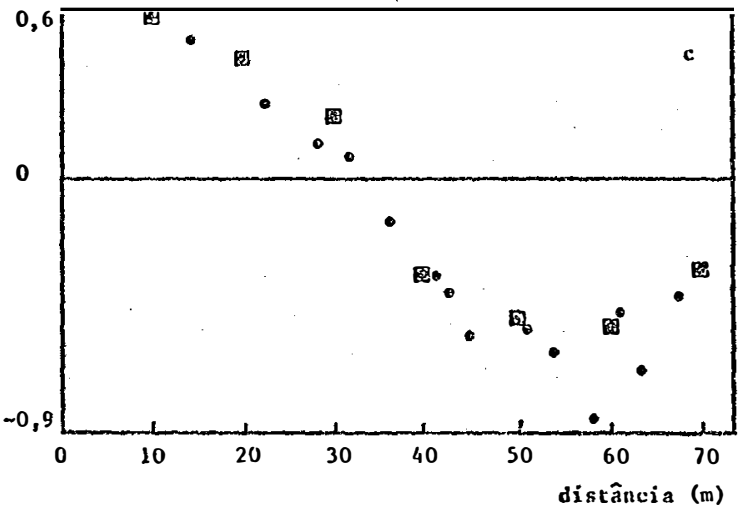

$\gamma(\mathrm{l})$

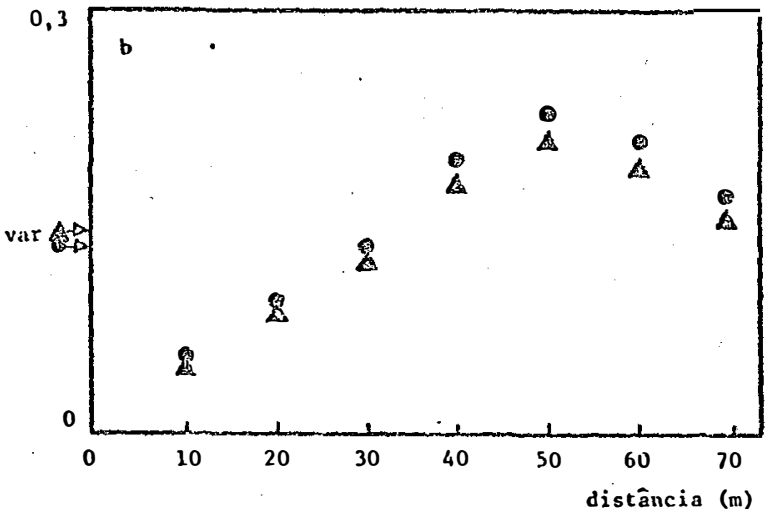
$\gamma(\mathrm{L})$

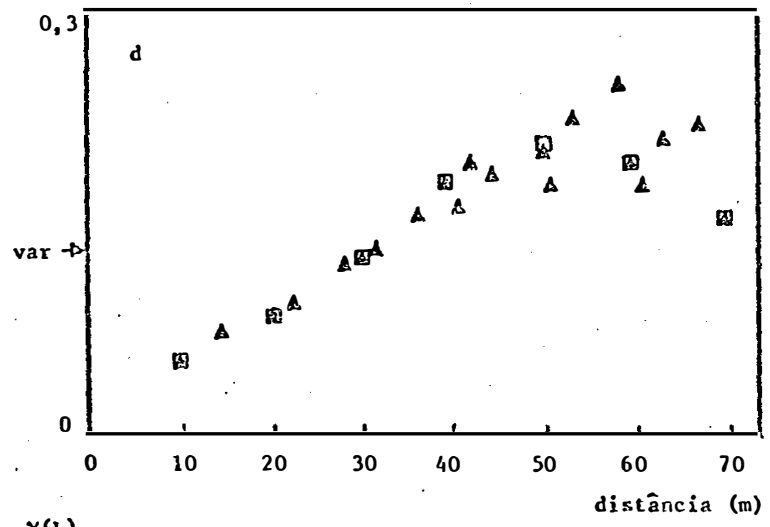

$Y(b)$

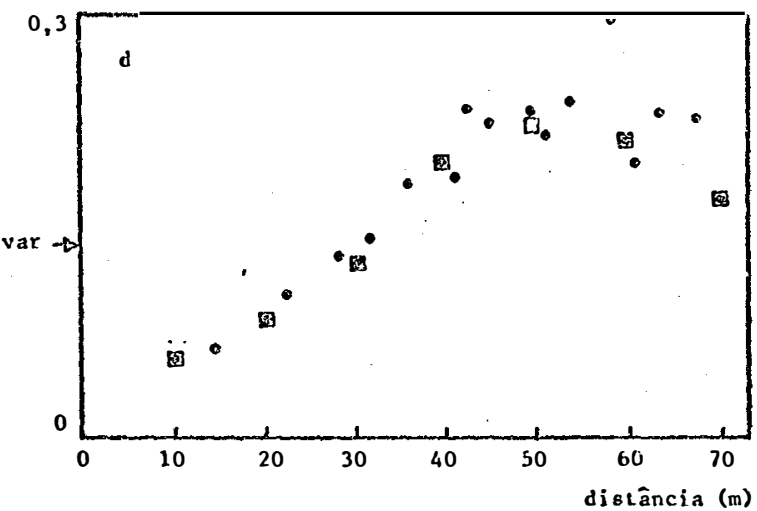

FIGURA 26 - Autocorrelogramas, $r(L)$ e semivariogramas, $\gamma(L)$ do hidrogênio. do solo antes da adubação (A, e pós-colheita (, , e para

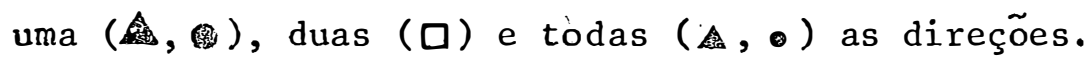


$r(\mathrm{~L})$

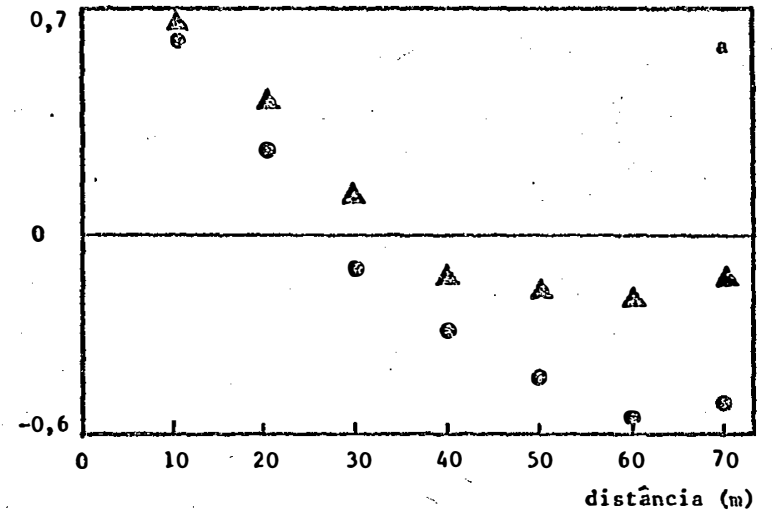

$r(\mathrm{~L})$

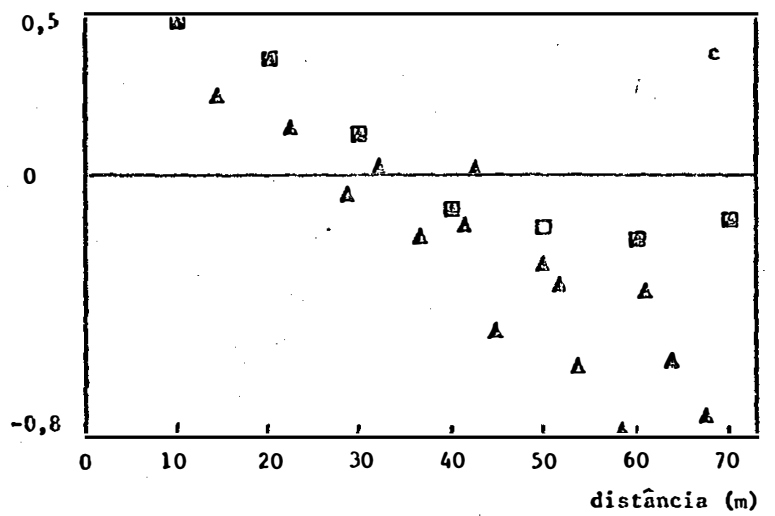

$r(L)$

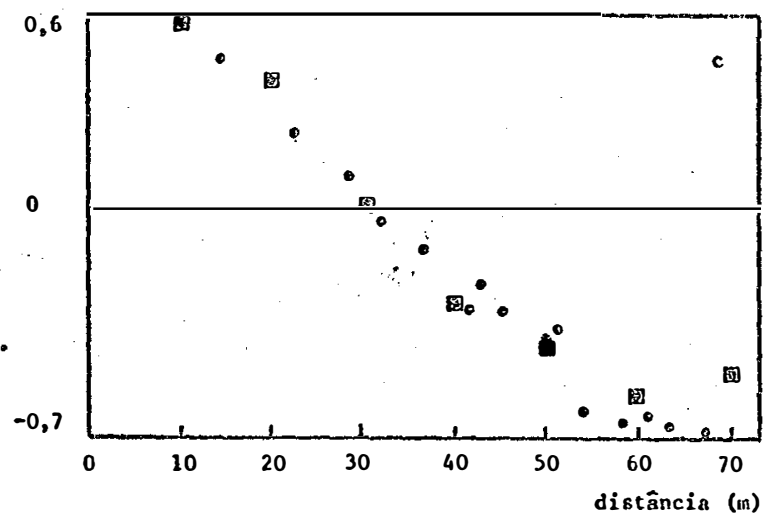

$\gamma(\mathrm{L})$

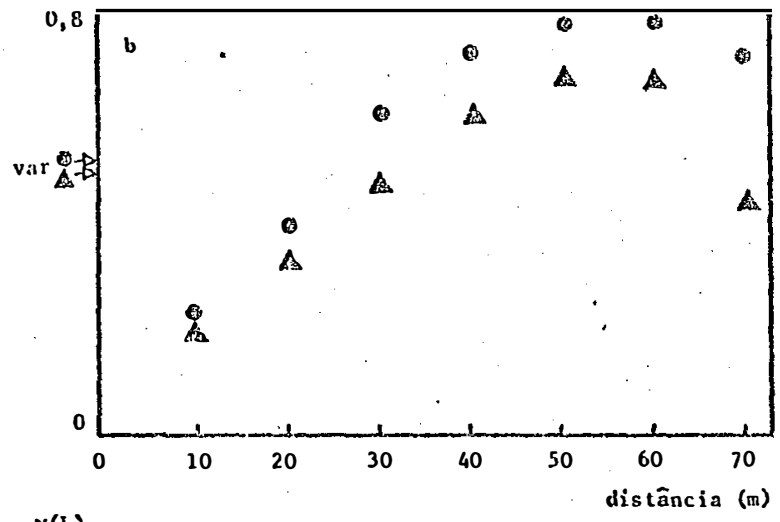

$\gamma(\mathrm{L})$

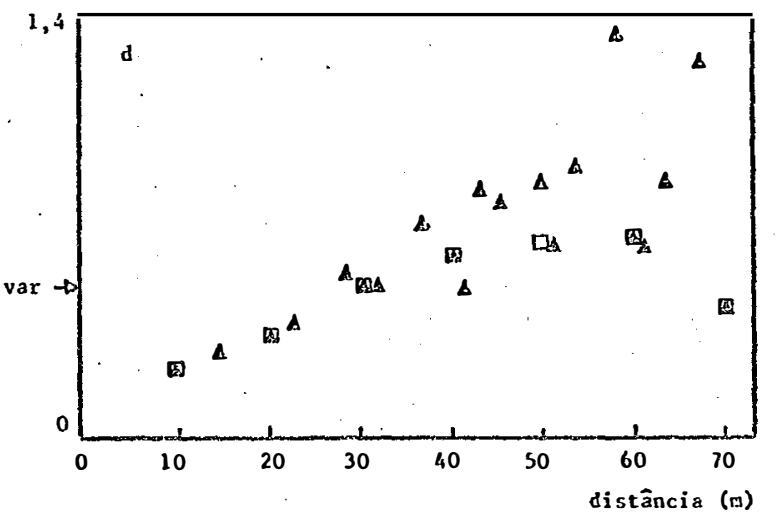

$\gamma(\mathrm{L})$

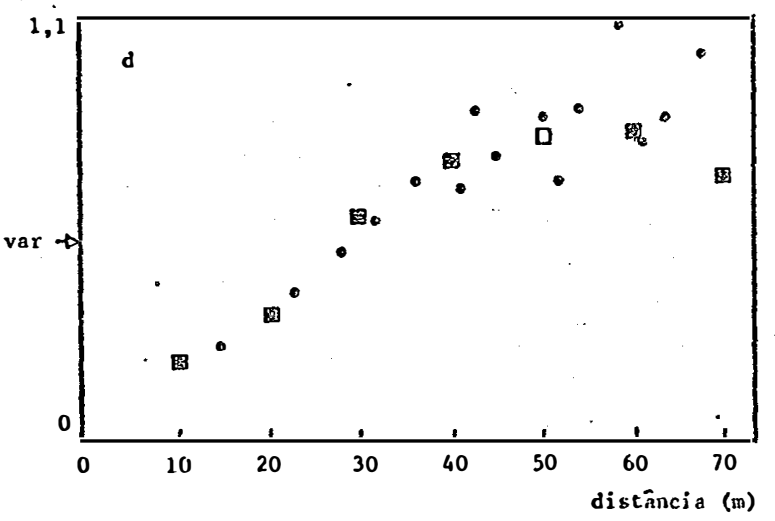

FIGURA 27 - Autocorrelogramas, $r(L)$ e semivariogramas, $Y(L)$ da soma de

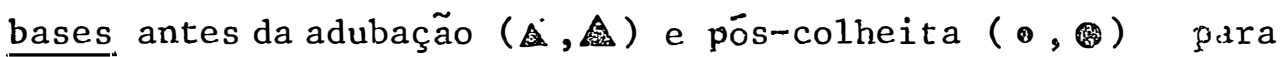
uma (A), duas ( $(\square)$ e todas $(\Delta, \bullet)$ as direções. 
$r(L)$
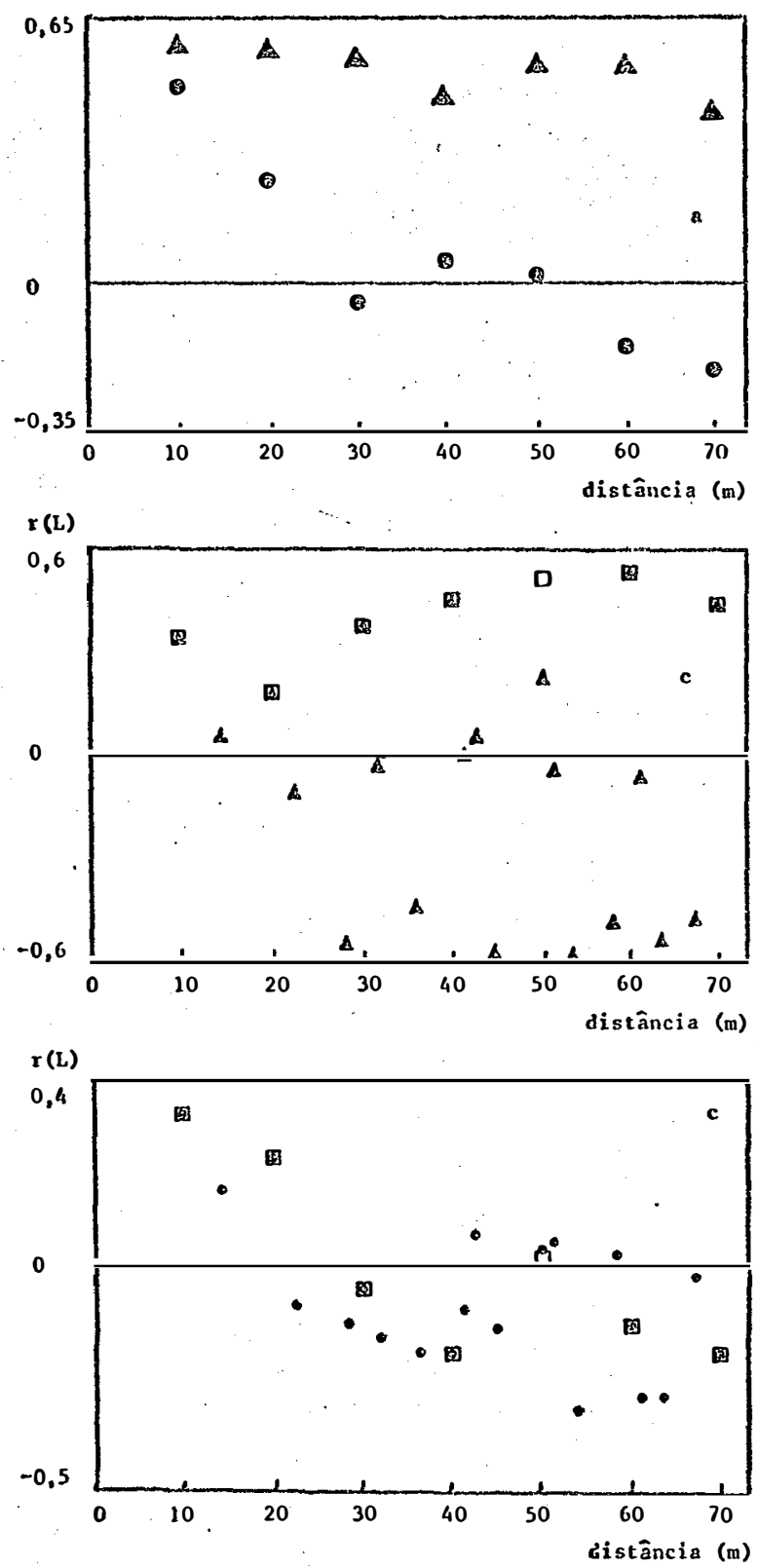

$\gamma(L)$

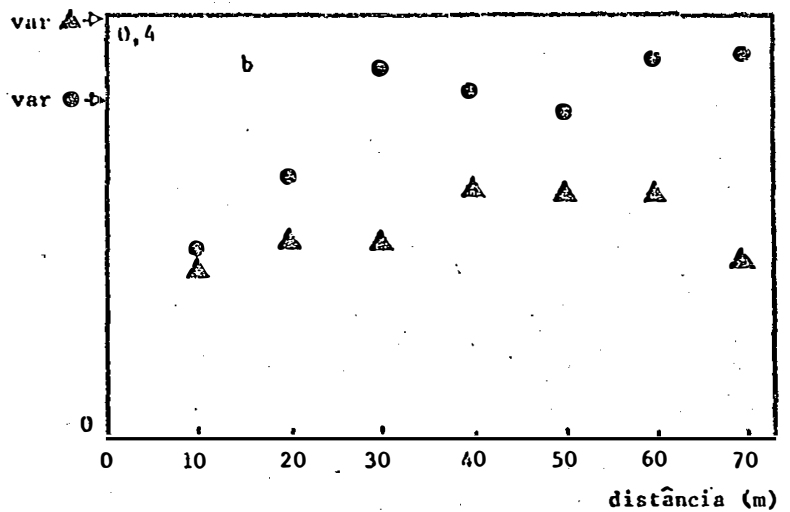

$\gamma(L)$

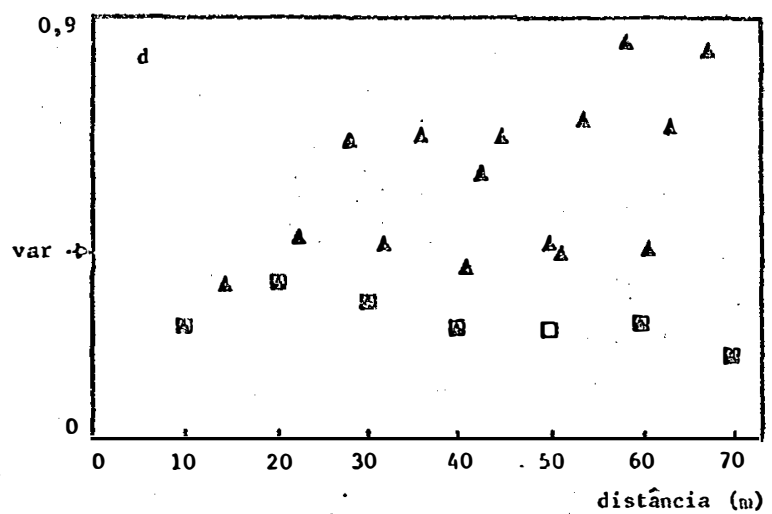

$\gamma(\mathrm{L})$

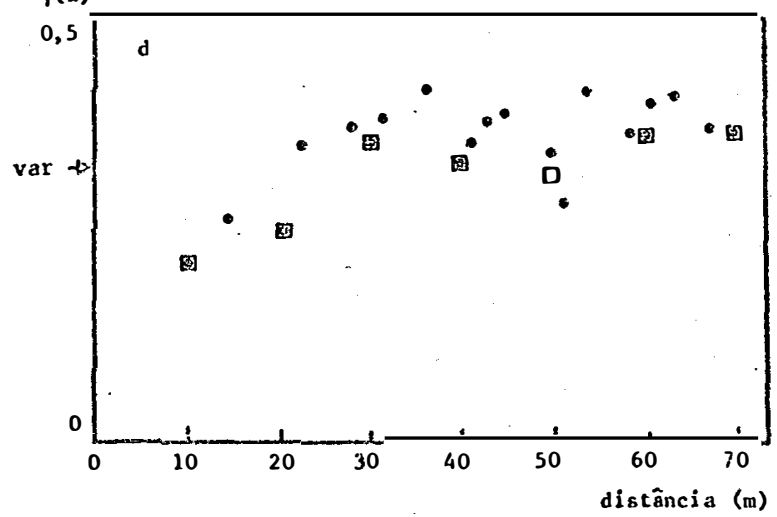

FIGURA 28 - Autocorrelogramas, $r(L)$ e semivariogramas, $\gamma(L)$ da CTC antes

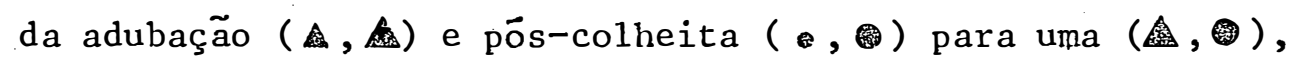
duas $(\square)$ e todas $(\mathbb{A}, \bullet)$ as direções. 
$r(1$.
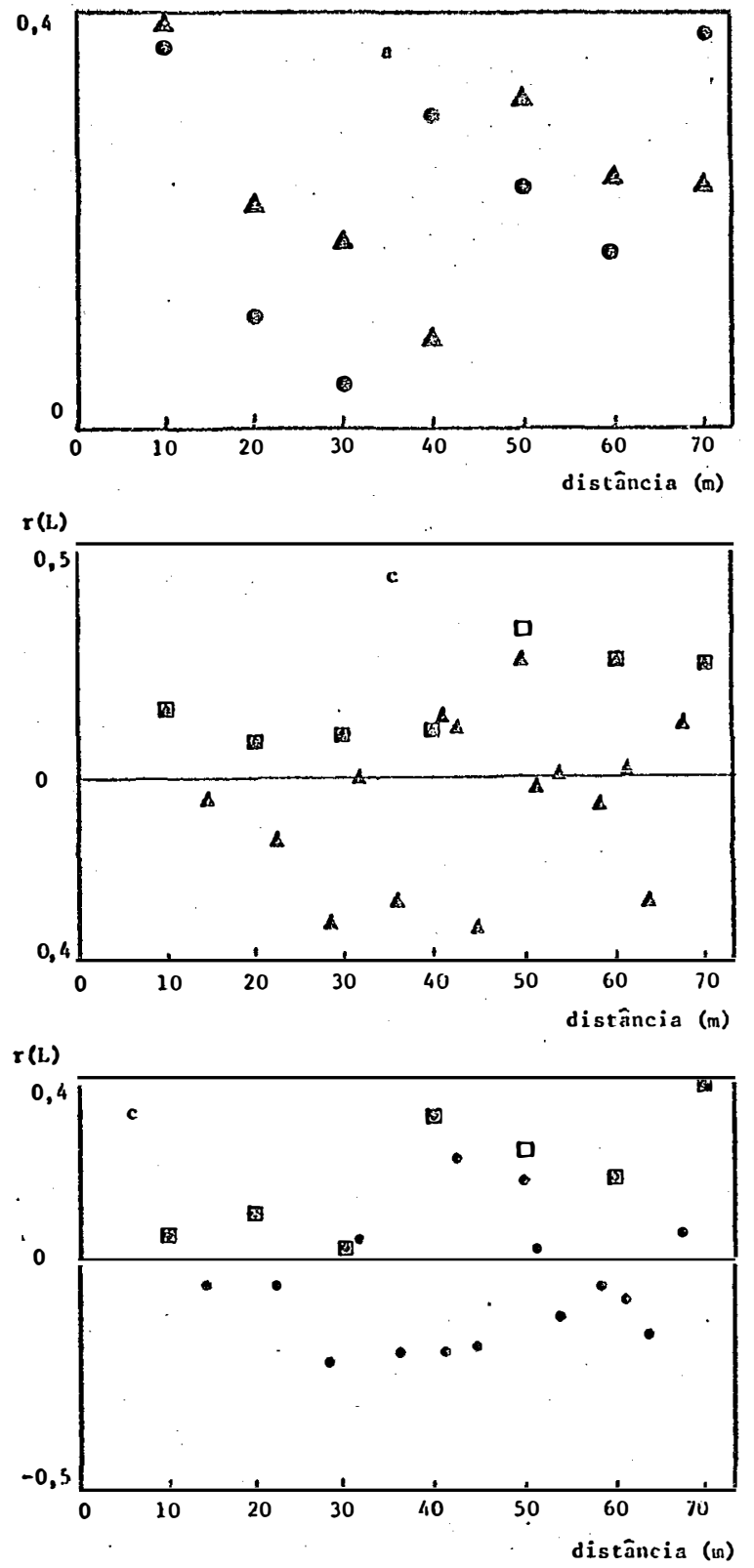

$\gamma(\mathrm{L})$

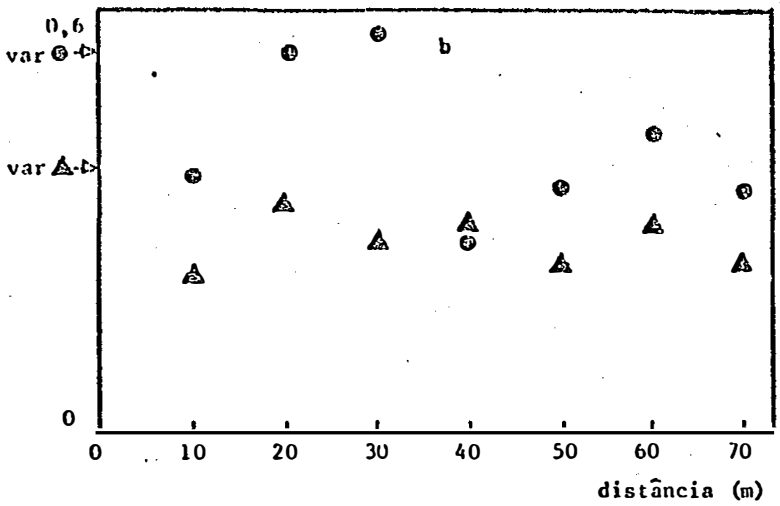

$\gamma(1)$
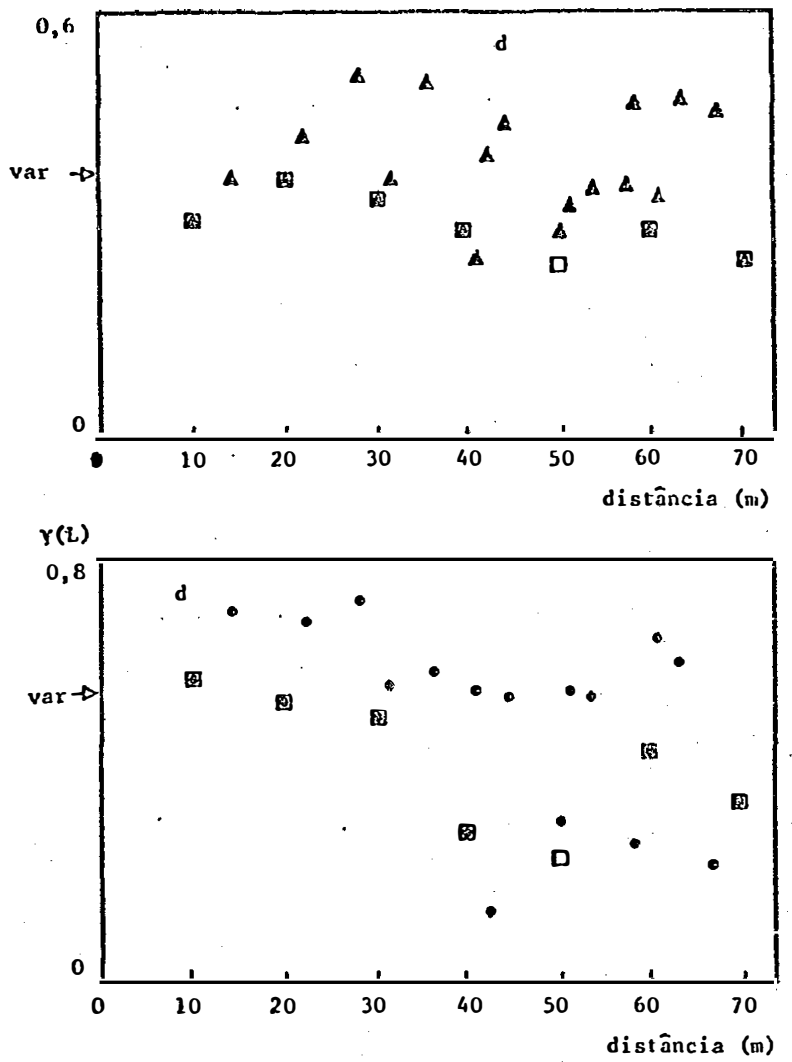

FIGURA 29 - Autocorrelogramas, $r(L)$ e semivariogramas, $Y(L)$ do zinco do. solo antes da adubação (番).e pōs-colheita $(0,0)$ para uma (A), duas ( $\square$ ) e todas (A, ) as direções. 
$r(L)$

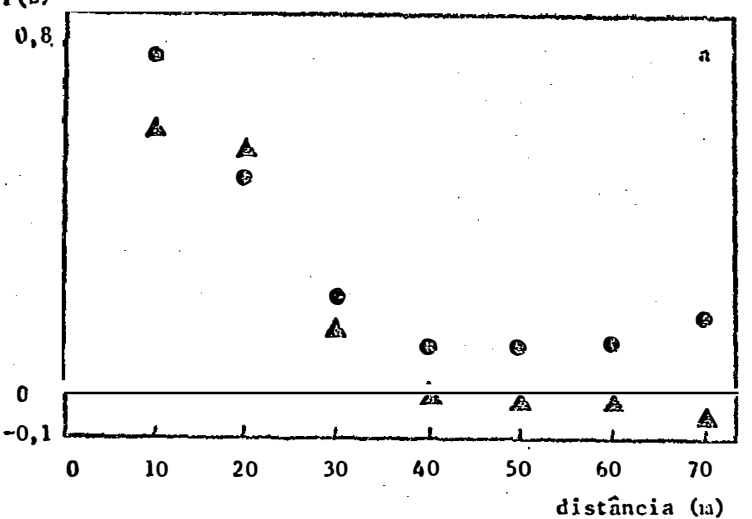

$r(L)$

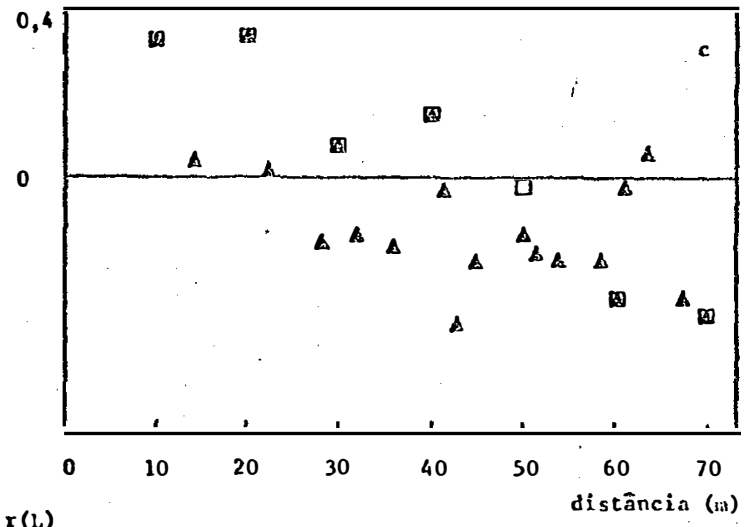

$r(L)$

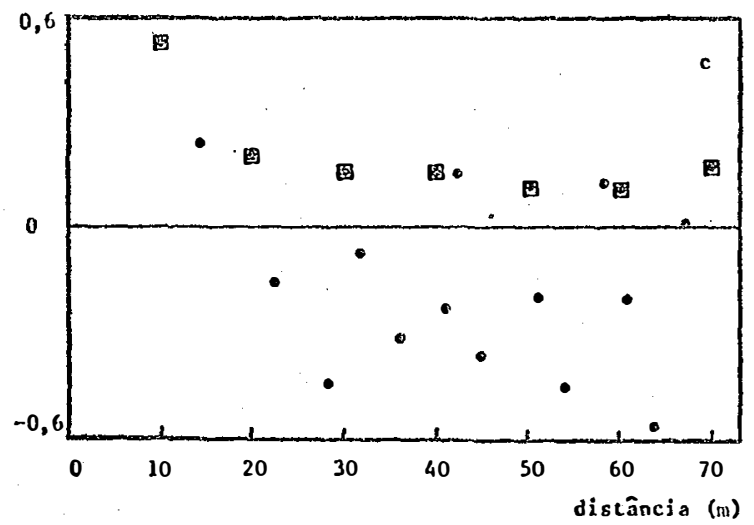

$\gamma(1)$

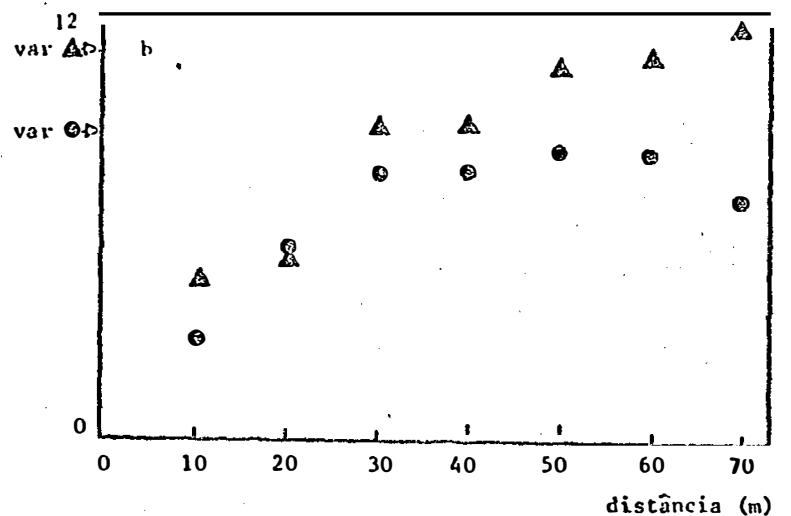

$\gamma(L)$

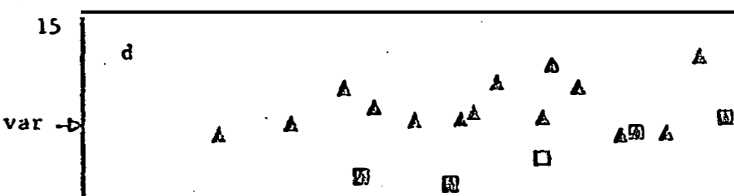

ำ
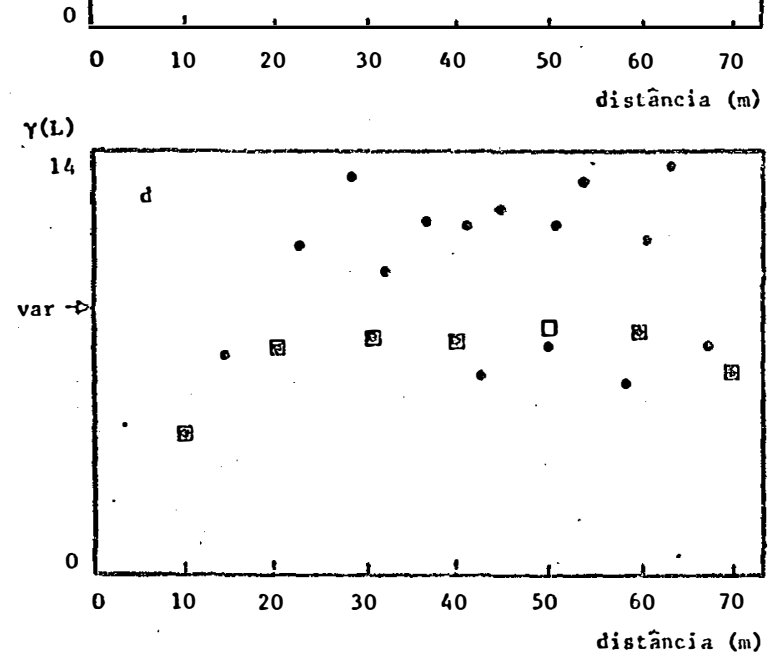

FIGURA 30 - Autocorrelogramas, $r(L)$ e semivariogramas, $\gamma(L)$ da argila antes da adubação (A, e pós-colheita ( , para uma (A ) , duas $(\square)$ e todas (, ) as direções. 
$r(L)$

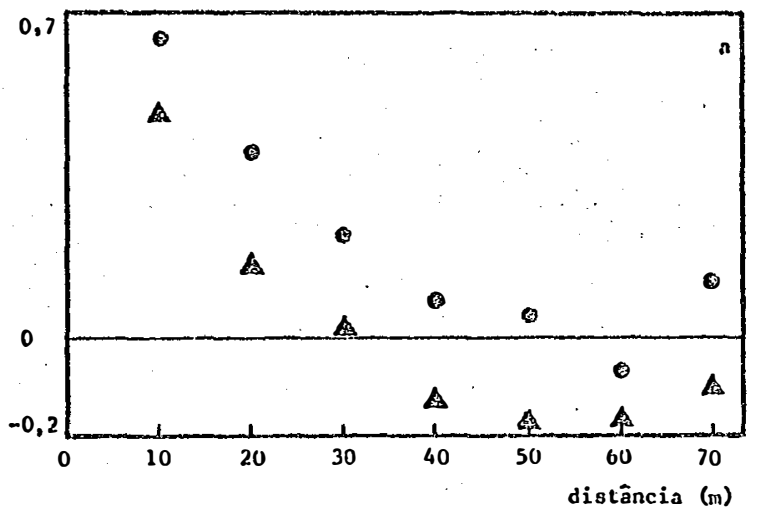

$r(\mathrm{~L})$

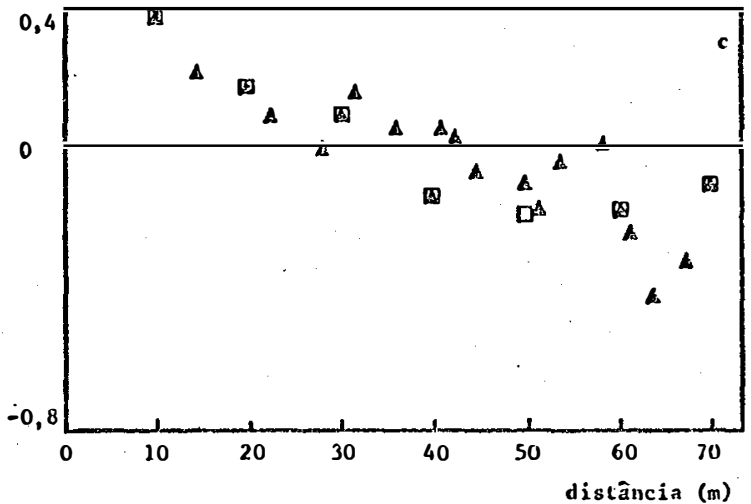

$r(\mathrm{~L})$

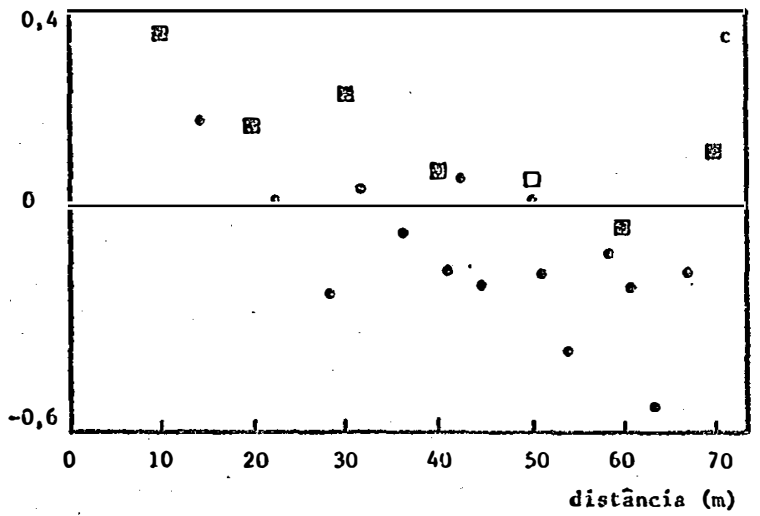

$Y(1$.

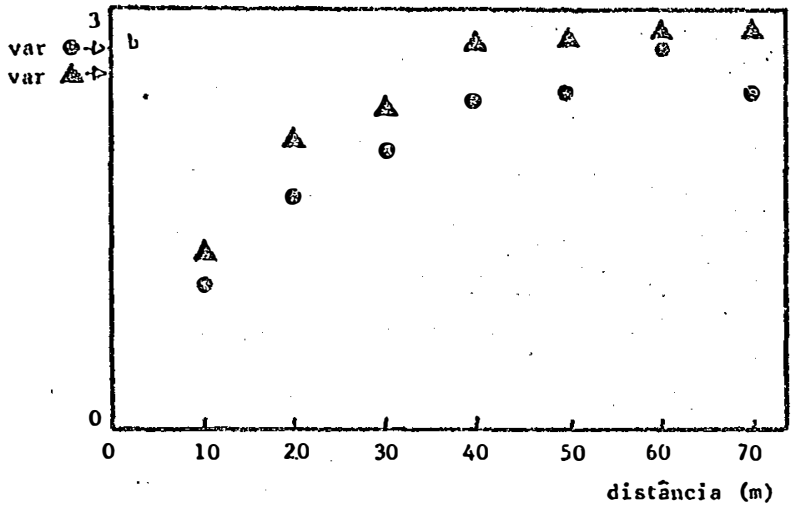

$r(L)$

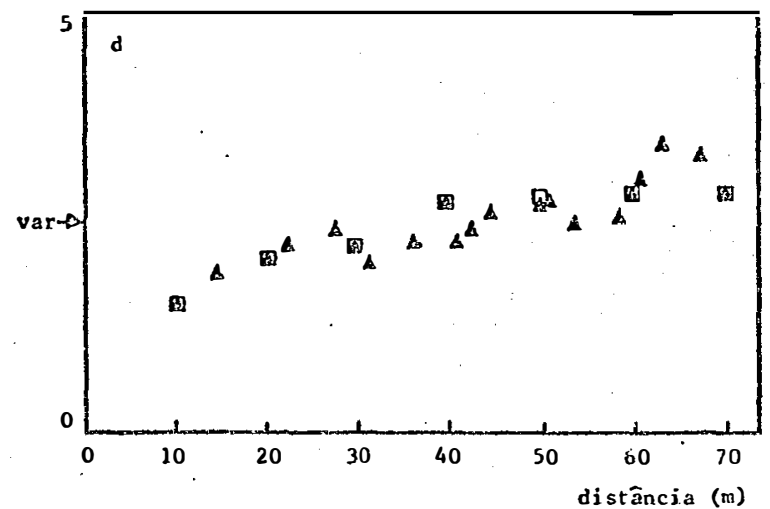
$\gamma(\mathrm{L})$

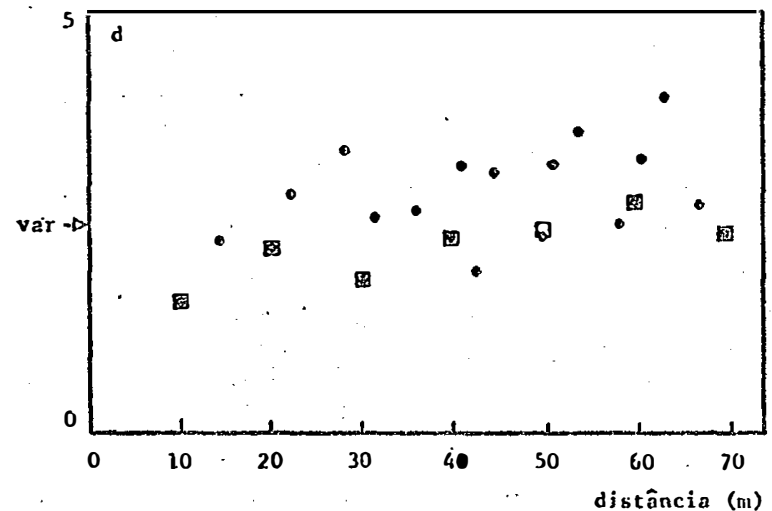

FIGURA 31 - Autocorrelogramas, $r(L)$ e semivariogramas, $\gamma(L)$ da areia an-

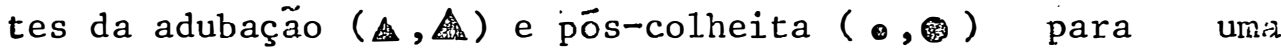

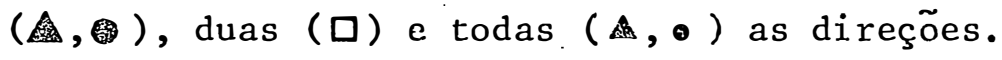


r(1.)

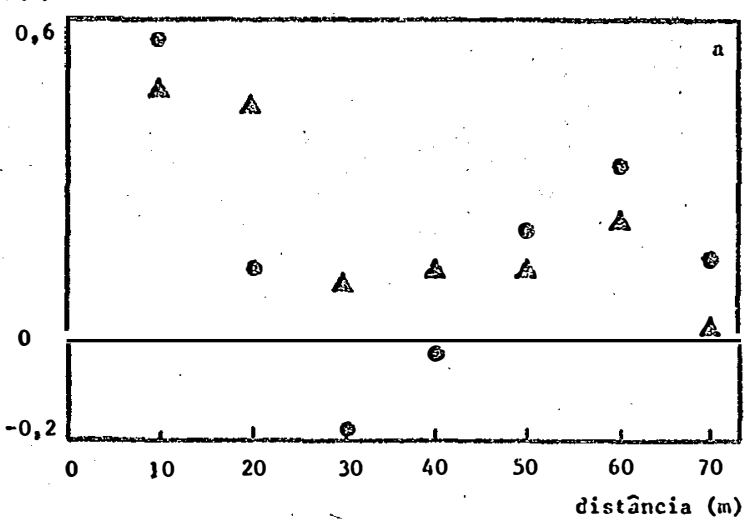

r(L)

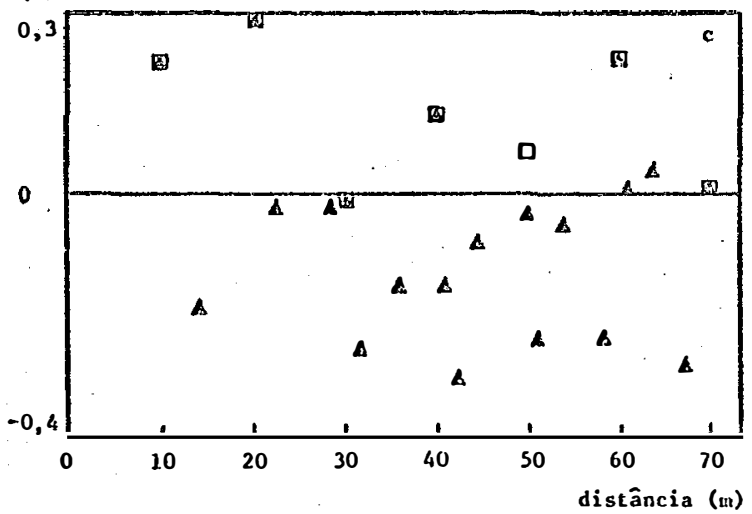

$r(\mathrm{~L})$

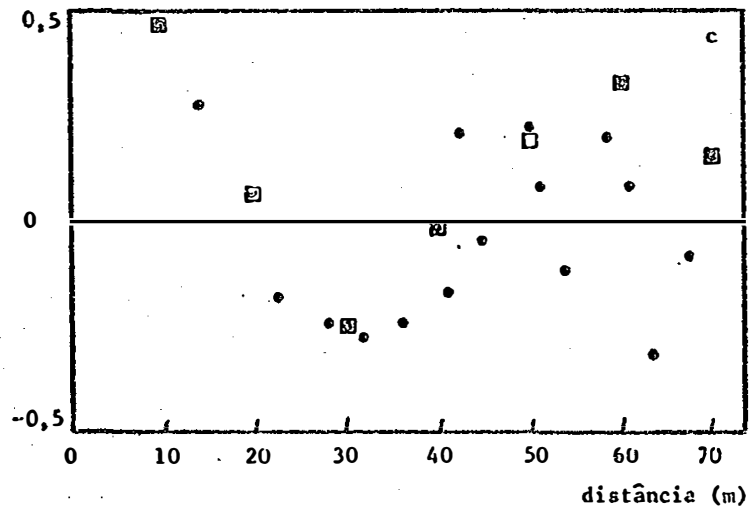

$r(1)$

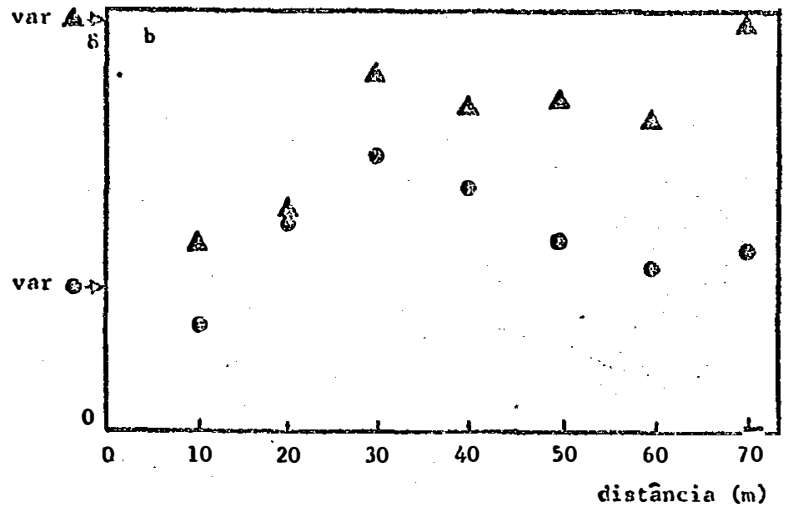

$\gamma(\mathrm{L})$

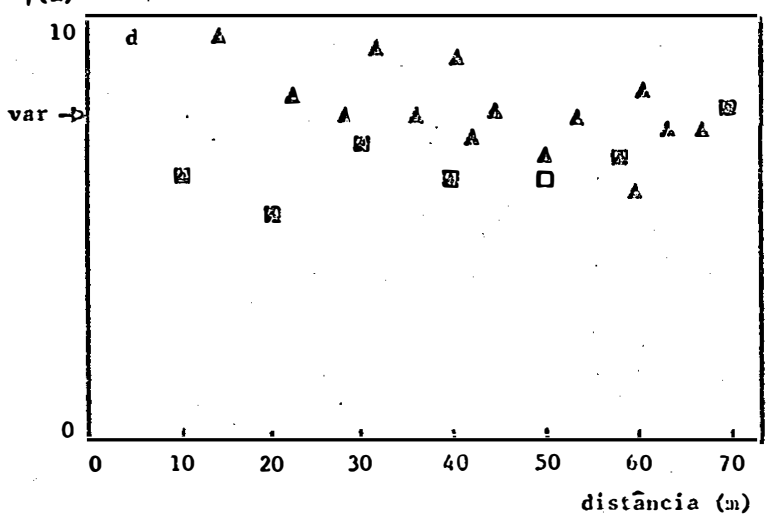
.$\gamma(\mathrm{L})$

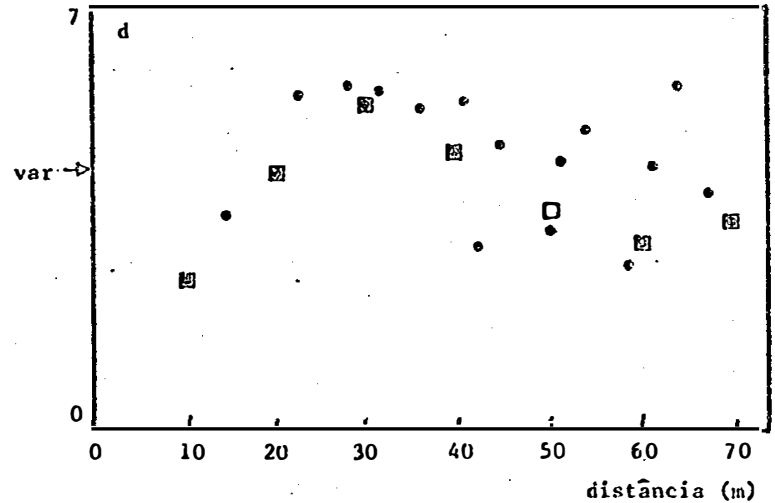

FIGURA 32 - Autocorrelogramas, $r(L)$ e semivariogramas, $\gamma(L)$ do silte an-

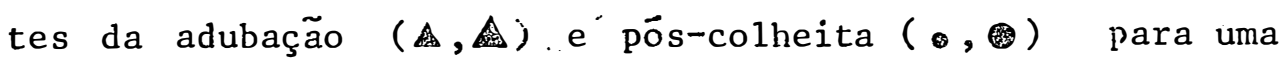
(, , duas $(\square)$ e todas $(A, \Theta)$ as direções. 

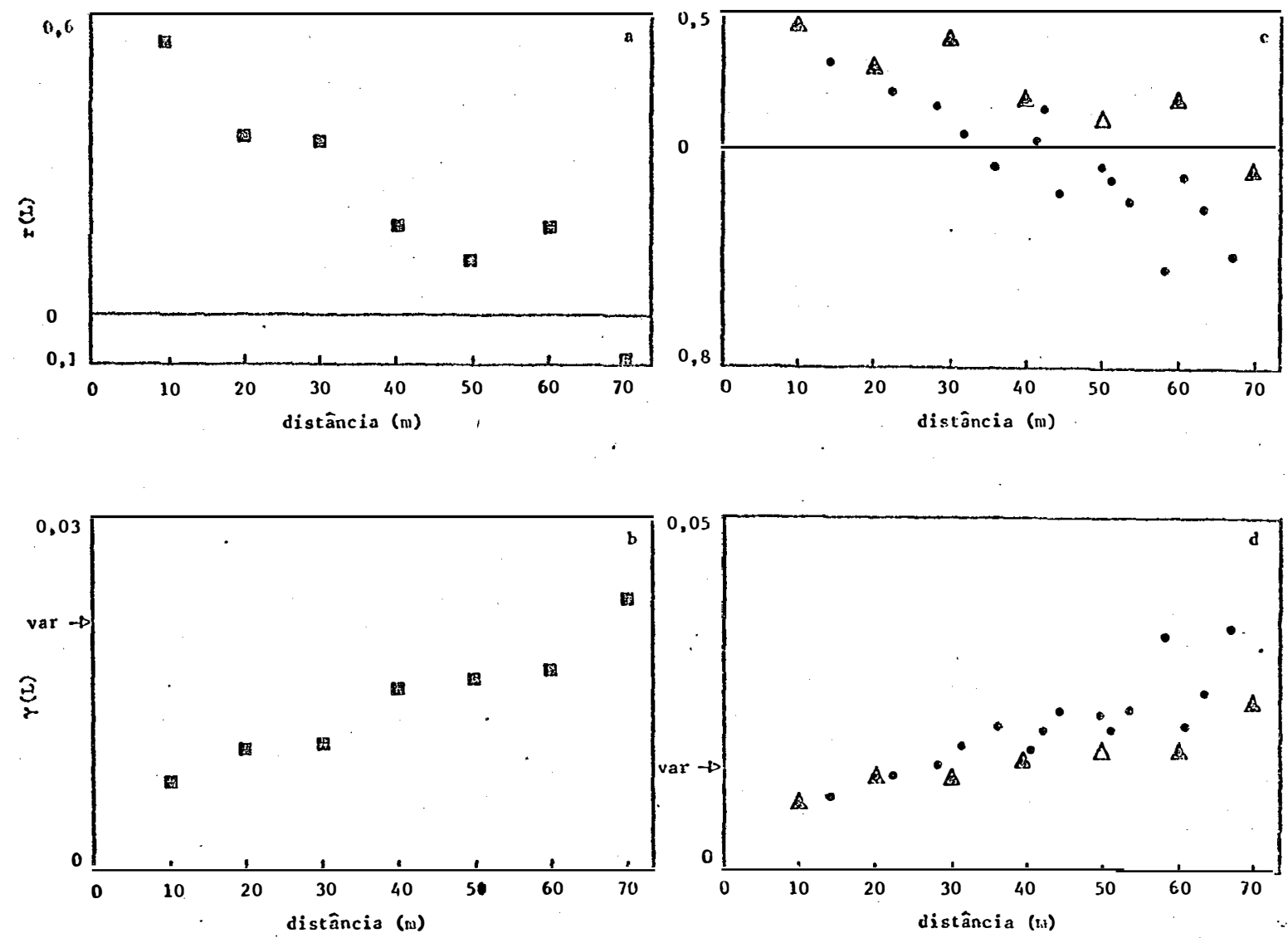

FIGURA 33 - Autocorrelogramas, $r(L)$ e semivariogramas, $\gamma(L)$ do teor de. nitrogênio ria planta para uma $($ 痁), duas $(\Delta)$ e todas $(\bullet)$ as direções. 

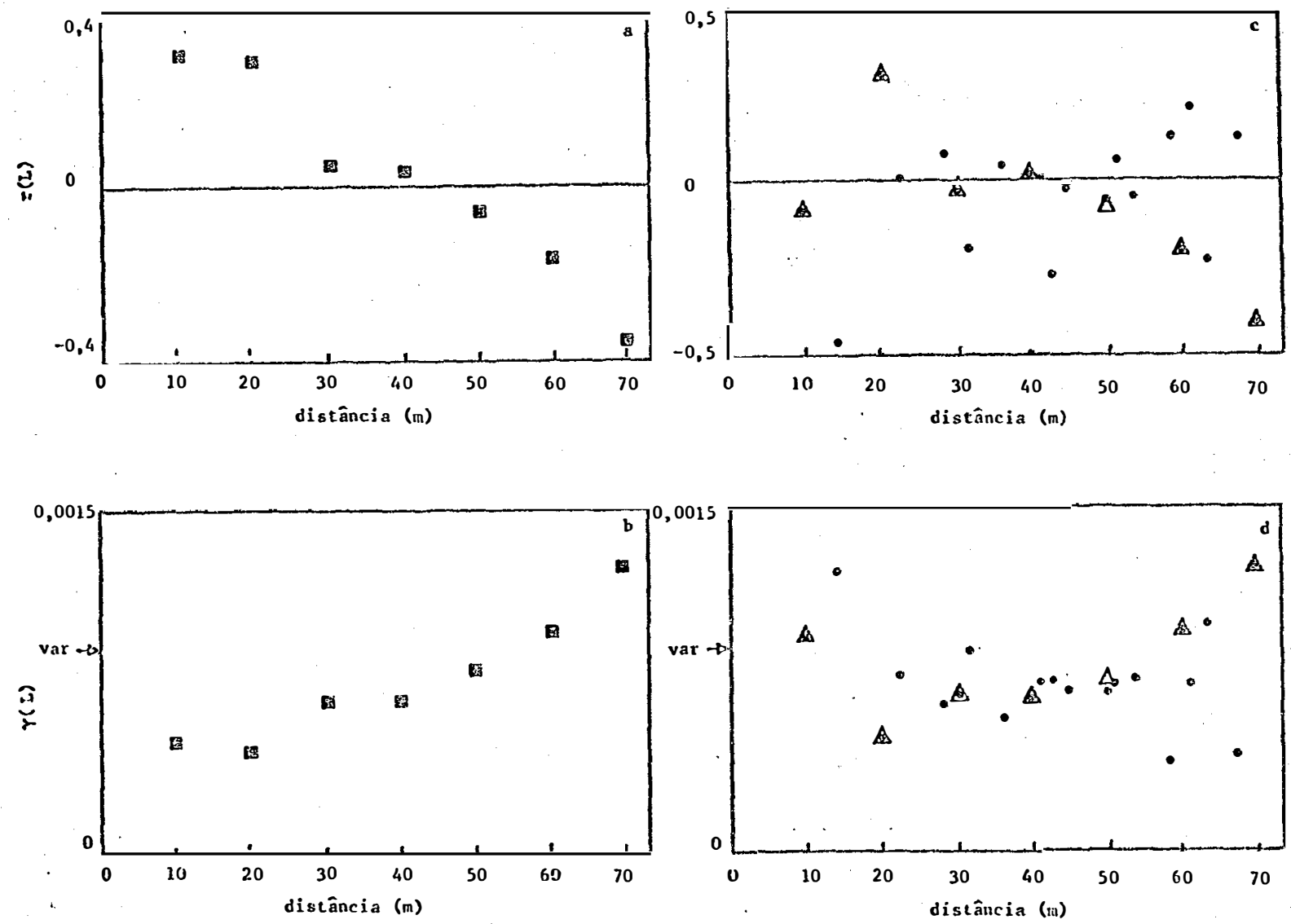

FIGURA 34 - Autocorrelogramas, $r(L)$ e semivariogramas, $\gamma(L)$ do teor de fósforo na planta para uma (四), duas $(\Delta)$ e todas $(\theta)$ as direções. 

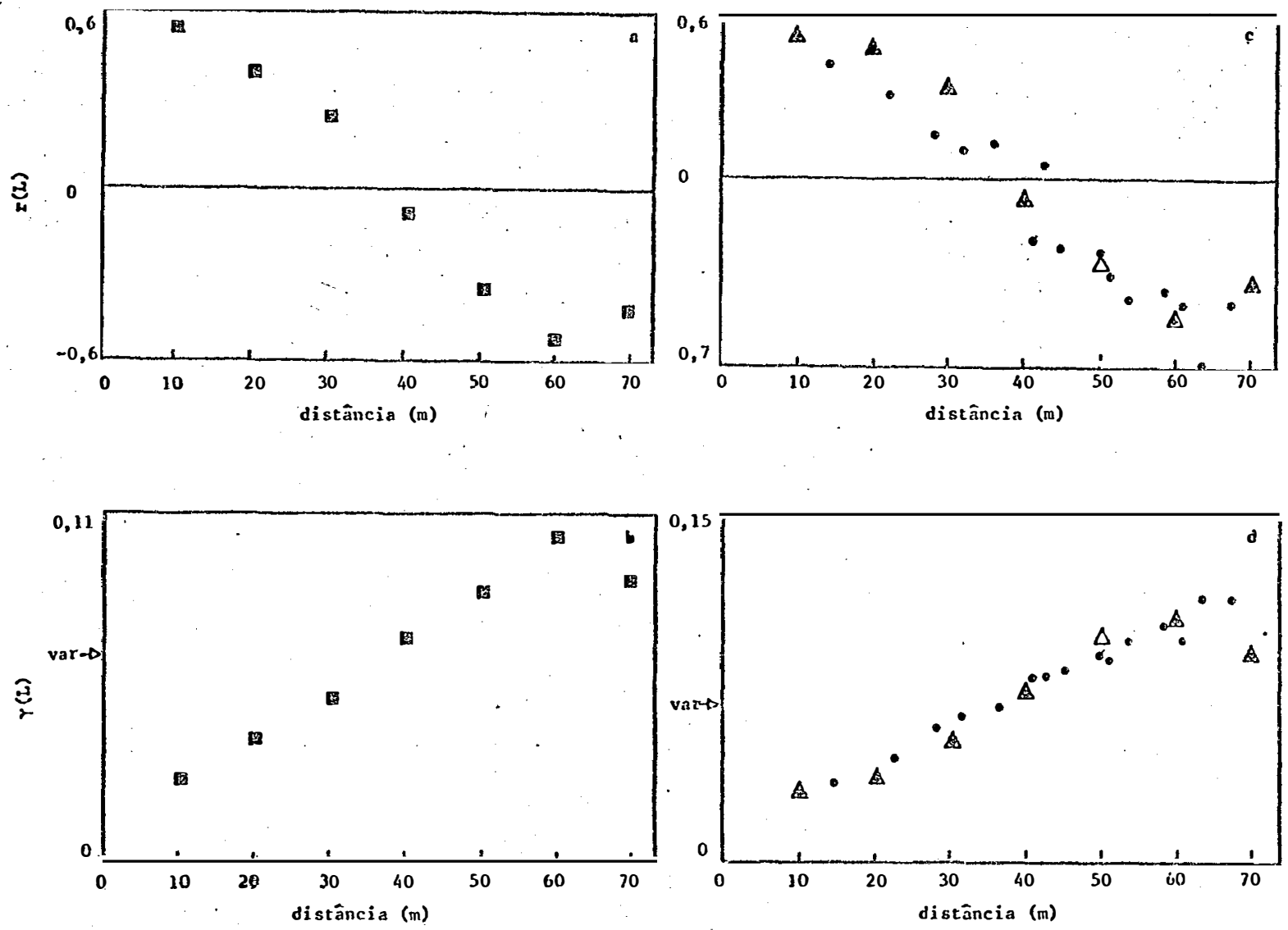

- FIGURA 35 - Autocorrelogramas, $r(L)$ e semivariogramas, $Y(L)$ do teor de. potássio na planta para uma ( direções. 

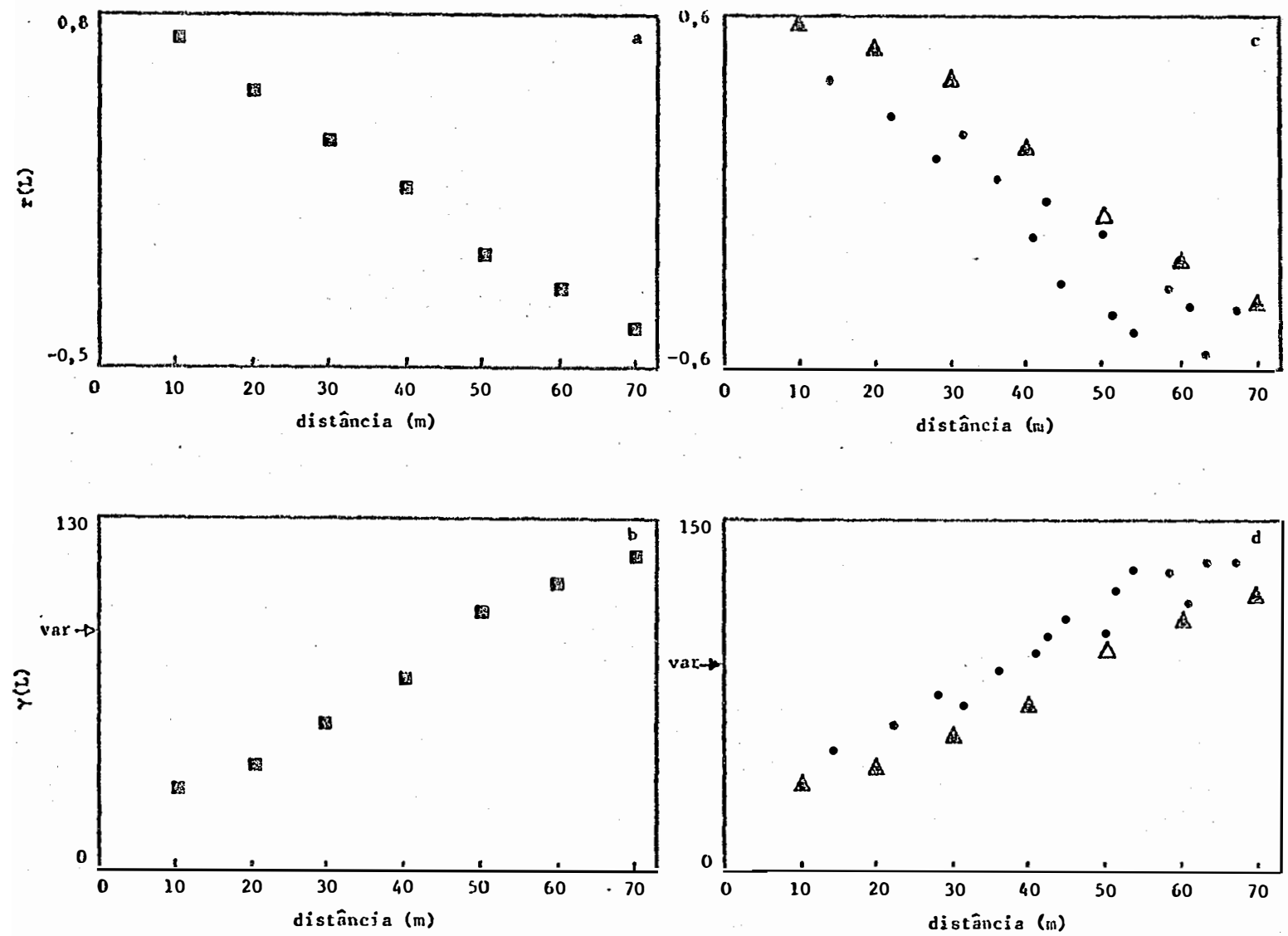

FIGURA 36 - Autocorrelogramas, $r(L)$ e semivariogramas, $\gamma(L)$ do teor de zinco na planta para uma (圈), duas $(\Delta)$ e todas $(\Theta)$ as direçöes. 

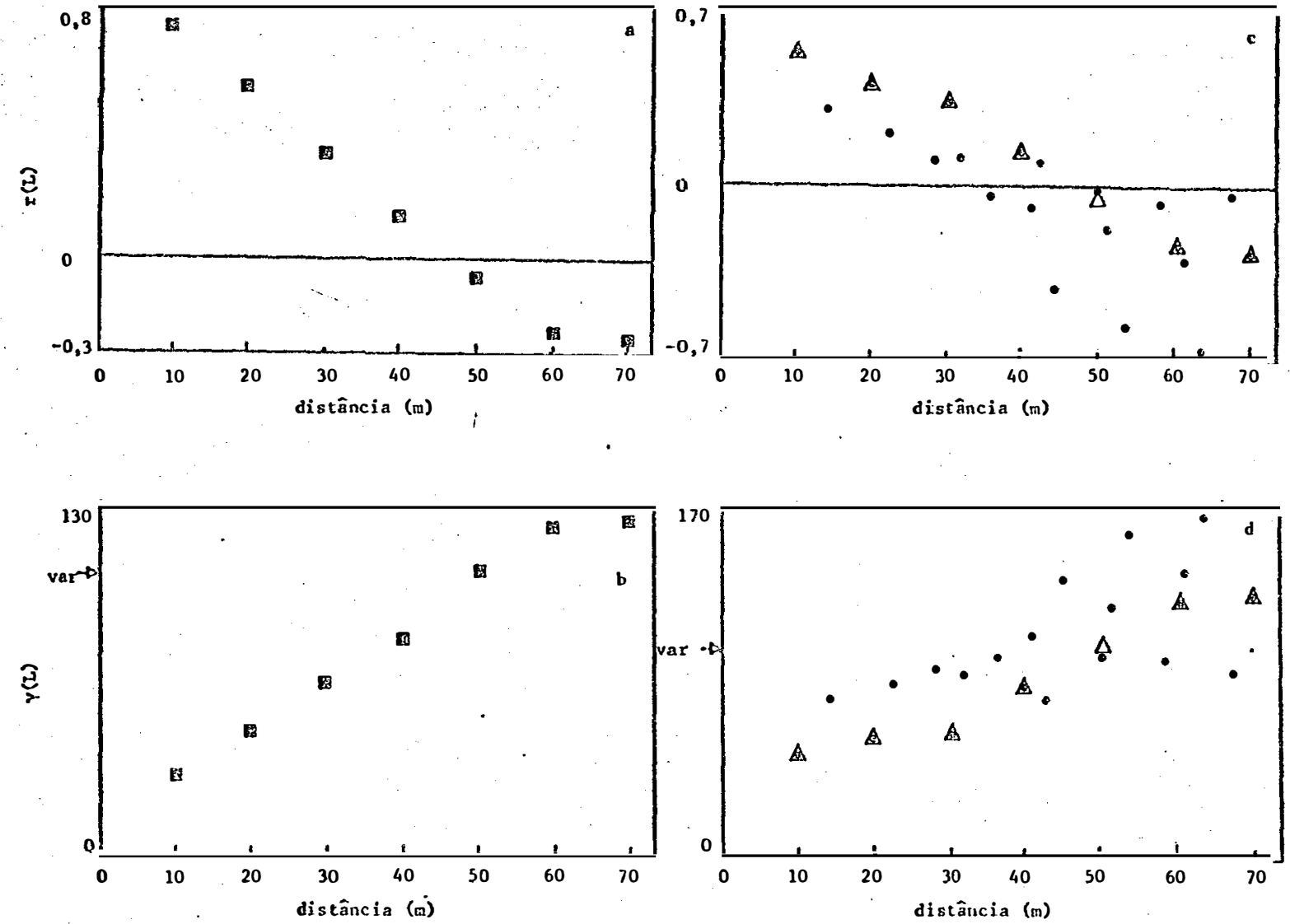

FIGURA 37 - Autocorrelogramas, $r(L)$ e semivariogramas, $\gamma(L)$ da relação. P/Zn na planta para uma (圈), duas $(\Delta)$ e todas $(\theta)$ as direções. 

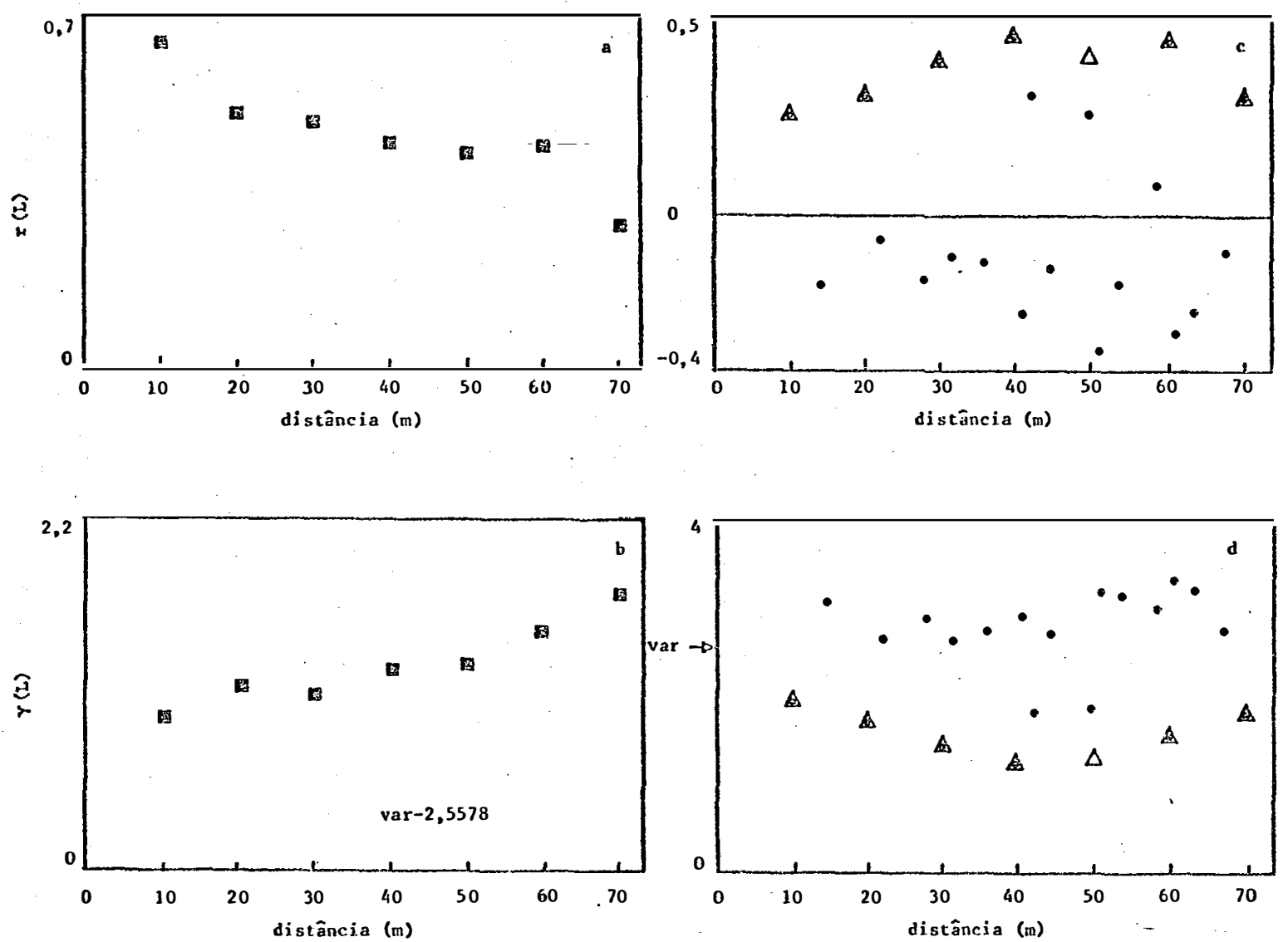

FIGURA 38 - Autocorrelogramas, $r(L)$ e semivariogramas, $\gamma(L)$ da extração de nitrogênio pela planta para uma (棦), duas $(\Delta)$ e todas (०) as direções. 

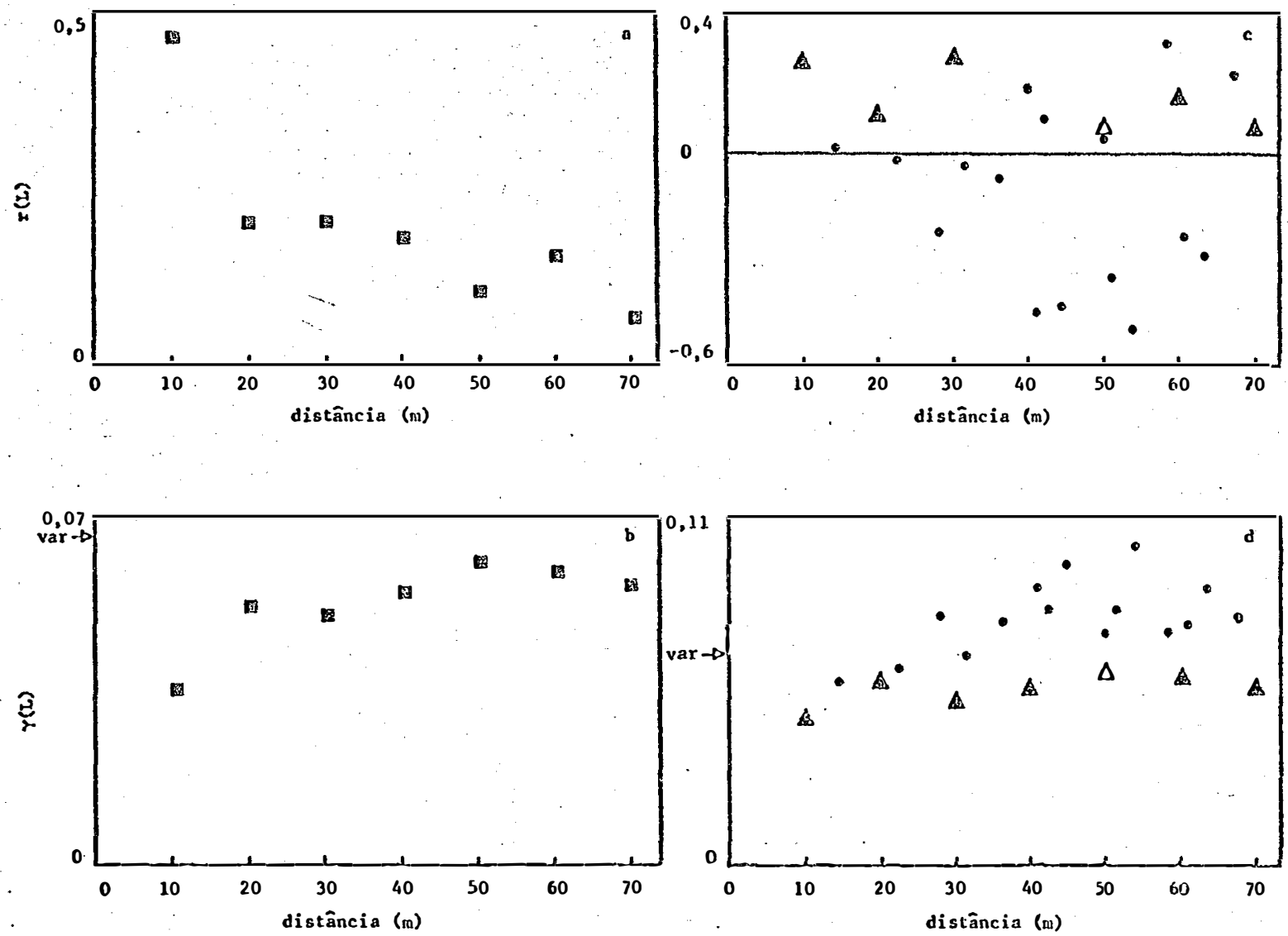

FIGURA 39 - Autocorrelogramas, $r(L)$ e semivariogramas, $\gamma(L)$ da extração. de fósforo pela planta para uma (图), duas $(\Delta)$ e todas $(\bullet)$ as direções. 

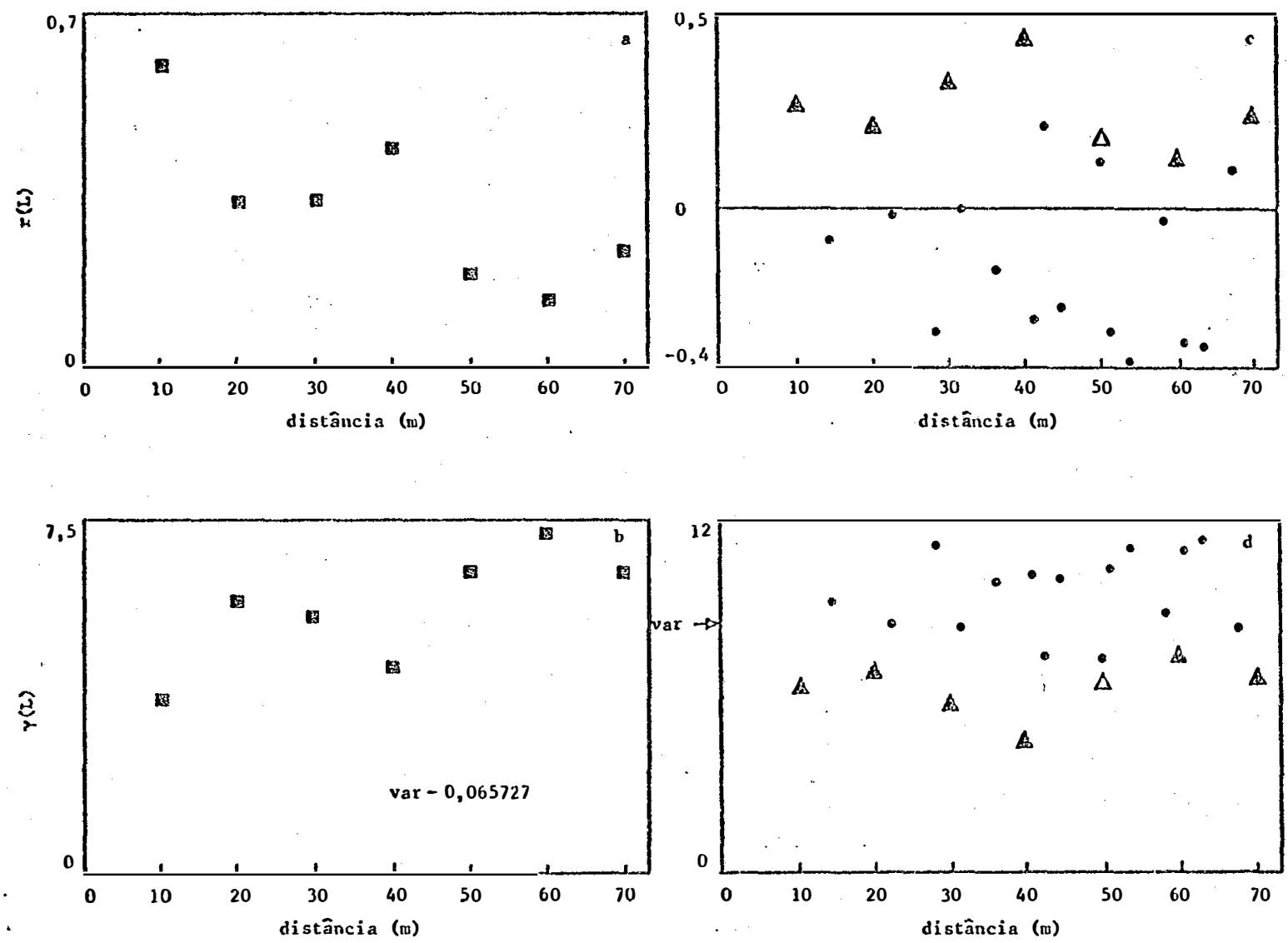

FIGURA 40 - Autocorrelogramas, $r(L)$ e semivariogramas, $\gamma(L)$ da extração de potássio pela planta para uma (橉), duas $(\Delta)$ e todas (०) as direções. 

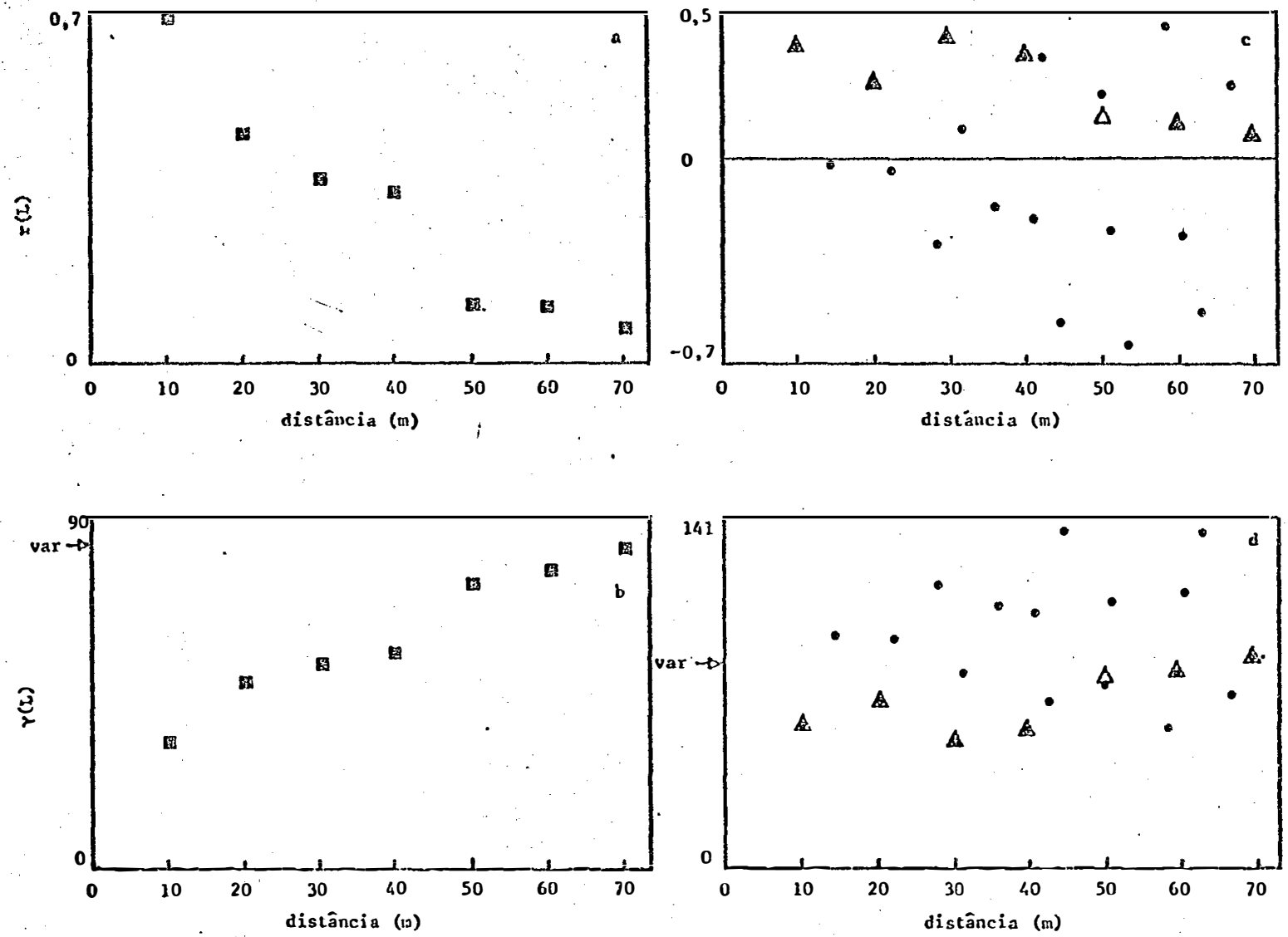

FIGURA 41 - Autocorrelogramas, $r(L)$ e semivariogramas, $\gamma(L)$ da extração de zinco pela planta para uma (圈), duas $(\Delta)$ e todas $(\theta)$ as direções. 


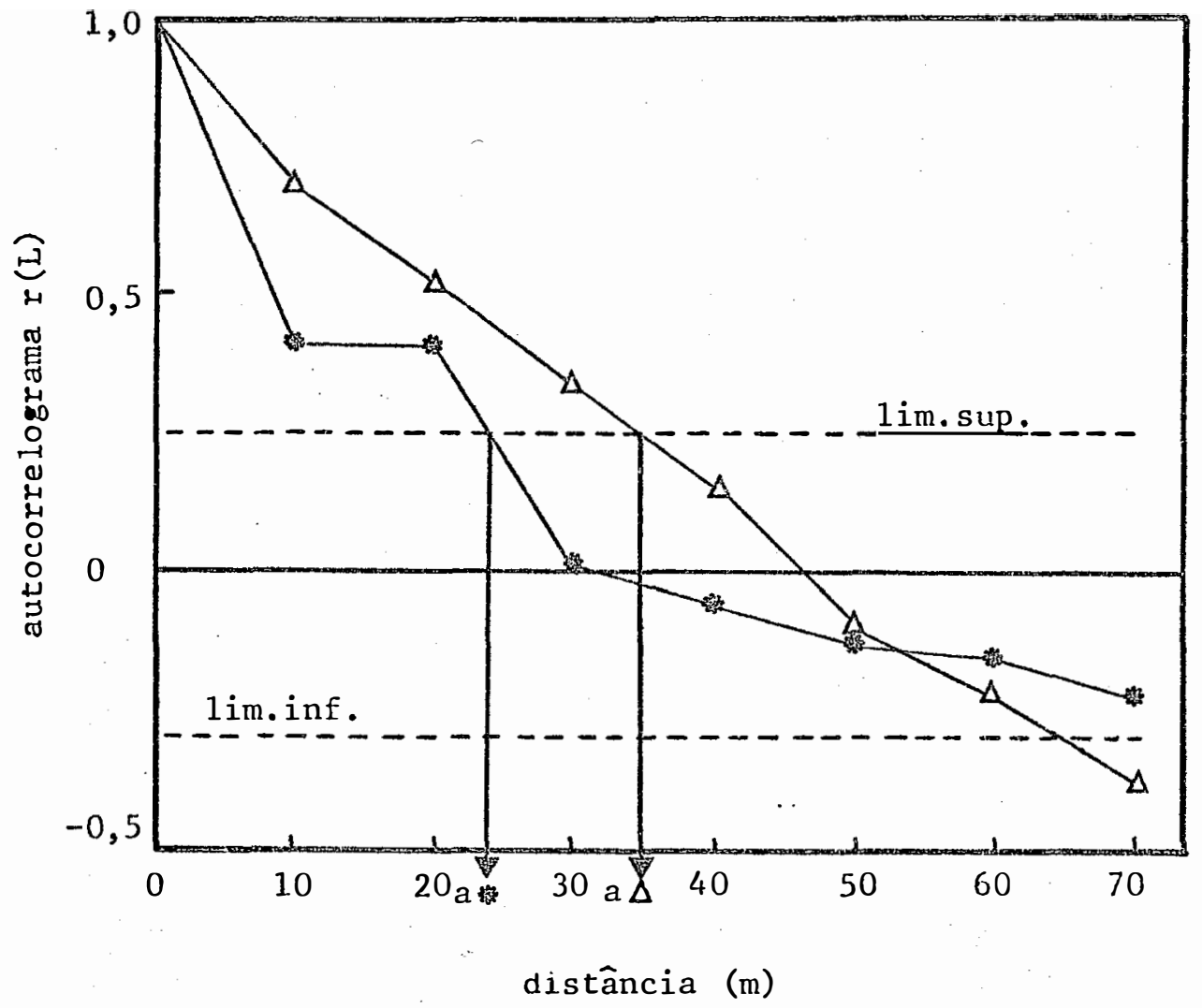

FIGURA 42 - Limites fixos de significância (95\%). Autocorrelograma da produção de arroz (a幽) e teor de zinco na planta $(a \Delta)$. Uma direção. 


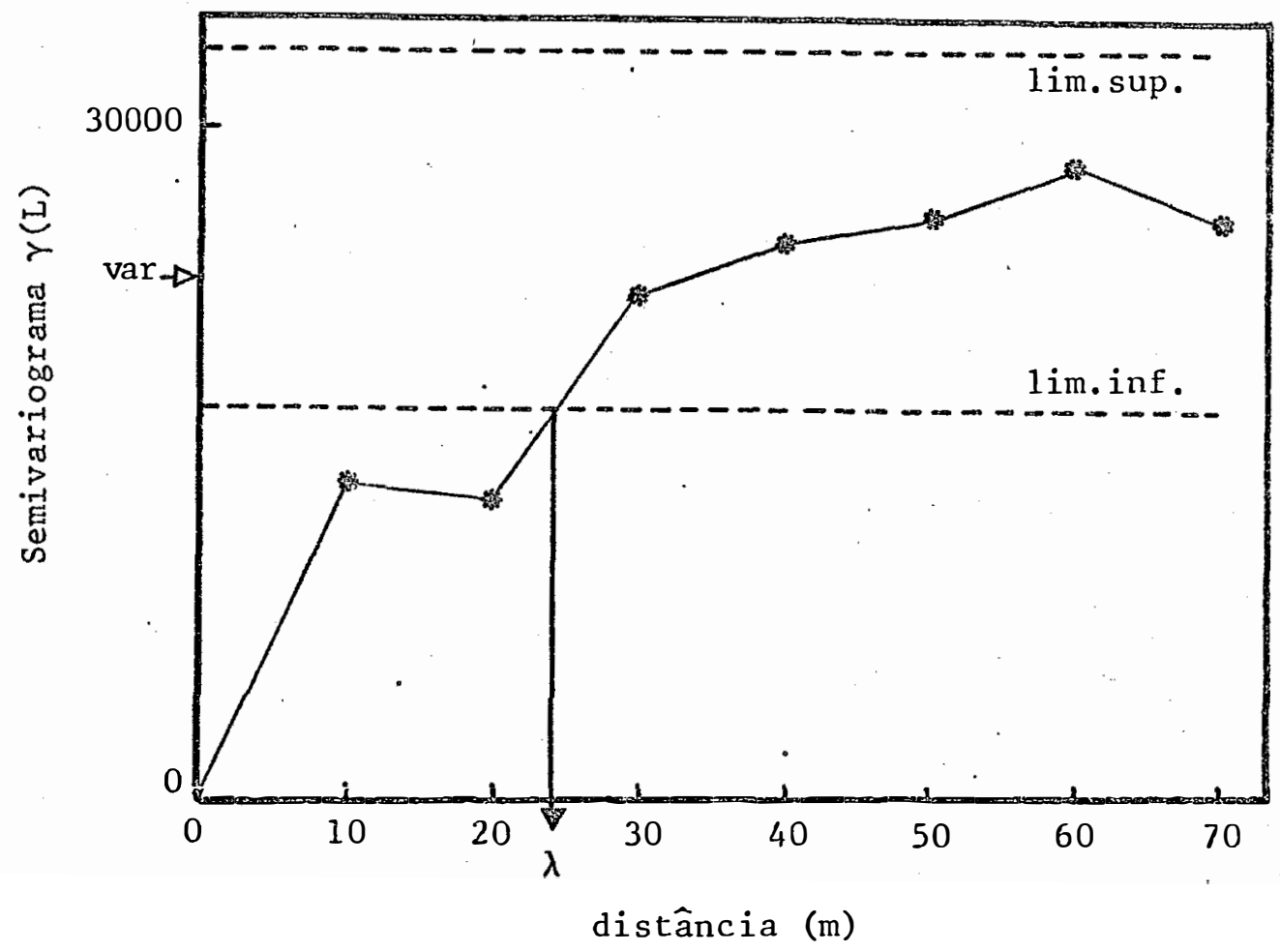

FIGURA 43 - Limites fixos de significância (95\%). Semivariograma da produção de arroz (uma direção). 


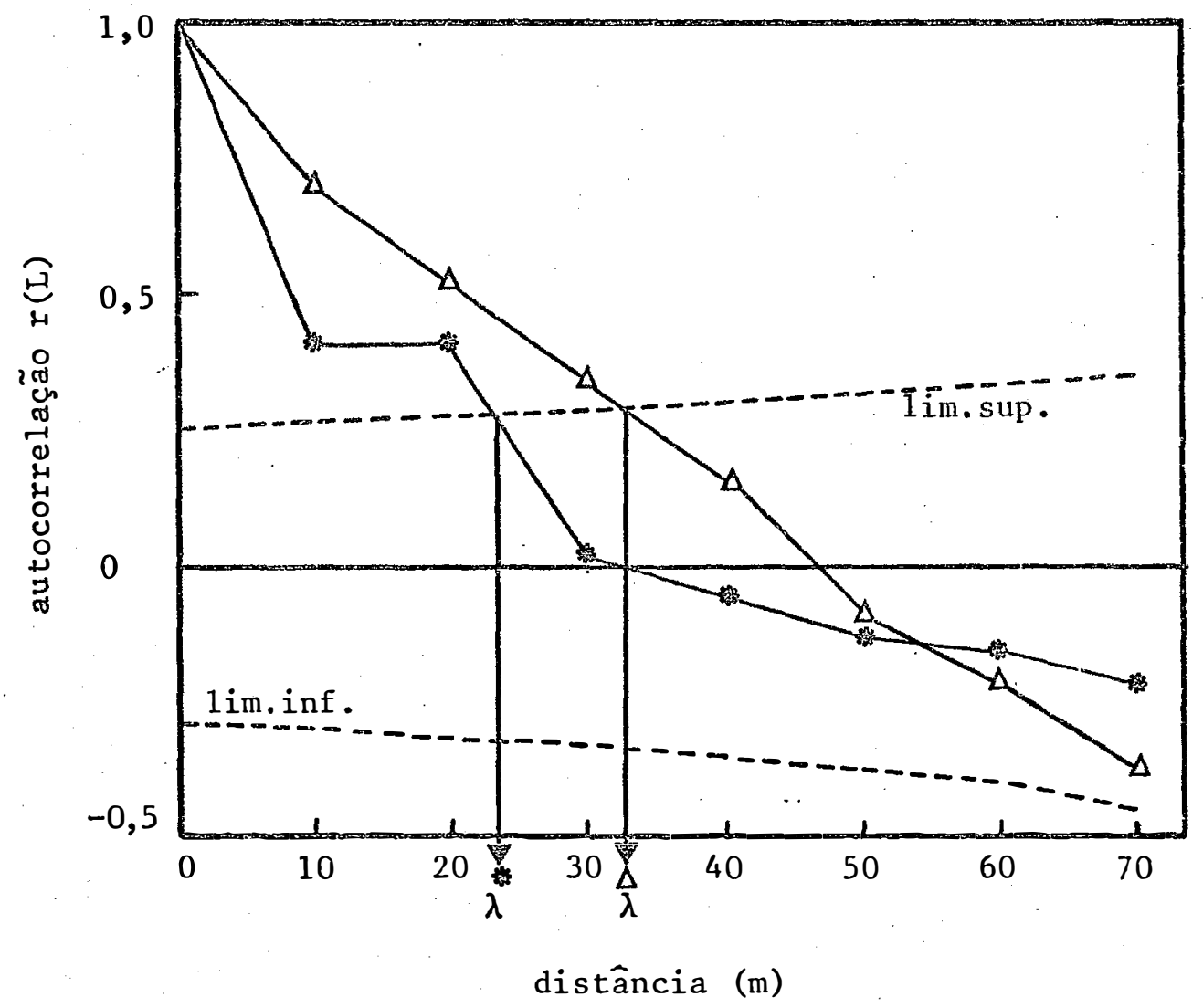

FIGURA 44 - Limites de significância (95\%) para cada r(L), considerando o número de pares. Autocorrelograma da produção de arroz (w) e teor de zinco na planta ( $\Delta$ ) (ppm). Uma direção. 


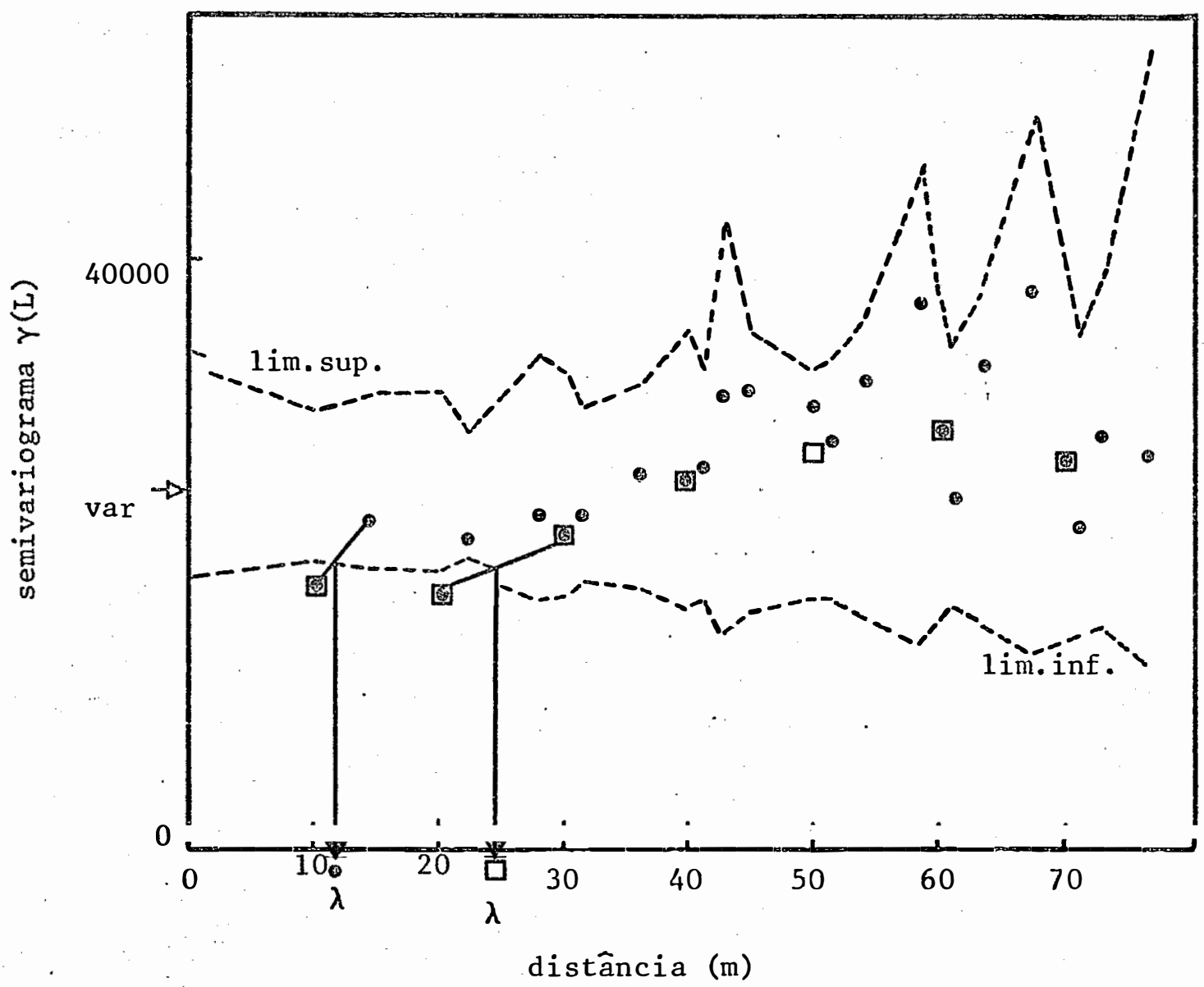

FIGURA 45 - Limites de significância (95\%) para cada $\gamma(\mathrm{L})$, considerando o número de pares. Semivariograma da produção de arroz (todas as direções e duas direções $\square$ ). 
TABELA 2 - Alcance para cada parâmetro, em metros, obtido pela escala integral (E.I.), "comprimentò da autocorrelação" (ka), "comprimento da semivariância " (kv) e limite superior da autocorrelação (a).

\begin{tabular}{|c|c|c|c|c|c|c|}
\hline \multirow[t]{2}{*}{ parâmetro } & \multicolumn{4}{|c|}{ direção } & \multirow{2}{*}{$\frac{\begin{array}{l}\text { duas } \\
\text { dir. }\end{array}}{\text { E.I. }}$} & \multirow{2}{*}{$\begin{array}{c}\begin{array}{c}\text { todas } \\
\text { dir. }\end{array} \\
\text { E.I. }\end{array}$} \\
\hline & $\mathrm{ka}$ & kv & $\mathbf{a}$ & E.I. & & \\
\hline produção $\mathrm{g} / \mathrm{m}^{2}$ & 33,5 & 33,5 & 23,5 & 17,33 & 17,12 & 13,78 \\
\hline matéria seca $\mathrm{g} / \mathrm{m}^{2}$ & $>$ & $>$ & 34,5 & $>29,18$ & $>29,05$ & - \\
\hline altura planta $\mathrm{cm}$ & $>$ & $>$ & $>70,0$ & $>55,65$ & $>53,10$ & - \\
\hline perfilhamento efetivo & 22,5 & 33,0 & $<10,0$ & - & - & - \\
\hline n! perfilhos $/ \mathrm{m}^{2}$ & $>$ & $>$ & 21,5 & $>27,15$ & - & - \\
\hline 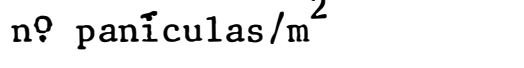 & 54,5 & $56, .5$ & 23,5 & 21,52 & - & - \\
\hline nọ grãos cheios/panícula & 28,5 & 29,0 & $<10,0$ & - & - & - \\
\hline peso de 100 gãos $g$ & 27,5 & 41,5 & 13,5 & 13,07 & 13,95 & 12,44 \\
\hline grãos chochos \% & 28,5 & $3.3,5$ & 16,5 & 13,99 & 11,54 & 13,36 \\
\hline $\begin{array}{l}\text { Indice de colheita } \\
\text { solo }\end{array}$ & 23,5 & 25,5 & $<10,0$ & - & - & - \\
\hline $\mathrm{pH}\left(\mathrm{a}_{\cdot} \mathrm{a}_{\bullet}\right)$ & 28,0 & 28,5 & 21,5 & 17,40 & 18,86 & 20,12 \\
\hline $\mathrm{pH}\left(\mathrm{p} \cdot \mathrm{c}_{.}\right)$ & 22,5 & 23,0 & 16,0 & 12,59 & 16,35 & 18,14 \\
\hline C org. (a.a.) \% & $>$ & $>$ & 42,5 & $>38,51$ & $>35,97$ & - \\
\hline C org. (p.c.) \% & $>$ & $>$ & 44,0 & $>37,20$ & $>33,56$ & 10,66 \\
\hline$P\left(a_{\cdot} a_{.}\right)^{1}$ & 38,5 & 38,0 & 26,5 & 20,16 & 18,55 & 14,00 \\
\hline$P(\text { p.c. })^{1}$ & 34,0 & 28,5 & 23,5 & 16,41 & 14,89 & 13,32 \\
\hline $\mathrm{K}\left(\mathrm{a} \cdot \mathrm{a}_{\cdot}\right)^{1}$ & 60,0 & 62,0 & 33,5 & 27,92 & 24,64 & 13,99 \\
\hline$k(p \cdot c \cdot)^{1}$ & 34,0 & 38,0 & 18,0 & 15,67 & 12,61 & 12,55 \\
\hline $\mathrm{Ca}\left(\mathrm{a} \cdot \mathrm{a}_{\cdot}\right)^{1}$ & 36,0 & 31,5 & 27,0 & 20,15 & 18,81 & 16,44 \\
\hline $\mathrm{Ca}\left(\mathrm{p} \cdot \mathrm{c}_{.}\right)^{1}$ & 41,0 & 36,0 & 31,0 & 24,35 & 21,09 & $1.8,26$ \\
\hline $\operatorname{Mg}\left(a_{\cdot} a_{\cdot}\right)^{1}$ & $>$ & 20,0 & $<10,0$ & - & - & - \\
\hline $\operatorname{Mg}(p \cdot c .)^{1}$ & 20,0 & 17,5 & $<10,0$ & - & 23,89 & 11,63 \\
\hline $\mathrm{A} 1\left(\mathrm{a} \mathrm{a}_{.}\right)^{1}$ & 16,0 & 14,0 & $<10,0$ & - & - & - \\
\hline A1 (p.c.) $)^{1}$ & 10,0 & 32,5 & $<10,0$ & - & - & - \\
\hline $\mathrm{H}(\mathrm{a} \cdot \mathrm{a} .)^{1}$ & 30,5 & 31,0 & 24,0 & 18,78 & 18,51 & 18,65 \\
\hline $\mathrm{H}\left(\mathrm{p} \cdot \mathrm{c}_{.}\right)^{1}$ & 32,5 & 31,0 & 25,5 & 19,36 & 19,72 & 20,32 \\
\hline
\end{tabular}


TABELA 2 - Alcance para cada parâmetro, em metros, obtido pela escala integral (E.I.), "comprimentó da autocorrelação" (ka), "comprimento da semivariância" (kv) e limite superior da autocorrelação (a).

\begin{tabular}{|c|c|c|c|c|c|c|}
\hline \multirow{2}{*}{ parâmetro } & \multicolumn{4}{|c|}{ uma direção } & \multirow{2}{*}{$\begin{array}{l}\begin{array}{l}\text { duas } \\
\text { dir. }\end{array} \\
\text { E.I. }\end{array}$} & \multirow{2}{*}{$\begin{array}{c}\begin{array}{c}\text { todas } \\
\text { dir. }\end{array} \\
\text { E.I. }\end{array}$} \\
\hline & $\mathrm{ka}$ & $\mathrm{kv}$ & $\mathrm{a}$ & E.I. & & \\
\hline soma de bases $\left(a_{\cdot} a_{.}\right)^{1}$ & 34,5 & 32,0 & 25,5 & 19,41 & 18,92 & 16,05 \\
\hline soma de bases $\left(p . c_{.}\right)^{1}$ & 27,5 & 25,5 & 21,0 & 16,00 & 17,96 & 19,98 \\
\hline $\operatorname{CTC}\left(a_{\cdot} a_{.}\right)^{1}$ & $>$ & $>$ & $>70,0$ & $>50,60$ & $>47,42$ & 11,40 \\
\hline $\operatorname{CTC}(p \cdot c .)^{1}$ & 28,5 & 25,5 & 20,5 & 16,99 & 15,56 & 12,57 \\
\hline $\mathrm{Zn}\left(\mathrm{a}_{\cdot} \mathrm{a}_{\cdot}\right) \mathrm{ppm}$ & $>$ & $>$ & 17,5 & $>33,97$ & - & - \\
\hline $\mathrm{Zn}\left(\mathrm{p} \cdot \mathrm{c}_{.}\right) \mathrm{ppm}$ & $>$ & 19,5 & 14,5 & $>33,48$ & - & - \\
\hline argila (a.a.) \% & 49,5 & 63,0 & 26,5 & 23,83 & 20,21 & 13,18 \\
\hline argila (p.c.) \% & $>$ & $>$ & 28,5 & $>31,30$ & $>28,13$ & 13,23 \\
\hline areia (a.a.) \% & 31,5 & 35,5 & 17,0 & 14,67 & 14,43 & 13,59 \\
\hline areia (p.c.) \% & 55,0 & 58,5 & 28,0 & 23,88 & 21,75 & 13,70 \\
\hline silte (a.a.) \% & $>$ & 70,0 & 25,0 & $>30,01$ & 14,42 & - \\
\hline silte (p.c.) \% & 24,0 & 13,0 & 17,5 & 13,65 & 13,46 & 12,71 \\
\hline planta & & & & & & \\
\hline $\mathrm{N} \%$ & 66,5 & 67,0 & 36,0 & $>30,35$ & 29,80 & 18,84 \\
\hline P \% & 43,5 & 55,5 & 22,0 & 16,44 & - & - \\
\hline $\mathrm{K} \%$ & 37,5 & 38,0 & 31,0 & 21,27 & 22,32 & 21,62 \\
\hline $\mathrm{Zn} \mathrm{ppm}$ & 44,5 & 46,5 & 33,5 & 26,10 & 25,48 & 22,21 \\
\hline $\mathrm{P} / \mathrm{Zn}$ & 46,0 & 46,5 & 33,5 & 26,06 & 24,49 & 20,11 \\
\hline extração $\mathrm{N} g / \mathrm{m}^{2}$ & $>$ & $>$ & $>70,0$ & $>46,64$ & $>44,21$ & - \\
\hline extração $P \mathrm{~g} / \mathrm{m}^{2}$ & $>$ & $>$ & 18,0 & $>28,39$ & $>27,66$ & - \\
\hline extração $\mathrm{k} \mathrm{g} / \mathrm{m}^{2}$ & $>$ & $>$ & 46,5 & $>36,41$ & $>34,64$ & - \\
\hline extração $\mathrm{Zn} \mathrm{mg} / \mathrm{m}^{2}$ & $>$ & $\begin{array}{l}70,0 \\
.\end{array}$ & 43,5 & $>34,10$ & $>32,06$ & - \\
\hline
\end{tabular}

$1_{\mathrm{me} / 100 \mathrm{ml} \text { de terra }}$

$\left(a_{\text {.a. }}\right)=$ antes da adubação

$\left(p_{.} c_{.}\right)=$pós-colheita 


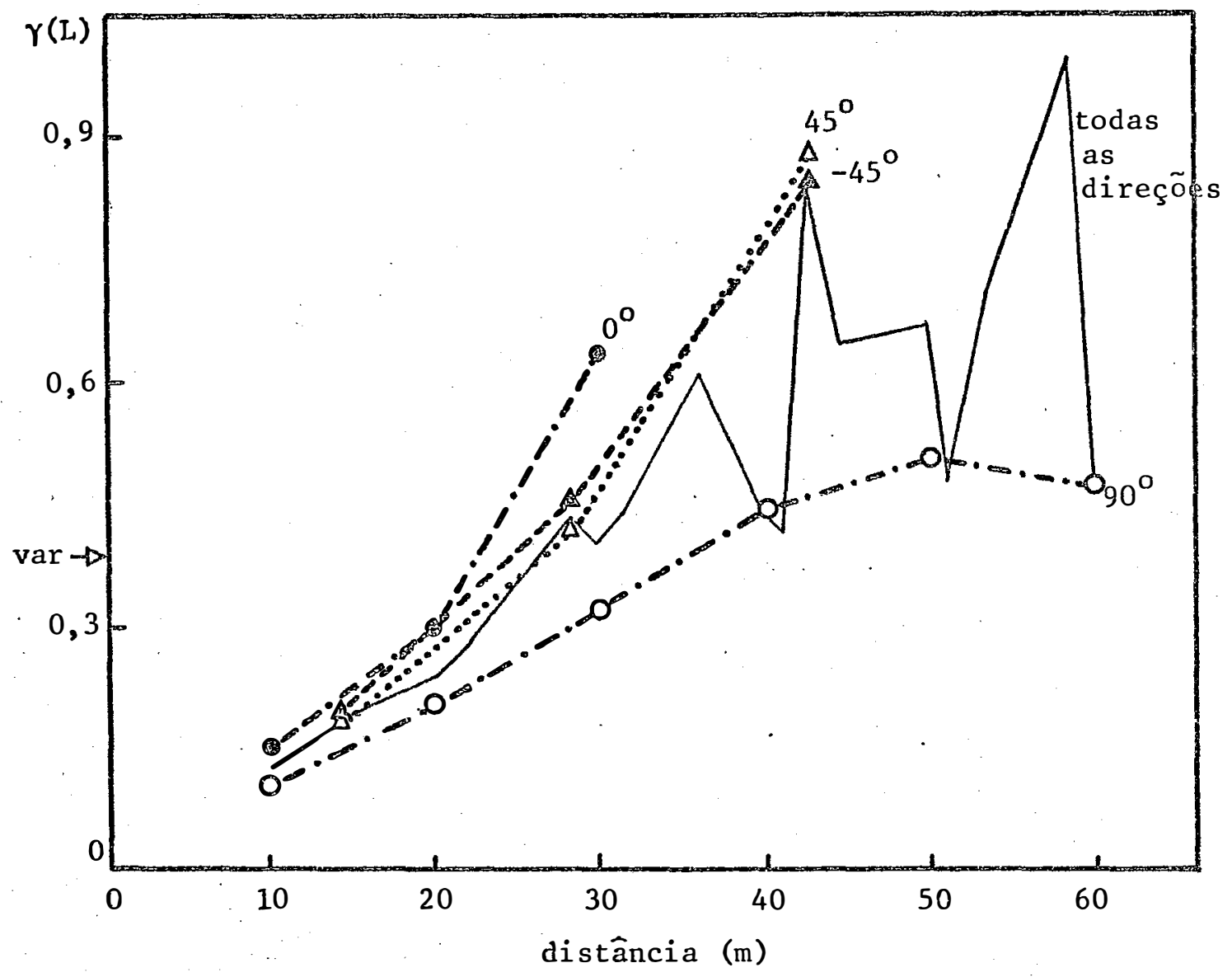

FIGURA 46 - Decomposição do semivariograma em quatro direções em comparação com todas as direções. Cálcio (p.c.). 


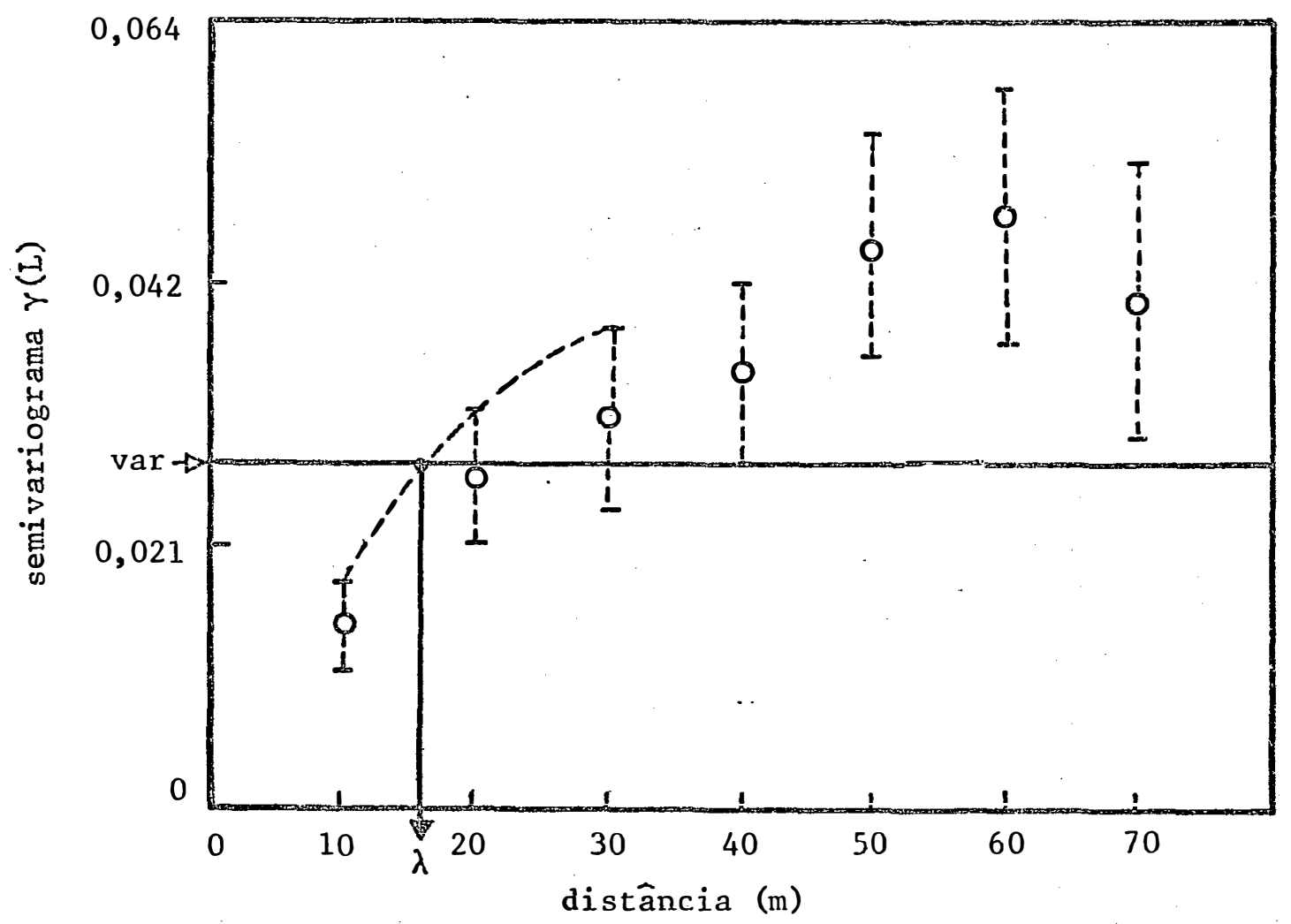

FIGURA 47 - Alcance $(\lambda)$ obtido através da amplitude do erro do gama médio (eq. 11), $\mathrm{pH}$ (p.c.). 


\section{DISCUSSก̃O}

Analisando os dados da Tabela 1 , observa-se que 0 maior coeficiente de variação encontrado foi de $69 \%$, referente à percentagem de grãos chochos por metro quadrado. De forma geral, o coeficiente de variação para os parâmetros referentes à planta foram mais elevados do que os referentes ao solo, onde o menor valor: foi encontrado na determinação do $\mathrm{pH}$ (próximo a 3\%). Os momentos estatísticos, como coeficiente de simetria, próximo a zero, e curtose, ao redor de três, indicam que a maioria das variāveis apresentou distribuição normal. Apenas para o fósforo (p.c.), magnésio (a.a. e p.c.), soma de bases (a.a.) e zinco (a.a. e p.c.), nas anālises de solos, e para percentagem de fósforo na anālise de planta, os valores das observações se concentraram ao redor da média, o que é representado por elevados valores de curtose. 0 afastamento de zero, para o coeficiente de simetria, indica um alongamento da cauda da distribuição dos dados observados, em relação à curva da distribuição normal. o alongamento para a direita é representado principalmente no caso do fósforo (p.c.) e do magnésio (a.a.), e uma leve tendência à esquerda pode ser indicada pelo coeficiente de simetria do peso de 100 grãos (SPIEGEL, 1976).

A importância da distribuição normal, enfatizada por HAAN (1977), no estabelecimento de limites, é justificada pelo fato deste intervalo de confiança depender de tabelas estatísticas ba- 
seadas nessa distribuição. Portanto, tanto para $r(L)$ como para $\gamma(L)$, os limites foram interpretados com cautela em situações de distribuição não normal.

\subsection{Autocorrelogramas e semivàriogramas para uma direção.}

Os autocorrelogramas foram divididos em três classes, conforme Figura 1, sugerida por GAJEM et alii. (1981) (item 2.2.2.).

Entre os autocorrelogramas que se assemelharam à $\mathrm{Fi}-$ gura la, com redução gradativa do $r(L)$ até atingir zero, dentro da distância em estudo, encontraram-se duas categorias: i) os que oscilaram ao redor de zero nos ültimos intervalos ("lags") e ii) os que continuaram decrescendo, apresentando valores, significativamente, negativos. A primeira categoria foi aqui representada pelos autocorrelogramas obtidos com: a produção de arroz, número de panículas, percentagem de nitrogênio e relação $\mathrm{P} / \mathrm{Zn}$ na planta; e no solo com potássio (a.a. e p.c.), cālcio (a.a. e p.c.), CTC (p.c.), $\operatorname{argila}\left(a_{\bullet} ._{\bullet}\right)$, areia (a.a. e p.c.) e silte (p.c.) (Figuras 9a, 14a, $33 a, 37 a, 22 a, 23 a, 28 a, 30 a, 31 a$ e 32a, respectivamente). Estes não ultrapassam o limite inferior, como no exemplo da Figura 42, o que, conforme DAVIS (1973), indica independência dos dados após certa distância. A segunda categoria de autocorrelogranas semelhantes à Figura la foi encontrada em: porcentagem de grãos, peso de 100 grãos, percentagem de fösforo, potảssio e zinco na planta; e no so-

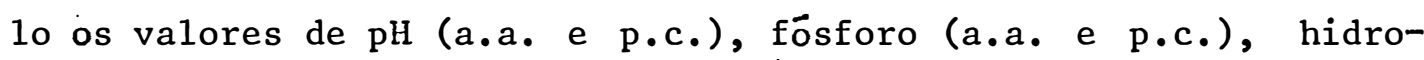
gênio (a.a. e p.c.) e soma de bases (a.a. e p.c.) (Figuras 17a, 16a, 34a, 35a, 36a, 19a, 21a, 26a e 27a, respectivamente). Nesses 
gräficos, a função autocorrelação prossegue decrescendo, apresentando valores significativamente negativos. Enquanto, segundo VAUCLIN et alii (1982), este tipo de série espacial não pode ser caracterizado pela autocorrelação por apresentar tendências, outros autores, como GUROVICH \& STERN (1983) consideram a existência de uma correlação negativa. No caso em questão, os valores da origem poderiam estar negativamente relacionados com os valores distanciados em torno de 60 a 70 metros, mas os semivariogramas correspondentes não confirmam esta interpretação, uma vez que a maioria indicou valores de $\gamma(L)$ crescentes. E importante salientar que, embora se tenha procurado uma justificativa para esta $\bar{u} 1$ tima categoria, cuidados devem ser tomados neste tipo de raciocínio, pois os pares das observações decrescem com o aumento da distância, ampliando os limites de significância, conforme mostra o exemplo da Figura 44 .

0 perfilhamento efetivo, número de gräos cheios, índice de colheita, magnésio (a.a. e p.c.) no sọlo e alumínio (a.a. e p.c.) no solo (Figuras 12a, 15a, 18a, 24a e 25a, respectivamente) apresentaram valores de $r(L)$ não diferente de zero jā no primeiro "lag" (com 95\% de significância), sendo seus autocorrelogramas anālogos à Figura 1b. Os dados desses parâmetros não denotam autocorrelação acima de 10 metros, podendo, portanto, conforme GAJEM et alii. (1981), serem considerados independentes.

Os parâmetros que se assemelharam à Figura 1c, apresentando autocorrelação a longo alcance, foram: matéria seca, altura de plantas, número de perfilhos, carbono orgânico (a.a. e p.c.), zinco do solo (a.a. e p.c.), $\operatorname{crc}\left(a_{\cdot} a_{\bullet}\right)$, silte (a.a.), argila (p. c.) e extração pela planta de nitrogênio, fósforo, potássio e zinco 
(Figuras 10a, 11a, 13a, 20a, 29a, 28a, 32a, 30a, 38a, 39a, 40a e 41a, respectivamente).

0 estudo da relação de dependência espacial entre as observações pode ser realizado, também, atravēs da estrutura da variância (DAVIS, 1973; WEBSTER, 1985). A avaliação da estrutura da variância foi de maior importância quando o autocorrelograma correspondente apresentou valores negativos de significância ou quando a função autocorrelação do parâmetro em estudo não foi sequencia1mente decrescente.

A maioria dos autocorrelogramas do tipo da Figura 1b, esteve vinculada a semivariogramas com puro efeito pepipta (efeito "nugget" puro) (Figuras 12b,18b, 24b e 25b), confirmando, de acordo com DAVID (1985); a independência dos dados acima do interva1o de amostragem.

Os semivariogramas das Figuras $20 \mathrm{~b}$ e $29 \mathrm{~b}$ (carbono orgânico e zinco no solo, respectivamente, ambos a.a. e p.c.), não definiram estrutura, embora apresentem algum tipo de relação de dependência. Estas funções poderiam fịcar melhor definidas se o experimento tivesse sido executado em maior extensão, onde as distâncias acima de 70 metros seriam consideradas, visando manter o critério sugerido por HAAN (1977).

5.2. Autocorrelogramas e semivariogramas para duas e todas as direções

Ao serem comparadas as Figuras de 9 a a 41 a com as $\mathrm{Fi-}$ guras de 9c a 41c, observa-se que para a maioria ocorreu redução de . r(L) desde os. "lags" iniciais. Isto mostra a interferência progres- 
siva na relação de dependência espacial, quando foi acrescentada a direção $0^{\circ}$ (para duas direções) e as diagonais (para todas as direções). Apenas número de grãos chochos, índice de colheita, magnēsio no solo (a.a. e p.c.) e alumínio no solo (a.a. e p.c.) obtiveram pequena elevação na função autocorrelação, com o aumento das direções em estudo (Figuras 17c, 18c, 24c e 25c, respectivamente).

Os semivariogramas mostrados pelas Figuras de 9d a $41 d$ refletem esta redução na dependência espacial, indicando maiores valores para $\gamma(L)$, exceto os das Figuras 21d (p.c.) e 27d (p.c.). Inclusive as modificações na estrutura de muitos semivariogramas podem ser observados confrontando as Figuras de $9 \mathrm{~b}$ a $41 b$ com as Figuras de $9 d$ a 41d. Constata-se, ainda, que quase sempre os valores das diagonais foram muito discrepantes, apresentando pontos dispersos a serem analisados. Estas flutuações parecem conduzir a resultados conflitantes, quando os gräficos são avaliados pelos limites fixos (Figura 43). Mas, quando o número de pares das observações é considerado para cada $\gamma(L)$ (Figura 45), verifica-se que os pontos referentes às diagonais, mais discrepantes do conjunto, são aqueles com menor número de pares e, portanto, possuemgrande intervalo entre os limites de significância da variância total das amostras.

\subsection{Alcance.}

Vārios enfoques podem ser dados em relação à medida de alcance, quando se utiliza o "comprimento da autocorrelação" (ka) ou o "comprimento da semivariância" (kv). Provindo de funções equivalentes (VIEIRA, 1981), estes valores devem guardar estreita relação in- 
dicando o espaço alêm do qual as amostras não estão correlacionadas entre si (LIBARDI et alii, 1985). Os alcances que diferiram entre ka e kv, da Tabela 2, foram devidos aos pontos próximos ao zero no autocorrelograma. Estes pontos resultaram em valores para $\gamma(\mathrm{L})$ a1gumas vezes maiores outras menores que a variância, alterando, assim, o resultado. Isto pode ser comprovado com o perfilhamento efetivo, peso de 100 grãos, \% de grãos chochos e no solo para fósforo (a.a. e p.c.), magnésio (a.a.), alumínio (p.c.) e zinco (p.c.). Destes parâmetros, apenas o perfilhamento efetivo, \% de grãos chochos e alumínio (p.c.) apresentaram distribuição normal.

0 sinal > utilizado para ka e kv na Tabela 2 indica que a distância de dependência foi superior aos 70 metros conside* rados.

- limite superior da autocorrelação (valor a) foi selecionado para fazer parte da Tabela 2 pelos seguintes motivos: i) embora seja um limite fixo (ver exemplo da Figura 42), este obterá valores próximos aos obtidos com o limite inferior no semivariograma (Figura 43), uma vez que ka e kv são próximos para a maioria dos parâmetros; ii) apesar do limite inferior variável (Figuras 44 e 45) e da amplitude do erro do gama médio (Figura 47) serem mais precisos, por considerarem o número de pares de observações para cada $r(L)$ ou $\gamma(L)$; o limite fixo da autocorrelação impõe maior praticidade no trabalho.

0 valor a (Tabela 2) definiu o alcance em todos os casos, com exceção da altura de plantas, CTC (a.a.) e extração de nitrogênio pela planta. Estas três variāveis revelaram dependência a longo alcance, acima do limite superior $(r(L)=0,2521)$. 
a < 10 metros apresentam um puro efeito pepita (efeito "nugget" puro), indicando que o alcance ou a relação de dependência poderia ser menor que o menor intervalo ("lag") estudado.

Com o propósito de comparar os diversos parâmetros estudados, segundo exemplo de VAUCLIN et alii. (1982), e ainda de indicar possíveis comportamentos isotrōpicos a campo, foi calculada a integral para uma direção, duas direções e todas as direções (Tabe1a 2). Dois critérios foram utilizados, quais sejam: i) ou o valor do primeiro "lag" deveria ser superior ao limite de significância de 95\% $(r(L)>0,262$ para uma direção com 48 pares, e $r(L)>0,210$ para duas e todas as direções com 87 pares), ou ii) os semivariogramas correspondentes deveriam apresentar algum tipo de estrutura. Sendo assim, os valores abaixo desses limites e os semivariogramas com efeito "nugget" puro,nitidamente identificado, foram excluídos do cálculo de escala integral.

0 parâmetro que pela escala integral (E.I.) se apresentou claramente isotrópico foi: o hidrogênio do solo (a.a. e p.c.) (Figura 26), sendo que, na Tabela 2, são encontradas desde relações de razoável isotropia até forte anisotropia.

De forma geral, para uma e duas direções, os valores de E.I. foram semelhantes, e valores menores de E.I. foram, em vārios casos; obtidos quando participaram todas as direções (exemplos: produção de arroz e a maioria dos parâmetros de solo).

Os problemas observados no uso da escala integral foram: i) quando os valores de $r(L)$ se apresentaram baixos a longas distâncias, o valor de E.I. ficou superestimado (extração de P, Figura 39a) e ii) quando altos valores iniciais de $r(L)$ atingiram o zero, à mêdia distância, então, a escala integral se apresentou sub- 
estimada (saturação de bases p.c., Figura 27a).

A indicação de isotropia poderia ser conseguida, tambẻm, com a decomposição das curvas dos semiváriogramas (WEBSTER, 1985), como mostra o exemplo da Figura 46. Mas, como a ārea experimental não permitiu a execução de mais pontos (com o mesmo intervalo) na sua largura, a decomposição ficou prejudicada, pois, na direção $0^{\circ}$, são obtidos apenas três pontos, dificultando a anālise grāfica.

Sob o ponto de'vista prático, como o valor da escala integral equivale ao diâmetro de āreas homogêneas no campo, verifica-se que, para uma direção, este valor è aproximadamente a metade do "comprimento da autocorrelação" (ka) (Tabela 2). Isto concorda com CAMPBELL (1985), o qual admite amostras independentes as separadas por mais de um valor de E.I. Se o objetivo for separar no campo subunidades homogêneas, baseadas na produção da cultura de arroz, por exemplo, āreas de $18,5 \mathrm{~m}$ x $21,7 \mathrm{~m}$ poderiam ser amostradas e tratadas individualmente quanto ao manejo (Figura 48). Apenas amostras para os parâmetros com E.I. próximos a 20 metros nas três situações (uma, duas e todas as direções) poderiam ser, neste caso, avaliadas (peso de 100 grãos, \% de grãos chochos, \% K, ppm Zn e relação P/Zn na planta; e pH, P, K, Ca, H, soma de bases, areia (a.a. e p.c.), $\operatorname{CTC}($ p.c.), $\operatorname{argila}($ a.a.) e silte (p.c.) no solo).

Mas, a título de experimentação agrĩcola, visando o uso da estatística clássica, as dependências espaciais, em geral, se mostraram de longo alcance. Apesar do valor a $(T a b e l a ~ 2)$ ter sido estimado apenas para uma direção, este poderia ser utilizado com maior precisão para definir apenas o alcance dos parâmetros com relativa isotropia (verificar Tabela 2 pela comparação dos resultados 
de E.I.).

Porēm, objetivando a obtenção de äreas sem relação de dependência na direção de $90^{\circ}$ (comprimento da ārea), onde possa ser englobada a maioria dos parâmetros, este campo experimental poderia ser dividido em dois talhões de $37 \mathrm{~m} \times 40 \mathrm{~m}$ (Figura 48). Desta forma, seriam excluídos os parâmetros com valor a acima de 50 metros, apenas três dos 47 estudados.

Ainda se a meta fosse apenas estudar as variäveis com alcance a menor que $10 \mathrm{~m}$ (Tabela 2), então os talhões poderiam ter apenas $20 \mathrm{~m} \times 20 \mathrm{~m}$, separados de 10 metros (perfilhamento efetivo, número de grãos cheios/panícula, índice de colheita e magnésio e alumínio do solo). 


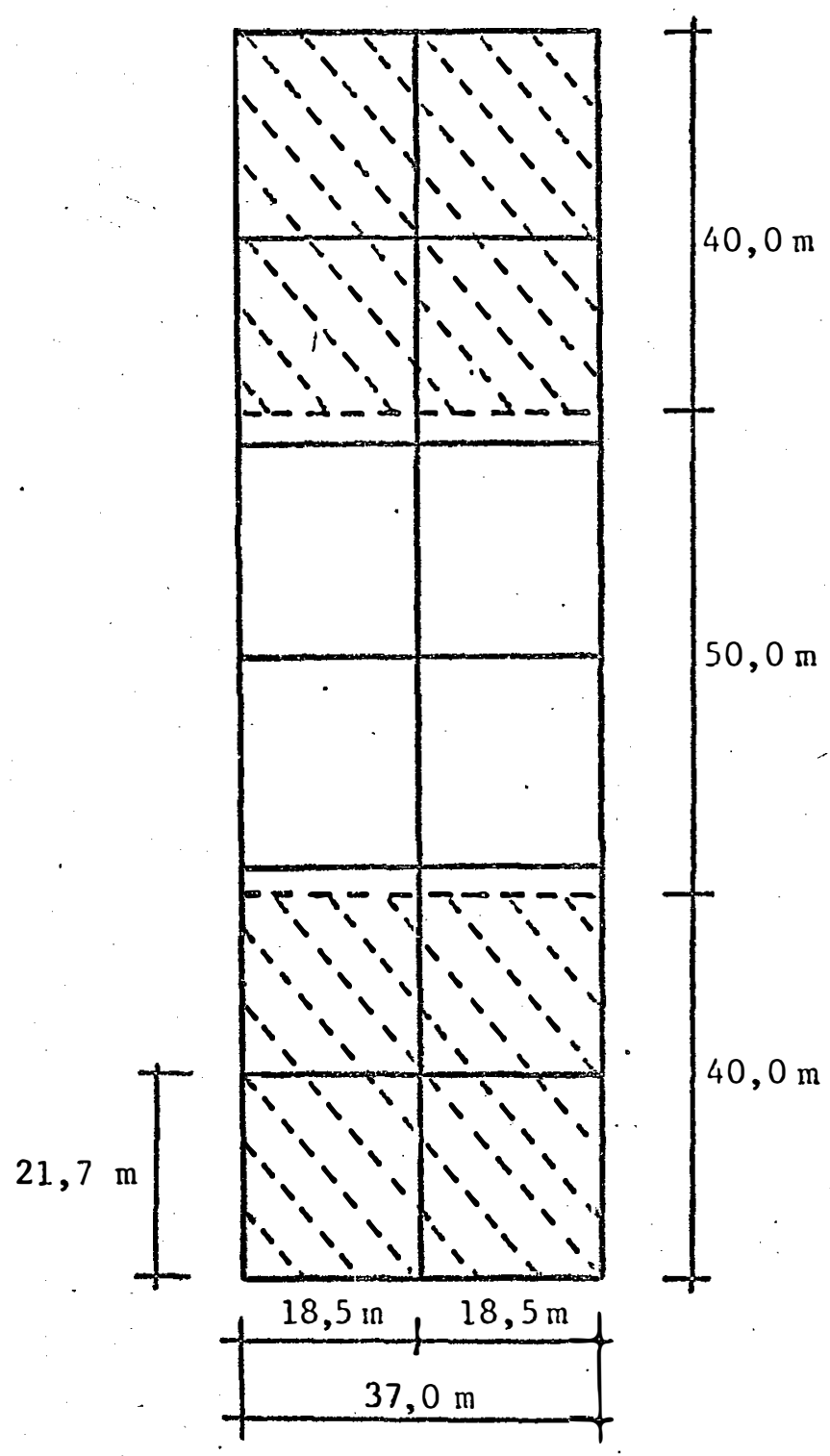

FIGURA 48 - Āreas homogêneas para produção de arroz e parâmetros com E.I. próximo a 20 metros (retângulos menores). Āreas independentes (retângulos tracejados). 


\section{CONCLUSÕES}

Tendo em vista o objetivo do presente trabalho, e a partir de seus resultados obtidos e discutidos, pode-se concluir que:

(1) Pelo conceito de escala integral, a ārea total em estudo não se mostrou homogênea para nenhum dos parâmetros levantados, quando foram analisados os três critérios de direção.

(2) A Teoria das Variāveis Regjonalizadas permitiu:

- estabelecer sub-unidades de amostragem ou de manejo individualizado;

- definir parcelas independentes, contanto que os parâmetros sejam devidamente selecionados em função do objetivo da coleta de dados.

(3) A parcela experimental apresentou relação de dependência, acima de 10 metros, em 41 dos parâmetros estudados 


\section{REFERÊNCIAS BIBLIOGRÁFICAS}

BATAGLIA, O.C.; TEIXEIRA, J.P.F.; FURLANI, P.R.; FURLANI, A.M.C.;

GALLO, J.R. Métodos de anālise química de plantas. Campinas, Instituto Agronômico de São Paulo. 31 p. Circular, 87.

BECKETT, P.H.T. \& WEBSTER, R. Soil variability: a review. Soils Fert., Harpenden, 34: 1-15, 1971.

BRESLER, E.; DASBERG, S.; RUSSO, D.; DAGAN, G. Spatial variability of crop yield as a stochastic soil process. Soil Sci. Soc. Am. J., Madison, 45: 600-605, 1984.

BUONA, J. Soil variability and soil survey. PROCEEDINGS OF A WORK SHOP OF THE ISSS AND THE SSSA, Las Vegas, 1984. Soil spatial. variability, Netherl'ands, 1985. p. 130-149.

BURGESS, T.M. \& WEBSTER, R. Optimal interpolation and isarithmic mapping of soil properties. J. Soil Sci., Oxford, 31: 315-331, 1980 .

CAMPBELL, G.S. Variation in soil properties. In: - Soil physics with basic. New York, Elsevier Sci. Pub1., 1985. V. 14, cap. 7, p. 60-72.

CASSEL, D.K. \& BAVER, A. Variability on soils below depth of tillage. Soil Sci. Soc. Amer. Proc., Madison, 39: 247-250, 1975. 
CATANI; R.A. \& JACINTHO, 0.A. Anālise química para avaliar a fertilidade do solo. Piracicaba, ESALQ/USP, 1974. Boletim Tëcnico-Científico, no 37. 54 p.

CLARK, I. Practical geostatistics. England, Applied Sci. Pub1. Ltd., 1979. 129 p.

CORMACK, R.M. \& ORD, J.K. Spatial and temporal analysis. in ecology. Maryland, Int. Coop. Pub1. House, 1979. V. 8, 356 p.

DAVID, M. Geostatistica1 on reserve estimation. New York, E1sevier Sci.Pub1., 1977. V. 8, 364 .

DAVIS, J.C. Statistics and data analysis. in geology. New York, John Wiley \& Sons, 1973. 550 p.

DONALD, C.M. In search of yield. J. Aust. Inst. Agric. Sci., Sydney, 28: 171-178, 1962 .

DUFFY, C.J. The analysis of water quality variations in streamaquifer systems: nonpoint sources. PROCEEDINGS OF A WORKSHOP OF THE ISSS AND THE SSSA, Las Vegas, 1984. Soil spatial variability, Netherlands, 1985. p. 195-208.

EMBRAPA. Manual de métodos de pesquisa em arroz - 1a. apr. Goiânia, Centró Nacional de Pesquisa - Arroz e Feijão, 1977. $106 \mathrm{p}$.

ESTADOS UNIDOS. Departamento de Agricultura. Soil taxonomy: a basic. system of soil classification to making and interpreting soil. surveys. Washington, 1979. Agr. Handbook no 436, 754 p.

FONSECA, H.; SOAVE, J.; AZZINI, L.E.; BANZATTON, V.; CAMARGO, O.B.A. 
Arruz- produção, pré-processamento e transformação agro-industrial. Piracicaba, FEALQ, 1983. V. 1,358 p.

GAJEM, Y.M.; WARRICK, A.W.; MYERS, D.E. Spatial dependence of physical properties of a typic torrifluvent soil. Soil Sci. Soc. Am. J., Madison, 45: 709-715, 1981.

GRUIJTER, J.J. \& MARSMAN, B.A. Transect sampling for reliable information on mapping units. PROCEEDINGS OF A WORKSHOP OF THE ISSS AND THE SSSA, Las Vegás, 1984. Soil spatial variability, Netherlands, 1985. p. 150-165.

GUROVICH, L.A. Estructura de la variabilidad espacial de las propriedades hidrodinamicas de los suelos. Ciencia e Investigacion Agraria, Chile, 9: 243-254, 1982.

GUROVICH, L.A. \& STERN, J. Variabilidad espacial de la velocidad de infiltración en el suelo. Ciencia e Investigacion Agraria, Chile, 10: 271-277, 1983a.

GUROVICH, L.A. \& STERN, J. Variabilidad espacial de la velocidad del agua en el suelo - Generacion de datos. Ciencia e Investigacion Agraria, Chile, 10: 35-41, 1983b.

GUTJAHR, A. Spatial variability: geostatistical methods. PROCEEDINGS OF A WORKSHOP OF THE ISSS AND SSSA, Las Vegas, 1984. Soil spatial variability, Netherlands, 1985. p. 9-34.

HAAN, C.T. Statistical methods in hidrology. Iowa, University Press, 1977. $378 \mathrm{p}$.

JOURNEL, A.G. \& HUIJBREGTS, Ch.J. Mining geostatistics. London, 
Academic Press, 1978. 600 p.

KILMER, V.J. \& ALEXANDER, L.T. Methods of making mechanical analysis of soils. Soil Sci., Baltimore, 68: 15-26, 1949.

LANDIM, P.M.B. Introdução à geoestatística. Rio Claro, UNESP, 1985. Publicação Didática no 2. 85 p.

LIBARDI, P.L.; PREVEDELlO, C.L.; PAULETTO, E.A.; MORAES, S.O. Variabilidade espacial da umidade, textura e densidade de partículas ao longo de uma transeção. Rev. Bras.. de Ciência do Solo, Campinas, 10: 85-90, 1986.

LINDSAY, W.L. \& NORVELL, W.A. Development of a DTPA soil test for zinc, iron, manganese, and copper. Soil Sci. Soc. Am. J., Madison, 42: 421-428, 1978.

McBRATNEY, A.B. The role of geostatistics in the design and analysis of field experiments with reference to the effect of soil properties on crop yield. PROCEEDINGS OF A WORKSHOP OF THE ISSS AND THE SSSA, Las Vegas, 1984. ' Soil spatial variability, Netherlands, 1985. p. 3-8.

MCBRATNEY, A.B. \& WEBSTER, R. Spatial dependence and classification of the soil along a transect in Northeast Scotland. Geoderma, Amsterdam, 26: 63-82, 1981a.

MCBRATNEY, A.B. \& WEBSTER, R. Detection of ridge and furrow pattern by spectral analysis of crop yield. Int. Statistical Review, Great Britain, 49: 45-52, 1981b. 
soil-water properties. Agric. Water Management, Amsterdam, 6: 93-109, 1983.

NIELSEN, D.R. \& CASSEL, D.K. Soil water management. In:

L'ANNUNZIATA, M.F. \& LEGG, J.0., ed. Isotopes and radiation in agricultural sciences. Soil-plant-water relationships. London, Academic Press, 1984. V. 1, cap. 2, "p. 35-64.

O'HALLORAN, I.P.; KACHANOSKI, R.G.; STEWART, J.W.B. Spatia1 variability of soil phosphorus as influenced by soil texture and management. Can. J. Soil Sci., Otawa, 65: 475-487, 1985.

PAULETTO, E.A. Estudos sobre dispersão da amostra de terra. Piracicaba, 1978. 68 p. (Mestrado- Escola Superiór de Agricultura "Luiz de Queiroz", da Universidade de São Paulo).

RANZANI, G.; FREIRE, 0.; KINJO, T. Levantamento da carta de solos. do município de Piracicaba. Piracicaba, ESALQ/USP, 1966. 85 p.

REICHARDT, K. Variabilidade espacial (e temporal) de solos. In: - Processos de transferência no sistema solo-plantaatmosfera. 4a. ed., Campinas, Fundação Cargi11, 1985. cap. 18, p. $391-416$.

RUSSO, D. \& BRESLER, E. Soil hydraulic properties as stochastic processes. Soil Sci. Soc. Am. J., Madison, 45: 682-687, 1981.

SNEDECOR, G.W. \& COCHRAN, W.G. Metodos estadisticos. Mexico, Ed. Continenta1, 1980. 703 p.

SPIEGEL, M.R. Estatística. São Paulo, Mc Graw-Hill do Brasil, 1976. $580 \mathrm{p}$. 
UEHARA, G.; TRANGMAR, B.B.; YOST, R.S. Spatial variability of soil properties. PROCEEDINGS OF A WORKSHOOP OF THE ISSS AND THE SSSA, Las Vegas, 1984. Soil spatial variability, Netherlands, 1985. p. 61-95.

VAUCLIN, M.; VIEIRA, S.R.; BERNARD, R.; HATFIELD, J.L. Spatial variability of surface temperature along two transects of a bare soil. Water Resour. Res., Washington, 18: 1677-1686, 1982.

VAUCLIN, M.; VIEIRA, S'.R.; VACHAUD, G.; NIELSEN, D.R. The use of cokriging with limited field soil observations. Soil Sci. Soc. Am. J., Madison, 47 : 175-184, 1983.

VIEIRA, S.R. Geostatistical analyses of some agronomical observations, Davis, 1981, 261 p. (Ph.D. - University of California).

VIEIRA;, S.R.; HATFIELD, J.L.; NIELSEN, D.R.; BIGGAR, J.W. Geostatistical theory and application to variability of some agronomical properties. California, Hilgardia Ed. Board, 1983. 75 p. Hilgardia n! 3.

VIEIRA, S.R.; NIELSEN, D.R.; BIGGAR, J.W. Spatial variability of field-measured infiltration rate. Soil Sci. Soc. Am. J., Madison, 45: $1040-1048,1981$.

WAGENET, R.J. Measurement and interpretation of spatially variable leaching processes. PROCEEDINGS OF A WORKSHOP OF THE ISSS AND THE SSSA, Las Vegas, 1984. Soil spatial variability, Netherlands, 1985, p. 209-235. 
WARRICK, A.W. \& NIELSEN, D.R. Spatial variability of soil physical properties in the field. In: HILLEL, D., ed. Applications of soil physics. New York, Academic Press, 1980. cap. p. 319-344.

WEBSTER, R. Automatic soil-Boundary location from transect data. Mathematical geology, New York, 5: 27-37, 1973.

WEBSTER, R. Quantitative spatial analysis of soil in field. New York, Springer-Verlag, New York, Advances Soil Science, 1985. v. 3, $69 \mathrm{p}$.

WEBSTER, R. \& BUTLER, B.E. Soil classification and survey studies at Ginninderra. Aust. J. Soil Res., Melbourne, 14: 1-24, 1976. WEBSTER, R.; CUANALO DE LA C., H.E. Soil transect correlograms of North Oxfordshire and their interpretation. J. Soil Sci., Oxford, 26: $176-194,1975$.

WIERENGA, P.J. Spatial variability of soil-water properties in irrigated soils. PROCEEDINGS OF - A WORKSHOP OF THE ISSS AND THE SSSA, Las Vegas, 1984. Soil spatial variability, Netherlands, 1985. p. 112-129.

WILDING, L.P. Spatial variability: its documentation, accommodation and implication to soil surveys. PROCEEDINGS OF A WORKSHOP OF THE ISSS AND THE SSSA, Las Vegas, 1984. Soil spatial variability, Netherlands, 1985. p. 166-194.

WOLLUM, A.G. \& CASSEL, D.K. Spatial variability of Rhizobium japonicum in two North Carolina soils. Soil Sci. Soc. Am. J., Madison, 48: 1082-1086, 1984.

XU, J. \& WEBSTER, R. A geostatistical study of topsoil properties in Zhangwu county, China. Catena, Braunschweig, 11: 13-26, 1984. 
$-103-$

A N E X O A 
PROGRAMA 1

AUTOCORRELOGRAMA E SEMIVARIOGRAMA PARA UMA DIREÇÃO

(CP 200) 


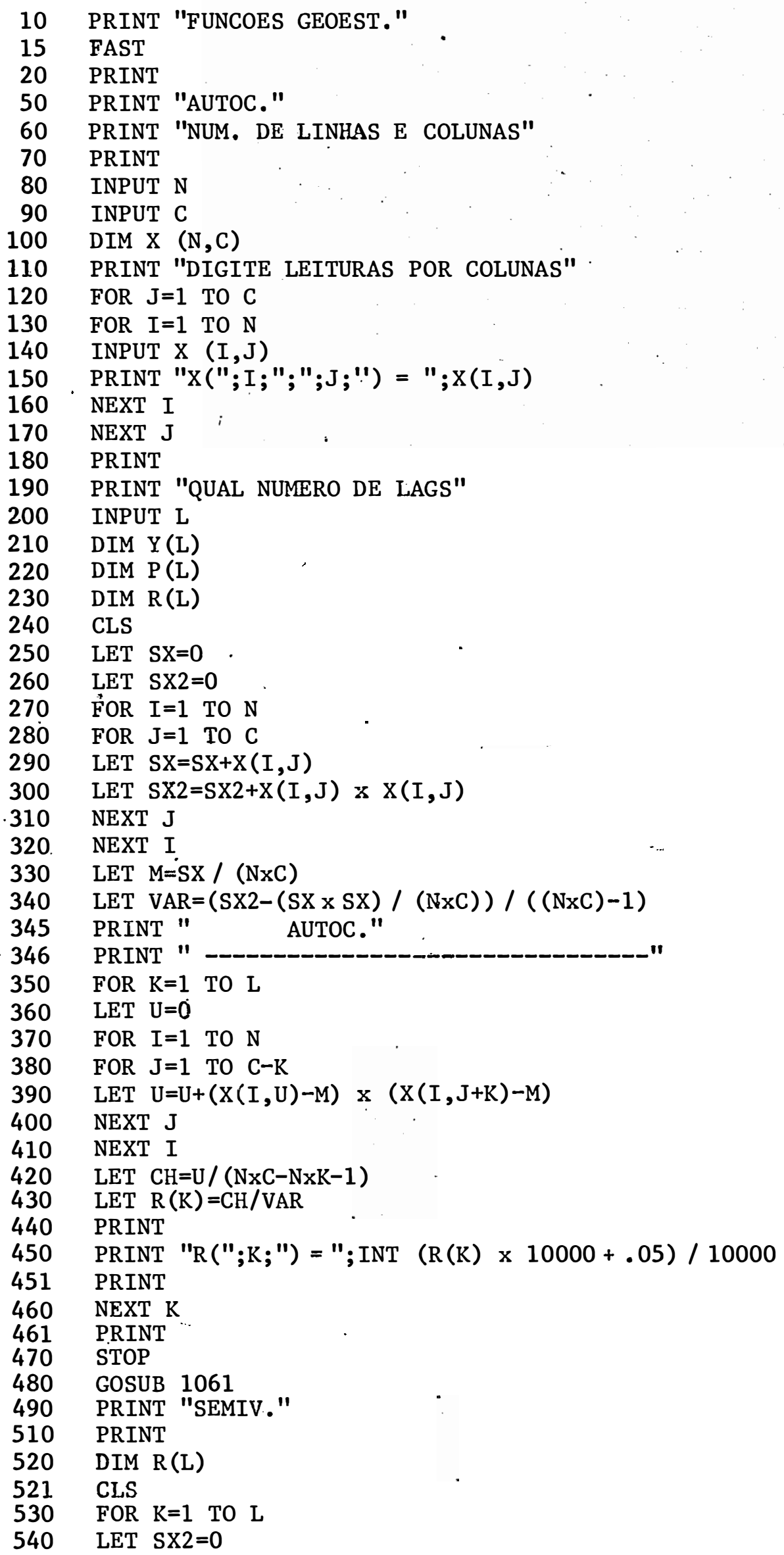


550

560

570

580

590

600

610

620

630

631

640

645

650

660

680

690

700

710

720

730

740

760

770

780

800

810

820

830

840

850

860

870

880

890

891

900

910

930

950

960

970

980

990

1000

1010

1060

1061

1070

1080

1090

1100

1110

1120

1130

1140

1150

1160

1170

1180

FOR $\mathrm{I}=1$ TO $\mathrm{N}$

FOR $\mathrm{J}=1$ TO $\mathrm{C}-\mathrm{K}$

LET $\mathrm{T}=\mathrm{X}(\mathrm{I}, \mathrm{J}+\mathrm{K})-\mathrm{X}(\mathrm{I}, \mathrm{J})$

LET $\mathrm{SX} 2=\mathrm{SX} 2+\mathrm{T} \times \mathrm{T}$

NEXT J

NEXT I

LET $P(K)=N x C-K x N$

LET $R(K)=S \times 2 /(2 \times P(K))$

NEXT K

PRINT " SEMIV."

PRINT TAB 3; "INDICE"; TAB 10;"PARES"; TAB 17;"GAMA"

PRINT

FOR $\mathrm{K}=1$ TO $\mathrm{L}$

PRINT TAB 3; K; TAB 10; INT (P(K) $\times 1000+.5) / 1000 ;$ TAB 17; INT $(R(K) \times 100000+.05) / 100000$

NEXT $K$

STOP

REM "MOMENTOS EST."

LET $S 1=0$

LET S2 $=0$

LET S $2=0$

LET $S 4=0$

FOR $\mathrm{I}=1$ TO $\mathrm{N}$

FOR J=1 TO $\mathrm{C}$

LET $Z T=X(I, J)$

LET S2 $=\mathrm{S} 2+\mathrm{ZT} x \mathrm{ZT}$

LET $\mathrm{S} 3=\mathrm{S} 3+\mathrm{ZT} x \mathrm{ZT} \times \mathrm{ZT}$

LET S4=S4+ZTxZTxZTxZT

NEXT J

NEXT I

LET DEV $=S Q R$ (VAR)

$\mathrm{LET} \quad \mathrm{CVA}=\mathrm{DEV} / \mathrm{M}$

LET M3 $=\mathrm{S} 3 /(\mathrm{NxC})-3 \times \mathrm{MxS} 2 /(\mathrm{NxC})+2 \times \mathrm{M} \times \mathrm{MxM}$

LET $M 4=S 4 /(\mathrm{NxC})-4 \times M x S 3 /(\mathrm{NxC})$

LET $M 4=M 4+6 \times M x M x S 2 /(\mathrm{NxC})$

LET $M 4=M 4-3 \times M x M x M x M$

LET $\mathrm{CSK}=\mathrm{M} 3 /(\mathrm{SQR} \quad($ VAR $x$ VARxVAR $))$

LET CKT $=$ M4/ (VARxVAR)

PRINT "MOMENTOS"

PRINT "NUM. DE AMOSTRAS="; TAB 20; NxC

PRINT "MEDIA="; TAB 20;M

PRINT "VARIANCIA="; TAB 20; VAR

PRINT "DESV. PAD.="; TAB 20; DEV

PRINT "COEF. VAR.="; TAB 20; CVA

PRINT "SKEWNESS="; TAB 20; CSK

PRINT "KURTOSE="; TAB 20; CKT

STOP

CLS

PRINT "DIGITE XO XMAX YO YMAX"

INPUT X0

INPUT XMAX

INPUT YO

INPUT YMAX

IF $\mathrm{Y} O<0$ THEN LET $\mathrm{PZ}=43 \mathrm{X}(\mathrm{YO} /(\mathrm{YMAX}-\mathrm{YO}))$

IF $\mathrm{YO}>0$. THEN LET $\mathrm{PZ}=0$

CLS

FOR $Z=42$ TO 0 STEP -1

PLOT $0, Z$

NEXT $Z$

FOR $W=0$ TO 55 


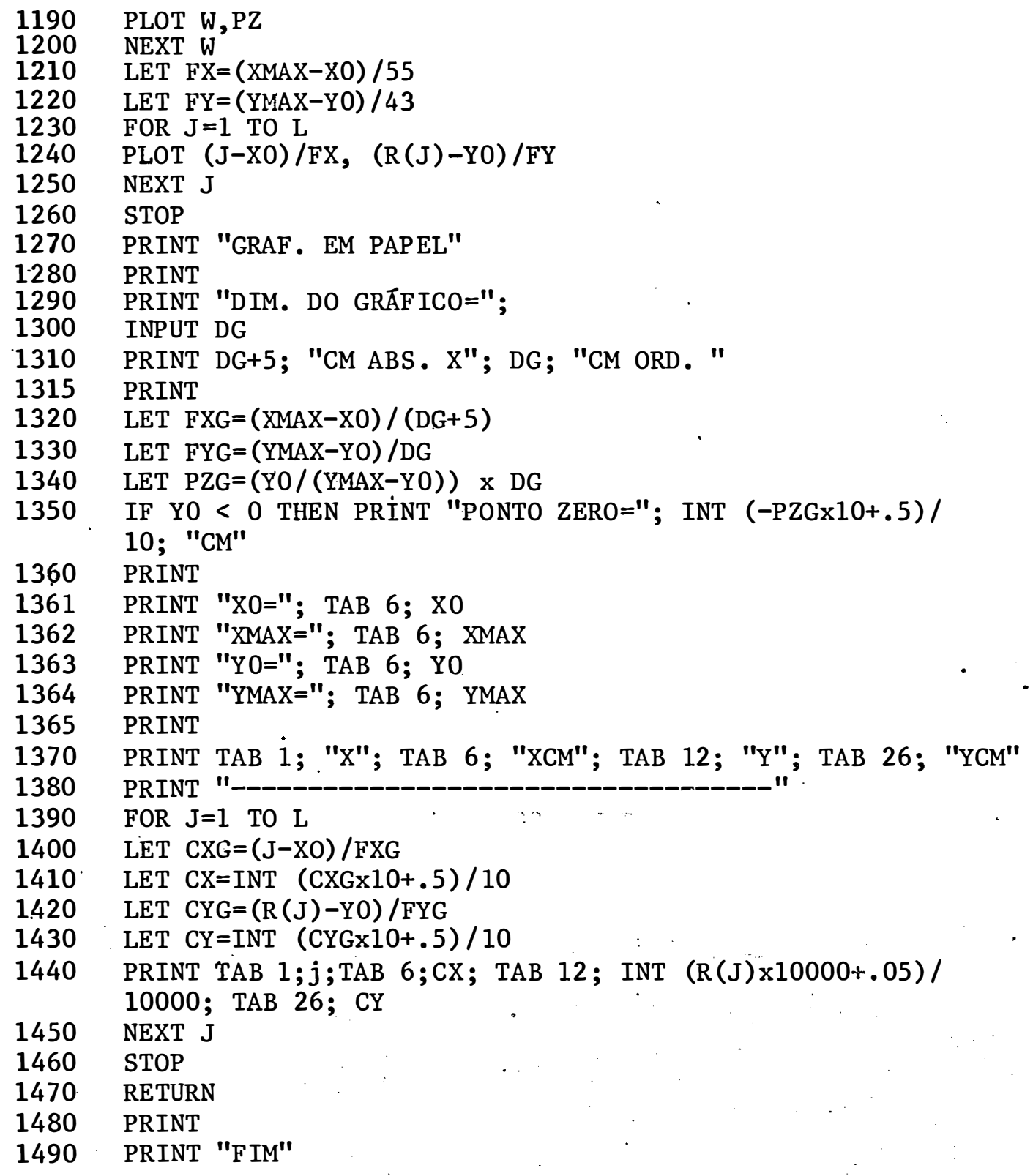


PROGRAMA 2

AUTOCORRELOGRAMA E SEMIVARIOGRAMA PARA TODAS AS DIREÇÕES (CP 200) 


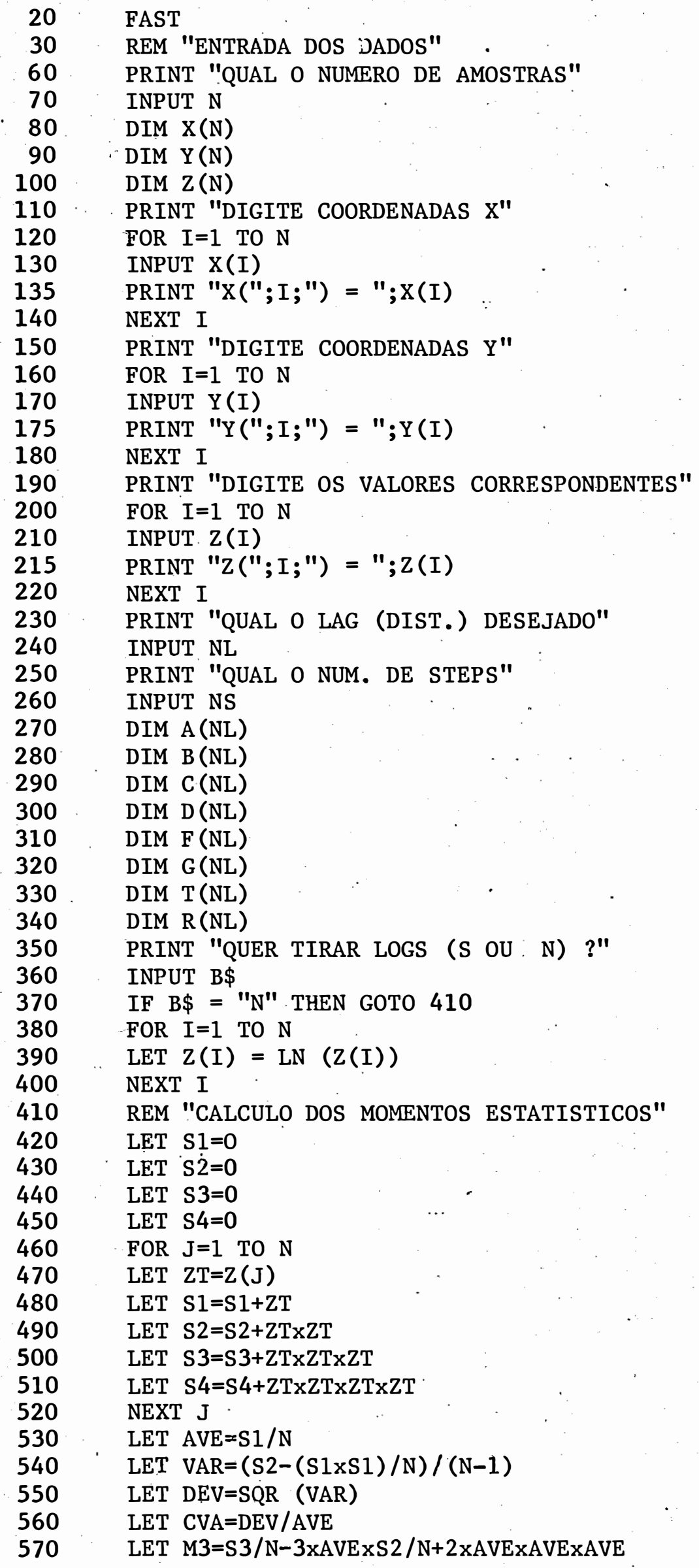




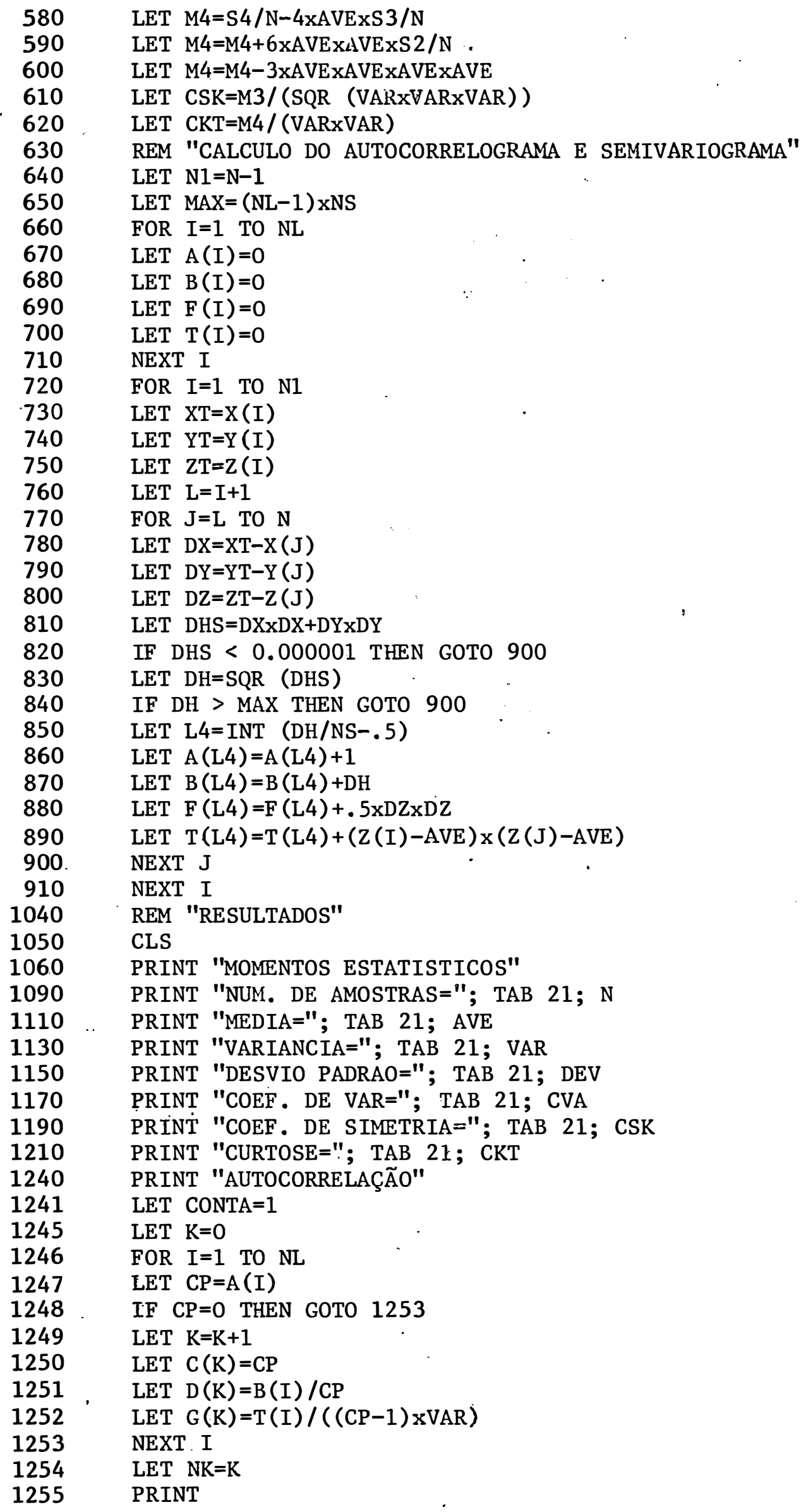


1270 PRINT TAB 3; "INDICE"; TAB 10; "PARES"; TAB 17; "DIST.";

TAB 24; "COEF.
1280 FOR I=1 TO NK

1290 PRINT TAB 3; I; TAB 10; C(I); TAB 17; INT (D(I) $\times 100+$

$1300 \quad$ NEXT I

1310 STOP

1320 GOSUB 1450

1325 PRINT "SEMIVARIOGRAMA:"

1326

1330

1331

1332

1333

1334

1335

1336

1337

1338

1339

1340

1360

1380

1390

1400

- LET CONTA=0

DIM G(NL)

LET $\mathrm{K}=0$

FOR $I=1$ TO NL

LET $\mathrm{CP}=\mathrm{A}(\mathrm{I})$

IF $\mathrm{CP}=0$ THEN GOTO 1339

LET $\mathrm{K}=\mathrm{K}+1$

LET $C(K)=C P$

LET $D(K)=B(I) / C P$

LET $G(K)=F(I) / C P$

NEXT I

LET $\mathrm{NK}=\mathrm{K}$

PRINT "NUM. DE LAGS="; TAB 21; NL

1420

1430

1440

1445

1450

1451

1460

1470

1480

1490

1500

PRINT "NUM. DE STEPS="; TAB 21; NS

PRINT

TAB TAB 23; "GAMA"

1510

1520

1530 FOR I=1 TO NK

1540

1550

1560

PRINT TAB 1; I; TAB 7; C(I); TAB15; INT (D (I) $\times 1000+.5) /$ 1000; TAB 23; INT. $(G(\operatorname{Ix} 1000+.5) / 1000$

1570

1580

1590

NEXT I

PRINT

STOP

PRINT

GLS

PRINT "PARA O GRĀFICO, DIGITE XO XMAX YO YMAX"

INPUT XO

INPUT XMAX

INPUT YO

INPUT YMAX

IF $\mathrm{YO}<0$ THEN LET $\mathrm{PZ}=43 \mathrm{x}(\mathrm{YO} /(\mathrm{YMAX}-\mathrm{YO})$ )

1600

IF $\mathrm{YO}>=0$ THEN LET $\mathrm{PZ}=0$

CLS

FOR Z=42 TO 0 STEP -1

PLOT $0, Z$

NEXT Z

FOR WE0 TO 55

PLOT $W, P Z$

1610

NEXT $W$

LET $F X=(X M A X-X 0) / 55$

1630

LET $F Y=(Y M A X-Y 0) / 43$

1640

FOR J=1 TO NK

1640

PLOT (D (J)-X0)/FX, (G(J)-Y0)/FY

STOP

NEXT J

1670

PRINT "GRAFICO EM PAPEL".

PRINT 
1680 PRINT "DIMENSOES DO GRAFICO="

1690 INPUT DG

1700 PRINT DG+5; "X"; DG; "CM"

1710 LET FXG $=(X M A X-X 0) /(D G+5)$

1720

LET FYG $=(Y M A X-Y O) / D G$

1730 LET PZG $=(Y O /(Y M A X-Y O)) \times D G$

1740 IF YO < 0 THEN PRINT "PONTO ZER0="; INT (-PZGx1000+.5)/ 1000; "CM"

1750 PRINT

1760 PRINT TAB 1; "PARES"; TAB 7; "X"; TAB 14; "XCM"; TAB 20; "Y"; TAB 28; "YCH"

1770 PRINT

1780

FOR J=1 TO NK

1790 LET CXG $=(\mathrm{D}(\mathrm{J})-\mathrm{XO}) / \mathrm{FXG}$

1800 LET CX=INT $(\mathrm{CXGX1000+.5)/1000}$

1810 . LET CYG $=(\mathrm{G}(\mathrm{J})-\mathrm{YO}) / \mathrm{FYG}$

1820 LET CY=INT $(\mathrm{CYGX1000+.5)/1000}$

1830 PRINT TAB 1; C(J); TAB 5; INT (D(J) x1000+.5)/1000; TAB

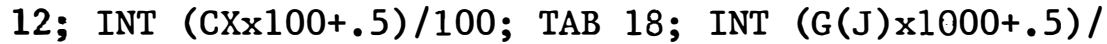

1840 1000; TAB 28; INT $(\mathrm{CY} \times 100+.5) / 100$

1841 PRINT

1845 IF CONTA=0 THEN GOTO 1970

1850 STOP

1860 RETURN

1970 PRINT

1980 PRINT "FIM" 
$-113$

A N E X B 
PAR Â E T R O S 


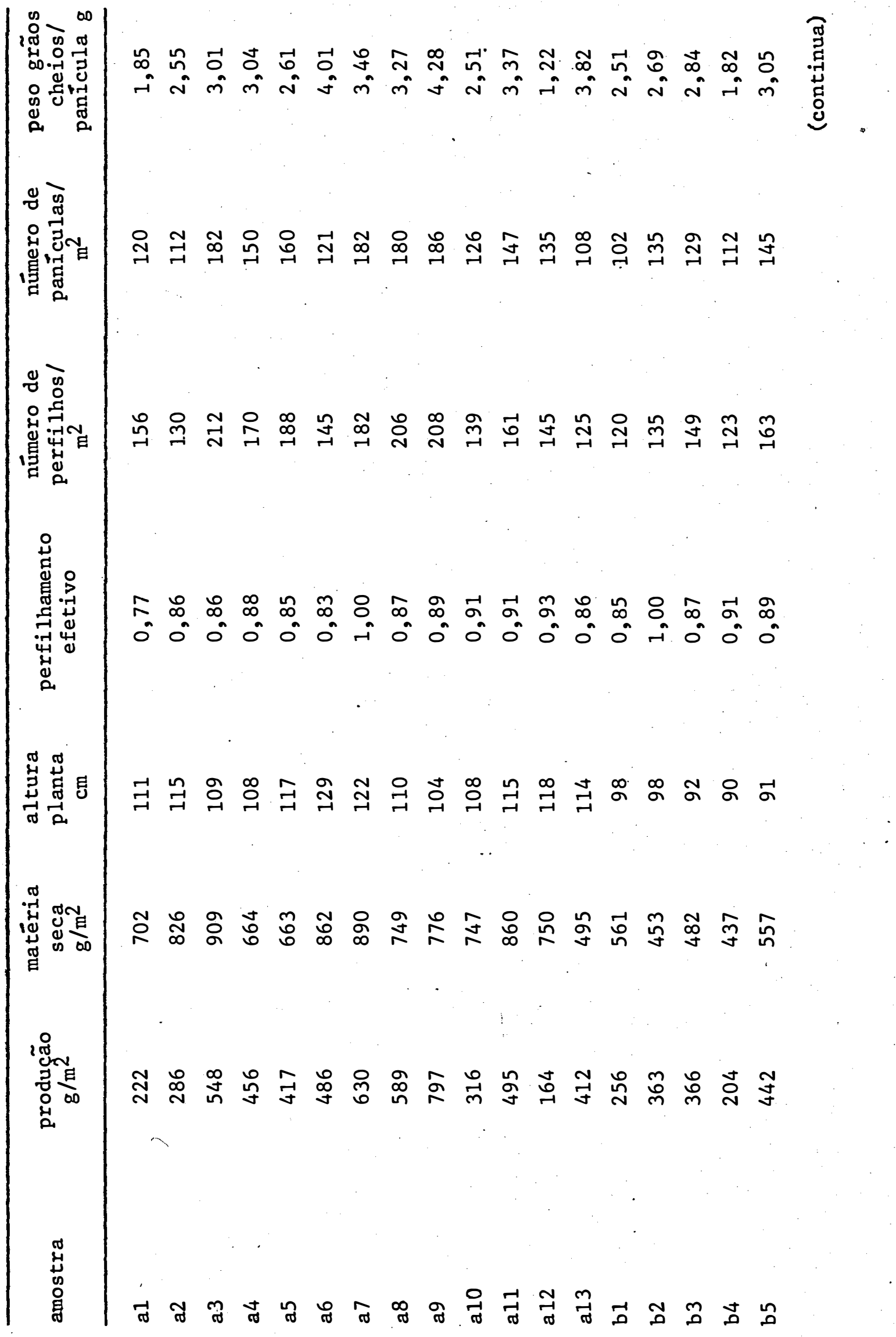




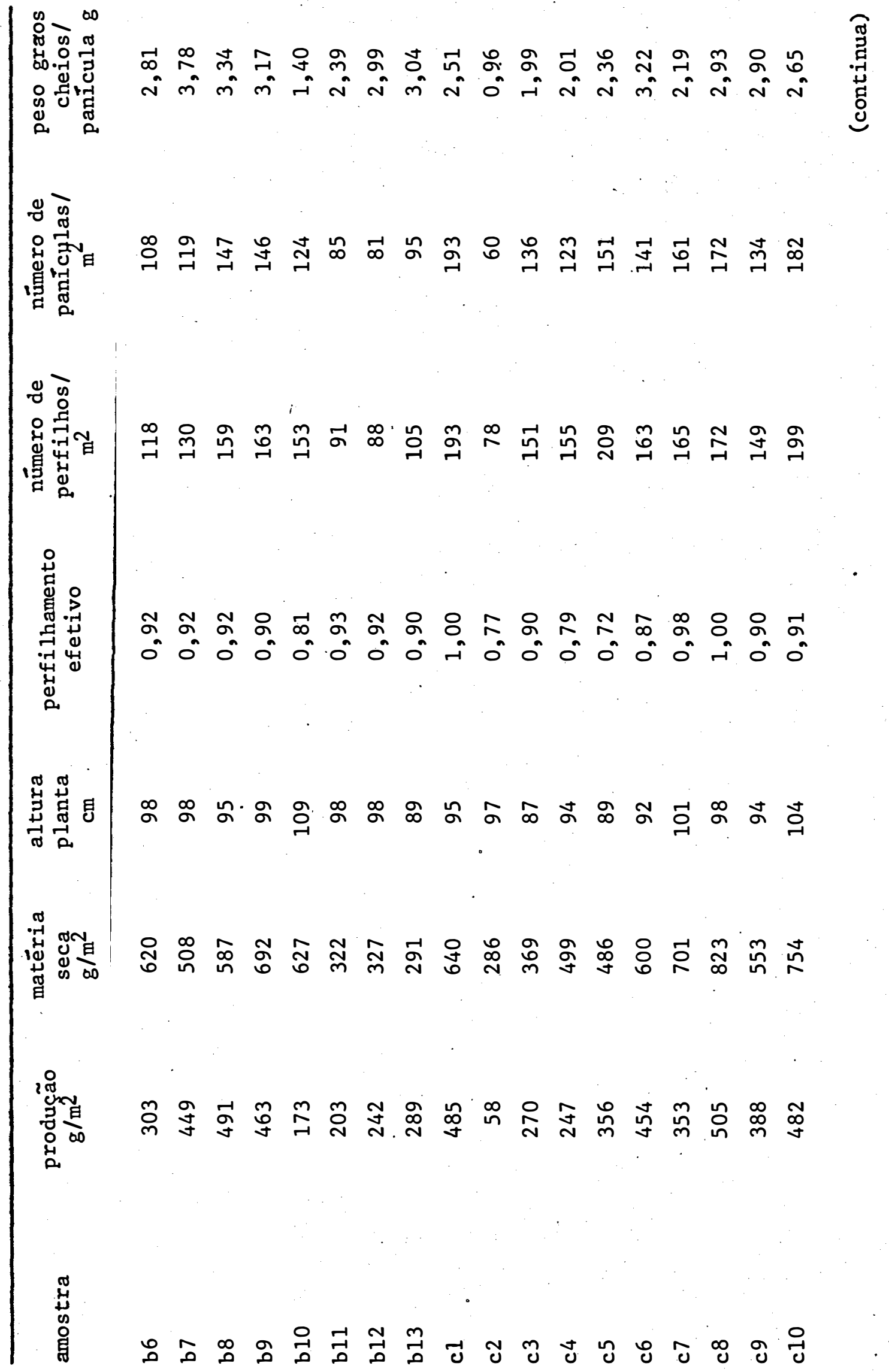




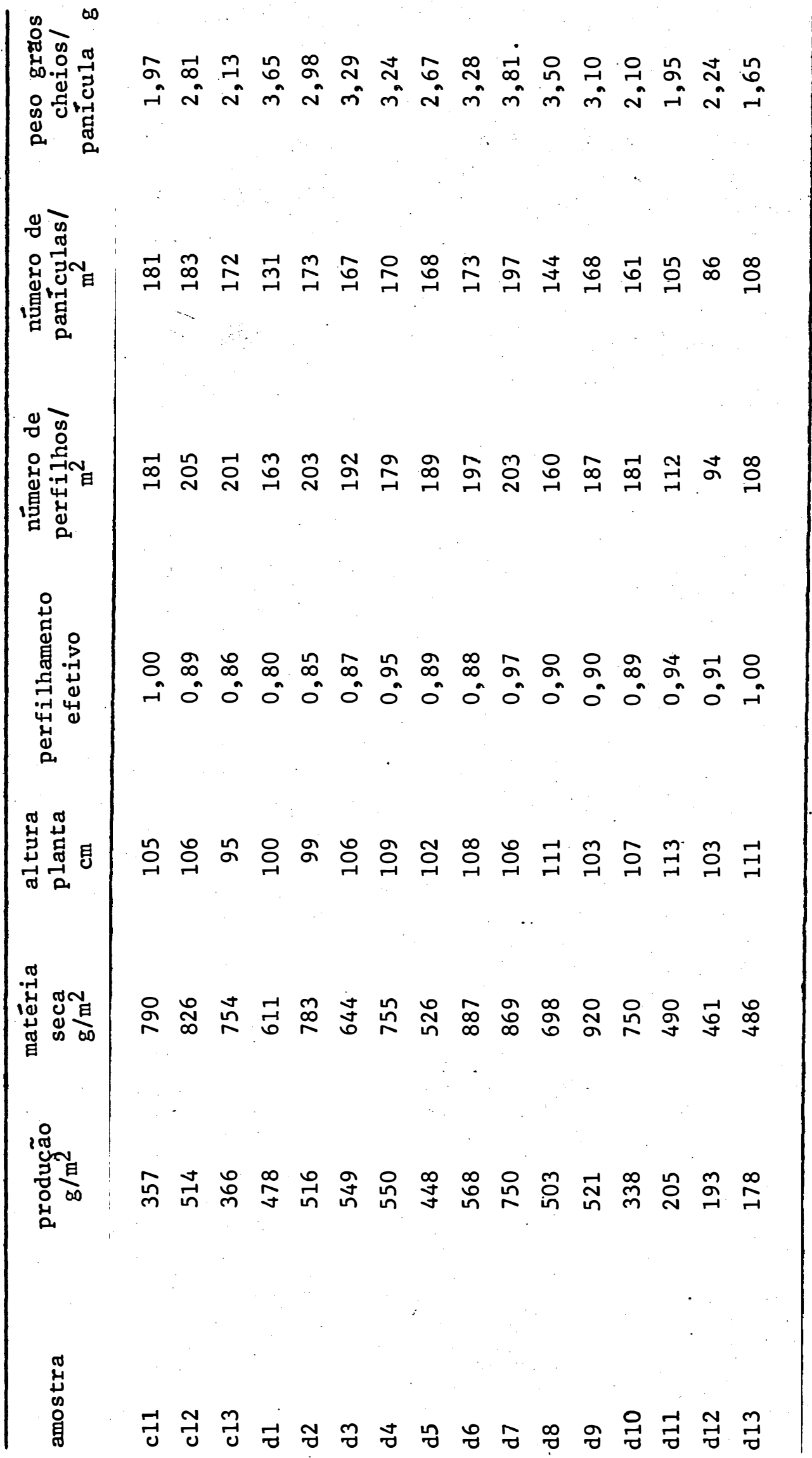




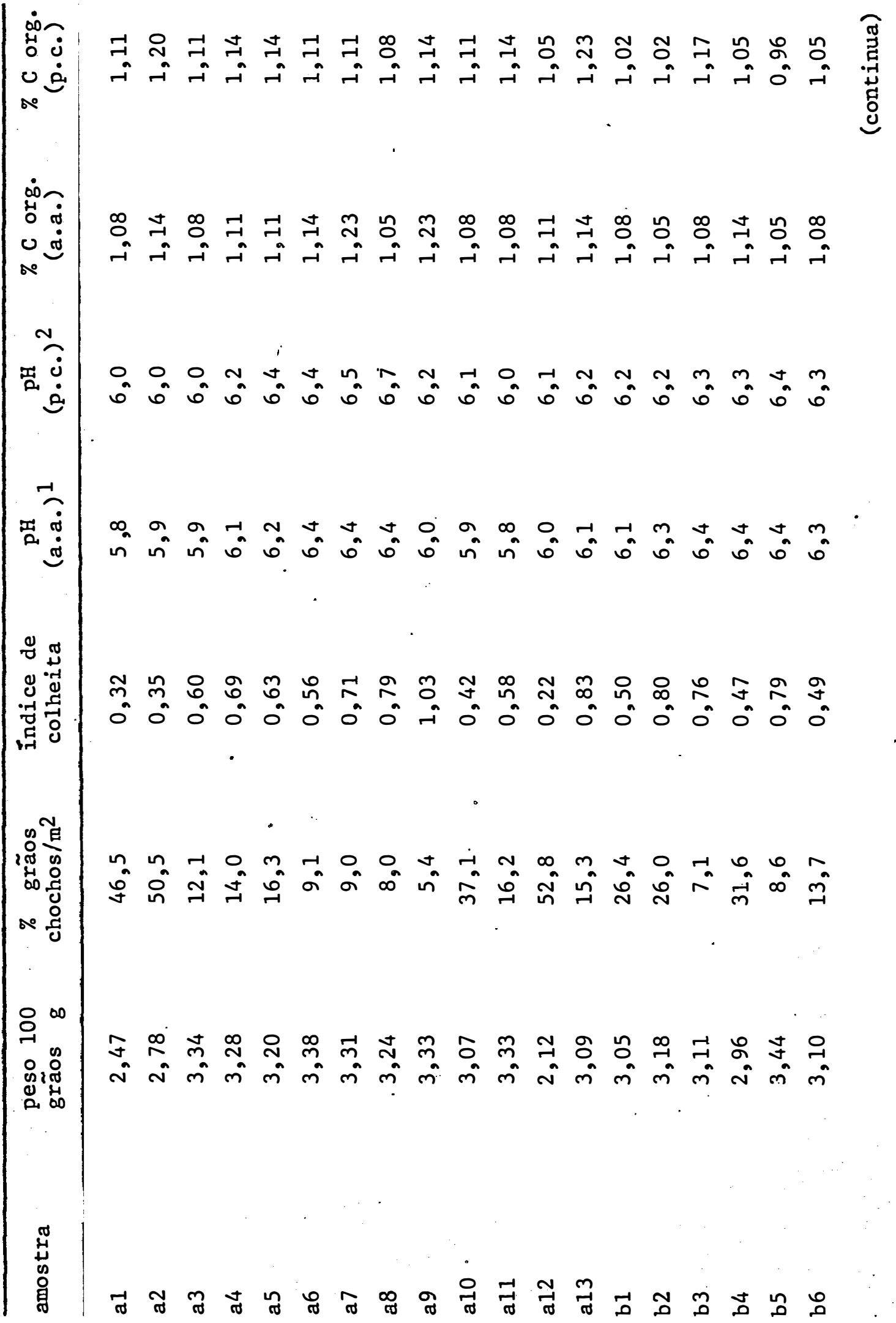




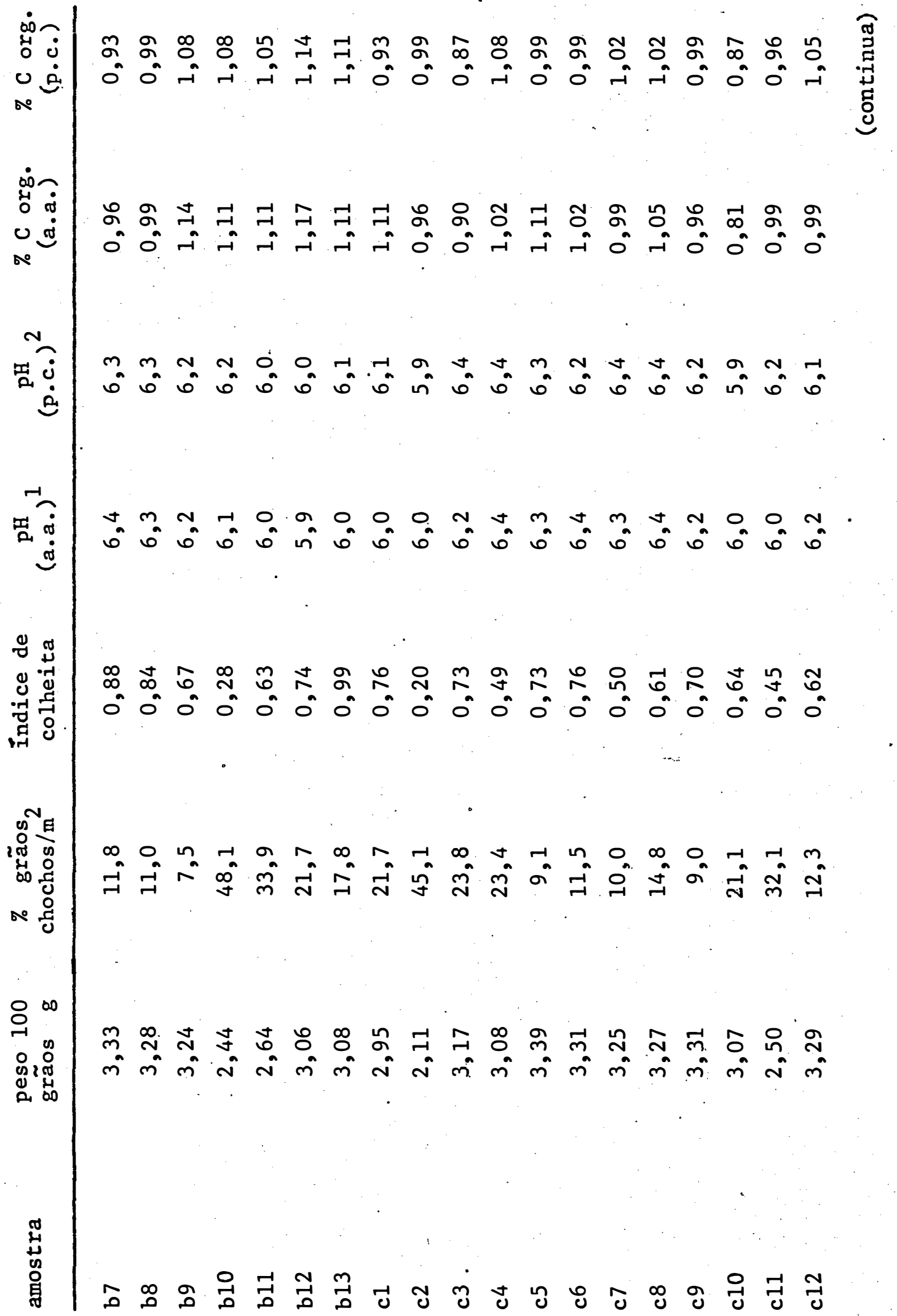




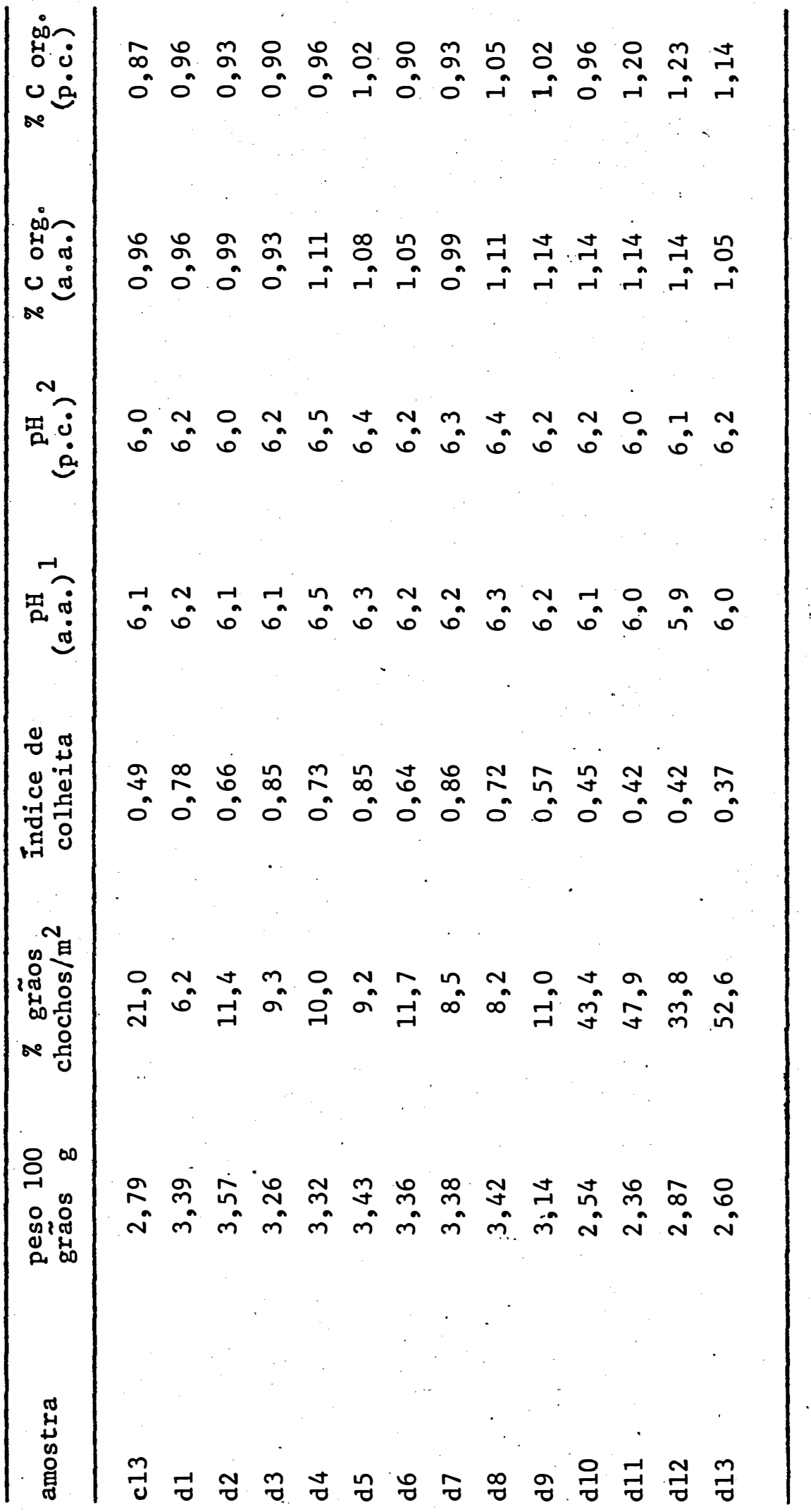




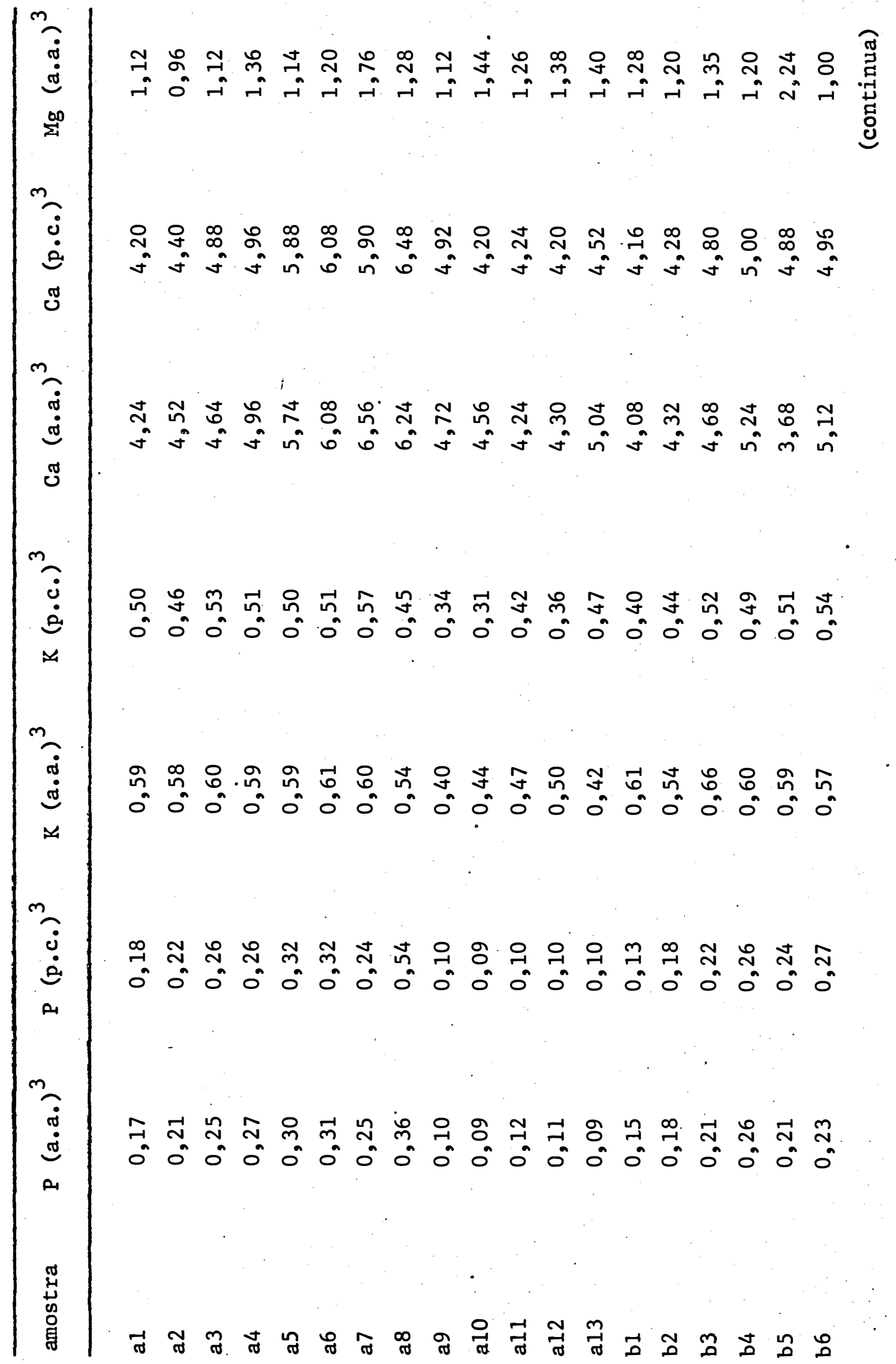




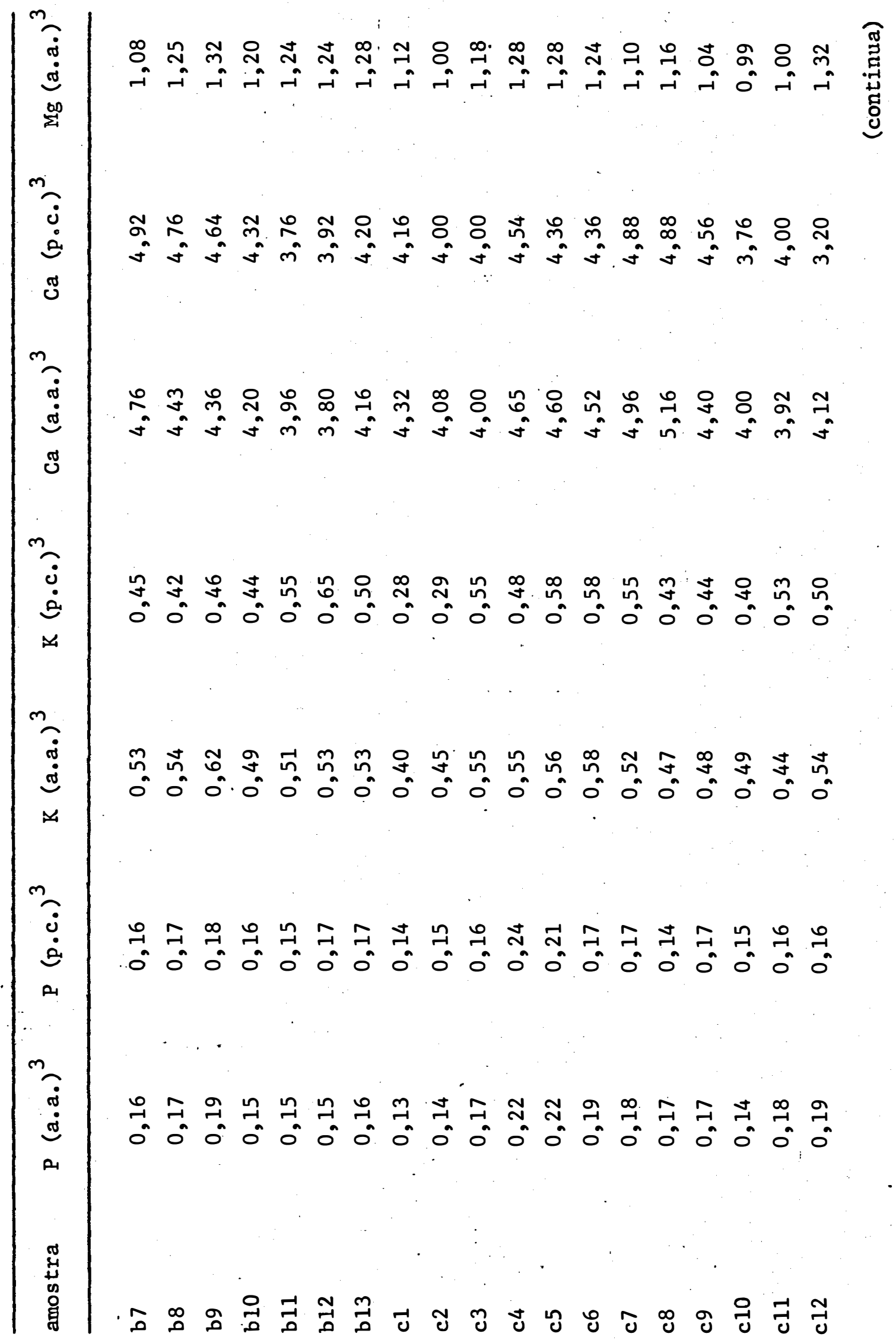




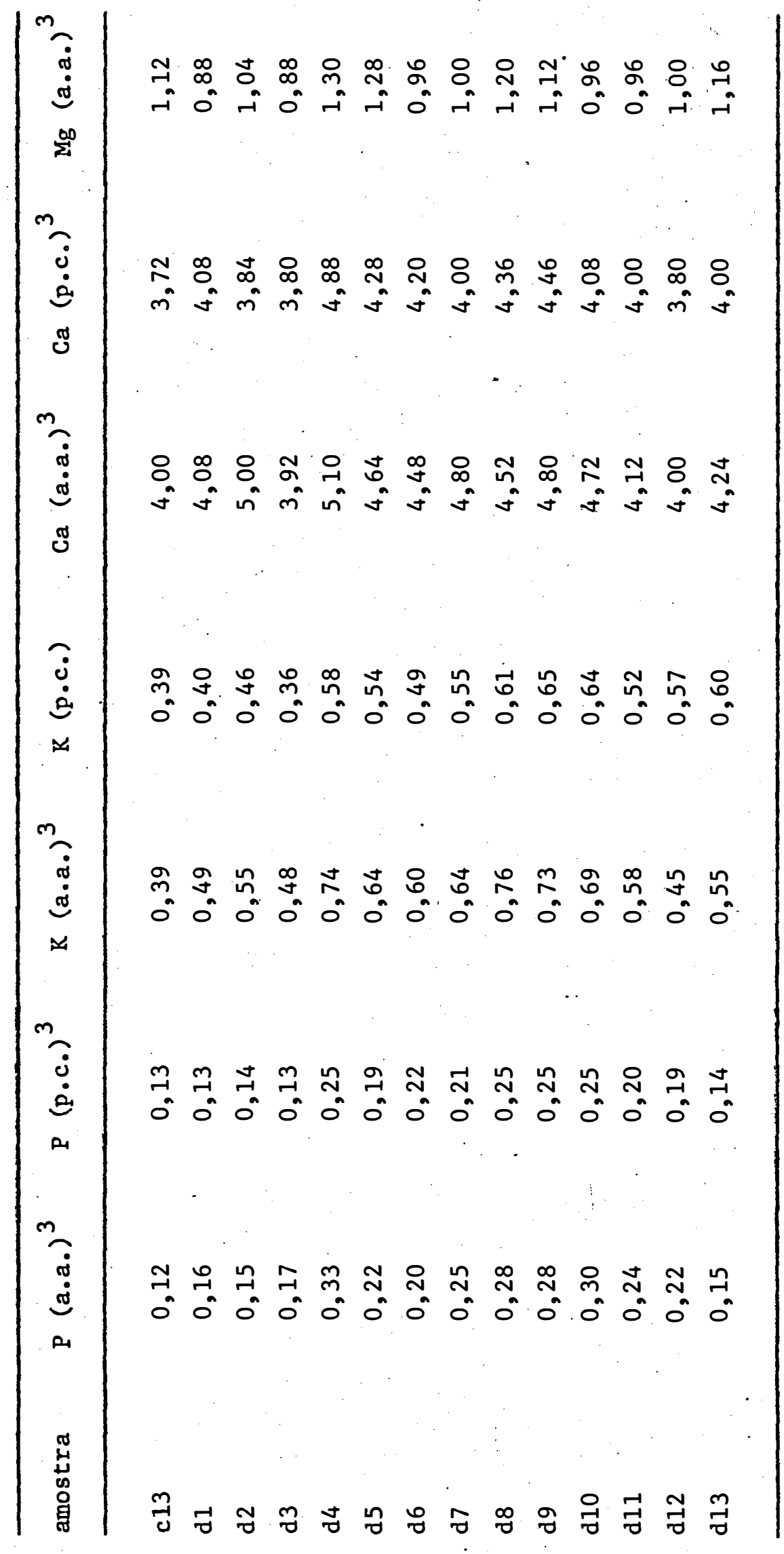




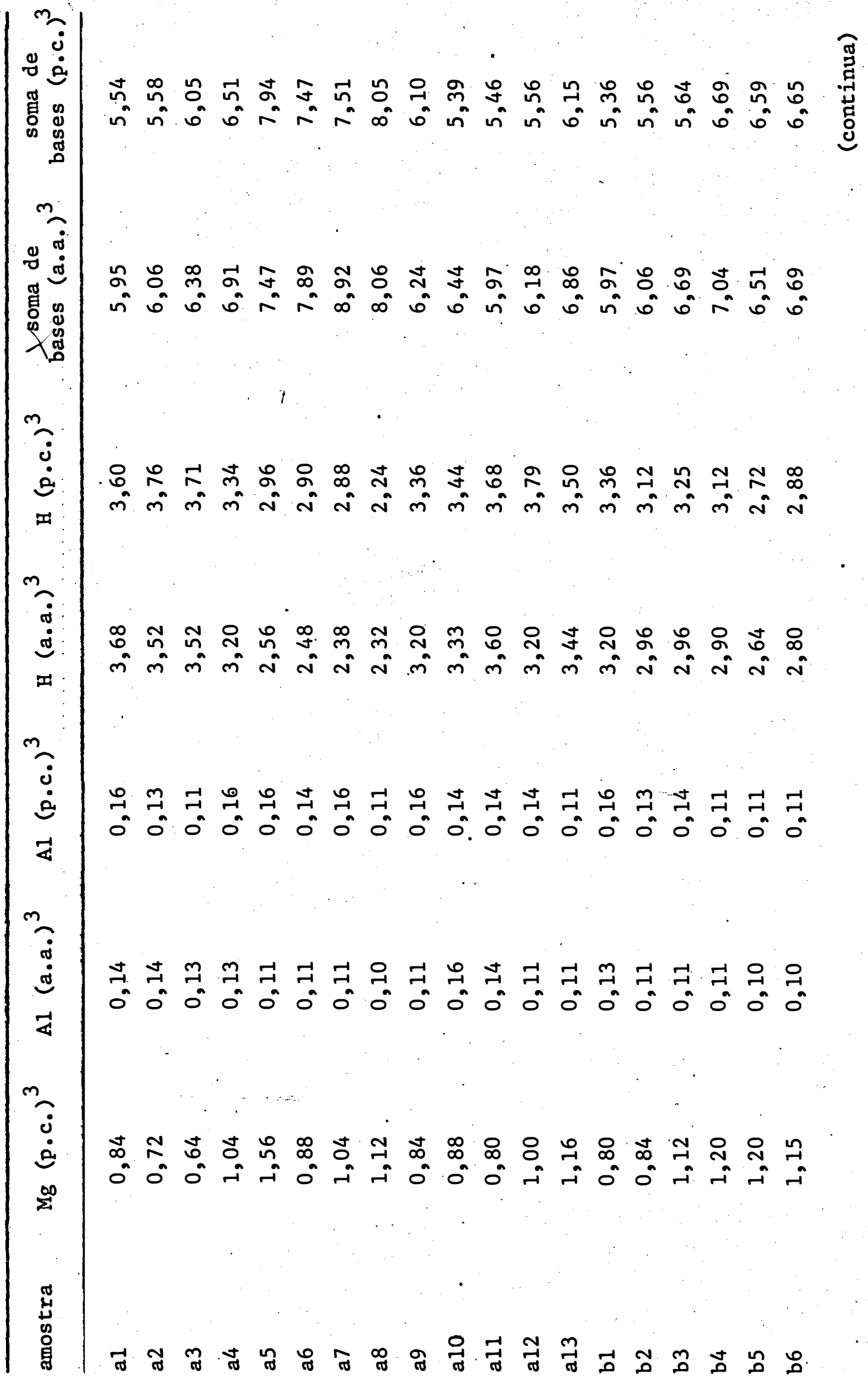




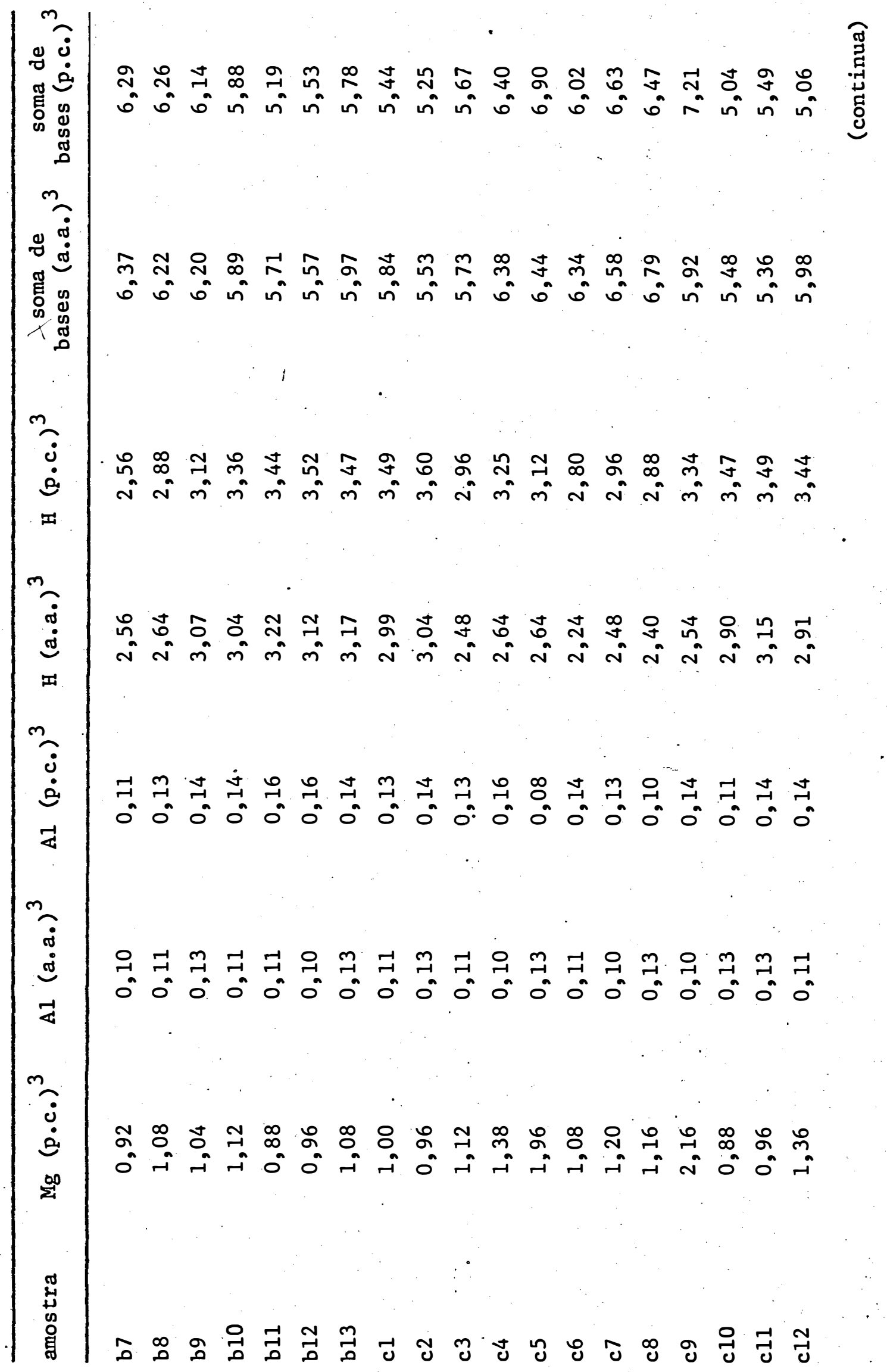




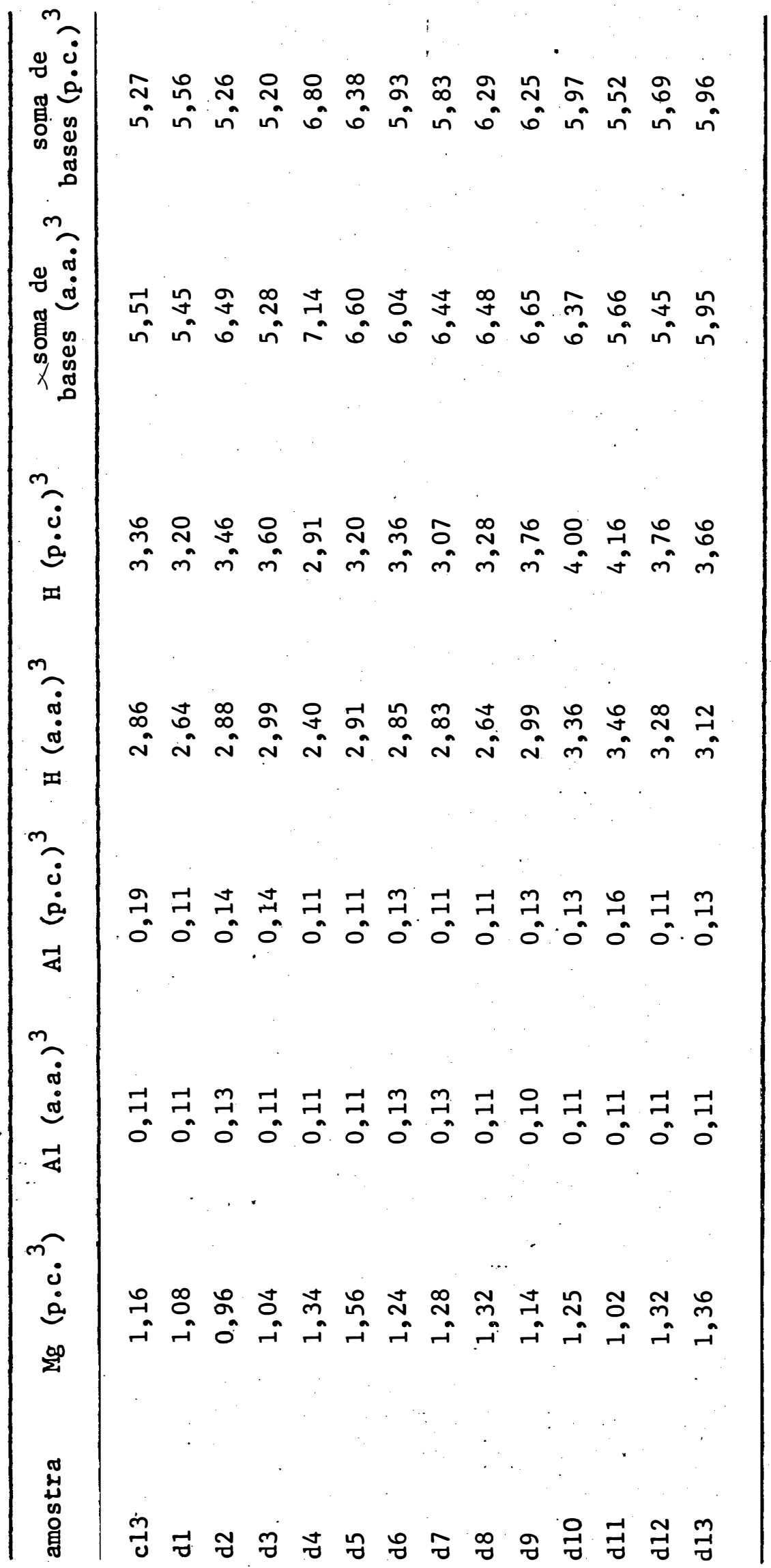




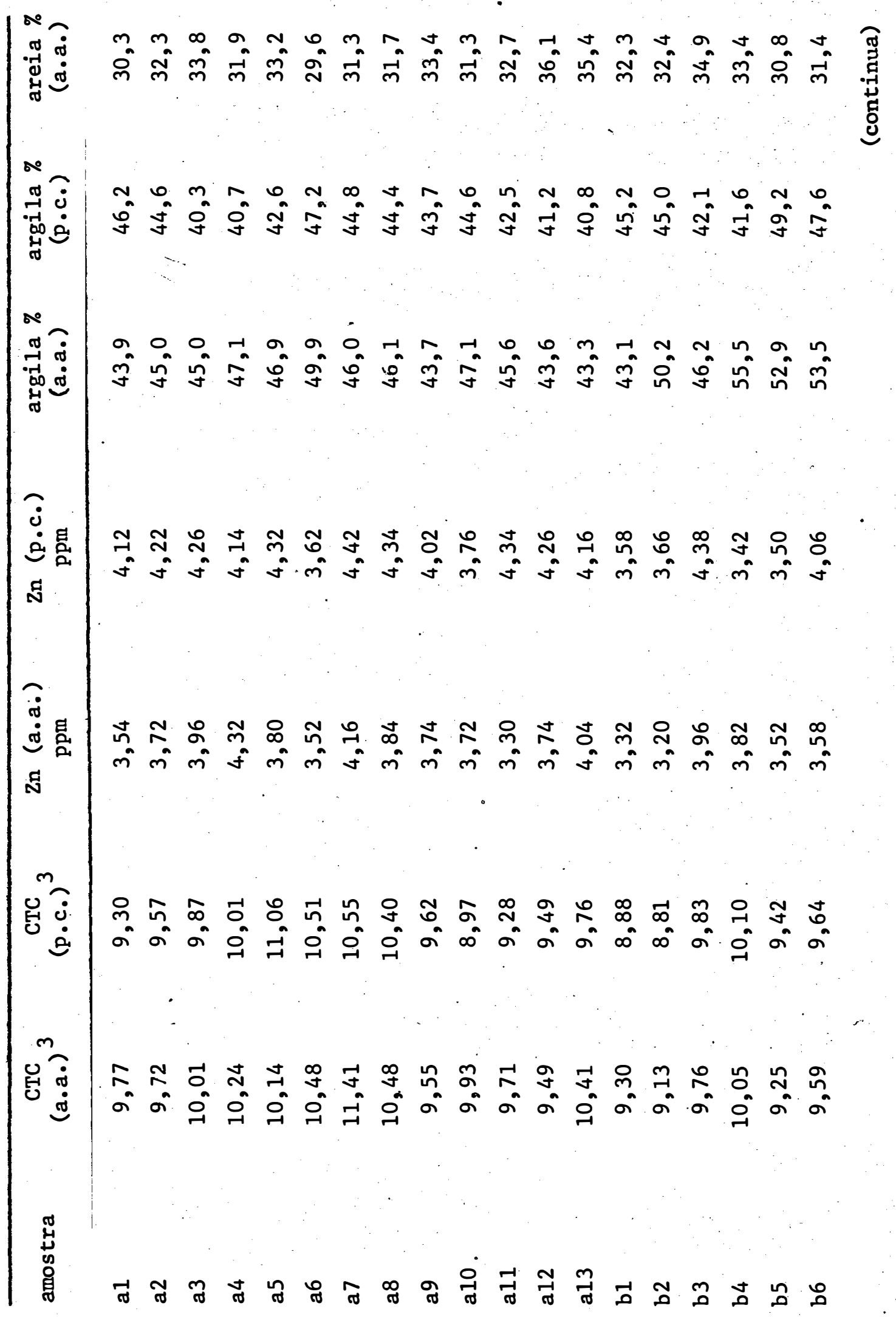




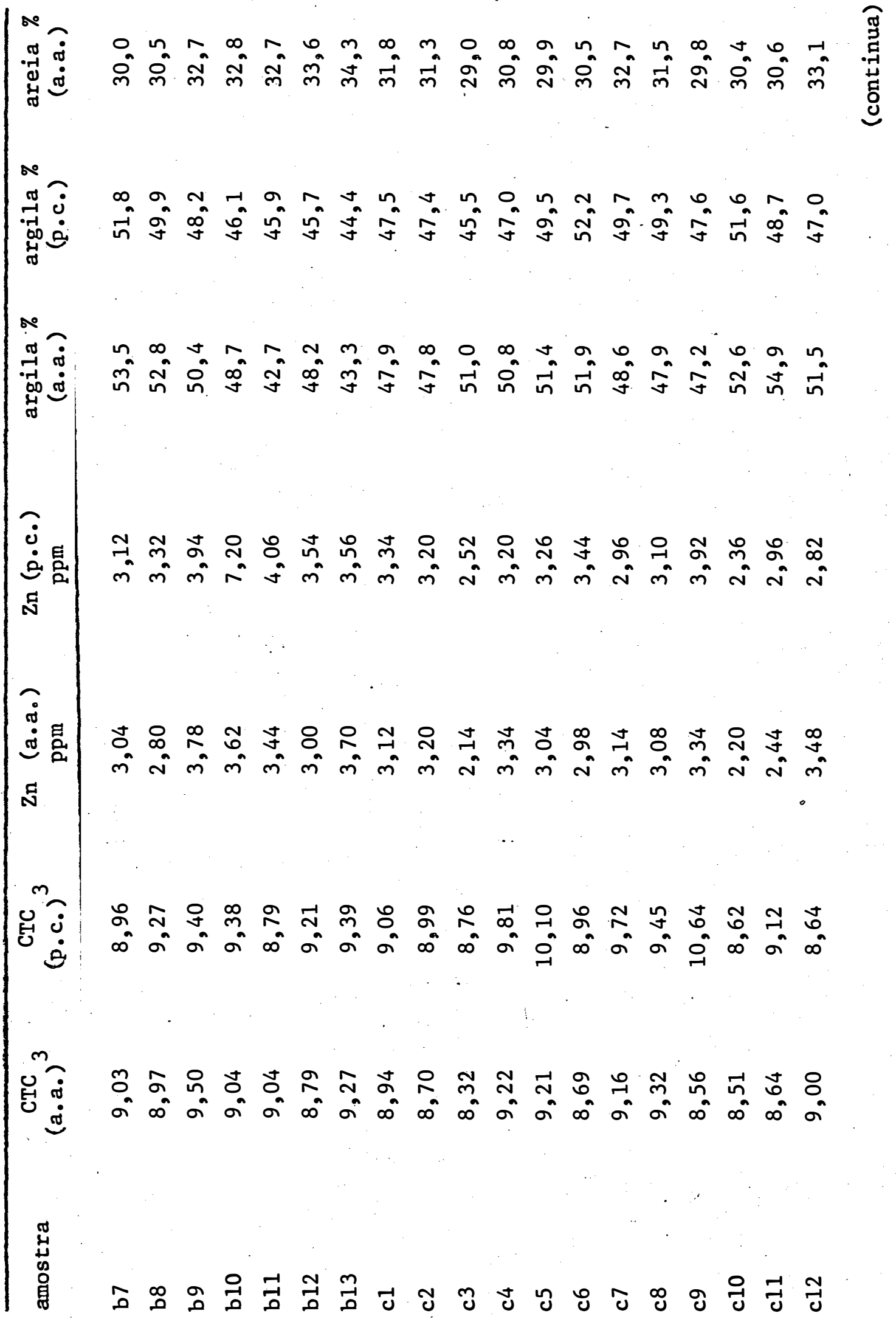




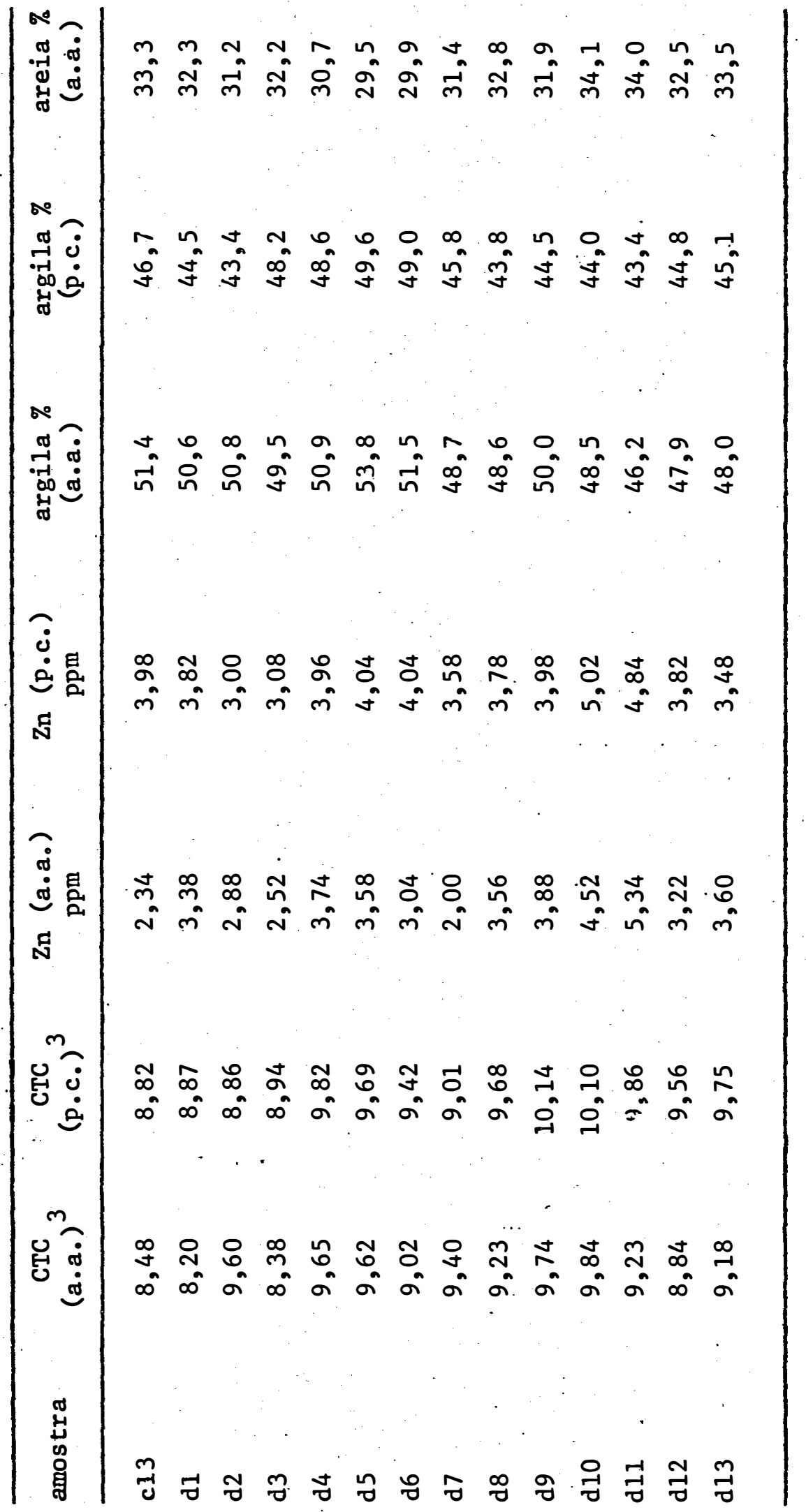




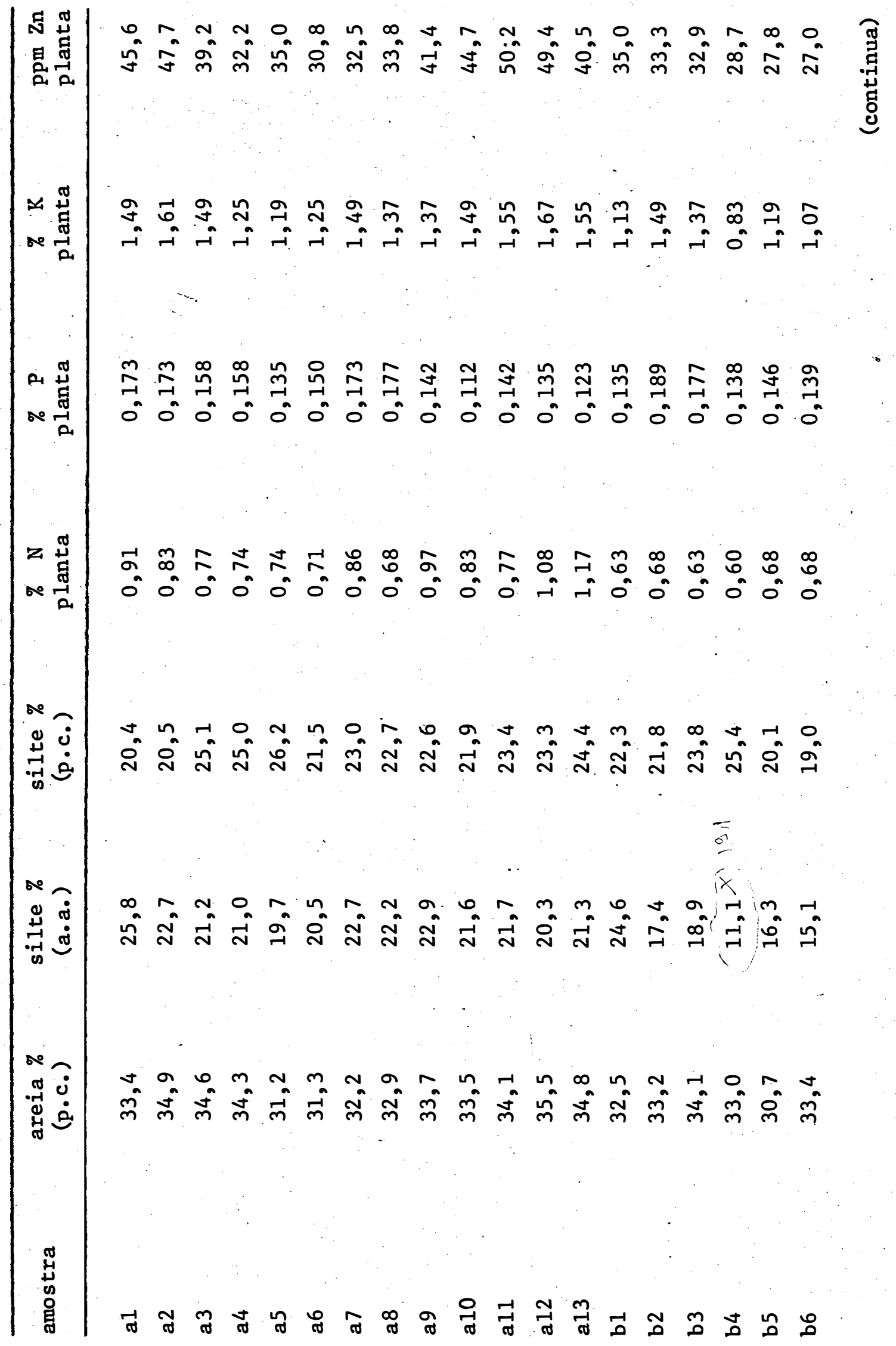




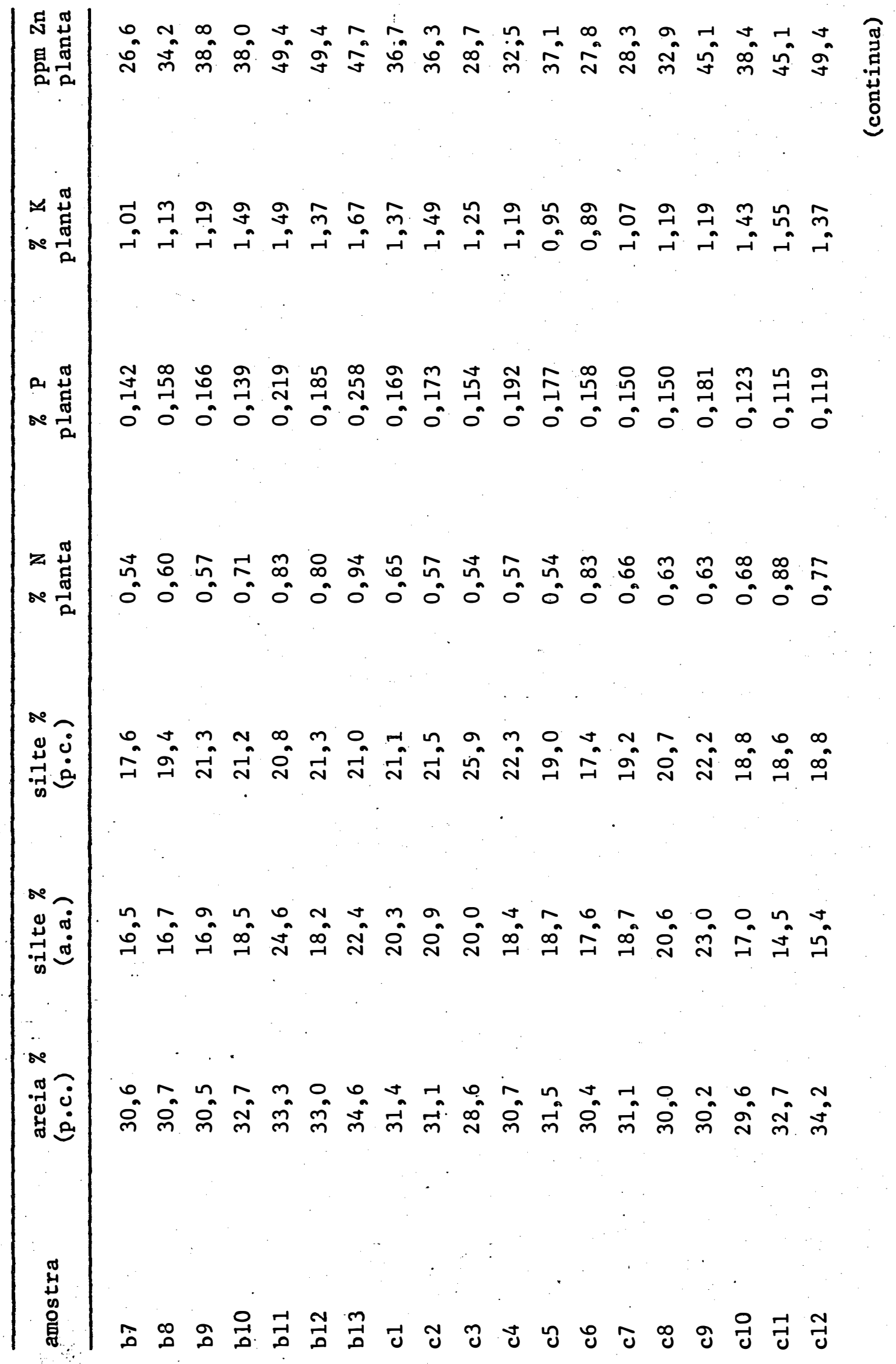




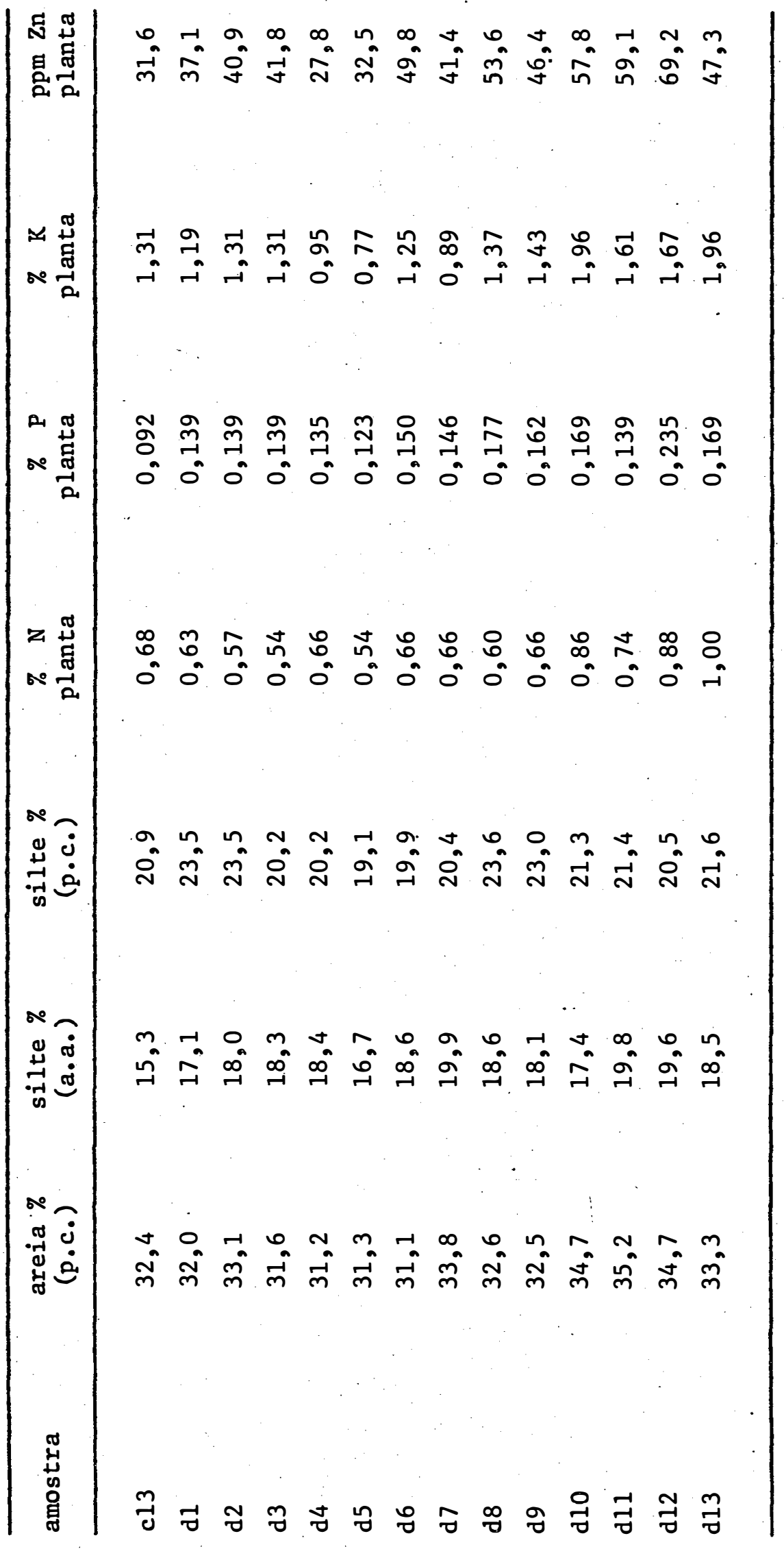


$-133-$

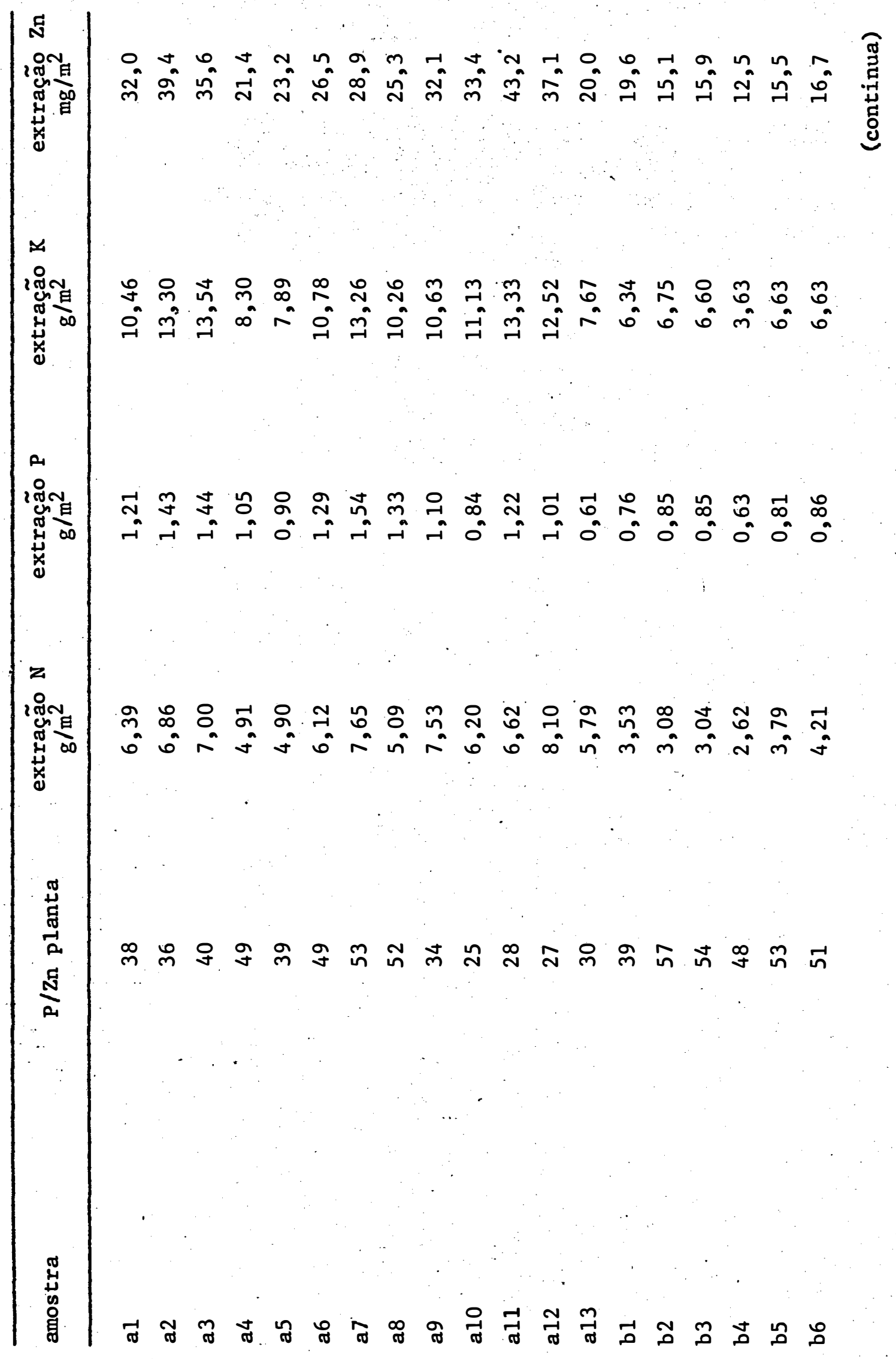




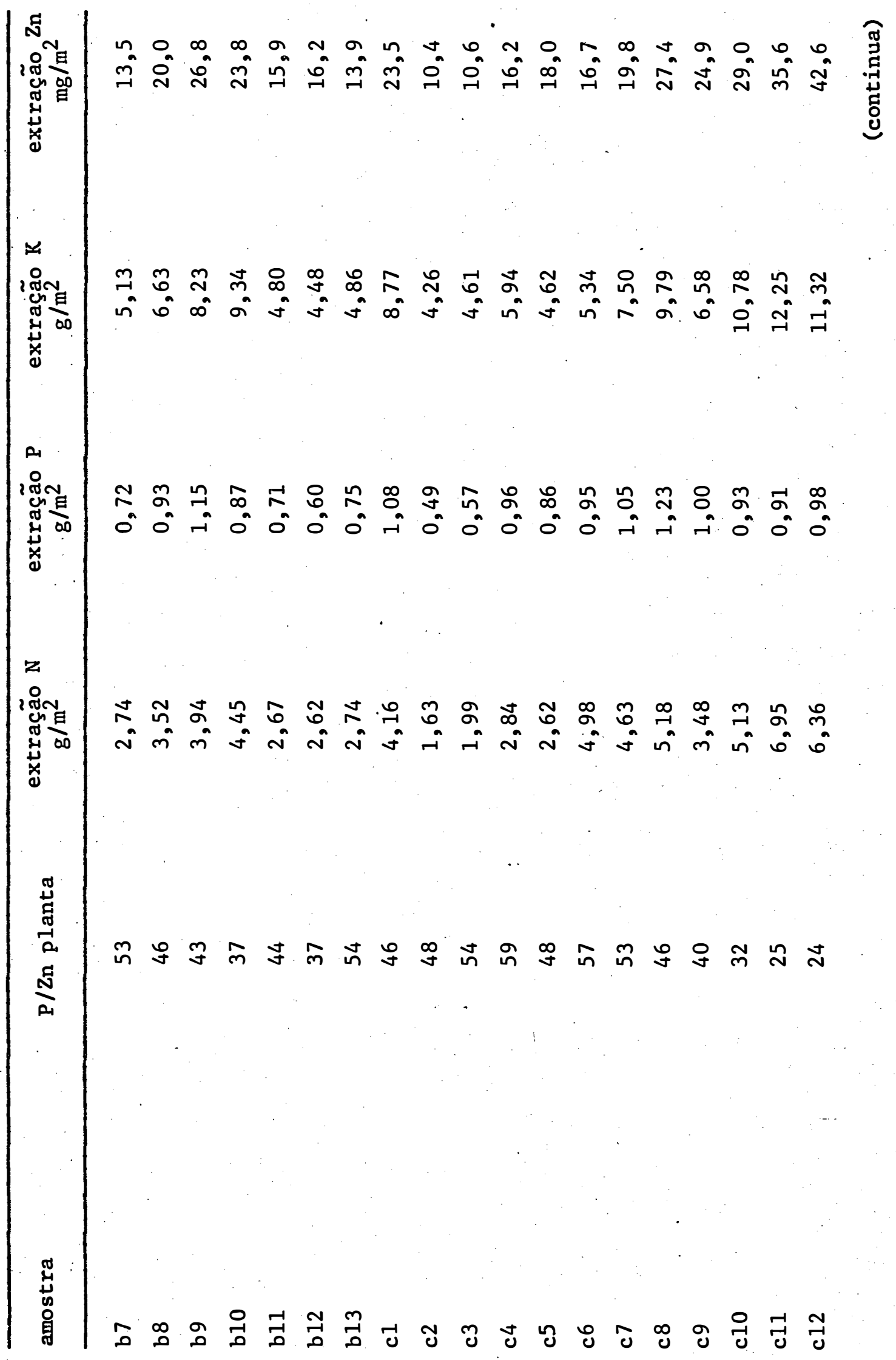




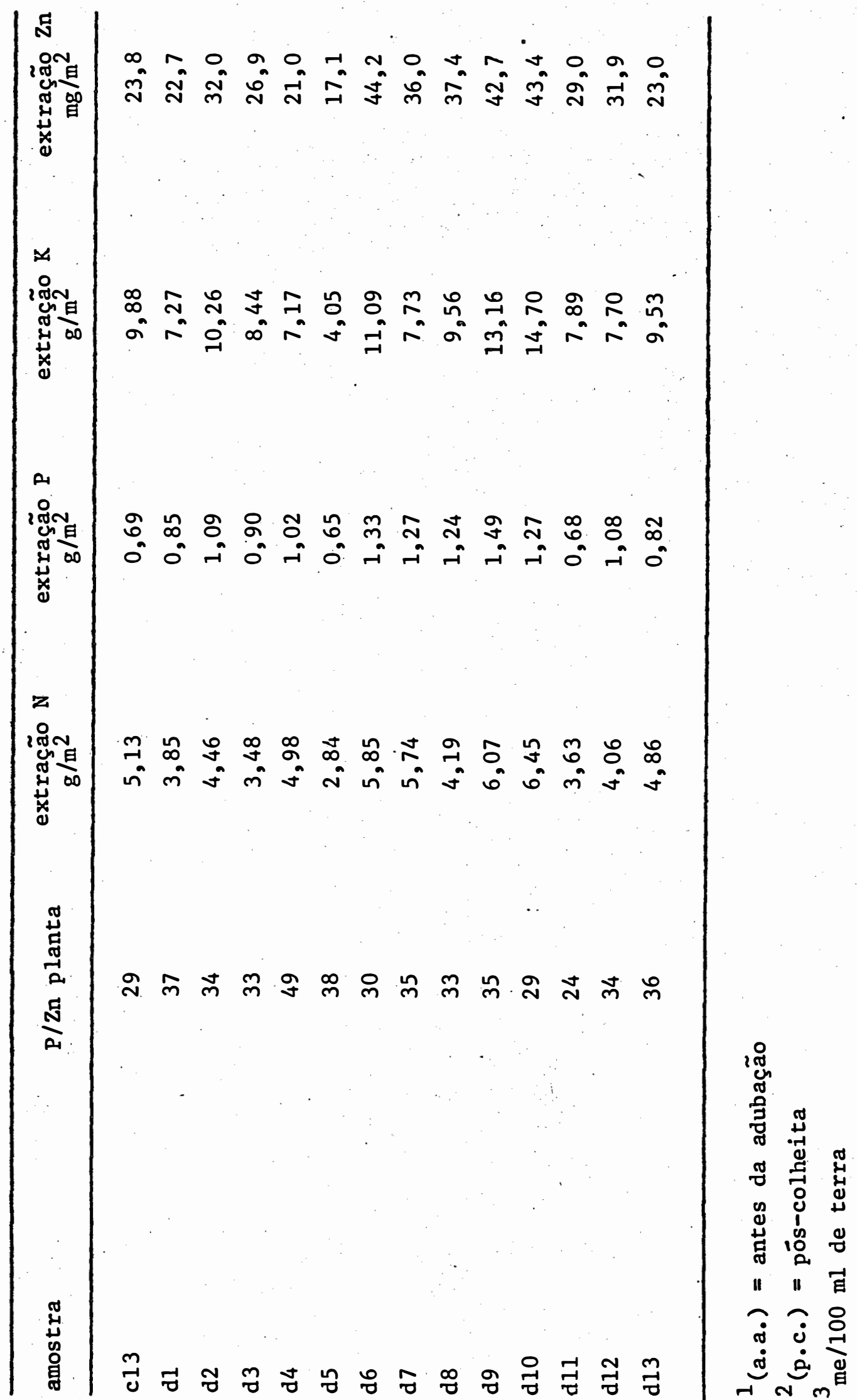


A N E X C C 
AUTOCORRELOGRAMAS E SEMIVARIOGRAMAS

CALCULADOS PARA UMA DIREÇÃO 


\begin{tabular}{|c|c|c|c|c|}
\hline parâmetro & $\begin{array}{c}\text { distância } \\
(\mathrm{m})\end{array}$ & $\begin{array}{l}\text { pares } \\
\text { (no) }\end{array}$ & $\begin{array}{c}\text { auṭocorrel ação } \\
r(I)\end{array}$ & $\begin{array}{c}\text { semivariân } \\
\gamma(L)\end{array}$ \\
\hline \multirow[t]{7}{*}{ produção. } & 10 & 48 & 0,4112 & 14109,7 \\
\hline & 20 & 44 & 0,4108 & 13117,1 \\
\hline & 30 & 40 & 0,0149 & 22551,8 \\
\hline & 40 & 36 & $-0,0662$ & 24790,5 \\
\hline & 50 & 32 & $-0,1318$ & 26285,3 \\
\hline & 60 & 28 & $-0,1661$ & 28294,7 \\
\hline & 70 & 24 & $-0,2173$ & 25910,1 \\
\hline \multirow[t]{7}{*}{ matéria seca } & 10 & 48 & 0,6125 & 11713,9 \\
\hline & 20 & 44 & 0,3730 & 16899,1 \\
\hline & 30 & 40 & 0,2666 & 18193,3 \\
\hline & 40 & 36 & 0,2234 & 20788,1 \\
\hline & 50 & 32 & 0,1683 & 23433,2 \\
\hline & 60 & 28 & 0,0419 & 28197,9 \\
\hline & 70 & 24 & 0,1177 & 25305,0 \\
\hline \multirow[t]{7}{*}{ altura planta } & 10 & 48 & 0,7538 & 20,66 \\
\hline & 20 & 44 & 0,6146 & 34,22 \\
\hline & 30 & 40 & 0,5360 & 40,43 \\
\hline & 40 & 36 & 0,6699 & 33,65 \\
\hline & 50 & 32 & 0,7215 & 30,56 \\
\hline & 60 & 28 & 0,5990 & 34,77 \\
\hline & 70 & 24 & 0,5319 & 37,10 \\
\hline \multirow[t]{7}{*}{ perf. efetivo. } & 10 & 48 & 0,0722 & 0,0033 \\
\hline & 20 & 44 & 0,0241 & 0,0034 \\
\hline & 30 & 40 & $-0,0203$ & 0,0037 \\
\hline & 40 & 36 & $-0,0629$ & 0,0040 \\
\hline & 50 & 32 & $-0,0988$ & 0,0041 \\
\hline & 60 & 28 & $-0,4333$ & 0,0055 \\
\hline & 70 & 24 & 0,0730 & 0,0033 \\
\hline
\end{tabular}




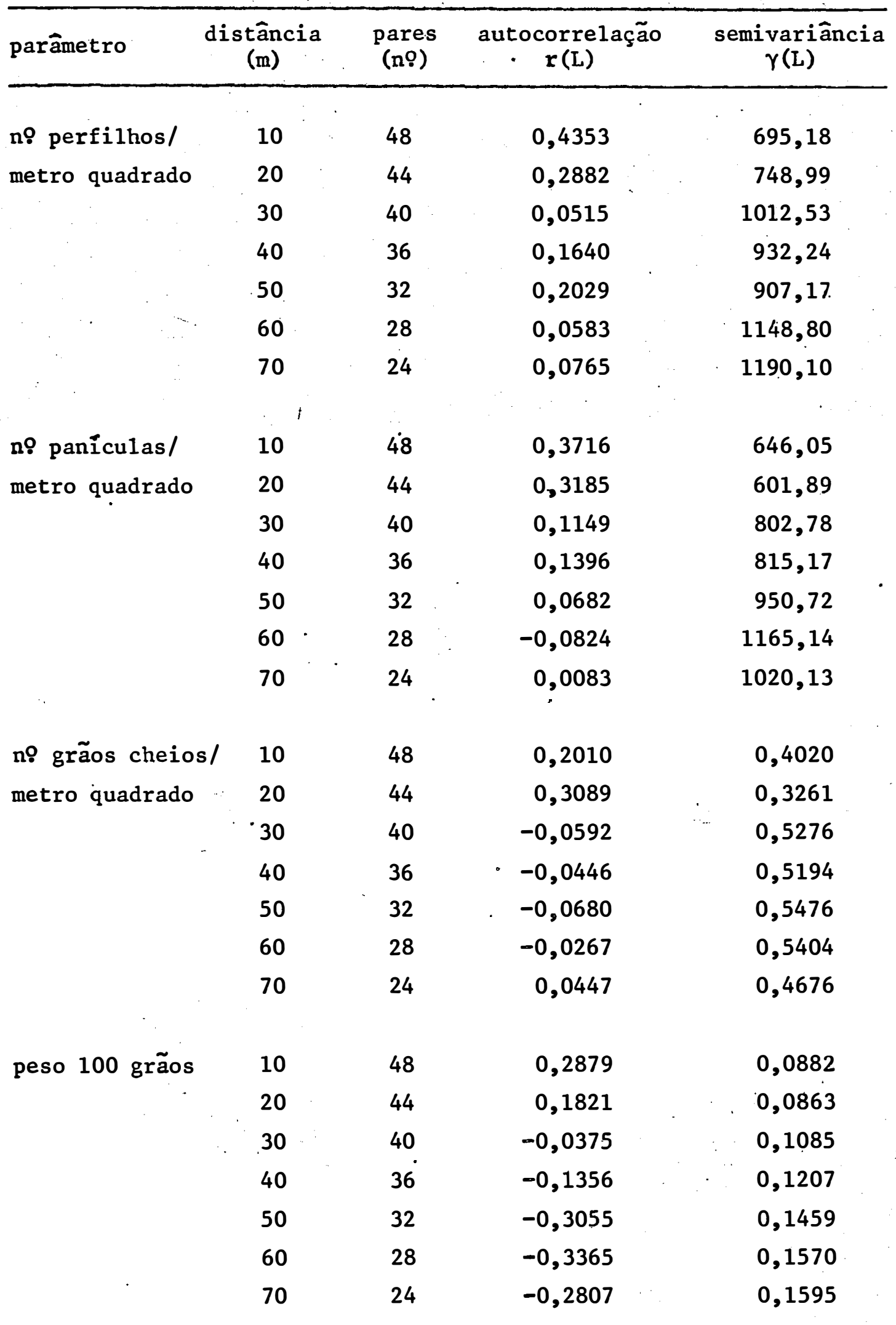




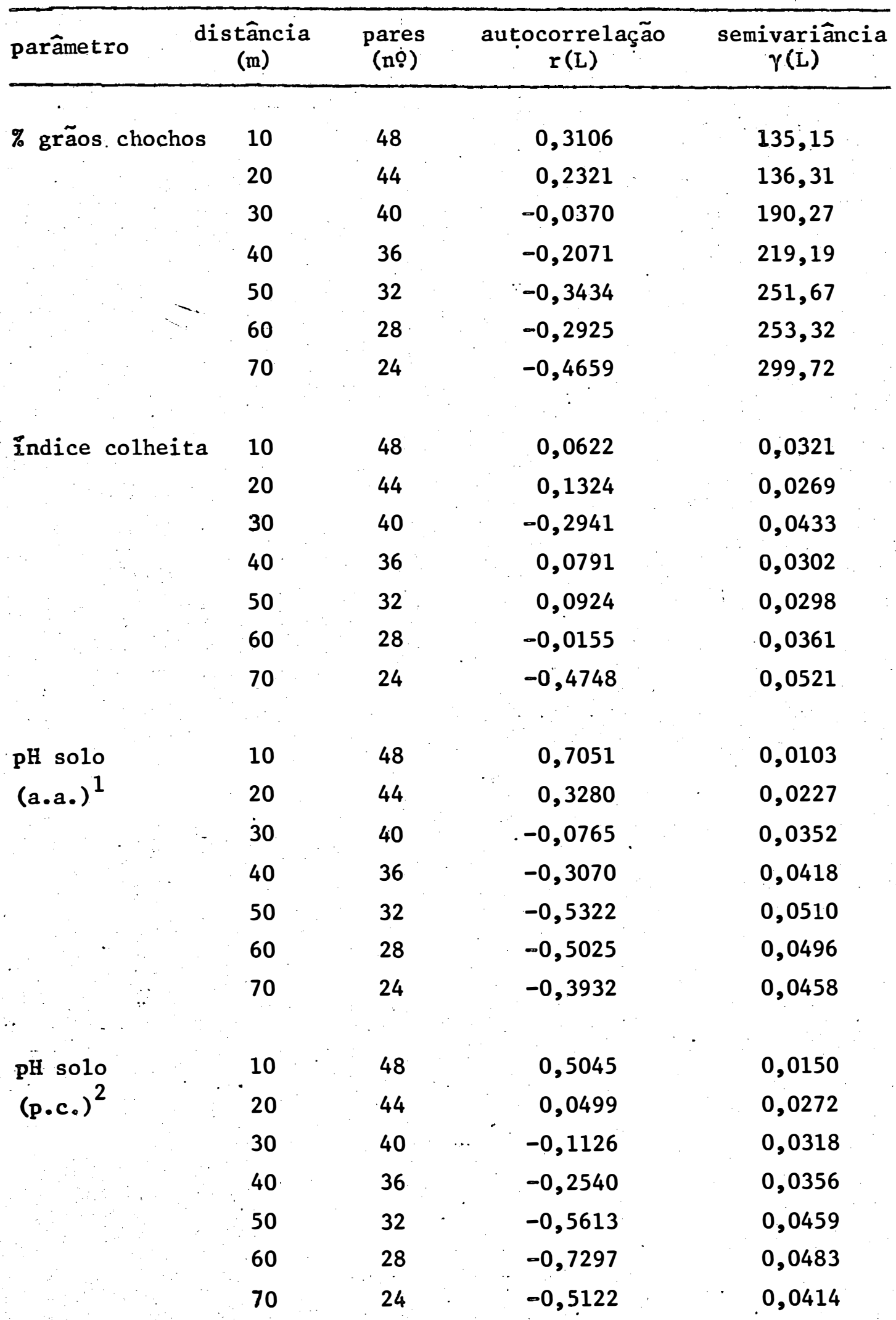




\begin{tabular}{|c|c|c|c|c|}
\hline parâmetro & $\begin{array}{c}\text { distância } \\
\text { (m) }\end{array}$ & $\begin{array}{l}\text { pares } \\
\text { (no) }\end{array}$ & $\begin{array}{c}\text { autocorrelaçãc } \\
\cdot \mathbf{r}(\mathrm{L})\end{array}$ & $\begin{array}{c}\text { semivariância } \\
\gamma(\mathrm{L})\end{array}$ \\
\hline C org. solo & 10 & 48 & 0,4685 & 0,0037 \\
\hline & 20 & 44 & 0,3268 & 0,0047 \\
\hline & 30 & 40 & 0,3453 & 0,0045 \\
\hline & 40 & 36 & 0,2815 & 0,0045 \\
\hline & 50 & 32 & 0,1486 & 0,0054 \\
\hline & 60 & 28 & 0,3021 & 0,0050 \\
\hline & 70 & 24 & 0,4076 & 0,0034 \\
\hline C org. solo & 10 & $48^{\circ}$ & 0,4898 & 0,0041 \\
\hline & 20 & 44 & 0,4086 & 0,0046 \\
\hline & 30 & 40 & 0,4523 & 0,0037 \\
\hline & 40 & 36 & 0,3381 & 0,0047 \\
\hline & 50 & 32 & 0,1303 & 0,0069 \\
\hline & 60 & 28 & 0,1596 & 0,0073 \\
\hline & 70 & 24 & 0,3212 & 0,0061 \\
\hline P solo & 10 & 48 & 0,5563 & 0,0017 \\
\hline$\left(a \cdot a_{0}\right)$ & 20 & 44 & 0,3659 & 0,0026 \\
\hline & 30 & 40 & 0,1877 & 0,0035 \\
\hline & 40 & 36 & - $-0,0397$ & 0,0041 \\
\hline & 50 & 32 & $-0,2840$ & 0,0051 \\
\hline & 60 & 28 & $-0,2833$ & 0,0047 \\
\hline & 70 & 24 & $-0,4522$ & 0,0057 \\
\hline P solo & 10 & 48 & 0,3496 & 0,0037 \\
\hline$\left(p . c_{.}\right)$ & 20 & 44 & 0,3098 & 0,0042 \\
\hline & 30 & 40 & 0,1023 & 0,0057 \\
\hline & 40 & 36 & $-0,1517$ & 0,0073 \\
\hline & 50 & 32 & $-0,3093$ & 0,0084 \\
\hline & 60 & 28 & $-0,2494$ & 0,0064 \\
\hline & 70 & 24 & $-0,4371$ & 0,0080 \\
\hline
\end{tabular}




\begin{tabular}{|c|c|c|c|c|}
\hline parâmetro & $\begin{array}{l}\text { distância } \\
\text { (m) }\end{array}$ & $\begin{array}{l}\text { pares } \\
(n+9)\end{array}$ & $\begin{array}{c}\text { autocorrelação } \\
\cdot r(\mathrm{~L})\end{array}$ & $\begin{array}{c}\text { semivariância } \\
\gamma(\mathrm{L})\end{array}$ \\
\hline K solo & 10 & 48 & 0,5675 & 0,0029 \\
\hline \multirow[t]{6}{*}{$\left(a_{\cdot} a_{0}\right)$} & 20 & 44 & 0,4237 & 0,0043 \\
\hline & 30 & 40 & 0,2734 & 0,0056 \\
\hline & 40 & 36 & 0,2177 & 0,0057 \\
\hline & 50 & 32 & 0,1016 & 0,0062 \\
\hline & 60 & 28 & 0,0125 & 0,0067 \\
\hline & 70 & 24 & $-0,2980$ & 0,0096 \\
\hline K solo & 10 & 48 & 0,4916 & 0,0036 \\
\hline \multirow[t]{6}{*}{$\left(p \cdot c_{0}\right)$} & 20 & 44 & 0,1916 & 0,0056 \\
\hline & 30 & 40 & 0,0821 & 0,0067 \\
\hline & 40 & 36 & $-0,0913$ & 0,0078 \\
\hline & 50 & 32 & $-0,1573$ & 0,0082 \\
\hline & 60 & 28 & $-0,0460$ & 0,0077 \\
\hline & 70 & 24 & $-0,0950$ & 0,0086 \\
\hline Ca solo & 10 & 48 & 0,5885 & 0,1624 \\
\hline \multirow[t]{6}{*}{$\left(a_{\circ} a_{\bullet}\right)$} & 20 & 44 & 0,4384 & 0,2312 \\
\hline & 30 & 40 & 0,1615 & 0,3456 \\
\hline & 40 & 36 & $-0,0964$ & 0,4634 \\
\hline & 50 & 32 & $=0,1818$ & 0,5111 \\
\hline & 60 & 28 & $-0,1723$ & 0,4689 \\
\hline & 70 & 24 & $-0,0184$ & 0,3081 \\
\hline Ca solo & 10 & 48 & 0,7868 & 0,1023 \\
\hline \multirow[t]{6}{*}{$\left(p \circ c_{0}\right)$} & 20 & 44 & 0,5337 & 0,2032 \\
\hline & 30 & 40 & 0,2769 & 0,3195 \\
\hline & 40 & 36 & 0,0169 & 0,4464 \\
\hline & 50 & 32 & $-0,1010$ & 0,5087 \\
\hline & 60 & 28 & $-0,1863$ & 0,4768 \\
\hline & 70 & 24 & $-0,1451$ & 0,4163 \\
\hline
\end{tabular}




\begin{tabular}{|c|c|c|c|c|}
\hline parâmetro & $\begin{array}{c}\text { distância } \\
\text { (m) }\end{array}$ & $\begin{array}{l}\text { pares } \\
\text { (no) }\end{array}$ & $\begin{array}{c}\text { autocorrelação } \\
\cdot \operatorname{r(L)}\end{array}$ & $\begin{array}{c}\text { semivariância } \\
\gamma(\mathrm{L})\end{array}$ \\
\hline Mg solo & 10 & 48 & 0,1024 & 0,0445 \\
\hline \multirow[t]{6}{*}{$\left(a \cdot a_{0}\right)$} & 20 & 44 & 0,0631 & 0,0486 \\
\hline & 30 & 40 & 0,1919 & 0,0449 \\
\hline & 40 & 36 & 0,2263 & 0,0464 \\
\hline & 50 & 32 & 0,0530 & 0,0435 \\
\hline & 60 & 28 & 0,1711 & 0,0427 \\
\hline & 70 & 24 & 0,0975 & 0,0387 \\
\hline Mg solo & 10 & $48^{\circ}$ & 0,2193 & 0,0611 \\
\hline \multirow[t]{6}{*}{$(p \cdot c \cdot)$} & 20 & 44 & 0,0047 & 0,0791 \\
\hline & 30 & 40 & 0,0570 & 0,0779 \\
\hline & 40 & 36 & 0,3266 & 0,0636 \\
\hline & 50 & 32 & 0,1456 & 0,0524 \\
\hline & 60 & 28 & $-0,0454$ & 0,0733 \\
\hline & 70 & 24 & 0,1459 & 0,0678 \\
\hline Al solo & 10 & 48 & 0,2097 & $1,14 \cdot 10^{-4}$ \\
\hline \multirow[t]{6}{*}{$\left(a_{\cdot} a_{0}\right)$} & 20 & 44 & $-0,1327$ & $2,21.10^{-4}$ \\
\hline & 30 & 40 & $-0,0391$ & $2,19 \cdot 10^{-4}$ \\
\hline & 40 & 36 & $-0,1769$ & $2,20.10^{-4}$ \\
\hline & 50 & 32 & . $-0,0749$ & $1,18.10^{-4}$ \\
\hline & 60 & 28 & 0,0293 & $1,17.10^{-4}$ \\
\hline & 70 & 24 & $-0,0927$ & $2,19.10^{-4}$ \\
\hline Al solo & 10 & 48 & 0,0140 & $4,03 \cdot 10^{-4}$ \\
\hline & 20 & $44^{\circ}$ & 0,1781 & $3,51 \cdot 10^{-4}$ \\
\hline & 30 & 40 & 0,0751 & $4,11,10^{-4}$ \\
\hline & 40 & 36 & $-0,1398$ & $5,14 \cdot 10^{-4}$ \\
\hline & 50 & 32 & 0,0119 & $4,20 \cdot 10^{-4}$ \\
\hline & 60 & 28 & $-0,2976$ & $5,56 \cdot 10^{-4}$ \\
\hline & 70 & 24 & $-0,1235$ & $4,89 \cdot 10^{-4}$ \\
\hline
\end{tabular}




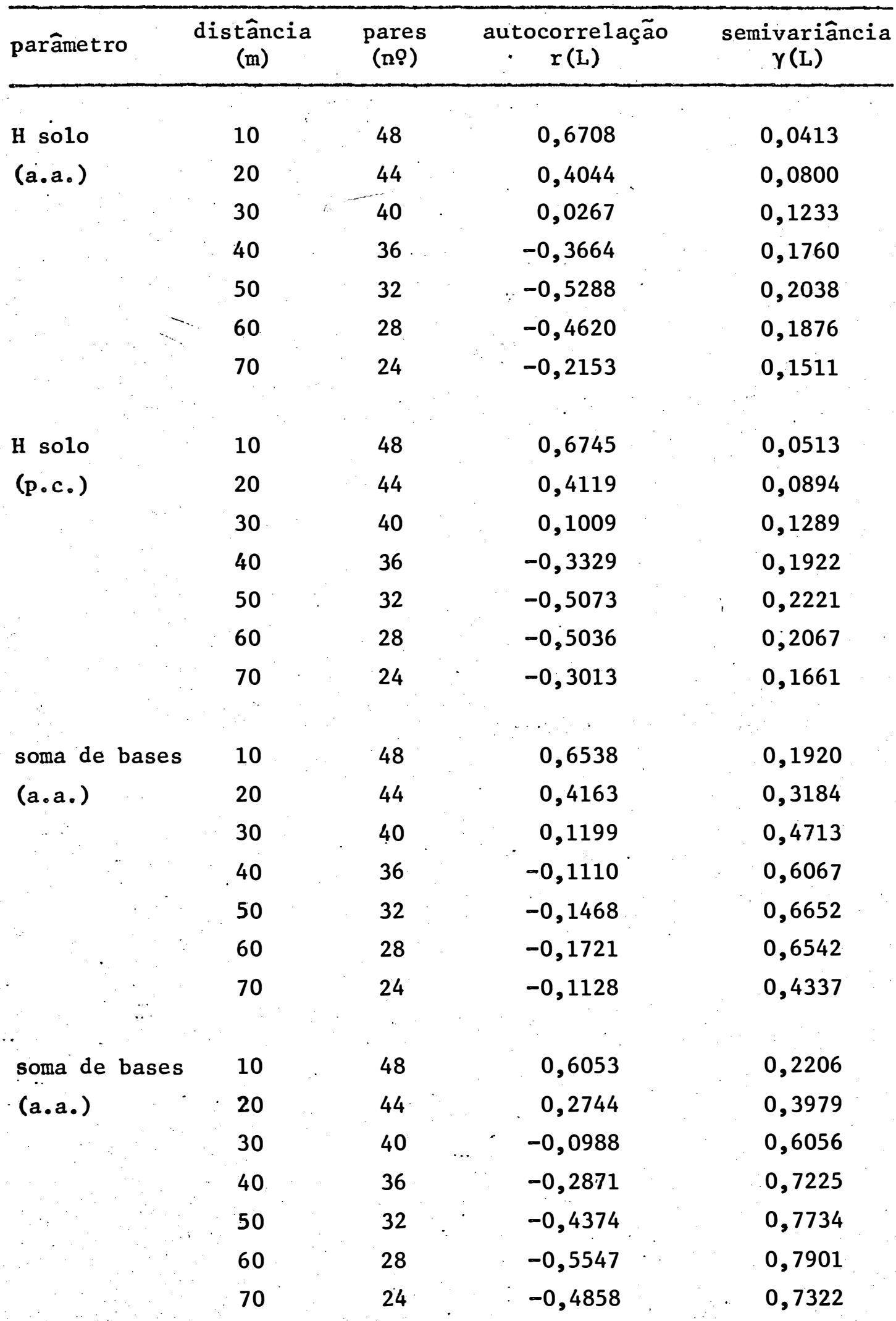




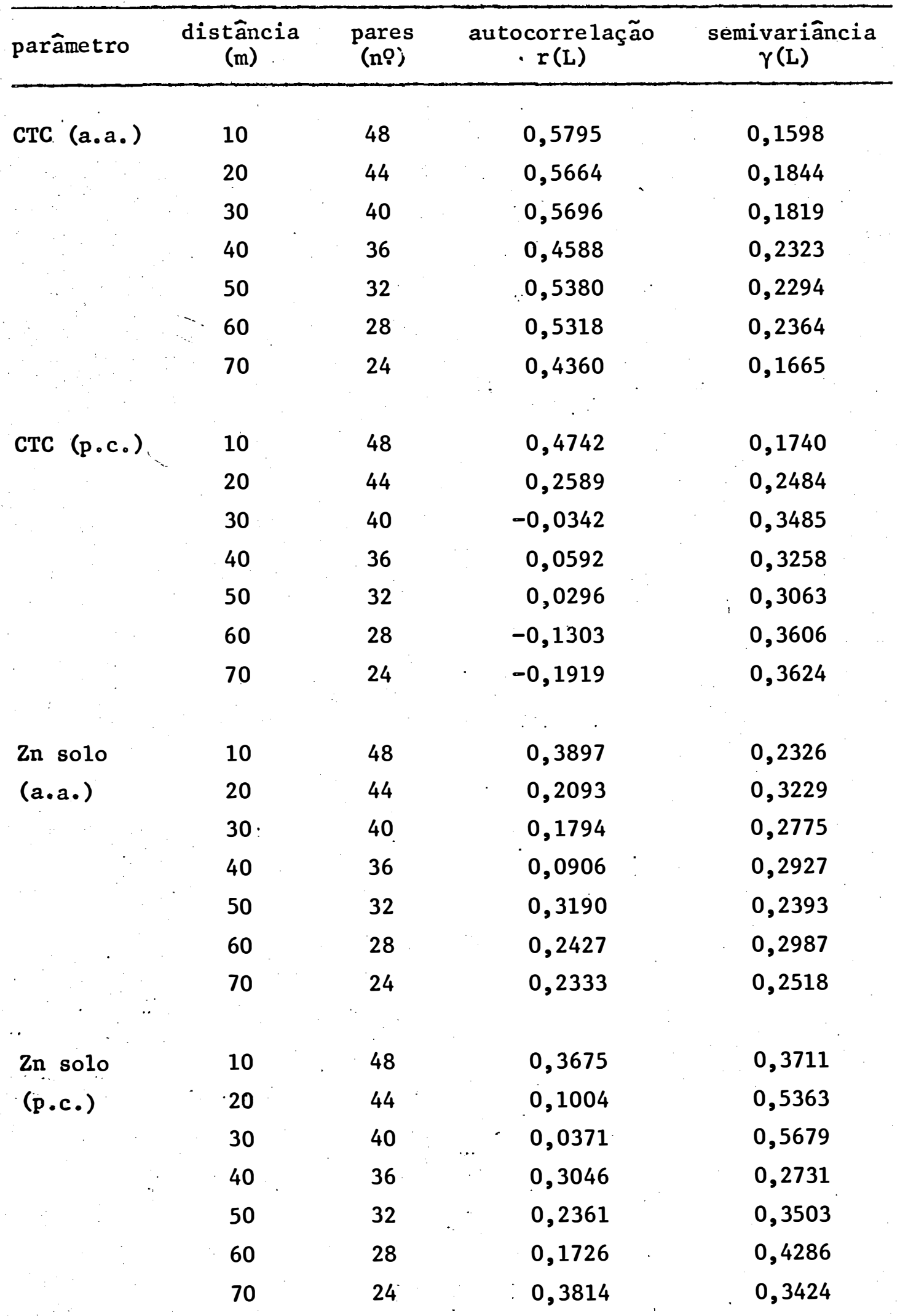




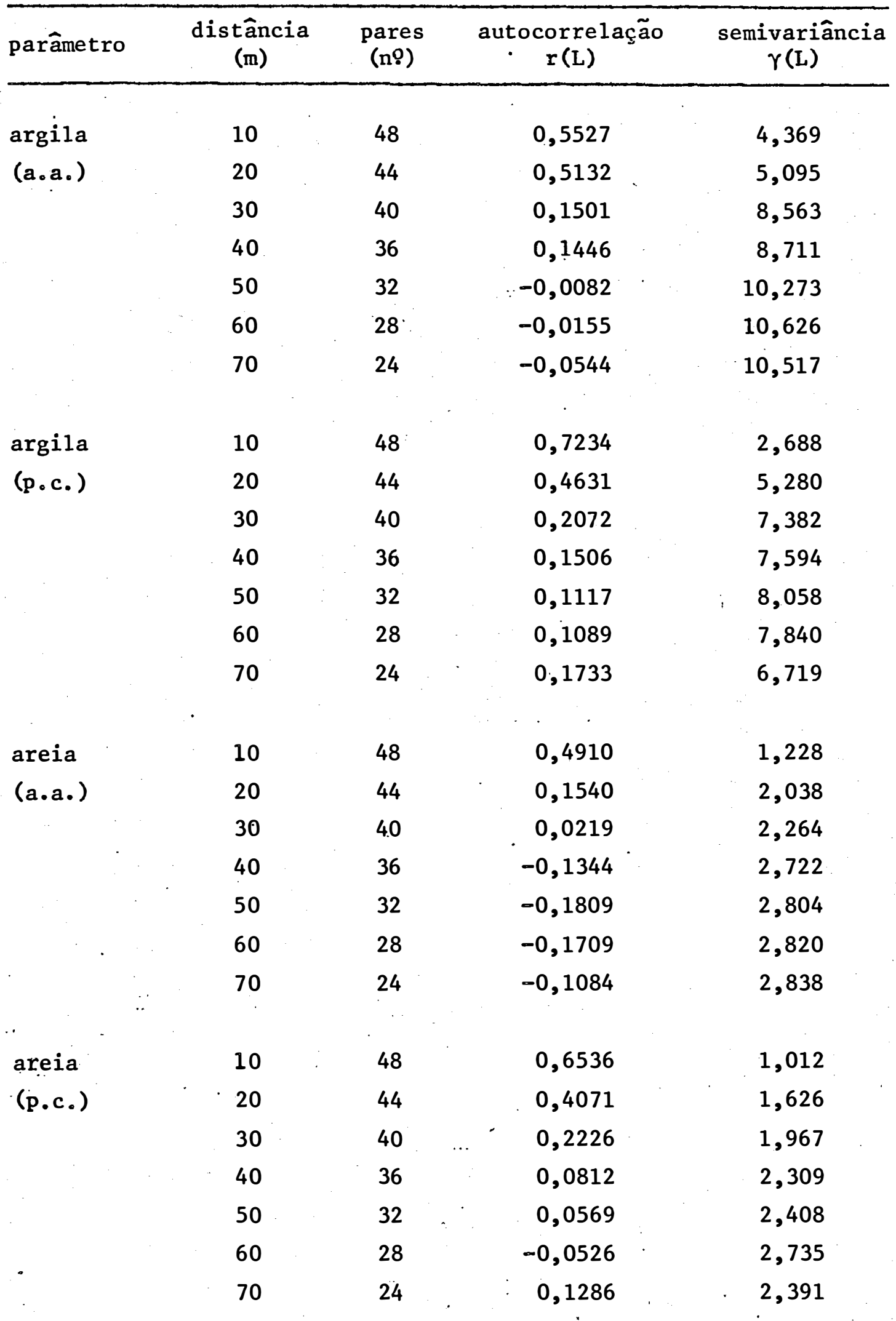




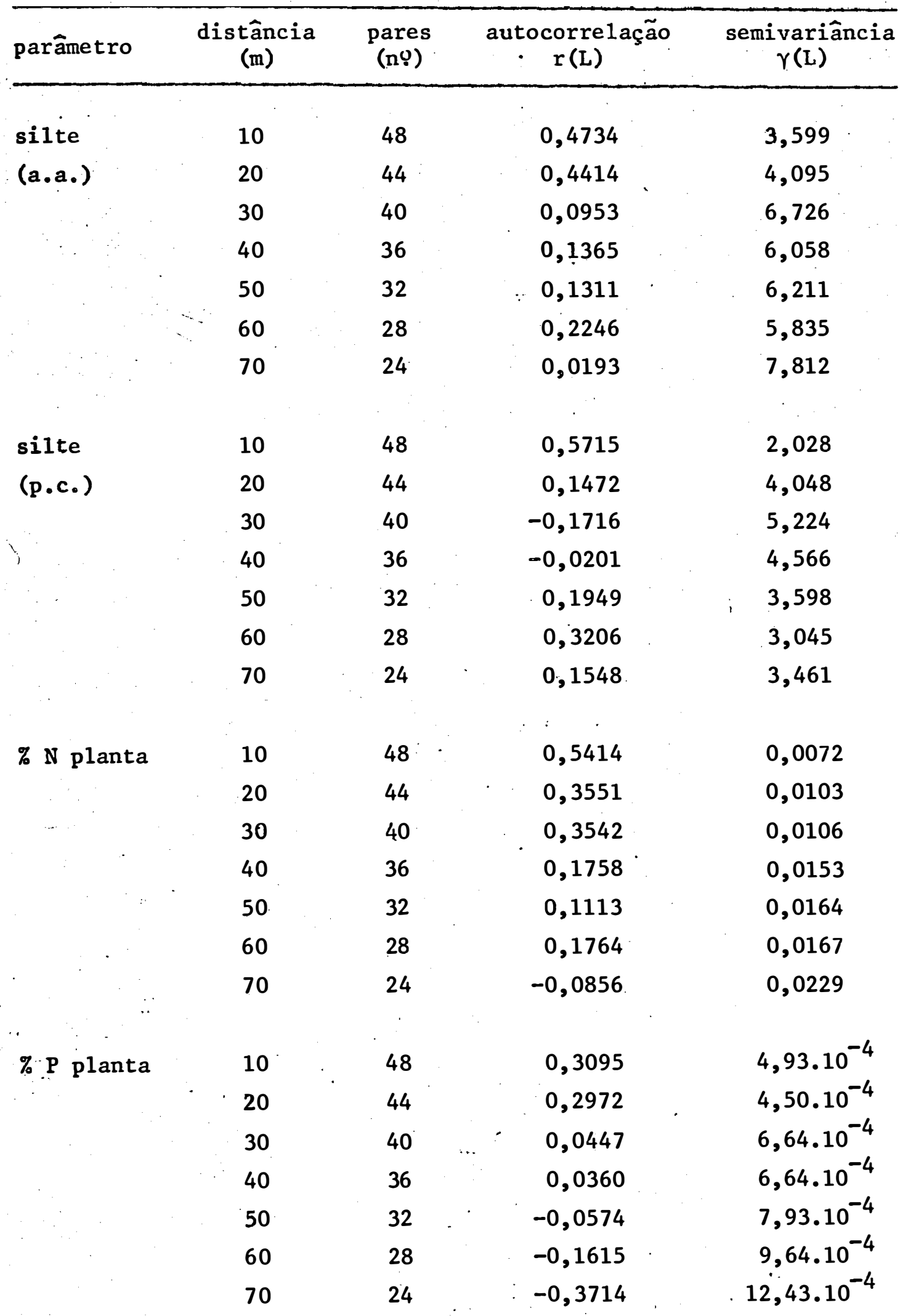




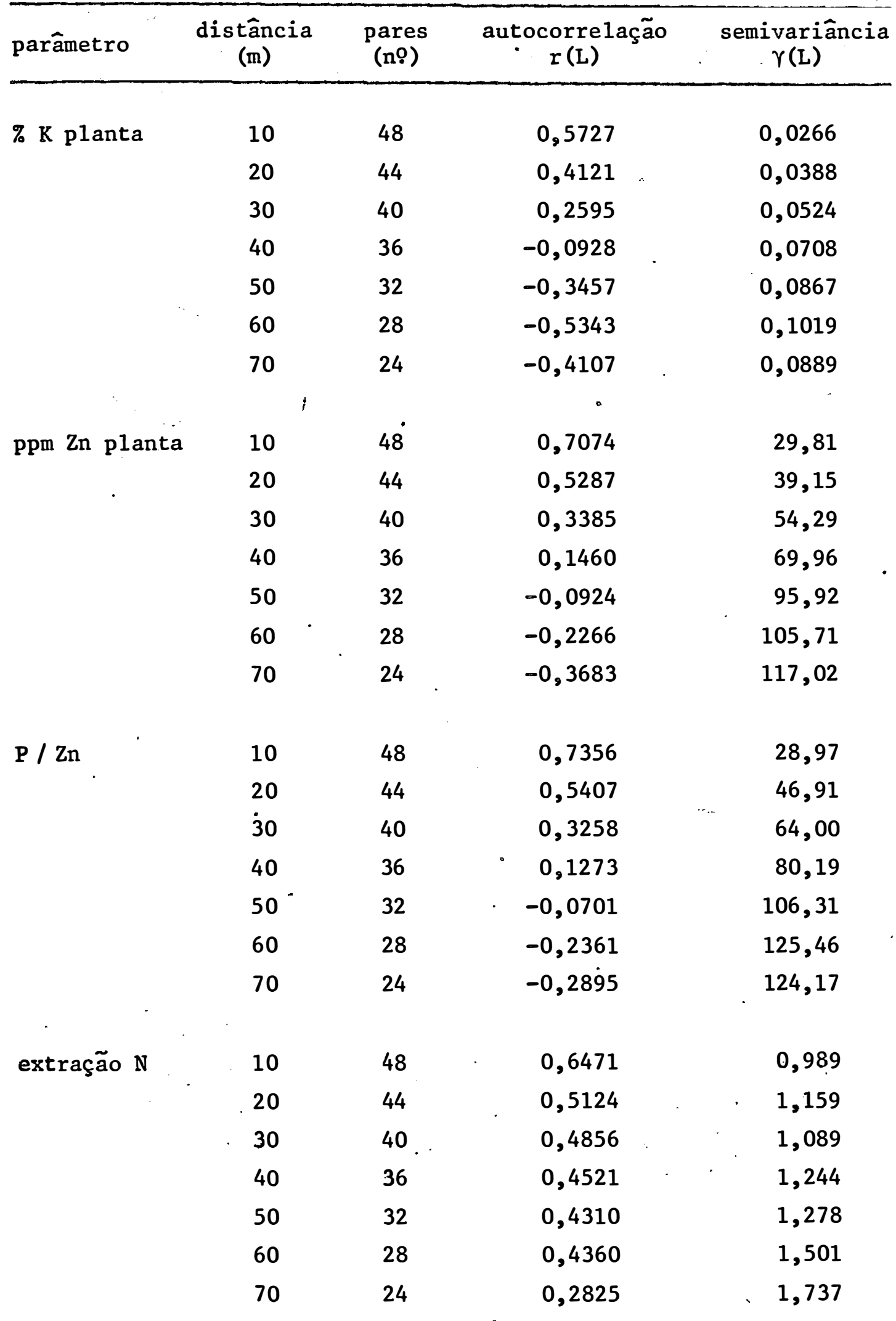




\begin{tabular}{|c|c|c|c|c|}
\hline parâmetro & $\begin{array}{l}\text { distância } \\
\text { (m) }\end{array}$ & $\begin{array}{l}\text { pares } \\
(\mathrm{n} 0)\end{array}$ & $\begin{array}{l}\text { autocorrelação } \\
\cdot r(I)\end{array}$ & $\begin{array}{c}\text { semivariância } \\
\gamma(L)\end{array}$ \\
\hline$\cdot$ & & & & \\
\hline \multirow[t]{7}{*}{ extração $P$} & 10 & 48 & 0,4653 & 0,0354 \\
\hline & 20 & 44 & 0,1976 & 0,0515 \\
\hline & 30 & 40 & 0,1984 & 0,0501 \\
\hline & 40 & 36 & 0,1783 & 0,0550 \\
\hline & 50 & 32 & 0,1013 & 0,0610 \\
\hline & 60 & 28 & 0,1476 & 0,0589 \\
\hline & 70 & 24 & 0,0675 & 0,0557 \\
\hline \multirow[t]{7}{*}{ extração $\mathrm{K}$} & 10 & 48 & 0,6049 & 3,710 \\
\hline & 20 & 44 & 0,3311 & 5,787 \\
\hline & 30 & 40 & 0,3307 & 5,457 \\
\hline & 40 & 36 & 0,4307 & 4,394 \\
\hline & 50 & 32 & 0,1769 & 6,410 \\
\hline & 60 & 28 & 0,1269 & 7,331 \\
\hline & 70 & 24 & 0,2310 . & 6,400 \\
\hline \multirow[t]{7}{*}{ extração $\mathrm{Zn}$} & 10 & 48 & 0,6938 & 31,56 \\
\hline & 20 & 44 & 0,4633 & 47,50 \\
\hline & 30 & 40 & 0,3691 & 52,92 \\
\hline & 40 & 36 & 0,3411 & 55,32 \\
\hline & 50 & 32 & 0,1175 & 76,49 \\
\hline & 60 & 28 & 0,1069 & 77,70 \\
\hline & $\quad 70$ & 24 & 0,0744 & 82,59 \\
\hline
\end{tabular}


AUTOCORRELOGRAMAS E SEMIVARIOGRAMAS

CALCULADOS PARA TODAS AS DIREÇÕES 


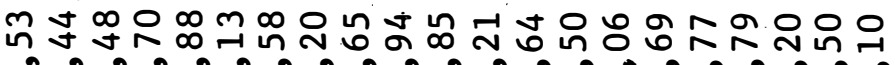

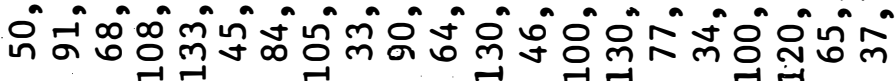

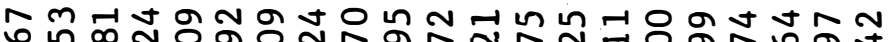
రำ

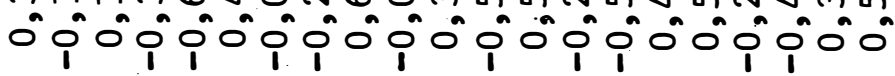

$\infty$ 의 겅요 $\infty$ 유

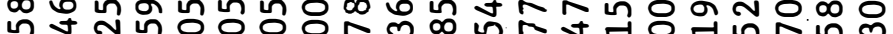
ทำ에

윽 근 ó

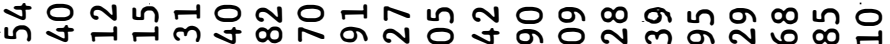
$\infty$ in

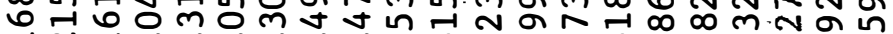

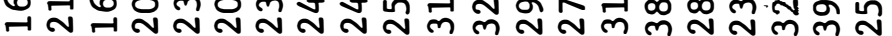

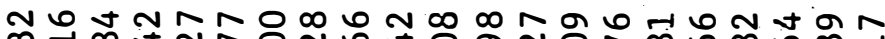

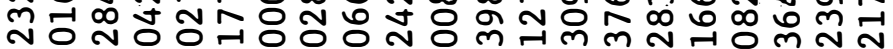

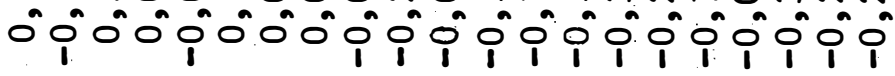

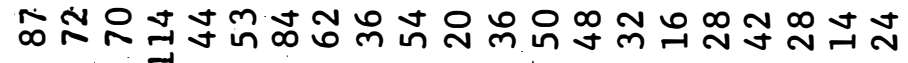

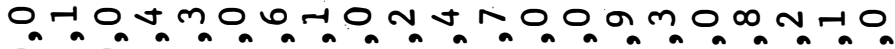

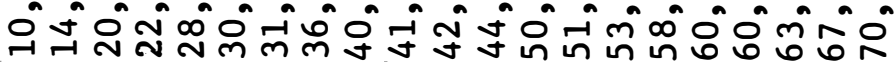









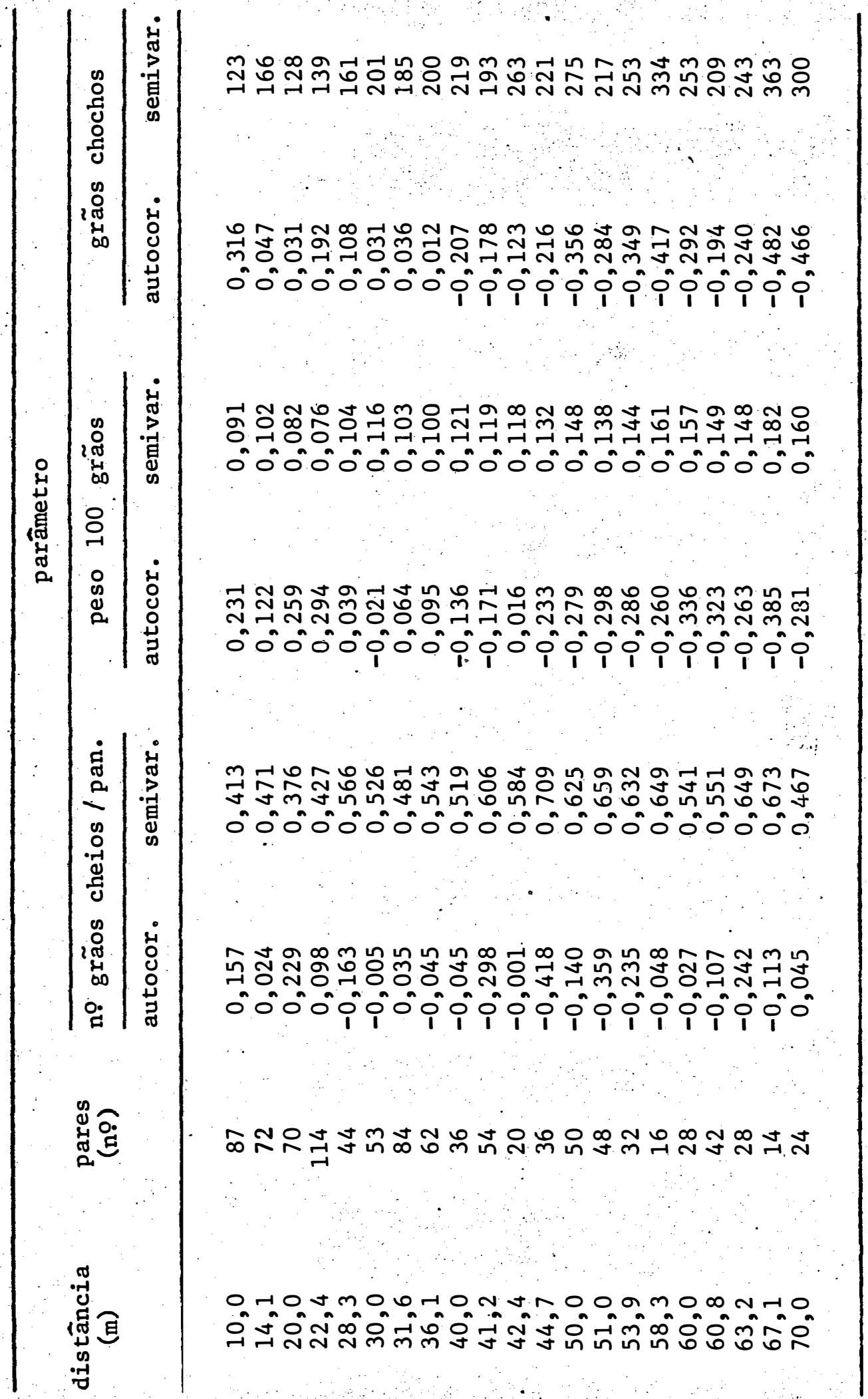









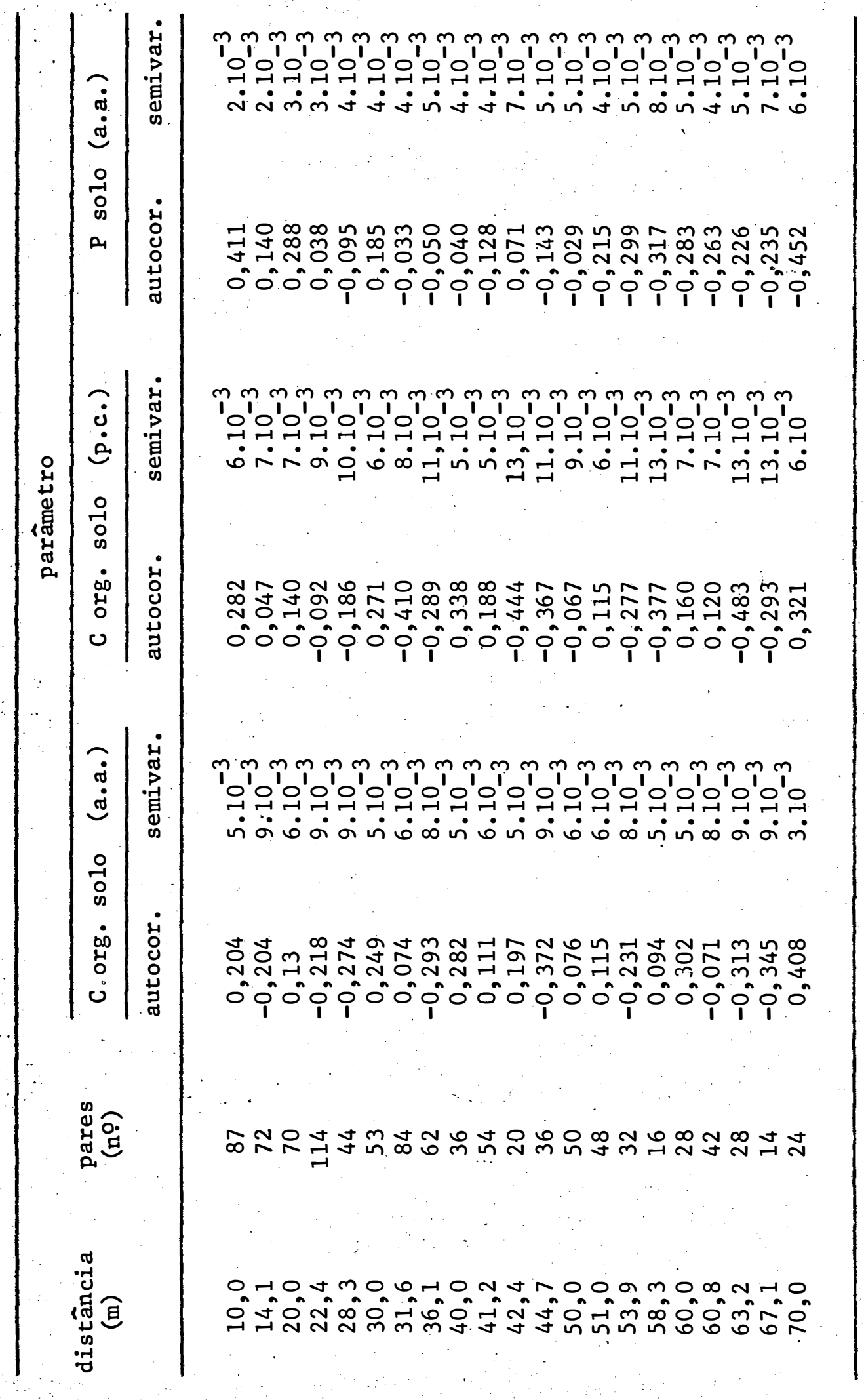




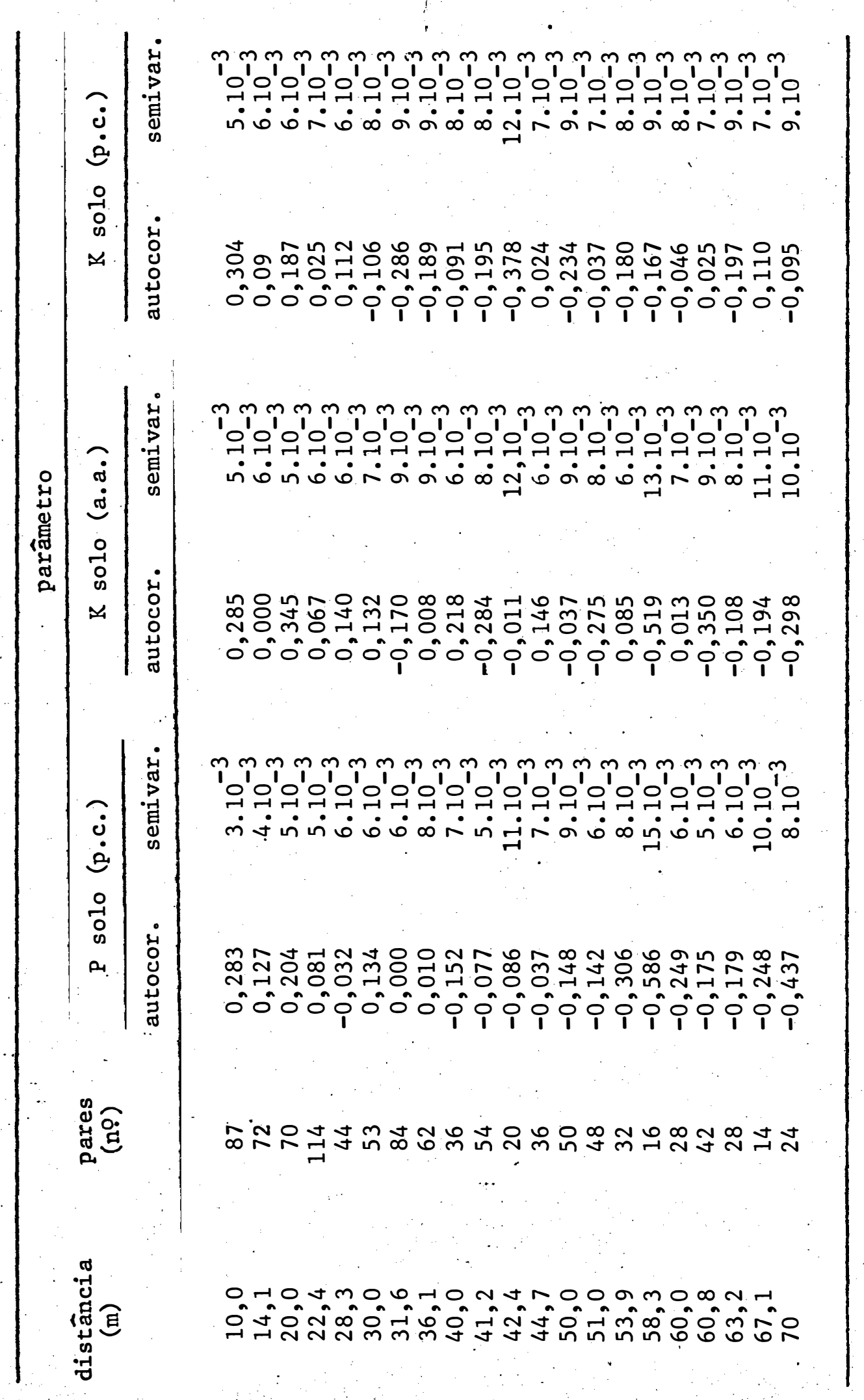




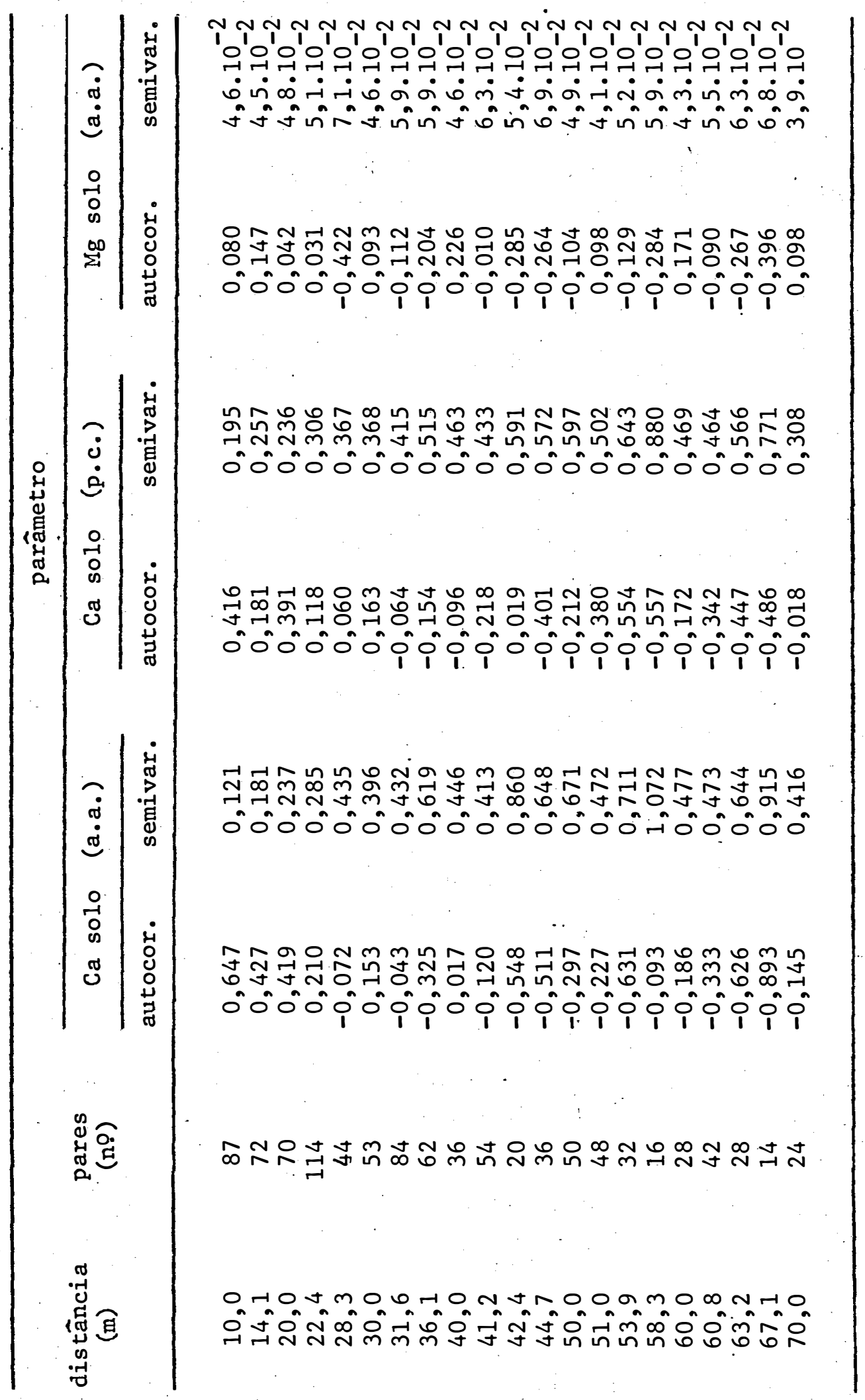




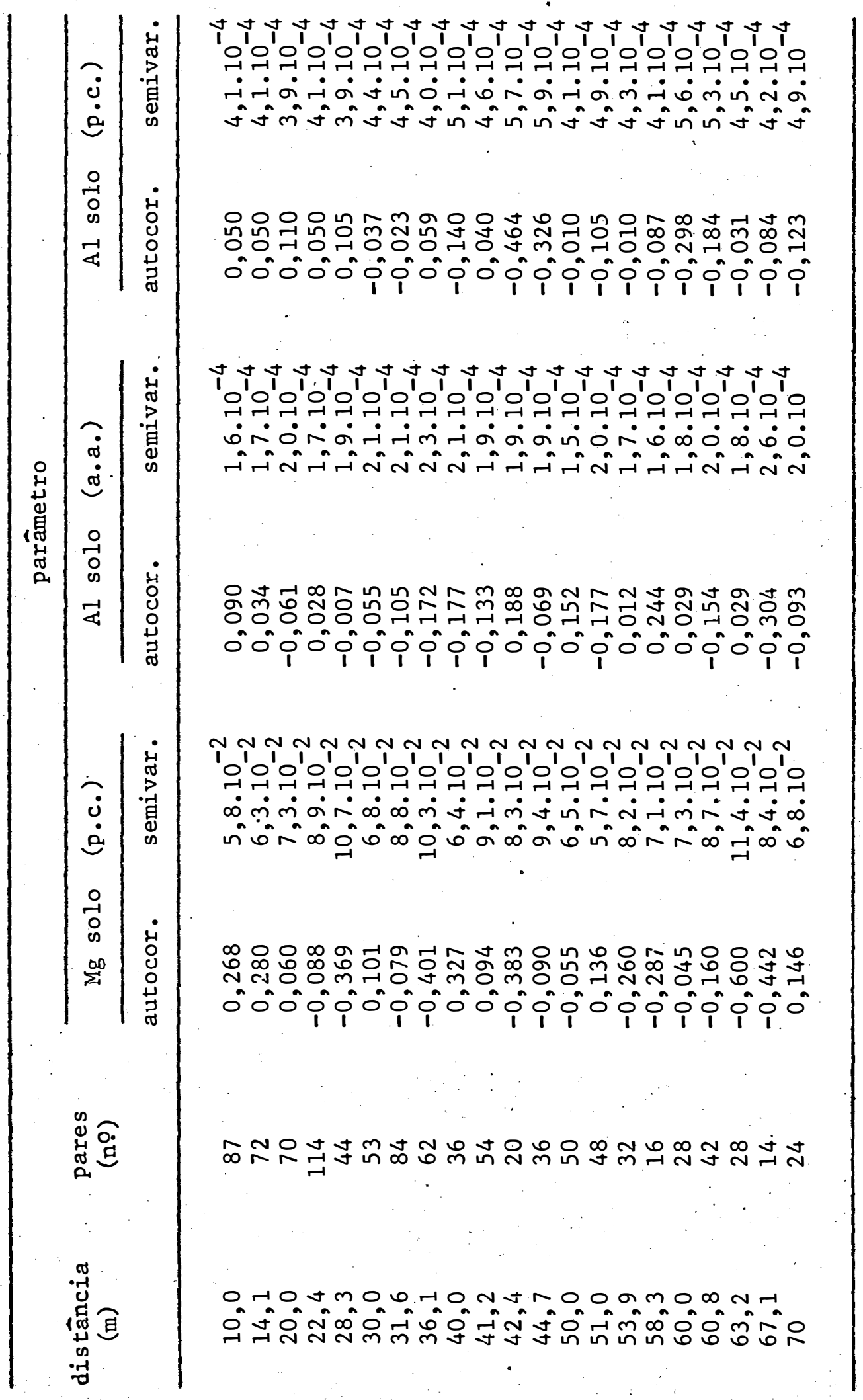




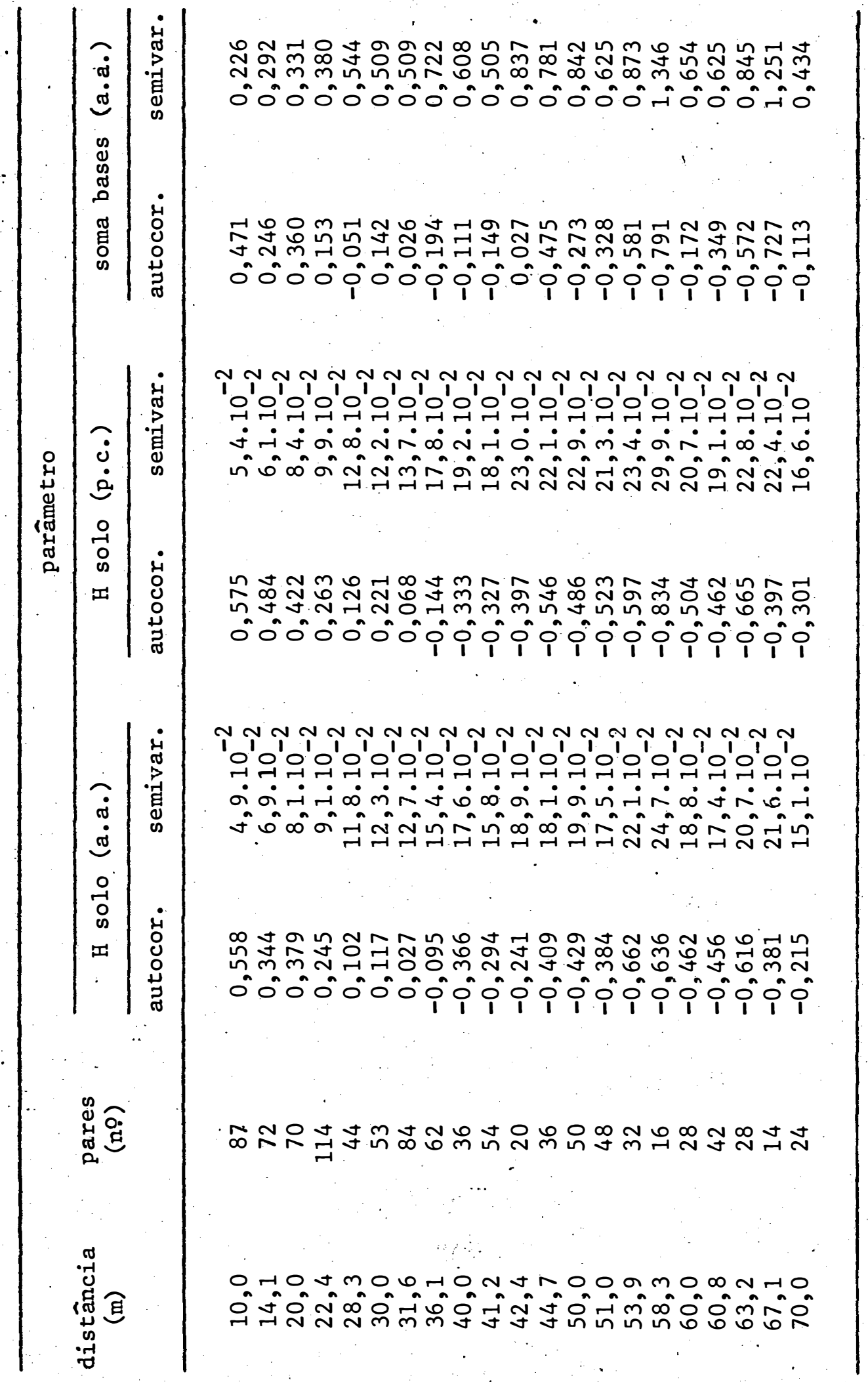




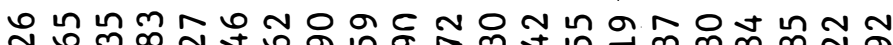

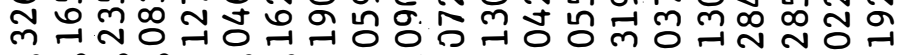
ó

m ฟิ సี సี ษ

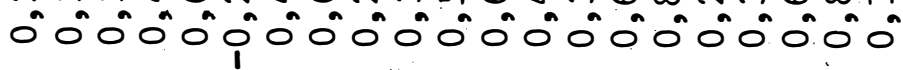

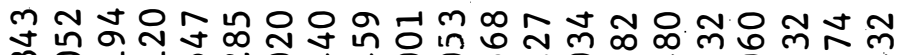
ฟ้ กิ้

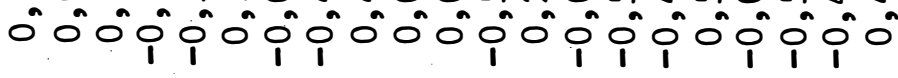

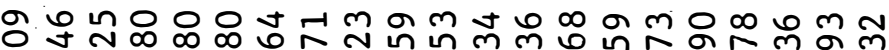
구ำ

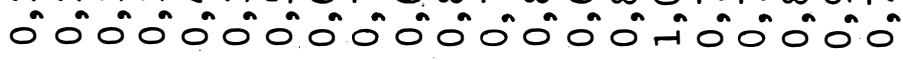

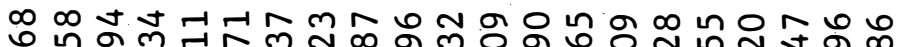

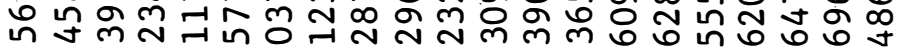

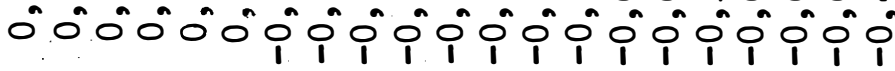

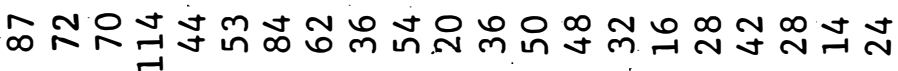

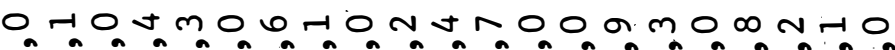

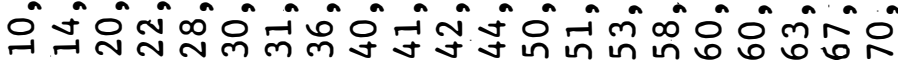




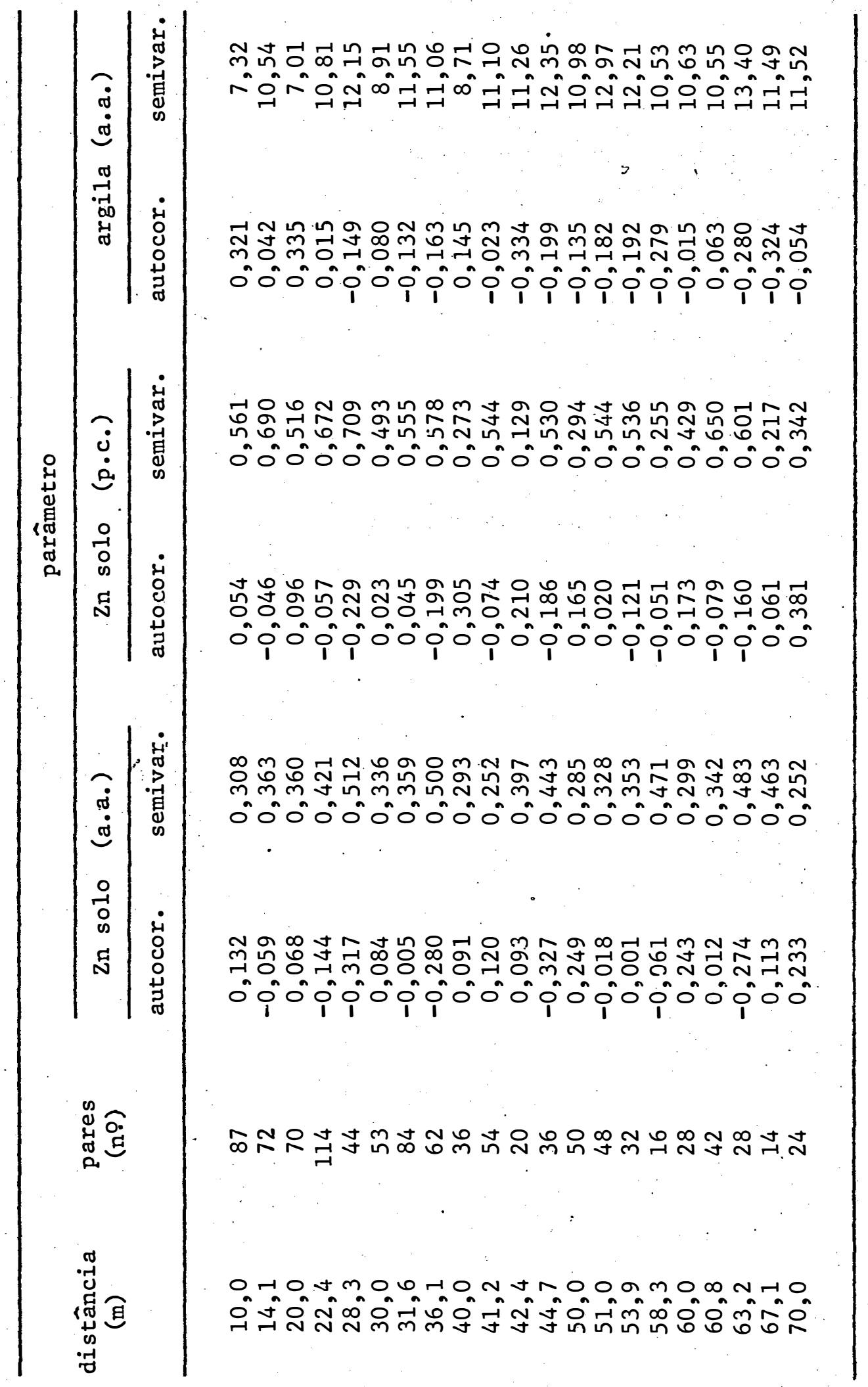




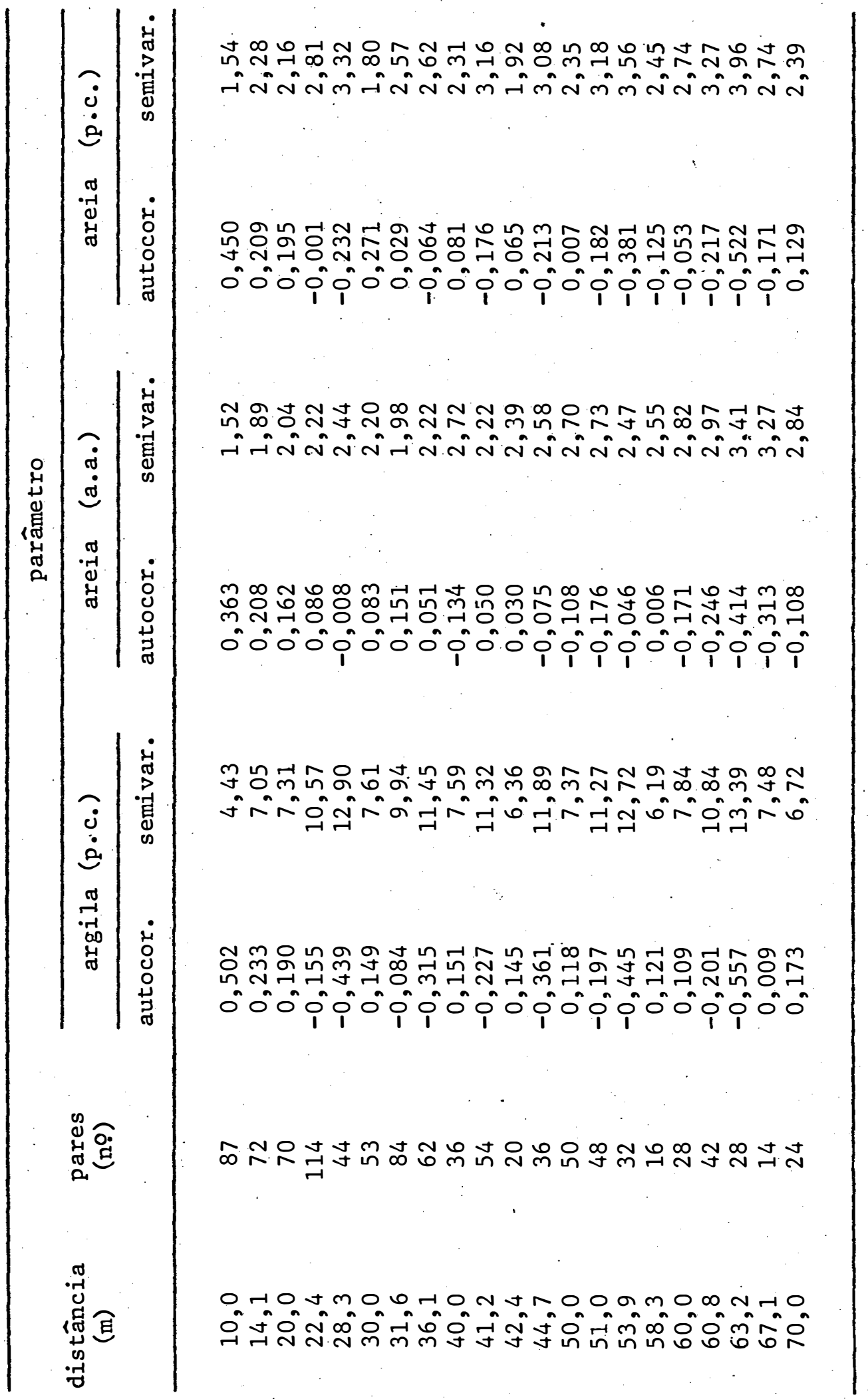




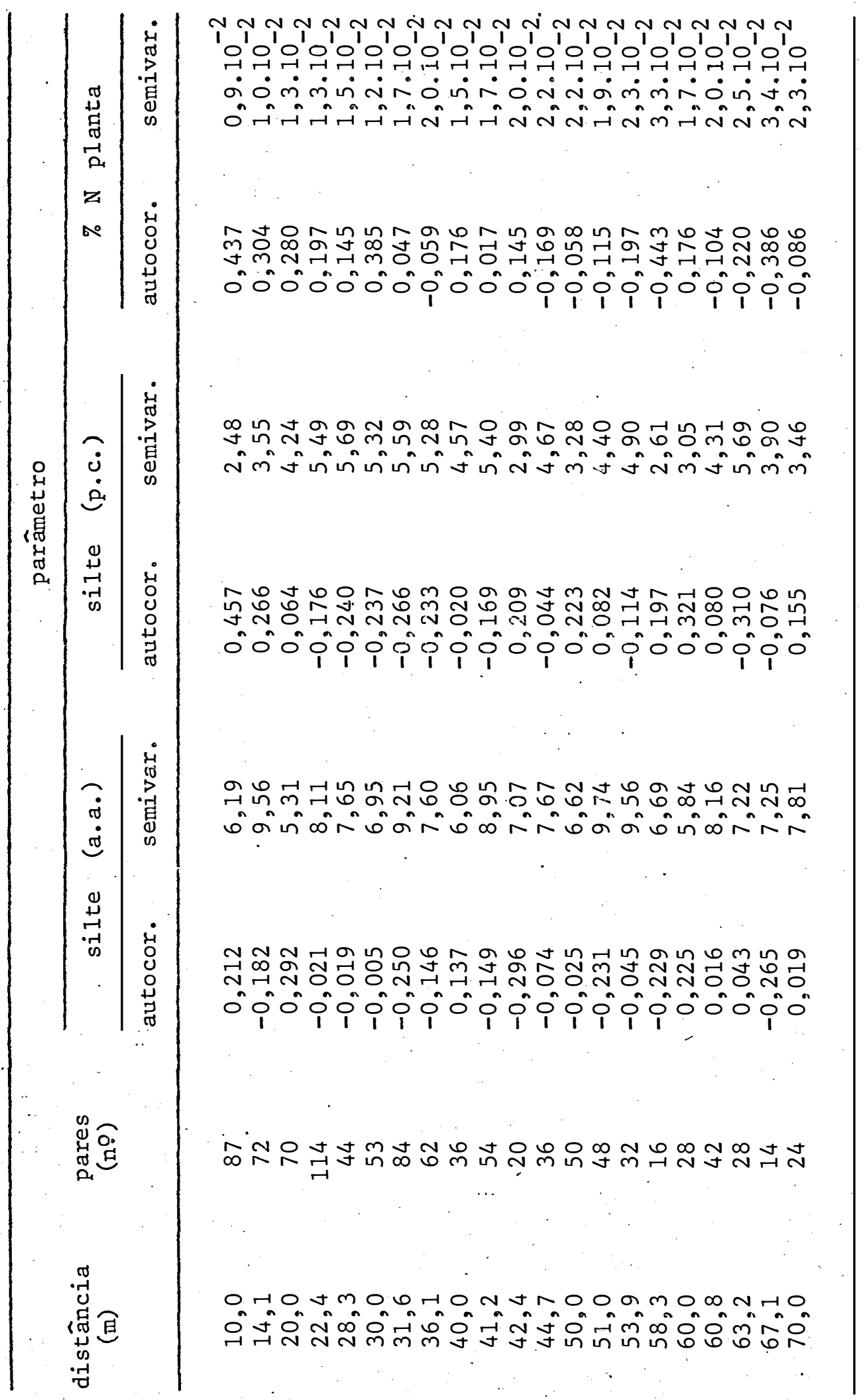




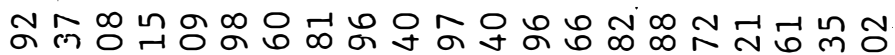

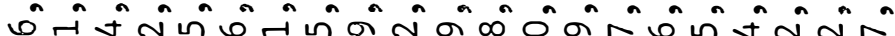
m

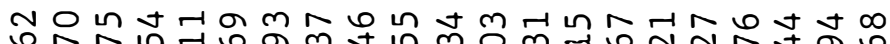

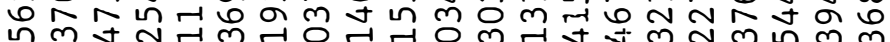

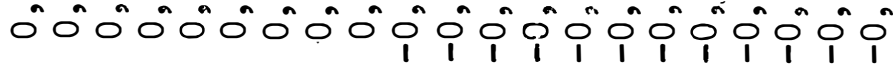

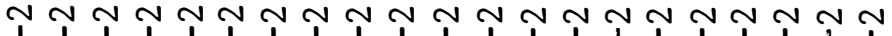

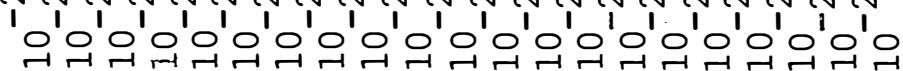

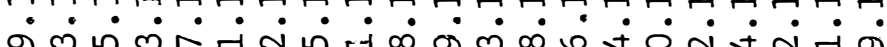

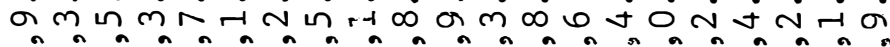

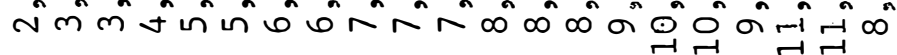

ด ช

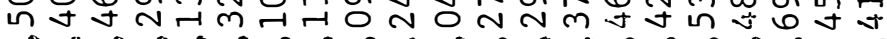

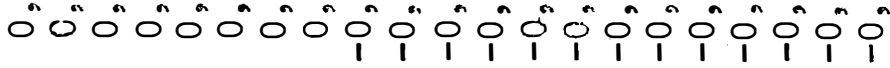

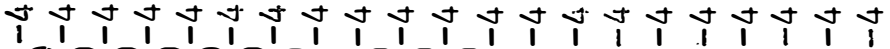

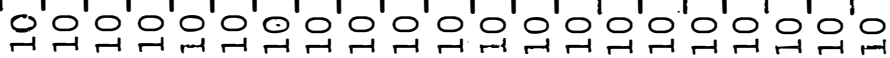

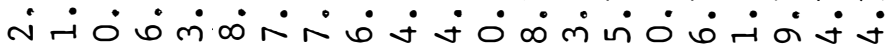

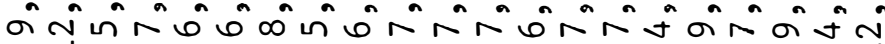
तथ

$m$ 에 $N m N N$ W 舟 1 ๙

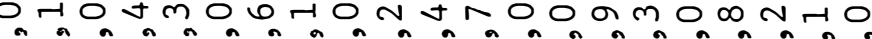
ல 


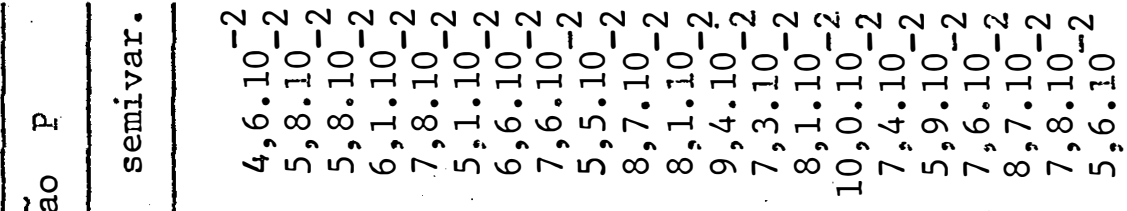

$m \infty m \circ-m$ ț $\infty$ t 0 \%

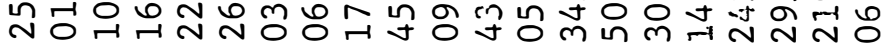

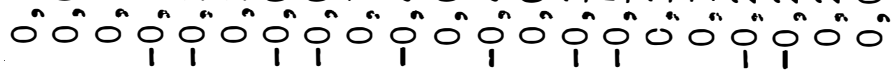

증유

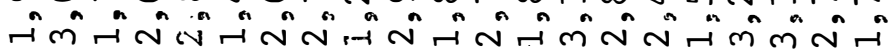

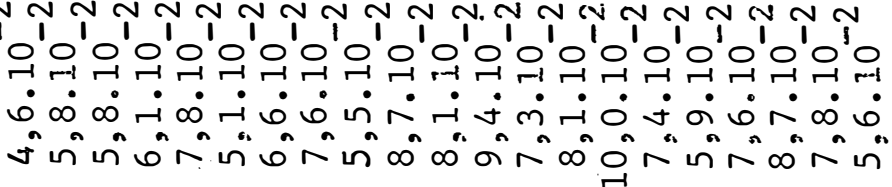

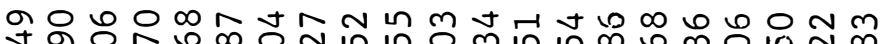

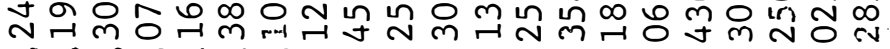

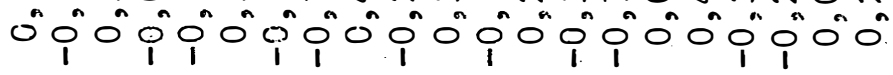

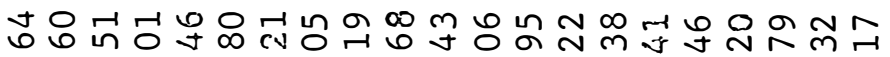

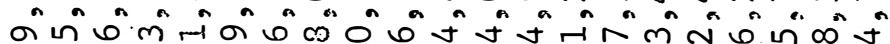

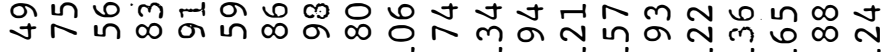

$\frac{N}{n_{1}}$

.

$$
\text { (1) }
$$

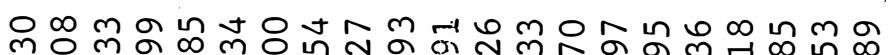

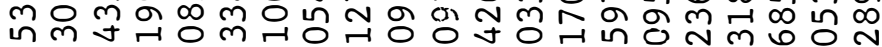

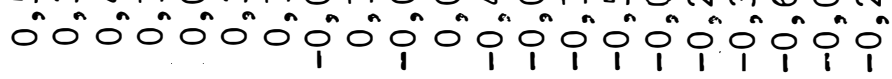

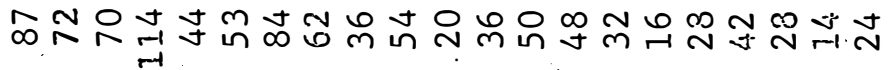

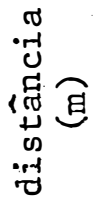

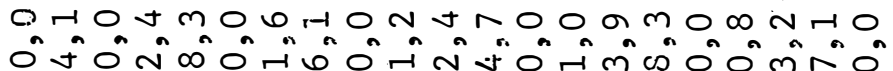

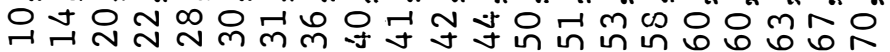




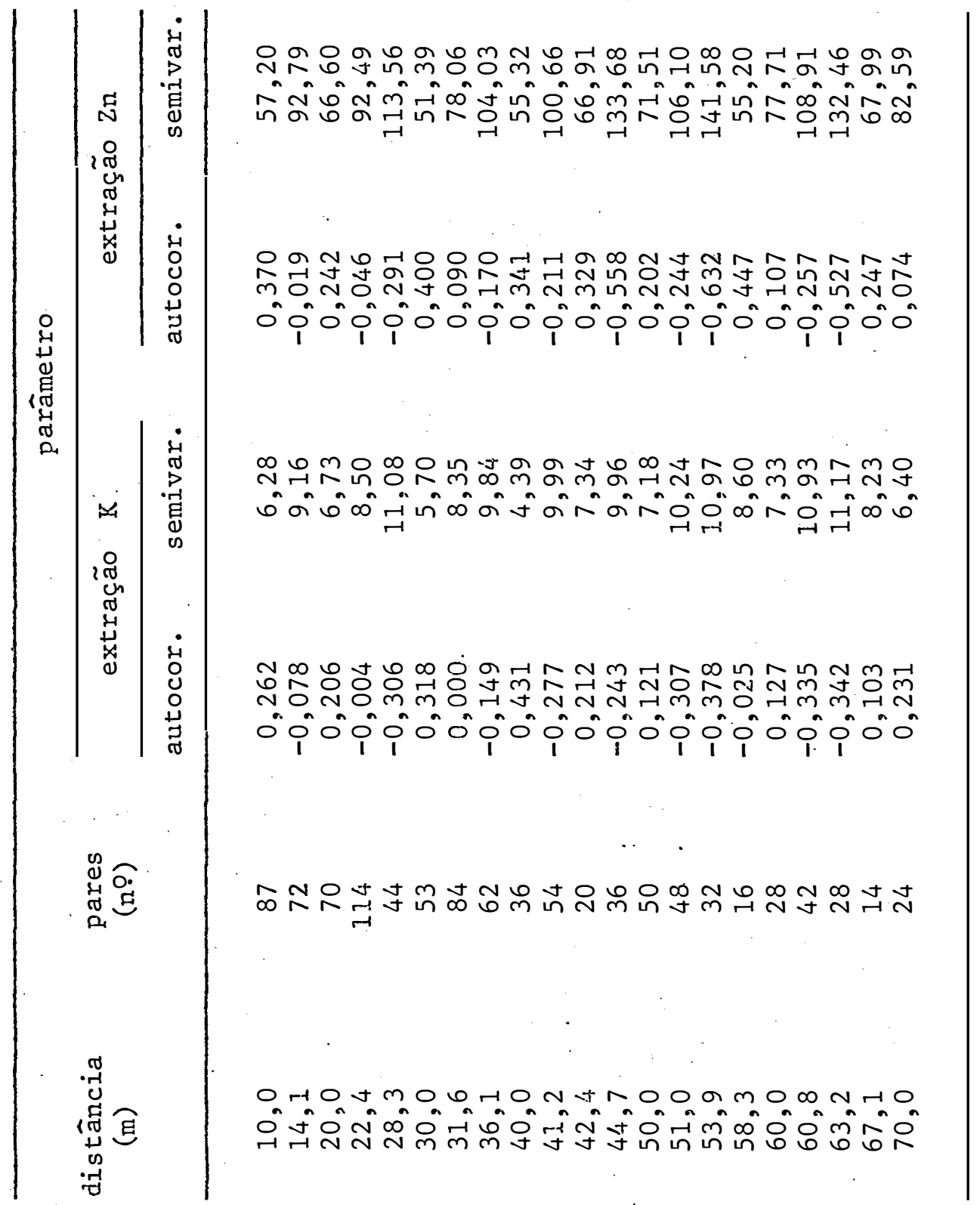

